\title{
Chemokine receptors CXCR4 and CCR5: \\ Cell surface expression, signaling and modulation by $\beta$-arrestin 2
}

\section{Doctoral thesis}

In partial fulfillment of the requirements for the degree

“Doctor rerum naturalium (Dr. rer. nat.)"

in the Molecular Medicine Study Program

at the Georg-August University Göttingen

\author{
submitted by \\ Marcel Liebick \\ born in
}

Wolmirstedt, Germany 


\section{Members of the thesis committee}

Supervisor:

Institute:

$2^{\text {nd }}$ member:

Institute:

$3^{\text {rd }}$ member:

Institute:

Date of Disputation:
Prof. Dr. Martin Oppermann

Department of Cellular and Molecular Immunology

Georg-August University Göttingen

Prof. Dr. Susanne Lutz

Institute of Pharmacology

Georg-August University Göttingen

Prof. Dr. Dieter Kube

Institute of Hematology and Oncology

Georg-August University Göttingen

Parts of this work were presented at:

$43^{\text {rd }}$ Meeting of the German Society of Immunology (DGfI)

Mainz, September 2013

Poster presentation

$17^{\text {th }}$ Meeting of the Signal Transduction Society (STS)

Weimar, November 2013

Oral presentation 


\section{AFFIDAVIT}

I herewith declare that my doctoral thesis entitled

"Chemokine receptors CXCR4 and CCR5: Cell surface expression, signaling and modulation by B-arrestin 2"

has been written independently with no other sources and aids than those indicated.

Marcel Liebick

Göttingen, September 2014 


\section{Acknowledgement}

First of all my apology to everyone who do not understand german good enough to follow all of my thoughts and statements in the german part of my acknowledgement. I know it from myself that the acknowledgement is nearly the most interesting part of a thesis for people who are not part of the committee which is responsible for the grading of the work. But for me it is more important that all people who are mentioned during my acknowledgement can understand the text, even those who do not understand English that well. If it's really important for you to understand everything ask someone who speaks german and Englisch good enough to summarize the following part for you.

Mein erster Dank an dieser Stelle geht an meinen "Main Supervisor" oder altmodisch Doktorvater Prof. Dr. Martin Oppermann. Beginnend mit den ersten Praktika während meines Biologiestudiums, über die Begleitung während meiner Diplomarbeit bis hin zur Betreuung meiner Doktorarbeit unter seiner Aufsicht hat er meinen wissenschaftlichen Werdegang entscheident mitgeprägt. Während jeder dieser Phasen war er stets offenherzig und hat mit seinen interessanten Gesprächen schon früh mein Interesse an der Immunologie und im späteren Verlauf an den G Protein gekoppelten Rezeptoren geweckt. Gerade letzteres ist nicht als Selbstverständlichkeit zu sehen, da ich mich noch gut an die Anfangszeit meines Studiums erinnere wo man eher dachte wie trocken und langweilig doch diese Art von Rezeptoren ist. Durch seine ständige Erreichbarkeit bei Problemen jeglicher Art und die vielen konstruktiven Diskussionen hat er entscheidenden Anteil am positiven Ausgang dieses Projektes. Des Weiteren möchte ich ihm an dieser Stelle noch einmal ausdrücklich für die Geduld während der Schreibphase meiner Doktorarbeit sowie für die zahlreichen sehr detaillierten Korrekturen eben dieser danken.

Ebenfalls danken möchte ich Prof. Dr. Susanne Lutz und Prof. Dr. Dieter Kube für ihre Begleitung und Unterstützung des Projekts im Rahmen des Thesis Committees. Die unkomplizierte Atmosphäre während unserer Meetings sowie die Diskussionen, die teilweise ein anderes Licht auf bestimmte Fragestellungen geworfen haben, waren eine echte Hilfe.

Danken möchte ich auch Denjenigen die über kurz oder lang mein Ein-Mann Labor etwas mit Leben gefüllt haben und die mich so über die letzten Jahre während der Arbeit begleitet, sowie ihren Teil zu dem Projekt beigetragen haben. An dieser Stelle wären zu nennen Benjamin Schlüter, Sarah Tjaden, Maike Schuldt, Henrik Steffen und Sarah Henze. Danke für eure Unterstützung. Die Zusammenarbeit mit Sarah Henze sei an dieser Stelle hervorgehoben, da wir zusammen sehr viel Spaß im Labor hatten und zugleich auch noch sehr produktiv waren was ja nicht immer selbstverständlich ist. Auf diesem Wege wünsche ich ihr viel Erfolg bei ihrer eigenen Dissertation. Du packst das.

Mein Dank gilt auch der Arbeitsgruppe Dressel sowie Engels. In besonderem Antje Isernhagen, Sebastian Monecke (im späteren Verlauf natürlich auch dir Carina (:) ) und Niklas Engels. Gerade in der Zeit wenn ich mal wieder allein im Labor stand waren unsere Gespräche in der Zellkultur über nicht immer ganz wissenschaftliche Themen doch immer eine sehr willkommene Abwechslung. Besonders Antje möchte ich an diese Stelle alles Gute für ihren Neustart in Down Under wünschen. Vielleicht läuft man sich ja irgendwann mal mehr oder weniger zufällig wieder über den Weg. Ich würde mich freuen. 
Auch wenn die oben genannten Personen für mich herausstechen geht mein Dank natürlich auch an die restliche Belegschaft der Immunologie in Göttingen. Durch die sehr entspannte Arbeitsatmosphäre und die zahllosen unterhaltsamen Gespräche während diverser Inkubationszeiten habt ihr euren Anteil zu dieser Arbeit beigetragen.

Zu guter Letzt richtet sich mein Dank natürlich auch an meine Familie. Meine Eltern haben mich über die Jahre mit allen ihnen zur Verfügung stehenden Mitteln bedingungslos in der Verwirklichung meiner Lebensziele unterstützt wofür ich sehr dankbar bin. Gleiches gilt für meine Großeltern. In diesem Sinne hoffe ich ihr seid zufrieden mit dem ersten Doktortitel in der jüngeren Familiengeschichte. Allerdings muss ich euch auf diesem Wege auch sagen, dass ihr euch bei den nächsten Treffen andere Gesprächsthemen ausdenken müsst als die Frage wie weit ich denn nun mit meiner Doktorarbeit bin. Mit am wichtigsten war und ist die bedingungslose Unterstützung meiner Freundin. Auf diesem Wege verspreche ich ihr, dass die ausgefallenen Urlaube sowie die durchgearbeiteten Wochenenden in naher Zukunft nachgeholt werden. An letzter Stelle möchte ich auch noch unserer Katze danken. Wie könnte ich Sie nur vergessen wo wir doch die letzen Monate in meiner Schreibphase ein unzertrennliches Duo waren und sie mich mit Ihrem permanenten haaren sowie sabbern immer wieder aufs Neue motiviert hat. An dieser Stelle hoffe ich sie übersteht die Zeit wenn ich wieder täglich ins Labor fahre unbeschadet und ohne weitere psychische Beeinträchtigungen.

In Gedenken an

Ingeborg Schwarz

* 13.04.1924 +06.09.2014

Danke für all das was eine tolle Großmutter ausmacht 


\section{Table of contents}

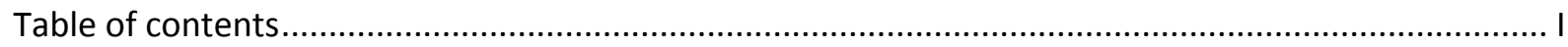

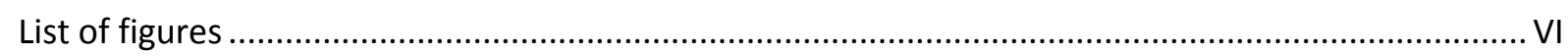

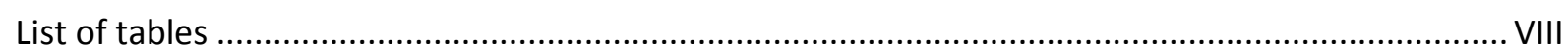

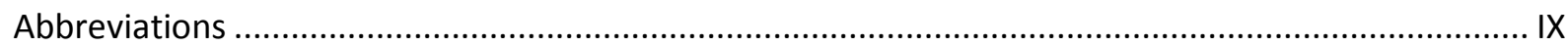

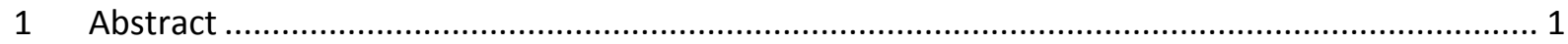

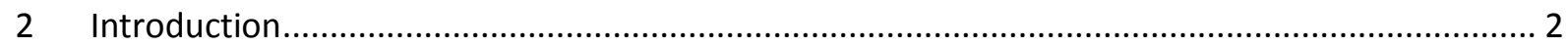

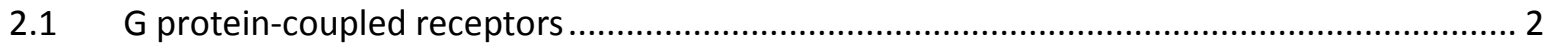

2.2 Chemokine receptors and their representatives CXCR4 and CCR5 .................................... 2

2.3 Classical model of $\mathrm{G}$ protein-coupled receptor signaling and cell surface regulation ............. 6

2.4 The multivalent adaptor protein $\beta$-arrestin and its role for cell signaling ............................ 9

2.5 Analysis of protein protein interactions by chemical induced dimerization ....................... 14

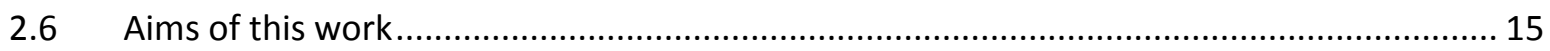

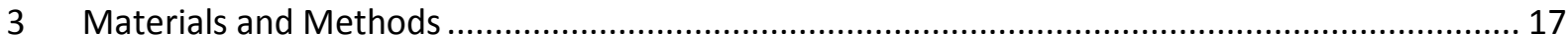

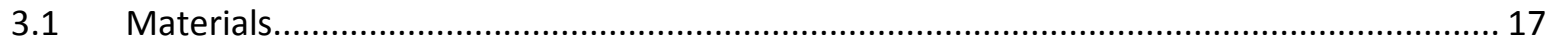

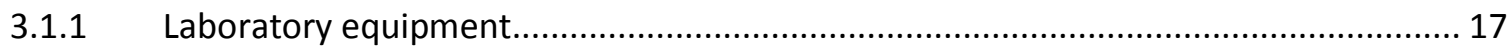

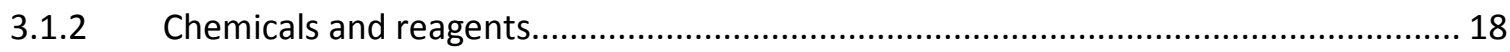

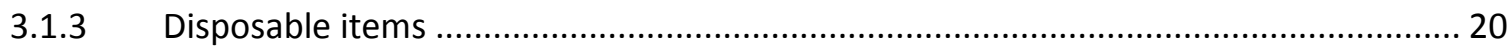

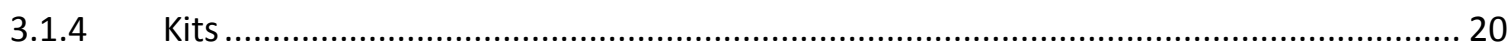

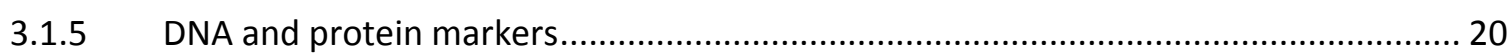

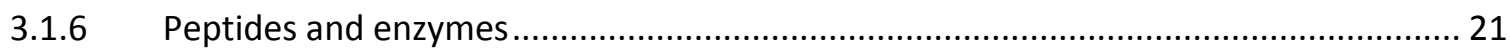

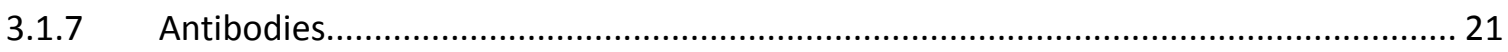

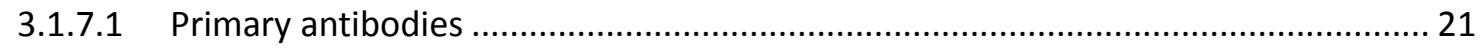

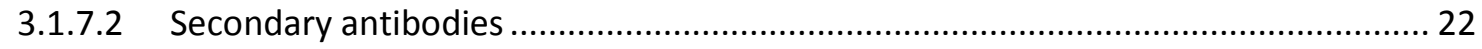

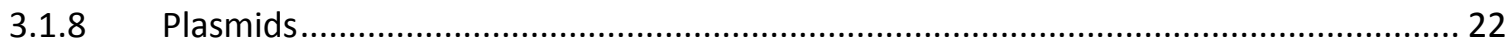

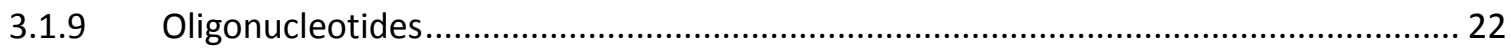

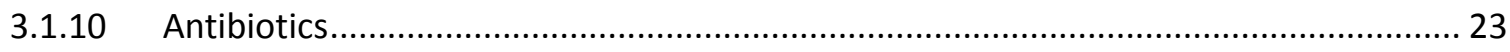

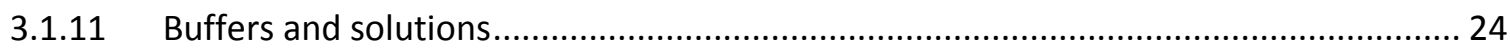

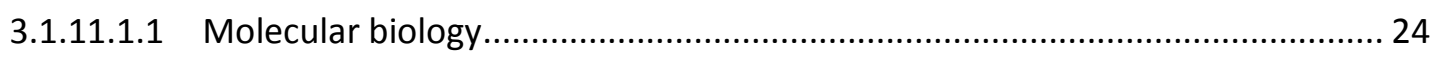

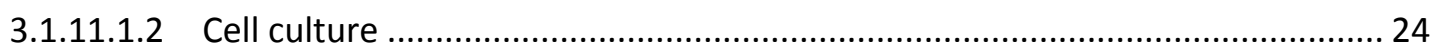

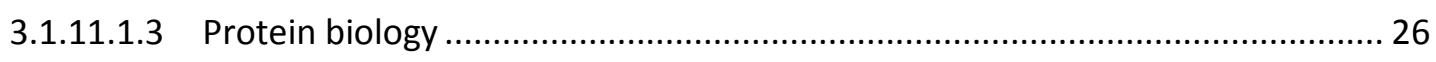

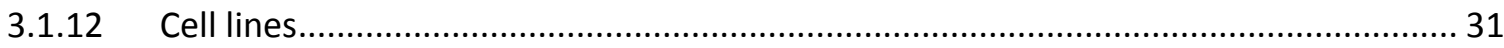

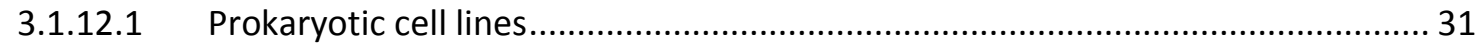

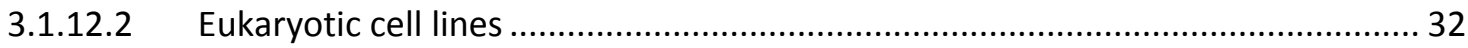




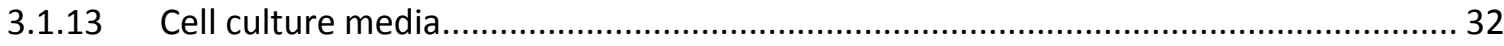

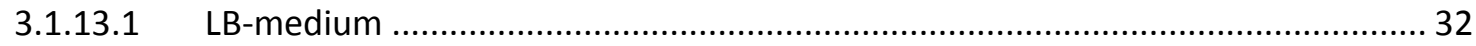

3.1.13.2 Media for mammalian cell culture .................................................................... 32

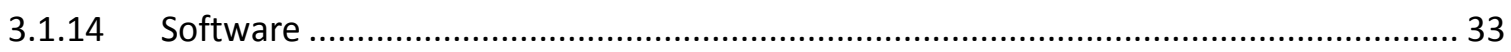

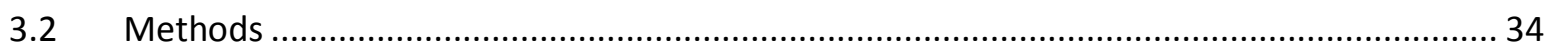

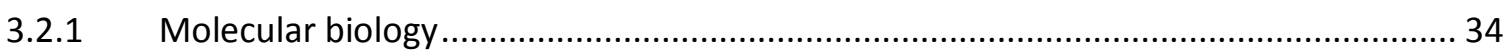

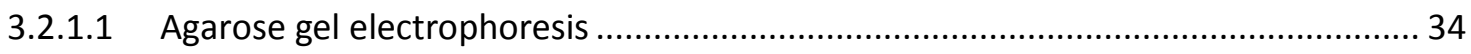

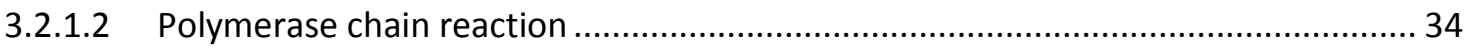

3.2.1.3 Purification of DNA fragments from PCR ............................................................... 34

3.2.1.4 Digestion and dephosphorylation of DNA ............................................................ 35

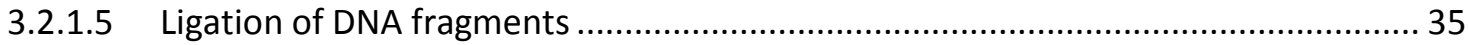

3.2.1.6 Heat-shock transformation of chemo-competent E.coli......................................... 35

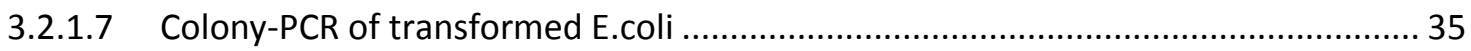

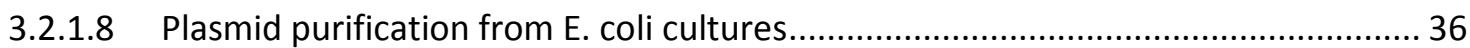

3.2.1.9 Phenol-Chloroform extraction and ethanol precipitation of DNA ........................... 36

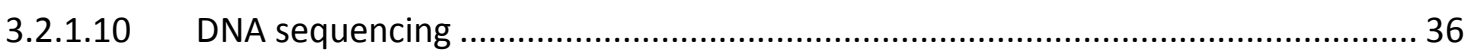

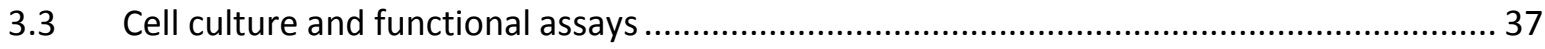

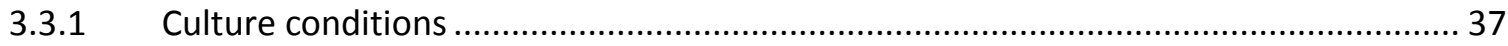

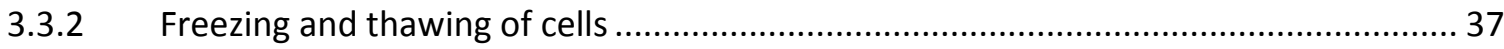

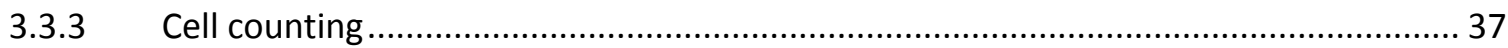

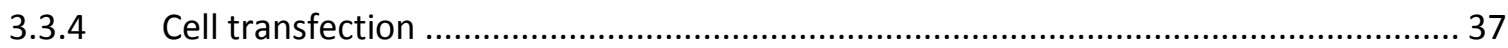

3.3.4.1 Transfection of RBL-cells using electroporation................................................... 37

3.3.4.2 Co-transfection of HEK293-cells using calcium-phosphate........................................ 38

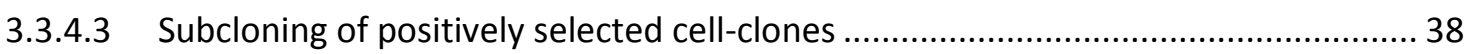

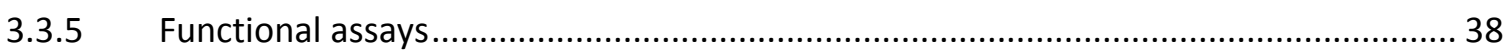

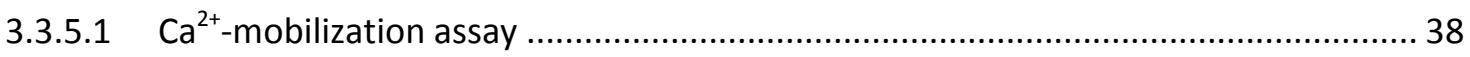

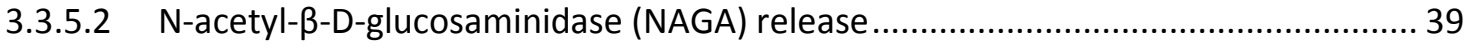

3.3.5.3 Phosphorylation/activation of ERK1/2 MAP-kinases after ligand and

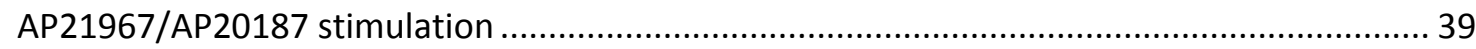

3.3.5.4 Quantification and visualization of internalization- and recycling processes of

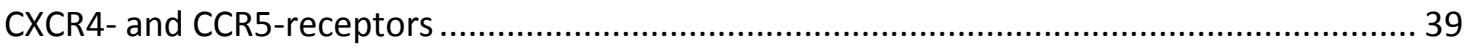

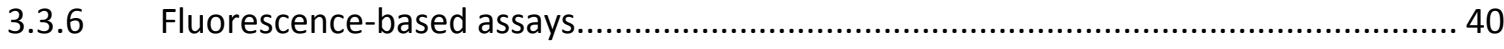

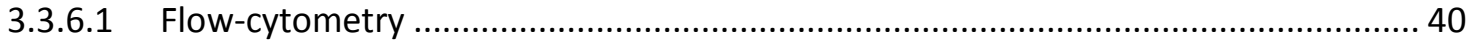

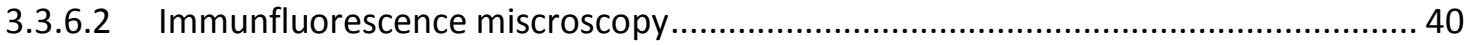

3.4 Generation of a monoclonal antibody against the acceptor-peptide (AP) ......................... 40 
3.4.1 Preparation of a KLH-peptide conjugate for immunization

3.4.2 Fusion of splenocytes with Ag8 cells and identification of positive hybridoma cell-clones.

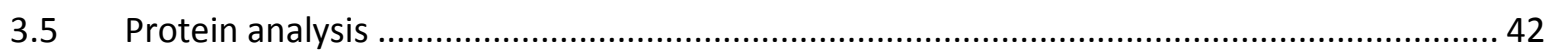

3.5.1 Sodium dodecyl sulfate polyacrylamide gel electrophoresis (SDS-PAGE) …................ 42

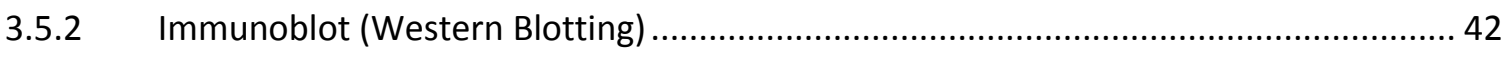

3.5.3 Enzyme-linked immunoabsorbent assay (ELISA) ........................................................... 43

3.5.4 Purification of membrane fractions from whole cell extracts using ultracentrifugation .

3.5.5 Expression and purification of biotin ligase A from E. coli BL21 (DE3) ........................ 43

3.6 Enzymatic and biochemical biotinylation of the acceptor peptide (AP) ............................. 44

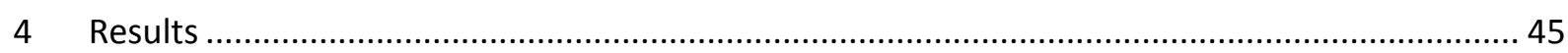

4.1 Biotin Ligase A-catalyzed biotinylation of an acceptor peptide - a new tool for internalization and recycling studies.

4.1.1 Generation of RBL cell-lines which stably express CXCR4-, CCR5- and CXCR4-CCR5 chimeric-receptors with an $\mathrm{N}$-terminal acceptor peptide

4.1.2 Generation of an AP-tag-specific antibody which enables detection of biotinylated or non-biotinylated forms.

4.1.2.1 Mutual interference of ligand and YC8 antibody-binding to AP-tagged receptors .. 46

4.1.2.2 Binding of YC8 to a synthetic acceptor peptide and its modulation by peptide biotinylation and streptavidin binding.

4.1.3 Biotin ligase $A-a$ tool for specific biotinylation-of membrane proteins

4.1.3.1 Purification of biotin ligase from E. coli lysates by nickel chelate chromatography. 48

4.1.3.2 Time and temperature-dependent biotinylation of a synthetic AP by BirA biotin ligase

4.1.4 Constitutive internalization of CXCR4,CCR5 and chimeric receptors and it's modulation by receptor agonists and antagonists

4.1.5 Modulation of CCR5 internalization by receptor ant-/agonists ................................... 51

4.1.6 Ligand-induced internalization and receptor recycling ............................................... 52

4.1.6.1 Quantification of ligand-driven internalization and recycling of biotinylated and anti-AP stained receptors...

4.1.6.2 Effects of the receptor antagonists TAK779 and AMD3100 on the recycling-rate after ligand-induced receptor-internalization.

4.1.6.3 Intracellular localization of biotinylated and anti-AP stained CCR5 during receptor internalization and recycling

4.2 Chemical-induced receptor homodimerization and $\beta$-Arrestin2 translocation in the absence of ligand binding 
4.2.1 Cloning strategy for the modification of CXCR4-, CCR5-receptor and $\beta$-arrestin2 with Dmr-domains.

4.2.2 Stable co-expression of DmrA-modified chemokine-receptors and $\beta$-arrestin2-DmrC in HEK293 cells 58

4.2.2.1 Surface expression of DmrA-modified CXCR4- and CCR5-receptorsom HEK293 transfectants 59

4.2.2.2 Structural integrity of a Dmr-A modified CCR5-receptors .59

4.2.2.3 Molecular weight shift of $\beta$-arrestin2-DmrC in comparison to native $\beta$-arrestin2 ... 60

4.2.3 Ligand independent AP21967-mediated translocation of $\beta$-arrestin2 to the plasma membrane

4.2.3.1 AP21967 leads to membrane translocation of $\beta$-Arrestin 2 in CXCR4-/CCR5-DmrA cell lines in a dose-dependent manner

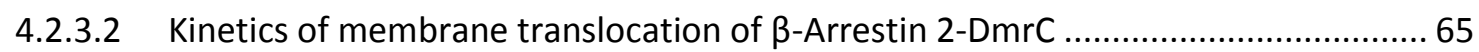

4.2.3.3 Ligand- vs. AP21967-stimulated $\beta$-Arrestin 2 translocation to the membrane ......

4.2.4 Functional consequences of chemical-induced $\beta$-Arrestin 2 translocation in the absence of ligand binding.

4.2.4.1 $\beta$-Arrestin 2 translocation leads to desensitization of ligand-induced calcium-mobilization

4.2.4.1.1 Expression of $\mathrm{G}_{\alpha q}$-proteins in stable co transfected HEK293 cells using a bicistronic vector system.

4.2.4.1.2 Effect of $G_{\alpha q}$ supplementation on ligand induced calcium-mobilization in transiently transfected cells

4.2.4.1.3 Attenuation of ligand-induced calcium mobilization by forced arrestin/receptor-complex formation 70

4.2.4.2 AP21967- vs. ligand-induced receptor internalization. 71

4.2.4.2.1 Kinetics of receptor internalization as determined by flow cytometry 71

4.2.4.2.2 Kinetics of AP21967-induced receptor internalization as determined by immunofluorescence.

4.2.4.2.3 Intracellular localization of receptors/ $\beta$-arrestin following ligand- or AP21967-treatment. 76

4.2.4.3 AP21967- vs. ligand-induced MAP kinase activation ... 78

4.2.4.3.1 Ligand- and AP21967-induced MAP kinase activation: effect of PTX..... 78

4.2.4.3.2 Ligand- and AP21967-induced MAP kinase activation: effect of co-expressed $\beta$-arrestin 2-DmrC.

4.2.4.3.3 Activation of $\mathrm{p} 42 / \mathrm{p} 44-\mathrm{MAPK}$ at different time points after ligand- and AP21967-treatment

4.2.4.3.4 Activation of $\mathrm{p} 42 / \mathrm{p} 44-\mathrm{MAPK}$ after incubation with different concentrations of AP21967 
4.2.5 Functional consequences of AP20187-induced receptor homodimerization. 80

4.2.5.1 Effect of AP20187 treatment on ligand-induced calcium-mobilization in Rec-DmrA cells

4.2.5.2 Effect of AP20187 on receptor internalization in Rec-DmrA/BArr-DmrC or Rec-DmrA cells

4.2.5.3 Effect of AP20187 treatment on p42/p44-MAPK phosphorylation in Rec-DmrA cells

4.2.5.4 Dose-response and kinetic of AP20187 induced p42/p44-MAPK phosphorylation .83

4.2.6 Effect of AP21967 and AP20187 on the activation of different MAP kinases............... 84

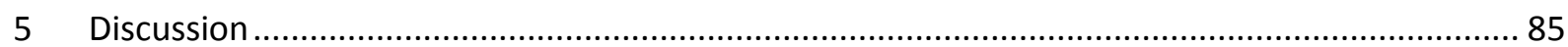

5.1 A biotin-based detection system for the analysis of transmembrane protein trafficking exemplified by internalization and recycling studies on CXCR 4 and CCR5 85

5.2 Cellular response on ligand-independent translocation of $\beta$-arrestin 2 to the receptor and the role of receptor homodimerization for receptor trafficking ..................................................... 91

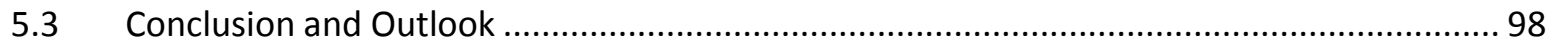

$6 \quad$ Bibliography 


\section{List of figures}

Figure 1: Two dimensional amino acid structure of the human chemokine receptor CCR5 ................. 5

Figure 2: Desensitization, internalization and recycling of GPCRs .................................................... 7

Figure 3: Three dimensional structure of the active and inactive conformational state of $\beta$-arrestin 1

Figure 4: Biased signaling either mediated by biased ligands or biased receptors ........................... 13

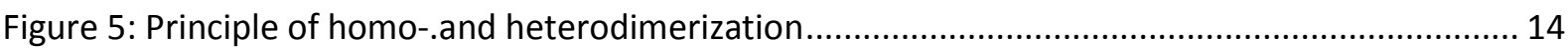

Figure 6: Heterodimerization system consisting of an $\mathrm{DmrA} / \mathrm{C}$ domain and an $\mathrm{A} / \mathrm{C}$ heterodimerizer. 15 Figure 7: Binding of the YC8 anti-AP antibodies and anti-receptor antibodies to CXCR4/CCR5 after pre-incubation with AP-peptide or ligand (flow cytometry).

Figure 8: Binding of anti-AP antibodies to the AP peptide and its modulation by peptide biotinylation and streptavidin binding

Figure 9: Affinity purification of biotin ligase A from E.coli lysates with NiNTA-agarose ..................... 49

Figure 10: Time and temperature dependent biotinylation of the AP peptide by BirA ....................... 50

Figure 11: Constitutive receptor internalization in the absence of receptor agonists ......................... 51

Figure 12: Influence of receptor ant-/agonists on the consitutive internalization of CCR5 .................52

Figure 13: Ligand-induced internalization and recycling of CXCR4, CCR5 and CXCR4-CCR5

Figure 14: Recycling of CXCR4- and CCR5-receptors in the presence of receptor antagonists ............ 55

Figure 15: Double immunofluoresence staining of RBL-CCR5 cells during the internalization and

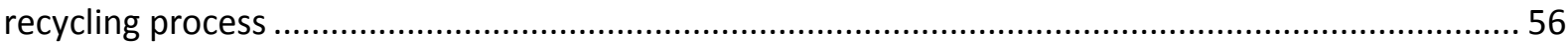

Figure 16: Cloning strategy for the generation of $\beta$-arrestin 2 and CXCR4/CCR5 DmrA/C fusion

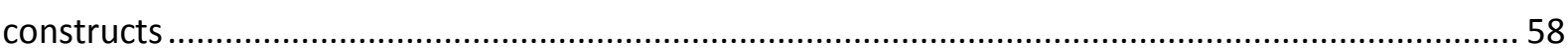

Figure 17: Expression of CXCR4- or CCR5-DmrA on transfected HEK293 cell lines...............................59

Figure 18: Expression of native vs. DmrA-modfied CCR5 in membrane fractions of HEK293 or RBL cells

Figure 19: Expression of native vs. DmrC modified $\beta$-arrestin 2 in lysates of transiently transfected HEK293 cells

Figure 20: $\beta$-Arrestin 2-DmrC recruitment to the membrane after treatment with different doses of AP21967 (immunoblot)

Figure 21: $\beta$-Arrestin 2-DmrC recruitment to the plasma membrane after treatment with 0 to 1000 nM AP21967 (immunofluorescence)

Figure 22: Kinetic of AP21967 induced $\beta$-Arrestin 2-DmrC translocation to the cell membrane (immunoblot)

Figure 23: Kinetics of AP21967-induced $\beta$-arrestin 2-DmrC translocation towards the cell membrane (immunofluorescence)

Figure 24: Comparision of ligand- and AP21967-induced $\beta$-Arrestin 2 translocation to the plasma membrane in stably transfected HEK293 CCR5-DmrA cells with $\mathrm{G}_{\mathrm{qo}}$ and GRK2 co-transfection

Figure 25: Expression of $\mathrm{G}_{\alpha q}$ variants $\left(\mathrm{G}_{\mathrm{q} 05} / \mathrm{G}_{\mathrm{qi}}\right)$ in HEK293 and stably cotransfected

Rec-DmrA/ $\beta$ Arr-DmrC cells using a bicistronic vector system 69

Figure 26: Ligand-induced calcium mobilization in CXCR4- or CCR5- cell lines which coexpress $\mathrm{G}_{\mathrm{q} 05} . .70$ Figure 27: Alterations of the calcium signal in CXCR4- CCR5- cell lines after AP21967 pretreatment . 70 Figure 28: Ligand- and AP21967-induced receptor internalization in stably transfected Rec-DmrA/BArr-DmrC or Rec-DmrA cells. 
Figure 29: Kinetics of AP21967-induced receptor internalization in CXCR4-DmrA/ $\beta$-Arrestin 2-DmrC cells (immunofluorescence)

Figure 30: Kinetics of AP21967-induced receptor internalization in CCR5-DmrA/ $\beta$-Arrestin 2-DmrC

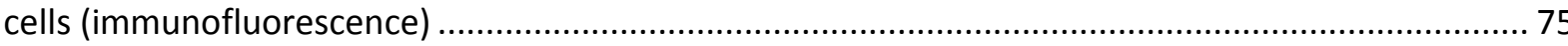

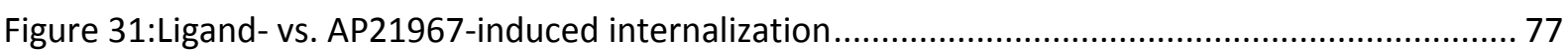

Figure 32: AP21967- vs. ligand-induced activation of p42/p44 MAPK; inhibition by PTX pretreatment

Figure 33: Kinetic of AP21967 vs. ligand induced activation of p42/p44 MAPK and their inhibition with PTX (immunoblot)

Figure 34: Detailed kinetics of AP21967- or ligand- induced activation of p42/p44 MAPK ................. 79

Figure 35: Dose response of AP21967-induced p42/p44 MAPK activation .......................................... 80

Figure 36: Influence of AP20187 on the ligand induced calcium release in stable tranfected HEK293 cells (transient transfection of $\mathrm{G}_{\mathrm{q} 05}$ )

Figure 37: Effect of AP20187 pretreatment on ligand-induced receptor internalization...................... 82

Figure 38: AP20187- vs. ligand-induced activation of p42/p44 MAPK in HEK Rec-DmrA cells............. 83

Figure 39: Detailed kinetic and dose response of AP20187 induced p42/p44 MAPK activation.......... 83

Figure 40: Effect of AP21967- or AP20187-treatment on the phosphorylation status of different MAP

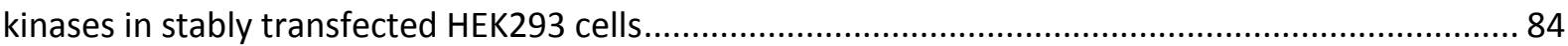

Figure 41: Overview of $\beta$-arrestin-mediated effects during GPCR signaling and trafficking ............... 92 


\section{List of tables}

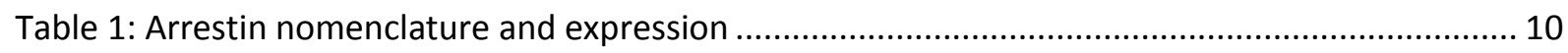

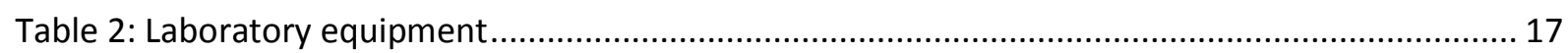

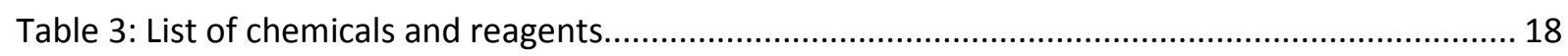

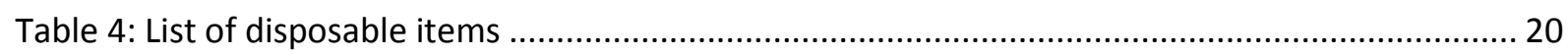

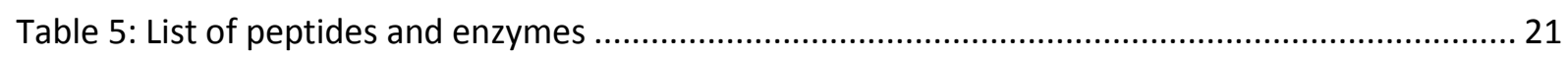

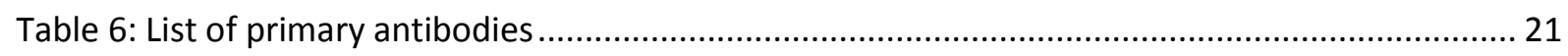

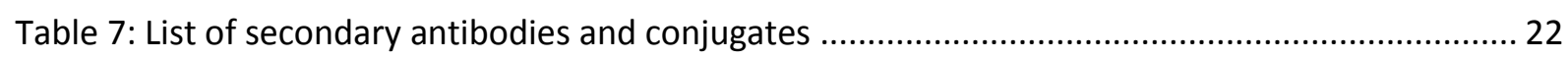

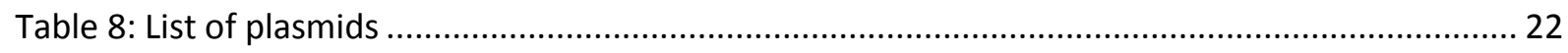

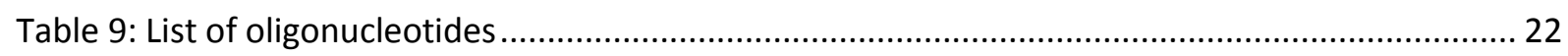

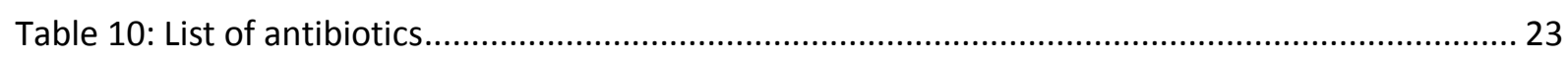

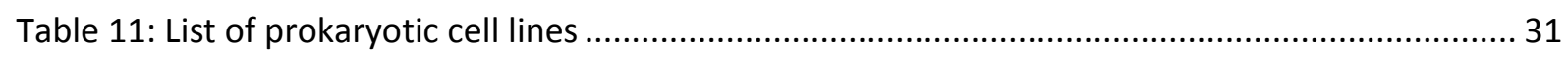

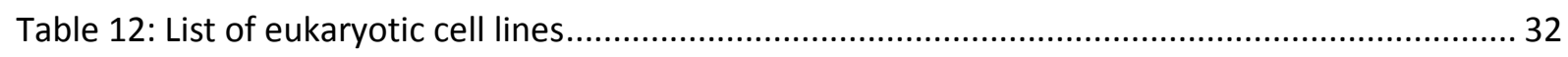

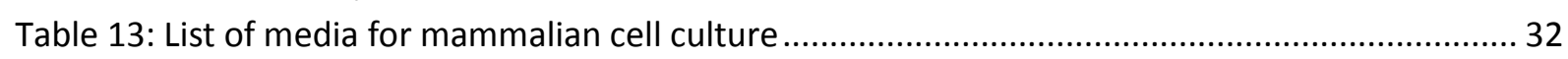

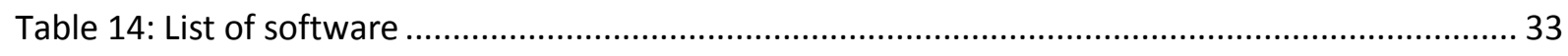

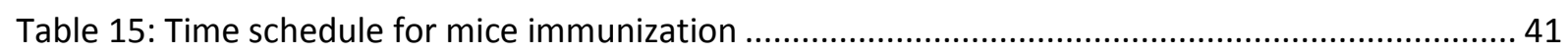

Table 16: Pipetting scheme for PEG-medium and PBS during cell-fusion ......................................... 41

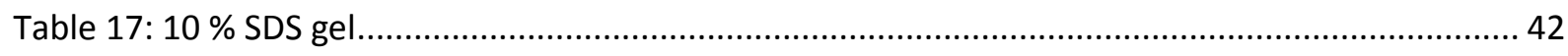

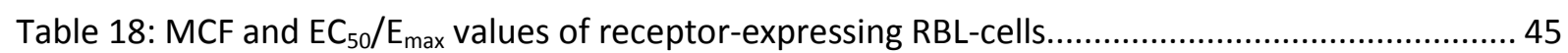




\section{Abbreviations}

${ }^{\circ} \mathrm{C}$

$\mu \mathrm{F}$

$\mu \mathrm{g}$

$\mu \mathrm{l}$

$\mu \mathrm{M}$

ABTS

Ahx

AIP4

Alexa

AM

AP

AP2

approx.

$\mathrm{AT}_{1 \mathrm{~A}} \mathrm{R}$

BirA

BM

bp

BRET

BSA

CAMP

CCR

CD

CDNA

CID

CMV

COPD

$\mathrm{C}-\mathrm{SrC}$

C-terminal

C-terminus

CXCR

DAG

$\mathrm{ddH}_{2} \mathrm{O}$

DMEM

DmrA

DmrC

DNA

dNTP

E. coli

EF1 $\alpha$

e.g

$\mathrm{EC}_{50}$

ECL

EDTA

ELISA

$E_{\max }$

ER

ERK
Minutes

Seconds

Celcius

Microfarad

Microgram

Microliter

Micromolar

2,2'-azino-bis(3-ethylbenzothiazoline-6-sulphonic acid)

Aminohexanoic acid

Atrophin 1-interacting protein 4

Alexa fluor

Acetoxymethyl ester

Acceptor peptide

Adaptor protein 2

approximately

Angiotensin II type $1 \mathrm{~A}$ receptor

Biotin ligase $A$

Binding medium

Base pairs

Bioluminescence resonance energy transfer

Bovine serum albumin

Cyclic adenosine monophosphate

cC chemokine receptor

Cluster of differentiation

Complementary DNA

Chemical-induced dimerization

Human cytomegalovirus

Chronic obstructive pulmonary disease

Proto oncogene tyrosine protein kinase Src

Carboxyl terminal

Carboxyl terminus

CXC chemokine receptor

Diacyl glycerol

Double-distilled water

Dulbecco's modified eagle medium

FKBP12

$F R B$

Deoxyribonucleic acid

Deoxyribonucleotide

Escherichia coli

Elongation factor 1-alpha

exempli gratia

Half maximal effective concentration

Enhanced chemiluminescence

Ethylenediaminetetraacetic acid

Enzyme-linked immunosorbent assay

Maximal effective concentration

Endoplasmic reticulum

Extracellular-signal-regulated kinase 


\begin{tabular}{|c|c|}
\hline FACS & Fluorescence-activated cell sorting \\
\hline FCS & Fetal calf serum \\
\hline FITC & Fluorescein isothiocyanat \\
\hline FKBP12 & FK506-binding protein \\
\hline FRAP & FKBP12 rapamycin-associated protein \\
\hline FRB & FKBP12 rapamaycin-binding domain \\
\hline FRET & Förster resonance energy transfer \\
\hline g & Gram \\
\hline $\mathrm{GABA}_{\mathrm{B}}$ & Gamma aminobutyric acid receptor \\
\hline GDP & Guanosine diphosphate \\
\hline GEF & Guanine nucleotide exchange factor \\
\hline GFP & Green fluorescent protein \\
\hline $\mathrm{G}_{\text {olf }}$ & Golfactory \\
\hline gp & Envelope glycoprotein \\
\hline GPCR & G protein-coupled receptor \\
\hline GRAFS & Glutamate, rhodopsin, adhesion, frizzled, secretin \\
\hline GRK & G protein-coupled receptor kinase \\
\hline GTP & Guanosine triphosphate \\
\hline h & Hour \\
\hline HA & Human influenza hemagglutinin \\
\hline HAG-CM buffer & Hepes buffer containing albumin, glucose, $\mathrm{Ca} 2+$ and $\mathrm{Mg} 2+$ \\
\hline HAT & Hypoxanthine, aminopterin, thymidine \\
\hline HBS & HEPES-buffered saline \\
\hline HEK & Human embryonic kidney \\
\hline HEPES & 4-(2-hydroxyethyl)-1-piperazineethanesulfonic acid \\
\hline HIV & Human immunodeficiency virus \\
\hline HRP & Horseradish peroxidase \\
\hline HT & Hypoxanthine, thymidine \\
\hline $\lg$ & Immunoglobulin \\
\hline IL & Interleukin \\
\hline $\mathrm{IP}_{3}$ & Inositol 1,4,5 trisphosphate \\
\hline IPTG & Isopropyl B-D-1-thiogalactopyranoside \\
\hline JAK & Janus kinase \\
\hline JNK & c-Jun N-terminal kinases \\
\hline kb & Kilobase \\
\hline kDa & Kilodalton \\
\hline KLH & Keyhole limpet hemocyanin \\
\hline $\mathrm{L}$ & Ligand \\
\hline LB & Lysogeny broth \\
\hline LCD & Liquid crystal display \\
\hline LESTR & Leukocyte-derived seven transmembrane domain receptor \\
\hline LMP & Latent membrane protein \\
\hline M & Molar \\
\hline $\mathrm{mA}$ & Milliampere \\
\hline mAbs & Monoclonal antibodies \\
\hline MAP & Mitogen-activated protein \\
\hline MCF & Mean channel of fluorescence \\
\hline Mdm2 & Mouse double minute 2 homolog \\
\hline MEK & Mitogen-activated protein kinase kinase \\
\hline MES & 2-(N-morpholino)ethanesulfonic acid \\
\hline Met & Methionine \\
\hline $\mathrm{mg}$ & Milligram \\
\hline
\end{tabular}




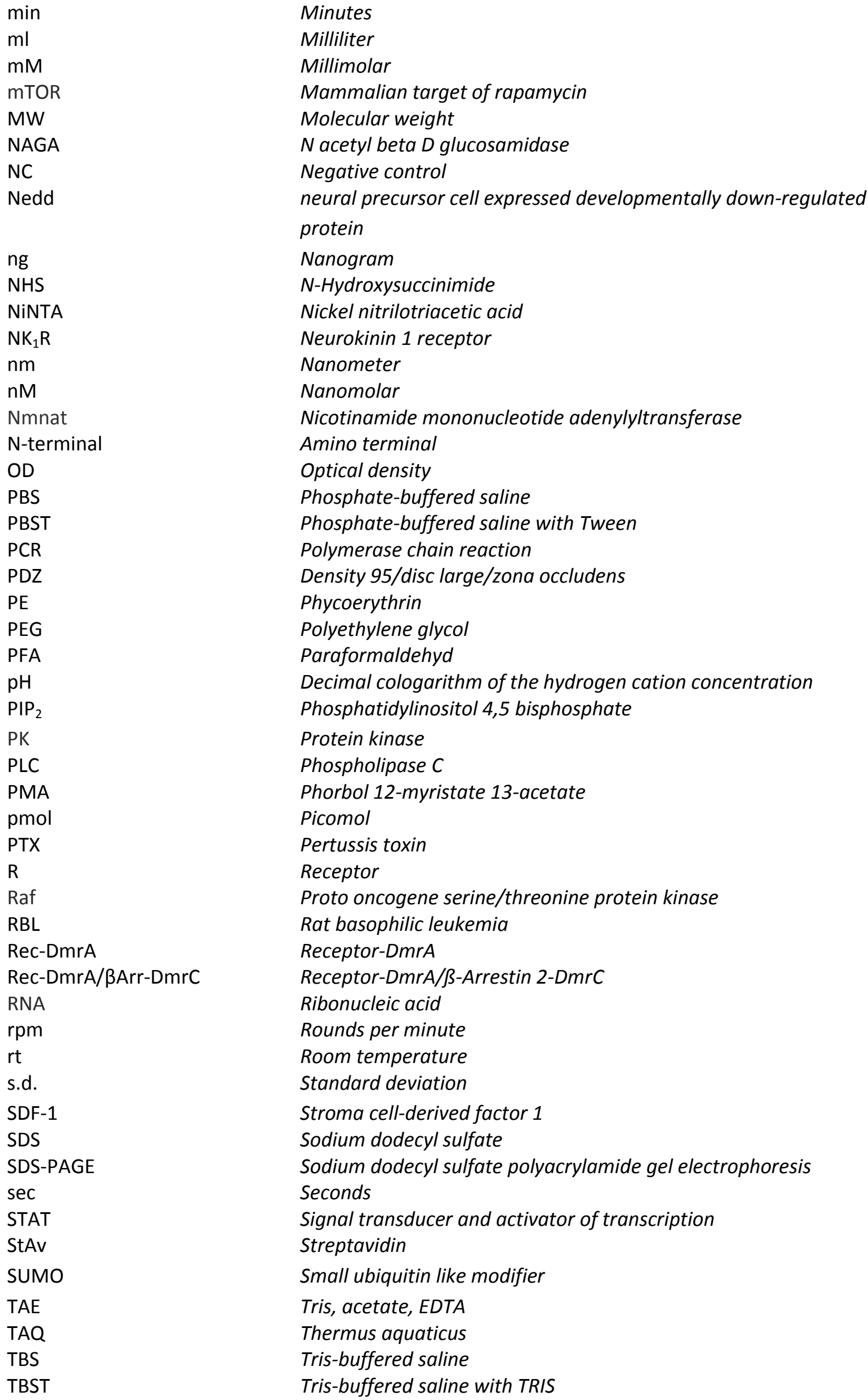

Nanogram

$\mathrm{N}$-Hydroxysuccinimide

Nickel nitrilotriacetic acid

Neurokinin 1 receptor

Nanometer

Nanomolar

Nicotinamide mononucleotide adenylyltransferase

Amino terminal

Optical density

Phosphate-buffered saline

Phosphate-buffered saline with Tween

Polymerase chain reaction

Density 95/disc large/zona occludens

Phycoerythrin

Polyethylene glycol

Paraformaldehyd

Decimal cologarithm of the hydrogen cation concentration

Phosphatidylinositol 4,5 bisphosphate

Protein kinase

Phospholipase C

Phorbol 12-myristate 13-acetate

Picomol

Pertussis toxin

Receptor

Proto oncogene serine/threonine protein kinase

Rat basophilic leukemia

Receptor-DmrA

Receptor-DmrA/ß-Arrestin 2-DmrC

Ribonucleic acid

Rounds per minute

Room temperature

Standard deviation

Stroma cell-derived factor 1

Sodium dodecyl sulfate

Sodium dodecyl sulfate polyacrylamide gel electrophoresis

Seconds

Signal transducer and activator of transcription

Streptavidin

Small ubiquitin like modifier

Tris, acetate, EDTA

Thermus aquaticus

Tris-buffered saline

Tris-buffered saline with TRIS 
TRIS

UV

V

$\mathrm{v} / \mathrm{v}$

$\mathrm{V}_{2} \mathrm{R}$

$\mathrm{w} / \mathrm{v}$

WHIM

WT

$x \mathrm{~g}$

$\beta_{2} A R$

$\beta A r r-D m r C$
Tris(hydroxymethyl)aminomethane)

Ultraviolet

Volt

Volume per volume

Vasopressin-2 Receptor

Weight per volume

Warts, hypogammaglobulinemia, infections and myelokathexis

Wild type

Gravitation

$\beta_{2}$ adrenergic receptor

$\beta$-Arrestin 2-DmrC 


\section{Abstract}

G protein-coupled receptors which mediate a large variety of different cellular effects have always been a field of significant interest for pharmaceutical research. Since it was shown that the chemokine receptors CXCR4 and CCR5 act as essential co-receptors for HIV-1 entry the interest in understanding the regulation of cell surface expression of these specific GPCR increased even more. The receptor expression at the cell surface is regulated by different mechanisms such as agonist-induced receptor endocytosis and subsequent receptor recycling, whereas boths effects are more or less distinct for different receptors. During recent years it was also shown that constitutive receptor endocytosis plays a prominent role in the circulation of receptors. Previous methods for the analysis of receptor cycling which used receptor-specific antibodies were not sensitive enough and lacked the potential to monitor constitutive receptor endocytosis in quantitative terms.

In this work an antibody-independent method based on specific biotinylation of an acceptor peptide (AP) by the enzyme biotin ligase $A$ was established. Exemplified by the quantification of the ligand-induced internalization and recycling of CXCR4 and CCR5 the robustness and high sensivity of the assay was demonstrated. Furthermore, the assay was not influenced by receptors which were freshly translocated to the cell surface without prior ligand binding. As an additional feature the assay provided the possibility for a detailed quantification of constitutive receptor endocytosis. In order to detect all receptors within a cell regardless of whether they had previously been expressed at the cell surface AP-specific monoclonal antibodies were generated which can be used for double immunofluorescence microscopy. These antibodies allow discriminations of biotinylated and non biotinylated receptors or detection of transmembrane proteins lacking high specific antibodies.

$\beta$-Arrestin 2 is a multivalent adaptor protein involved in receptor signaling as well as endocytosis which binds to various intracellular proteins. Recent reports challenged the classical concept of GPCR signaling via heterotrimeric $G$ proteins and postulated a higher relevance of receptor homodimerization or binding of $\beta$-arrestins to the receptor. To circumvent $G$ protein activation after ligand binding a chemical-induced dimerization system consisting of three components was used. Either a FKBP12 (DmrA) or FRB (DmrC) domain was fused to the C-terminus of CXCR4/CCR5 and $\beta$-arrestin 2. Treatment of Rec-DmrA/ $\beta$ Arr-DmrC cell lines with AP21967 led to dose- and time-dependent recruitment of $\beta$-arrestin 2 to the receptor in the absence of ligand stimulation. AP21967-induced translocation of $\beta$-arrestin 2 to the receptor significantly decreased ligand-induced $G$ protein-mediated calcium release. In cell lines without $\beta A$ rr-DmrC expression no alterations were obtained. AP21967-binding also provoked a ligand-independent internalization of CXCR4/CCR5 which was on a comparable level as ligand-induced internalization. Interestingly, the AP21967-induced recruitment of $\beta$-arrestin 2 to the receptor was sufficient to mimic the specific, ligand-induced intracellular receptor distribution of either CXCR4 or CCR5. Whereas AP21967 treatment led to a $\beta$-arrestin 2 receptor desensitization and internalization it was not sufficient to mediate receptor signaling via the MAP kinases ERK 1/2. AP20187-induced receptor homodimerization had no detectable effect on either receptor desensitization or the phsophorylation level of ERK 1/2. However AP20187 pretreament led to an enhanced ligand-induced internalization in Rec-DmrA cell lines. In summary, the results obtained within this work contribute to a more detailed understanding of $\beta$-arrestin-mediated functions during chemokine receptor trafficking and demonstrated the applicability of a highly sensitive, biotin-based detection system for the analysis of trafficking of transmembrane proteins. 


\section{Introduction}

\subsection{G protein-coupled receptors}

Transmembrane receptors may be viewed as a link between an organism and its environment as they relay signals from the external to intracellular parts of the body. G protein coupled receptors form the largest group of transmembrane receptors with more than 800 members identified to date (Bjarnadóttir et al., 2006). With its seven transmembrane domains, including three internal and three external loops, GPCRs can bind to a nearly endless variety of ligands such as hormones, neurotransmitters, chemokines, calcium ions or even odors and light (Pin, 2000). According to current phylogenetic analysis the GPCR family can be divided into five main families, e.g. glutamate, rhodopsin, adhesion, frizzled, and secretin receptors (GRAFS classification). The rhodopsin group of GPCR is by far the largest group and is divided into four subgroups (Schiöth \& Fredriksson, 2005; Bjarnadóttir et al., 2006). GPCRs are expressed on a multitude of different tissue cells which is, besides their ligand variety, the main reason for their significance for several physiological processes including regulation of immune responses, senses for taste and smell and the behavior during stress situations (Lefkowitz, 2013). GPCR mutations and increased expression levels are responsible for several disorders especially in the field of endocrine diseases (Vassart \& Costagliola, 2011). Errors of GPCR trafficking can lead to cardiac diseases or chronic heart failure and also play an important role during tumor development and metastasis (Dorsam \& Gutkind, 2007; Salazar et al., 2007). These facts taken together are the reason why GPCRs are by far the most important drug targets. Approx. $40 \%$ of the currently prescribed drugs target GPCR (Filmore, 2004). Due to their variety and the high amount of orphan GPCRs without known ligand the pharmacological relevance of GPCRs is undoubted and a field of ongoing interest (Tang et al., 2012).

\subsection{Chemokine receptors and their representatives CXCR4 and CCR5}

Chemokine receptors are a subfamily of GPCRs which are activated by binding of chemotactic cytokines, also known as chemokines (Allen et al., 2007). Currently the structure and function of more than 20 typical or atypical chemokine receptors and approx. 50 chemokines is known (Schall \& Proudfoot, 2011). Chemokine receptors are expressed on various cell types in different tissues and exhibit a high signaling variety, since most chemokine receptors bind more than one chemokine ligand in a non exclusive manner (Rollins, 1997). Chemokines are 8 - 14 kDa peptides and contain a variable number of highly conserved cysteins residues (Zlotnik et al., 2006). According to the assembly of their $\mathrm{N}$-terminal cystein residues chemokines are divided into 4 groups $\left(\mathrm{C}, \mathrm{CC}, \mathrm{CXC}, \mathrm{CX} \mathrm{C}_{3}\right)$ with the two main groups CC chemokines and CXC chemokines. In CC chemokines both cysteins are adjacent, whereas a variable amino acid separates them in CXC chemokines. This system is used for the classification of either chemokines (L) or chemokine receptors (R). Thus, CCL5 is a CC chemokine and binds to the CC chemokine receptor CCR5 (Charo \& Ransohoff, 2006; Zlotnik et al., 2006). At the same time CCL5 also binds to CCR1 and CCR3, while CCR5 binds CCL3 and CCL4 as well (Pakianathan et al., 1997; Blanpain et al., 1999). This illustrates the non-exclusive, promiscuous pairing of chemokine ligands and receptors.

The biological significance of chemokine signaling is diverse but can be most likely summarized as a cell homing system. Sequestered chemokines are responsible for generating a chemokine gradient which can be utilized by chemokine receptor expressing cells for cell migration into distinct niches within and outside of immune organs. According to this principle cells of the immune system can be directed to an inflammatory site and initiate host defense (Murdoch \& Finn, 2000). The chemokine 
homing system also plays an important role during ontogeny of the hematopoietic system and is critical for correct cardiac development (Juarez \& Bendall, 2004; Agarwal et al., 2010). Chemokines are also responsible for the development, maintenance and the correct structure of secondary lymphoid organs (Randall et al., 2009; Schall \& Proudfoot, 2011). On the other hand, alterations in chemokines and their receptors are responsible for several disorders such as rheumatoid arthritis and multiple sclerosis (CCR1 and CCR2), asthma (CCR3), COPD (CXCR1 and CXCR2) and atherosclerosis $\left(\mathrm{CX}_{3} \mathrm{CR} 1\right.$ ) (Charo \& Ransohoff, 2006). Chemokine receptors CXCR4 and CCR5 act as essential CD4-dependent coreceptors for cellular entry of HIV-1 strains (Alkhatib, 2010). Both receptors are of significant interest for the pharmacological industry as a potential target to block HIV infection by blocking the coupling between HIV and CXCR4/CCR5 (Kuritzkes, 2010).

CXCR4, also known as leukocyte-derived seven- transmembrane domain receptor (LESTR) or fusin, was originally characterized as an orphan receptor which is highly expressed on leucocytes with unknown biological significance (Loetscher et al., 1994). Shortly afterwards it was revealed that CXCR4 is the main viral receptor for "T-tropic" HIV strains (Feng et al., 1996). Until now the only known CXCR4 ligand is stroma cell-derived factor 1 (SDF-1), also known as CXCL12 (Bleul et al., 1996). CXCL 12 is a highly conserved chemokine with six splicing variants, each exhibiting slightly different biological functions (Yu et al., 2006; Alkhatib, 2010). Among these CXCL12 $\alpha$ is the dominant isoform which undergoes rapid degradation in the bloodstream (Janowski, 2009). Besides its crucial role for controlling attraction and activity of leukocytes during immune responses, CXCR4 is also responsible for the embryonic development of the hematopoietic and nervous system (Zou et al., 1998; Contento et al., 2008; Li \& Ransohoff, 2009). CXCR4 is also expressed on various cancer cells and is relevant for cell proliferation and the direction of metastatic cells into organs with high local CXCL12 production, which makes the CXCR4/CXCL12 axis an interesting target for cancer therapy (Peled et al., 2012; Peled \& Tavor, 2013; Wald et al., 2013). The importance of CXCR4 and its corresponding ligand is underlined by the fact that gene deletion of either the receptor or the ligand is embryonic lethal and is responsible for defects during the development of the vascular and the central nervous system (Ma et al., 1998; Tachibana et al., 1998; Zou et al., 1998; Takabatake et al., 2009). Deletion of the CXCL12 gene results in defective $B$ and myeloid cell development and deformities of the cardiovascular and neuronal system (Nagasawa et al., 1996; Alkhatib, 2010).

Because of its role in diverse signaling pathways CXCR4 activation is strictly regulated. After CXCL12 binding, C-terminal receptor motifs containing serine and threonine residues are rapidly phosphorylated. This leads to desensitization and subsequent internalization of the activated receptor (Haribabu et al., 1997; Signoret et al., 1997; Orsini et al., 1999). CXCR4 truncation mutations which do not contain specific C-terminal serine/threonine motifs exhibit desensitization defects and impaired receptor internalization (Haribabu et al., 1997). For a prolonged receptor down regulation upon CXCL12 activation CXCR4 is internalized. In general, internalized GPCRs are either recycled back to the cell surface or degraded (Marchese et al., 2003). Although it was demonstrated that part of internalized CXCR4 recycle back to the cell surface, the main fraction of CXCR4 receptors are degraded (Marchese \& Benovic, 2001; Marchese et al., 2003; Zhang et al., 2004). The sorting process which mediates most of the internalized receptor population into degradative lysosomes is mediated by the ubiquitin ligase AIP4, which ubiquitinates the CXCR4 receptor at one of three lysine residues at positions 317, 325 and 329 of the C-terminal region (Marchese \& Benovic, 2001; Marchese et al., 2003).

Although all these details about CXCR4 trafficking are already known several structural aspects of CXCR4 remained unclear until the first crystal structures of CXCR4 were revealed (Wu et al., 2011). 
Besides detailed analysis of orientation and length of the different segments of the receptor (intraand extracellular loops, $\mathrm{C}$ - and $\mathrm{N}$-terminus) data from the crystallographic analysis confirm the concept of receptor homo- and heterodimerization. Regarding receptor homodimerization the crystallographic images determine specific contact sites, which are present in all found homodimers of CXCR4 and which appear to be crucial for receptor homodimerization (Wu et al., 2011). Binding of specific ant-/agonists to one of the homodimerized receptors induces minimal changes of the receptor conformation which lead to either a positive or negative cooperative effect ( $\mathrm{Wu}$ et al., 2011). Tranfering this concept to CXCR4 heterodimerization with CCR2 and CCR5, whereby both dimers show a negative cooperative effect, this observation is potentially of significant interest to the pharmaceutical industry (Sohy et al., 2007; Sohy et al., 2009; Wu et al., 2011). Regarding the binding of CXCL12 dimers to either monomeric or dimeric CXCR4 receptors electrostatic analysis show that ligand and receptor interact in various stoichiometric variants which show a highly dynamic fluctuation (Wu et al., 2011). This steady change in the stoichiometry between receptor and ligand is interesting since it was postulated that monomeric and oligomeric ligands can trigger different cellular reactions (Paavola et al., 1998; Appay et al., 1999; Czaplewski et al., 1999; Veldkamp et al., 2009).

So far only one clinical syndrome is known which is related to CXCR4 dysfunction and impaired receptor internalization. Warts, hypogammaglobulinemia, infections and myelokathexis syndrome (WHIM) is the result of a frameshift mutation in the CXCR4 gene causing a truncated receptor with a defect in receptor desensitization and internalization. This genetic defect leads to prolonged receptor signaling (Hernandez et al., 2003; Gulino et al., 2004; Balabanian et al., 2005).

With its seven transmembrane domains including three internal and external loops CCR5 is another typical representative for GPCRs (Figure 1). In contrast to CXCR4, the CCR5 receptor forms an internal $\mathrm{N}$-terminal disulfide bond and is palmitoylated at its C-terminus (Oppermann, 2004). In the beginning it was assumed that CCR5 can be activated by three different agonists CCL3, CCL4 and CCL5, which are till today the only full agonists for CCR5 (Murphy \& Tiffany, 1996; Alkhatib, 2010). Later on, more agonists with different binding affinities and activation potentials were discovered, including CCL7 which acts as a natural receptor antagonist (Blanpain et al., 1999).

Recently, the crystal structure of CCR5 in a complex with the HIV entry inhibitor Maraviroc was described (Tan et al., 2013). Besides a high similarity to the structure of CXCR4 the most prominent difference is the deeper and larger binding site for receptor antagonists like Maraviroc (Tan et al., 2013). Interestingly, the deeper binding pocket for CCR5 antagonists does not lead to masking of the ligand binding pocket by the $\mathrm{N}$-terminus and the second extracellular loop as it is the case for CXCR4 after antagonist binding (Tan et al., 2013). Furthermore it was determined that two recognition sites are crucial for ligand binding. The second site is blocked for chemokine interactions by Maraviroc binding which explains its inhibiting effect of Maraviroc (Tan et al., 2013). So far Maraviroc was described as an inverse agonist which stabilizes the receptor in an inactive state (Garcia-Perez et al., 2011). This model is confirmed by crystallographic analysis since Maraviroc binding occupies residues which are crucial for the change into an active receptor form. Additionally Maraviroc binding leads to a more dense packaging of the $\alpha$ helices precluding ligand binding to CCR5 (Tan et al., 2013).

In contrast to CXCR4, CCR5 expression is closely linked to tissues and cell lines involved in immune reactions (Oppermann, 2004). CCR5 is mainly expressed on macrophages, T lymphocytes and dendritic cells mediating their activation and migration during an inflammatory response (Longden et al., 2008). CCR5 is also expressed on microglia cells and plays a role in microglia recruitment and 


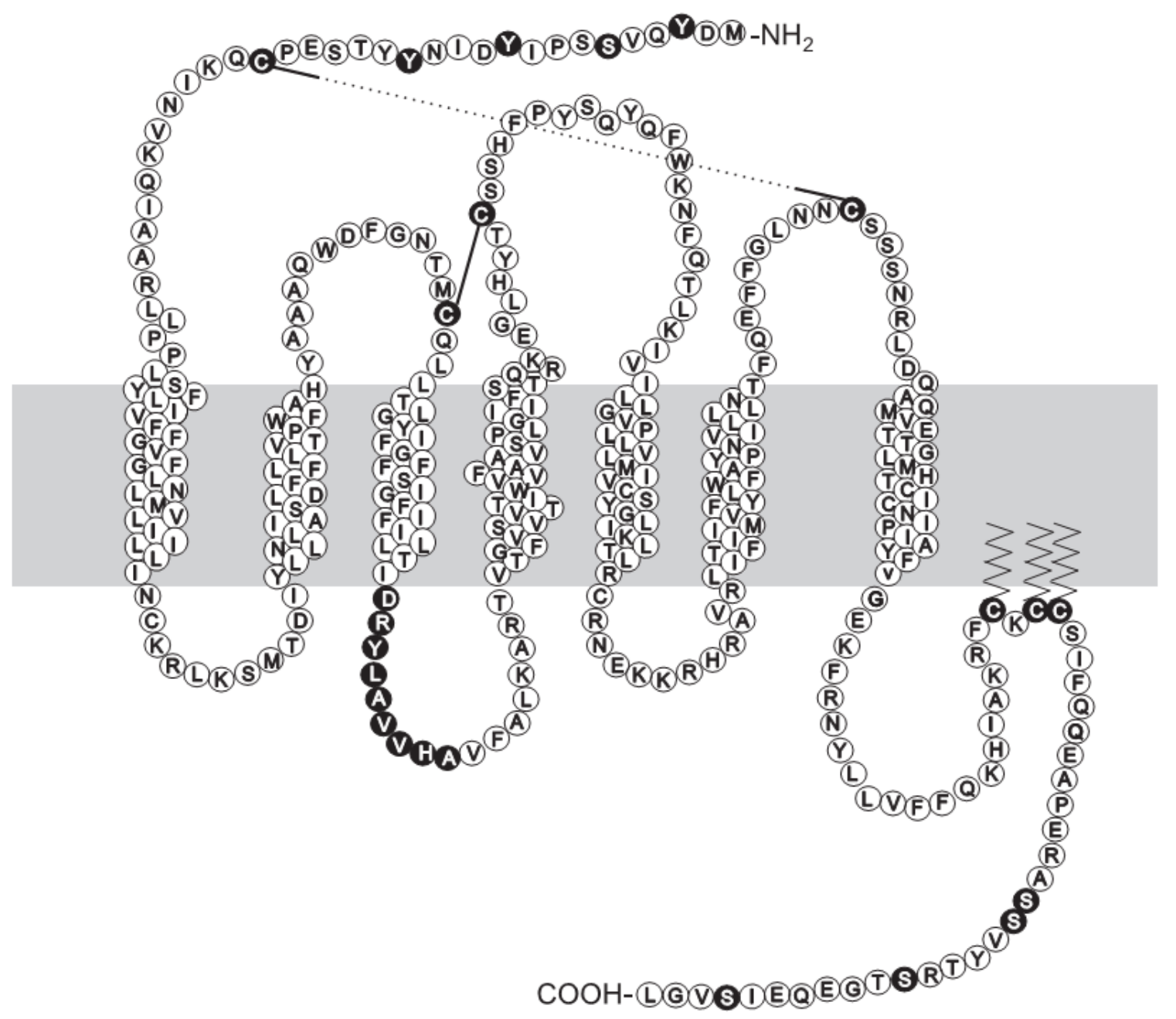

Figure 1: Two dimensional amino acid structure of the human chemokine receptor CCR5

Schematic overview of the alignment of amino acids of CCR5 and their orientation in the extracellular space (top), the cell membrane (grey) and intracellular space (bottom). The receptor consists of seven hydrophobic transmembrane domains forming three internal and three external loops. In the extracellular space the receptor establishes a disulfide bond between two cysteine residues located on the aminoterminus and the third extracellular loop, whereas the $\mathrm{C}$-terminus is palmitoylated at three distinct cystein residues which function as a membrane anchor. Amino acids which are crucial for receptor function are shown filled. Figure taken from Oppermann 2004.

activation during brain development and after severe brain injuries (Cowell et al., 2006). Studies with CCR5-deficient mice reveal an enhanced susceptibility for parasite and influenca A infections, thus underlining the crucial role of CCR5 during immune response. ( Mack et al., 2001). On the other hand, CCR5 deletion leads to enhanced lymphocyte infiltration into the lamia propria of the colon and an increased tolerance towards lipopolysaccharide induced immune responses (Zhou et al., 1998; Andres et al., 2000).

CCR5 also undergoes rapid phosphorylation of C-terminal serine residues after ligand activation (Oppermann et al., 1999; Pollok-Kopp et al., 2003). Mutations or truncations of these serine residues or the palmitoylation sites result in impaired desensitization and internalization of the receptor (Kraft et al., 2001). Receptor phosphorylation in combination with $\beta$-arrestin binding to a DRY motif located in the second internal loop initiates clathrin-mediated internalization of CCR5 into early endosomes (Pollok-Kopp et al., 2003; Lagane et al., 2005; Drake et al., 2006). In contrast to CXCR4, CCR5 rapidly recycles back to the cell surface via recycling endosomes after it was internalized (Mueller \& Strange, 
2004). Receptor recycling is mediated, in part, by a postsynaptic density $95 /$ discs large/zona occludens (PDZ) interacting sequence located in the C-terminal tip of CCR5 (Delhaye et al., 2007). The PDZ domain can be utilized for protein-protein interactions which are crucial for endosomal sorting of CCR5 in recycling endosomes (Alkhatib, 2010). Recycled receptors which are displayed at the cell surface are not inevitably detached from the activating agonist, although endosomes are progressively acidified which facilitates dissociation of the ligand-receptor complex (Schaeffer et al., 2004). Instead ligand-occupied receptors rapidly reinternalize until the ligand detaches or the receptor is degraded (Signoret et al. 2000).

Besides their involvement in disorders of the immune system CXCR4 and CCR5 also play a key role as coreceptors for HIV-1 infections (Cilliers et al., 2003). The HIV fusion is initiated by activation of the virus envelope glycoprotein gp 120 by CD4 binding and subsequent binding to CXCR4 or CCR5 which triggers gp41 to mediate the fusion with the cell membrane. So far several entry inhibitors targeting either CXCR4 or CCR5 have been developed, among them Maraviroc, Viroviroc or AMD3100 (Hendrix et al., 2004; Westby \& van der Ryst, 2005). Most of these therapeutics are receptor antagonists which bind to the receptor and thus inhibit HIV-1 binding without activating cellular signaling (Kuritzkes, 2010). Individuals homozygous for a 32 base pair deletion in the CCR5 gene are essentially protected against HIV-1 infections (Samson et al., 1996). The base pair deletion leads to the expression of a truncated form of CCR5 which is retained within the ER and not transported to the plasma membrane where it may assist signaling and cell surface regulation (Venkatesan et al., 2001). Approx. 5 to $14 \%$ of the European population exhibit this gene defect which results in functional CCR5 deficiency (Sabeti et al., 2005). Since these individuals do not suffer from any noticeable immunodeficiency pharmacological blockade of CCR5 appears a safe strategy with limited site effects (Barmania \& Pepper, 2013).

\subsection{Classical model of G protein-coupled receptor signaling and cell surface regulation}

The classical model of $\mathrm{G}$ protein signaling is based on ligand-induced activation of GPCR as described in Figure 2 (Woehler \& Ponimaskin, 2009). Ligand binding to the receptor leads to a conformational rearrangement of the three dimensional protein fold of the receptor which allows the receptor to bind and activate different downstream effector proteins (Hoffmann et al., 2008). It is assumed that binding of different ant-/agonists leads to different receptor conformations which trigger different signaling pathways, respectively (Baker \& Hill, 2007).

The classical model of monomeric receptors interacting with monomeric ligands is more and more replaced by the concept of receptor homo- and heterodimerization (Terrillon \& Bouvier, 2004b; Milligan, 2013). Until now it is not fully understood whether receptor dimerization occurs during receptor biosynthesis or is induced by binding of monomeric or dimeric receptor ligands (Milligan, 2004). Also it is highly debated whether receptor dimers and monomers assume different functions during cell signaling and trafficking (Gurevich \& Gurevich, 2009). So far the results indicate that receptor dimerization may serve either as a desensitization mechanism or has the potential to activate dimerized receptors via a positive allosteric effect as it's the case for the $G A B A_{B 1} R$ and $G_{A B A} R$ receptor (Robbins et al., 2001; Gurevich \& Gurevich, 2009). Desensitization is achieved by co-internalization of dimerized receptors or a direct reduction of the signaling efficiency after receptor dimerization as described for the neurotensin receptor (Hüttenrauch et al., 2005; Gurevich \& Gurevich, 2009). For the pharmalogical aspect this mutual influence of receptors can be of greater importance since targeting of one receptor may have a direct influence on a second receptor (Milligan, 2004). Dimeric receptors do also play a keyrole in the heterozygous form of the 


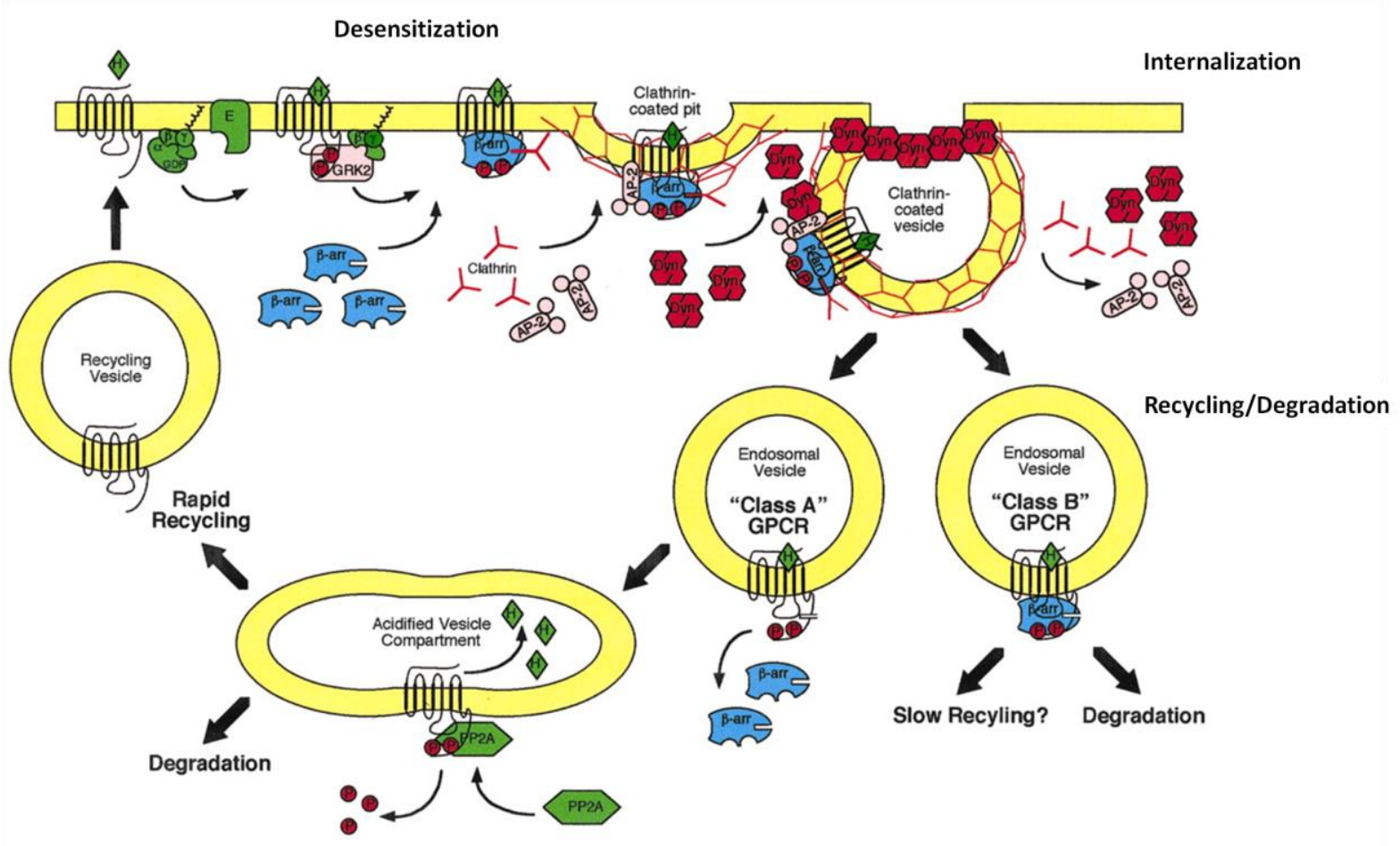

Figure 2: Desensitization, internalization and recycling of GPCRs

Receptor activation is mediated by binding of a receptor agonist (e.g hormone; $\mathrm{H}$ ), which induces a conformational change of the receptor. The conformational change promotes binding of a heterotrimeric $\mathrm{G}$ protein, consisting of an $\alpha$ and $\beta \gamma$-subunit, to the intracellular interface of the receptor. Exchange of the bound GDP at the $\alpha$-subunit for GTP leads to dissociation of the heterotrimeric complex into $\alpha$ - and $\beta \gamma$-subunits each activating distinct signaling pathways. Recruited GRKs phosphorylate serine and threonine residues in the receptor $C$-terminus to allow binding of $\beta$-arrestins. $\beta$-Arrestin binding inhibits rebinding of reassembled G-proteins by steric hindrance which leads to termination of $G$ protein-mediated signaling by $G$ protein effectors $(E)$. Receptor internalization is initiated by binding of proteins of the endocytic machinery (AP2 and clathrin) to $\beta$-arrestin. Clathrin coated pits containing receptor ligand complexes are closed by dynamin and sequestered into the cytoplasm. Once internalized, class A receptors dissociate from $\beta$-arrestin and are sorted into acidified vesicles. Acidification facilitates ligand dissociation whereas the receptor is dephosphorylated by GPCR-specific protein phosphatases such as PP2A. Subsequently the receptor rapidly recycles back to the cell membrane. Class $B$ receptors show a prolonged binding to $\beta$-arrestins and are either sorted for degradation by ubiquitination catalyzed by a $\beta$-arrestin bound ubiquitin ligase (e.g. Mdm2) or slowly recycled back to the cell membrane. Figure modified from Luttrell \& Lefkowitz 2002.

CXCR4-related WHIM syndrome. The mutated receptor coexpressed with a WT receptor leads to an overall enhanced signaling accompanied by a defect in desensitization and internalization (Balabanian et al., 2005; Lagane et al., 2008). Regarding CCR5 it was postulated that ligand-induced receptor dimerization directly triggers the JAK/STAT signaling pathway (Mellado et al., 2001a). Both results underline once again the importance and the potential of receptor dimerization. Despite all these findings the functional significance of receptor dimerization remains still unclear especially since it was reported that several GPCRs can modulate signaling in a strictly monomeric form (Whorton et al., 2007; Kuszak et al., 2009). Therefore, a system to mimic receptor homodimerization would be desireable to analyze the consequence of receptor homodimerization in the absence of previous ligand activation.

General signal transduction of activated GPCRs is mediated by heterotrimeric G proteins consisting of an $\alpha$ - and a $\beta \gamma$-subunit. Currently four different families containing several members of $\alpha$-subunits are discriminated $\left(G_{\alpha S}, G_{\alpha i / o}, G_{\alpha q / 11}, G_{\alpha 12 / 13}\right)$. Each $G_{\alpha}$-subunit mediates the activation and/or regulation of different cellular pathways, thus contributing to a high variety of potential cellular responses after GPCR activation (Milligan \& Kostenis, 2006). Five $\beta$ - and twelve $\gamma$-subunits are 
described, extending the possible combinations for heterotrimeric $\mathrm{G}$ proteins and their potential signaling capacity even more (Milligan \& Kostenis, 2006). Although it is known that the ligand-induced conformational change of the receptor promotes binding of the heterotrimeric $G$ proteins it is still not fully understood how the binding between receptor and $G$ proteins is achieved (Wettschureck \& Offermanns, 2005). After activation of the receptor the $G$ protein complex binds to C-terminal residues, whereby the receptor acts as a guanine nucleotide exchange factor (GEF) facilitating an exchange of the $\alpha$ bound GDP to GTP (Ritter \& Hall, 2009). GTP binding leads to a dissociation of the heterotrimeric complex into $\alpha$ and $\beta \gamma$-subunit and dissociation of the subunits from the receptor to influence various mediators of downstream signaling such as ion channels, adenylyl cyclase, phosphodiesterase and phospholipase C (Exton, 1996; Sunahara et al., 1996; Yamada et al., 1998). G protein signaling is terminated by the GTPase function of the $\alpha$-subunit which catalyzes the hydrolysis of GTP to GDP (Wettschureck \& Offermanns, 2005). In its GDP-bound state the $\alpha$-subunit can reattach to the $\beta \gamma$-subunit and is available for newly activated receptors (CabreraVera, 2003).

Due to their ability to activate several different signaling pathways GPCR desensitization is a highly regulated process involving protein kinases (PKA and PKC) and GPCR kinases/ $\beta$-arrestins, respectively (Luttrell \& Lefkowitz, 2002; Drake et al., 2006). Both protein kinases can be activated by second messengers which emerge during GPCR activated signaling cascades (Newton, 1995; Das et al., 2007). PKA is activated by binding to cAMP which is generated by the $\mathrm{G}_{\alpha}$-activated enzyme adenylate cyclase (Neumann et al., 2014). On the other hand PKC activation is mediated by a signaling cascade triggered by the $\beta \gamma$ subunit which activates phospholipase $C$ which cleaves the protein phosphatidylinositol 4,5-biphosphate $\left(\mathrm{PIP}_{2}\right)$ into the second messengers inositol $(1,4,5)$ trisphosphate $\left(\mathrm{IP}_{3}\right)$ and diacylglycerol (DAG). PKC is either activated directly by binding of DAG or by the $\mathrm{IP}_{3}$ triggered release of calcium ions from internal storages (Falkenburger et al., 2013). Activated protein kinases phosphorylate serine and threonine residues in the receptor C-terminus which leads to a direct impairment of $\mathrm{G}$ protein binding in the absence of $\beta$-arrestin binding (Luttrell \& Lefkowitz, 2002). Since activated protein kinases have the potential to phosphorylate more than one receptor this form of desensitization is more general (heterologous desensitization) (Chuang et al., 1996). On the other hand GPCR kinases specifically phosphorylate serine and threonine residues of GPCRs but in contrast to protein kinases they are not activated by second messengers. Instead they phosphorylate preferentially residues of agonist-occupied GPCRs (Luttrell \& Lefkowitz, 2002). GRK phosphorylation leads to the recruitment and binding of $\beta$-arrestin to the activated receptor which results in a specific desensitization of one receptor (homolougus desensitization). Binding of $\beta$-arrestin to the phosphorylated receptor is sufficient to block rebinding of $G$ proteins by steric hindrance (Luttrell \& Lefkowitz, 2002). In addition $\beta$-arrestins act as scaffolding proteins for various proteins including the $\beta 2$-subunit of AP2 which mediates endocytosis of the activated receptor via clathrin-coated pits (Goodman et al., 1996; Laporte et al., 1999; Marchese, 2014).

Once receptors are internalized and transported to early endosomes they are sorted either for receptor degradation or recycle back to the cell surface (Marchese et al., 2003). A factor which determines the fate of internalized receptors is the duration of $\beta$-arrestin binding to the receptor, which differs between class $A$ (short arrestin binding) and class B (prolonged arrestin binding) GPCRs (Drake et al., 2006). $\beta$-Arrestin interacts with ubiquitin ligases which catalyze ubiquitination of the receptor at distinct motifs as described for CXCR4 (Marchese \& Benovic, 2001; Marchese et al., 2003). Subsequent to ubiquitination the receptor is directed into lysosomes for proteosomal degradation (Marchese \& Benovic, 2001). On the other hand, GPCRs such as CCR5 are sorted into recycling endosomes for rapid relocation back to the cell membrane (Mueller et al., 2002; Marchese, 
2014). Responsible for the sorting into recycling endosomes are distinct motifs of the receptors such as the PDZ motif of CCR5 (Delhaye et al., 2007). During their passage through recycling endosomes ligand detachment is facilitated by acidification of the endosomal milieu. In parallel the receptor is subsequently dephosphorylated by protein phosphatases to be available for restimulation at the cell surface (Luttrell \& Lefkowitz, 2002).

Over the last years the most common method to analyze receptor trafficking was receptor specific staining with fluorochrome-labeled antibodies combined with flow cytometry or immunofluorescence microscopy (Anselmo et al., 2014). Less commonly applied methods include the counting of radioactivity during a radioligand uptake assay or antibody feeding where bound receptors are co-internalized with the receptor (Arancibia-Cárcamo et al. 2006; Sorkin \& Duex 2010). However all these methods have several limitations regarding their sensitivity. So far it was assumed that receptor internalization is a process which requires ligand activation. During the recent years studies revealed that GPCRs can undergo constitutive endocytosis without previous ligand binding (Scarselli \& Donaldson, 2009; Uwada et al., 2014). This effect can not be detected with the described methods since it is masked by translocation of newly synthesized and recycled receptors to the cell surface. The same problem occurs when receptor recycling after ligand-induced internalization is measured. The net recycling rate of a specific receptor population can not be quantified since classical methods can not discriminate between receptors which remain on the cell surface after ligand treatment and those receptors which already recycled back or are newly synthesized and translocated to the cell membrane. In order to determine the net and constitutive internalization rate of a receptor it would be useful to establish a system which is able to tag and track a specific receptor population through the whole internalization and recycling process.

\subsection{The multivalent adaptor protein $\beta$-arrestin and its role for cell signaling}

Arrestins belong to a small protein family with four different representatives (arrestin 1 to 4 ) which play a crucial role for the mediation and regulation of GPCR signaling (Lefkowitz \& Shenoy 2005; Moore et al. 2007). Table 1 gives an overview on the arrestin nomenclature, including commonly used alias names and the cellular expression of each arrestin subtype.

Long time before the relevance of $\beta$-arrestins for cell signaling was known, visual arrestin (arrestin 1 ) was discovered in the retina (Wacker et al., 1977). Later on it was found that visual arrestin binds to rhodospin after its activation, which leads to an "arresting effect" of G protein-mediated effects (Zuckerman \& Cheasty, 1986). Similarities in the structure and function of rhodopsin, $\beta_{2}$-adrenergic receptor and associated proteins led to the discovery of the two non-visual arrestins arrestin 2 and 3 (also known as $\beta$-arrestin 1 and 2), which interact with ubiquitously expressed GPCRs to regulate the signaling of those receptors (Lohse et al., 1990; Attramadal et al., 1992). The fourth member arrestin 4 is preferentially expressed in retinal cones and was discovered by homology cloning (Craft, 1995). Through the rest of the work we used the alias nomenclature. 


\section{Table 1: Arrestin nomenclature and expression}

Besides the systematic names (arrestin 1 to 4) several alias names were established over the years. Its immunogenicity and high expression level in photoreceptor cells are responsible for the alternative names S-antigen (soluble antigen) and visual arrestin for arrestin 1 . Due to its ability to inhibit signaling of the $\beta_{2}$-adrenergic receptor in several tissue cells arrestin 2 was initially named $\beta$-arrestin 1 . The higher homology of arrestin 3 to $\beta$-arrestin 1 than to arrestin 1 was the reason for the alternative name $\beta$-arrestin 2. Arrestin 4 was termed $X$ arrestin or cone arrestin because of the gene location on the $X$ chromosome and its preferred expression in retinal cones. Data taken from Gurevich 2014.

\begin{tabular}{ccc}
\hline Nomenclature & Alias & Expression \\
\hline Arrestin 1 & S-antigen, visual Arrestin & Retinal rods, pineal gland \\
Arrestin 2 & $\beta$-Arrestin 1, & Ubiquitous \\
Arrestin 3 & $\beta$-Arrestin 2 & Ubiquitous \\
Arrestin 4 & X-Arrestin, cone arrestin & Retinal cones \\
\hline
\end{tabular}

For the interaction between GPCR and arrestin two requirements must be complied. First, the receptor must be present in its active form, which is achieved by ligand binding and subsequent conformational change of the receptor (Hoffmann et al., 2008). The second requirement is the GRK-mediated phosphorylation of residues in the C-terminus and at times the third intracellular loop of the receptor. Under these conditions all four arrestin variants can interact with GPCRs (Gurevich, 2014). Due to their different cellular expression and different receptor specificity, a large variety of arrestin-mediated effects is ensured (Gurevich, 2014). Of both requirements the phosphorylation pattern which is necessary for arrestin activation is far better understood. Studies with (visual) Arrestin 1 showed that single phosphorylations at the receptor C-terminus are not sufficient for Arrestin binding. Double phosphorylation can promote a weak binding of Arrestin, whereas phosphorylation of three different phosphorylation sites leads to full arrestin binding including a conformational change (Kraft et al., 2001; Vishnivetskiy et al., 2007). These requirements seem less strict regarding the binding of $\beta$-arrestin $1 / 2$ (arrestin $2 / 3$ ), where phosphorylation of a serine cluster appears more important for receptor binding (Krasel et al., 2008).

Recently crystallographic analysis of $\beta$-arrestin 1 could demonstrate the structural differences between its active and inactive form (Figure 3) (Arun Shukla et al., 2013). The conformational change is triggered by a two step recognition system. A phosphate sensor detects phosphorylated residues in the receptor $\mathrm{C}$-terminus, whereas a second sensor in $\beta$-arrestin recognizes ligand-induced changes in the receptor core (Gurevich \& Gurevich, 2006; Shukla et al., 2014). If both requirements are met $\beta$-arrestin 1 changes towards its active form which involves several structural changes. The most prominent one is a $20^{\circ}$ twist of the C- and $\mathrm{N}$-terminus relative to each other (Shukla et al., 2013). In addition to this twist the $\mathrm{N}$-terminus and other protein loops (finger-, middle- and lariat-loop) undergo further structural changes which are crucial for $\beta$-arrestin 1 activation (Shukla et al., 2013). All loops are highly flexible and change their orientation after receptor binding, whereas the finger loop seems to be most important for the discrimination between active and inactive GPCRs due to its direct interaction with the receptor core (Shukla et al., 2013; Shukla et al., 2014). 

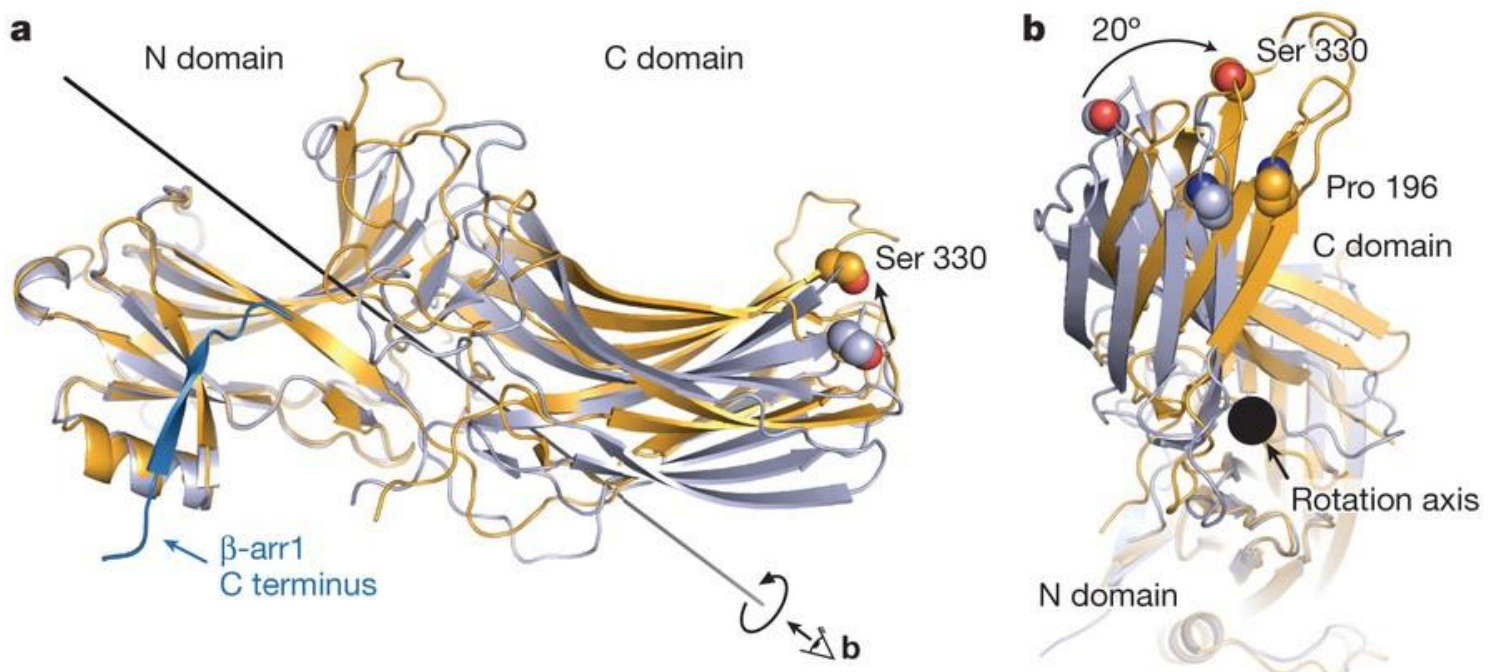

$\mathrm{N}$ domain

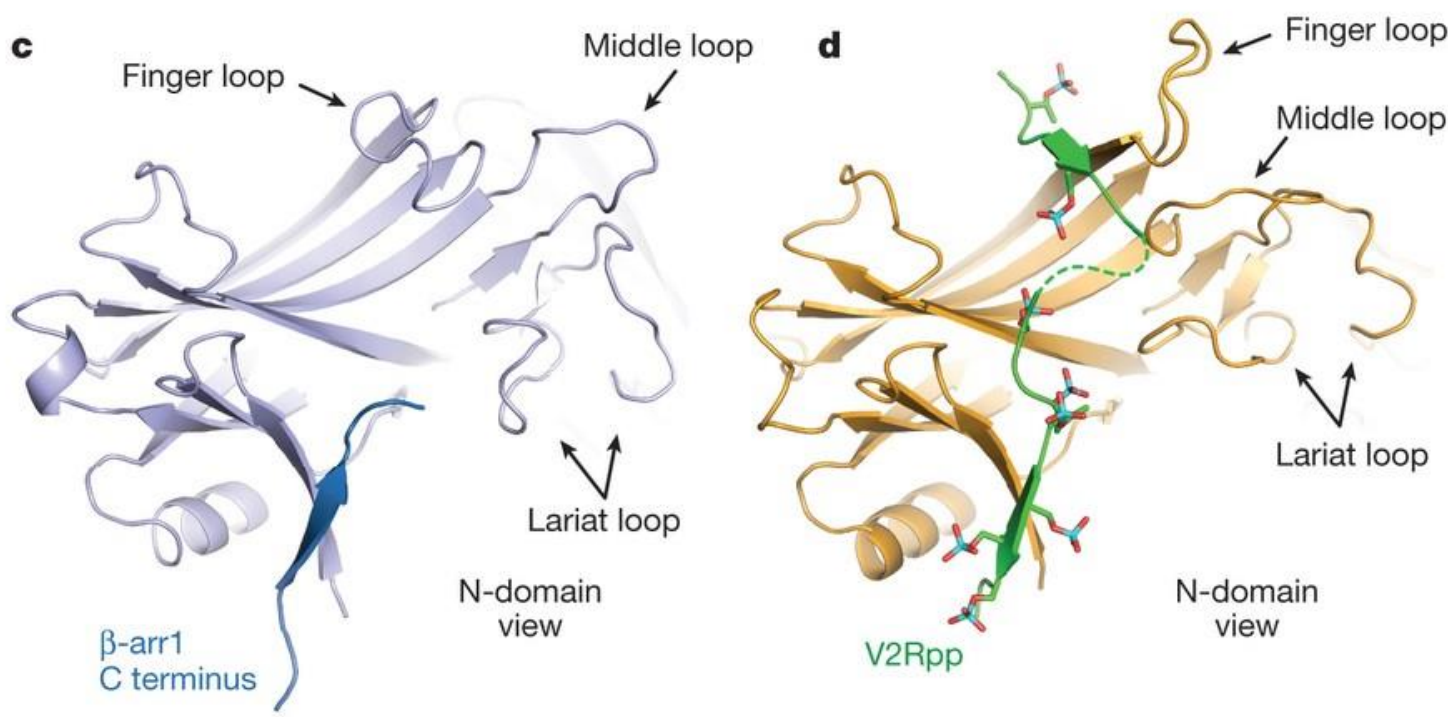

Figure 3: Three dimensional structure of the active and inactive conformational state of $\boldsymbol{\beta}$-arrestin 1

Three dimensional structure of $\beta$-arrestin 1 in its inactive (light blue) and active state (gold). a) Topview of $\beta$-arrestin 1 aligned on the $\mathrm{N}$ domains. Upon activation a $20^{\circ}$ rotation (black rotation axis) and shift of the $\mathrm{N}$ - and $\mathrm{C}$-terminus (dark blue) relative to the each other is visible. b) Lateral view of the rotation process for the $\mathrm{C}$-terminal domain around the rotation axis (black dot). c) Topview of an inactive $\beta$-arrestin 1 without binding to phosphorylated receptor resdues. Important regions are highlighted. d) Topview of an activated $\beta$-arrestin 1 bound to phosphorylated receptor residues (V2 vasopressin- receptor-derived phosphopeptide V2Rpp; green; phosphorylated residues are shown as stick models). Modified from Shukla et al. 2013..

While it was presumed that all GPCRs are phosphorylated equally after ligand binding, recent reports show that the GRK-mediated receptor phosphorylation is dependent on specific ligands which trigger the process and the GRK downstream of the receptor (Gurevich, 2014). For systematic reasons, GPCRs were divided into class A and B regarding their phosphorylation pattern (Oakley et al., 2000). Class $A$ receptors are proposed to bind $\beta$-arrestin 2 with higher affinity than $\beta$-arrestin 1 , whereas class $B$ receptors bind both $\beta$-arrestins with an equal preference (Oakley et al., 2000). Furthermore the duration of arrestin binding differs in both receptor classes. Whereas class $\mathrm{A}$ receptors show a short arrestin binding, class B receptors show a prolonged binding to arrestin (Luttrell \& Lefkowitz, 2002). Among the early described effects of arrestins was the inhibition of $G$ protein-mediated signaling in the visual system (Wilden et al., 1986). Thereby arrestin 1 causes the best possible adaptation to photonic activation of rhodopsin by sensitive regulation of $\mathrm{G}$ protein-mediated signaling through binding to the phosphorylated receptor (Arshavsky et al., 2002). Thereby binding of 
arrestin blocks rebinding of reassembled $\mathrm{G}$ proteins by steric hindrance, which subsequently leads to a disruption of $\mathrm{G}$ protein-mediated signaling (Lefkowitz, 1998). This principle can be transferred to $\beta$-arrestin $1 / 2$ and their interaction with GPCRs in non visual tissues (Sibley et al., 1987).

After discovery of the desensitization effect of arrestins additional studies revealed a contribution of $\beta$-arrestins to the ligand-induced receptor internalization (Goodman et al., 1996). This effect appeared to be limited to $\beta$-arrestin $1 / 2$ and was the first significant difference in comparison to visual arrestins which lacked this ability (Goodman et al., 1996). After binding to GRK-phosphorylated receptors $\beta$-arrestin couples the whole complex to $\beta_{2}$-adaptin, a subunit of AP2, and mediates transfer of activated receptors into clathrin coated pits from where they are internalized into early endosomes (Kang et al., 2013). Afterwards internalized receptors are sorted for recycling or degradation (Marchese et al., 2003). Thereby differentiation into class A and B receptors as introduced before may play an important role since class $B$ receptors show prolonged binding to $\beta$-arrestin compared to class A receptors (Luttrell \& Lefkowitz, 2002). This prolonged binding may be crucial for ubiquitination of internalized receptors, since it was demonstrated that $\beta$-arrestin also interacts with several E3 ubiquitin ligases such as Mdm2 (Shenoy et al., 2001).

According to this model, $\beta$-arrestin plays a more prominent role for the regulation of GPCR signaling than previously expected. $\beta$-Arrestin-mediated internalization leads on the one side to receptor degradation but on the other side also promotes dephosphorylation of internalized receptors and subsequent recycling back to the cell surface for repeated rounds of signaling (Gurevich, 2014). This model indicates that $\beta$-arrestin binding is not restricted to activated receptors but also acts as adaptor protein which couples receptors to several other proteins which are relevant for GPCR trafficking (Ma \& Pei, 2007).

Among the proteins which use $\beta$-arrestin as a scaffold protein are proteins which are involved in distinct signaling pathways like c-Src or the MAP kinases ERK 1/2 and p38 (Lefkowitz \& Shenoy 2005; Shenoy et al. 2006). Activation of these signaling proteins is mechanistically closely related to clathrin-mediated receptor internalization (Luttrell et al., 2001). During recent years a model has evolved according to which GPCR signaling is segmented into three distinct signaling waves. The first waves occurs after ligand activation of the receptor at the cell membrane, the second wave correlates with $\beta$-arrestin binding and the third is triggerd by GPCRs which are internalized via endosomes (Lohse \& Calebiro, 2013). The $\beta$-Arrestin-mediated signaling wave leads among other effects to the phosphorylation of ERK $1 / 2$, which is organized in a complex with the kinases Raf and MEK (Chang et al., 2003). Thereby Raf and MEK consecutively catalyze the phosphorylation of ERK $1 / 2$, which itself is responsible for the phosphorylation of several membrane proteins (Gurevich, 2014). Furthermore, activated ERK can translocate into the nucleus where it promotes the transcription of a distinct DNA subset (Pearson et al., 2001). ERK $1 / 2$ as well as Raf, prefer binding to the membrane-bound form of $\beta$-arrestin, which indicates that $\beta$-arrestin-mediated signaling is closely linked to $\mathrm{G}$ protein activation after ligand stimulation (Coffa et al., 2011; Coffa et al., 2012). These findings formed the basis for a revised model of "biased" GPCR signaling (Figure 4) (Drake et al., 2008).

Biased GPCR signaling refers to the principle that biased ligands or receptors promote specific modes of signal transduction, respectively (Rajagopal et al., 2010; Reiteret al., 2012; Rajagopal et al., 2013). It is assumed that binding of biased ligands stabilize slightly different receptor conformations which lead to either a $G$ protein-biased or $\beta$-arrestin-biased receptor response (Rajagopal et al., 2013). Furthermore it is assumed that the variety of receptor conformations provoke a specific phosphorylation pattern ("bar code") which is mediated by different GRKs and in turn allows different proteins to interact with the C-terminus of the receptor (Reiter et al., 2012). Apart from 


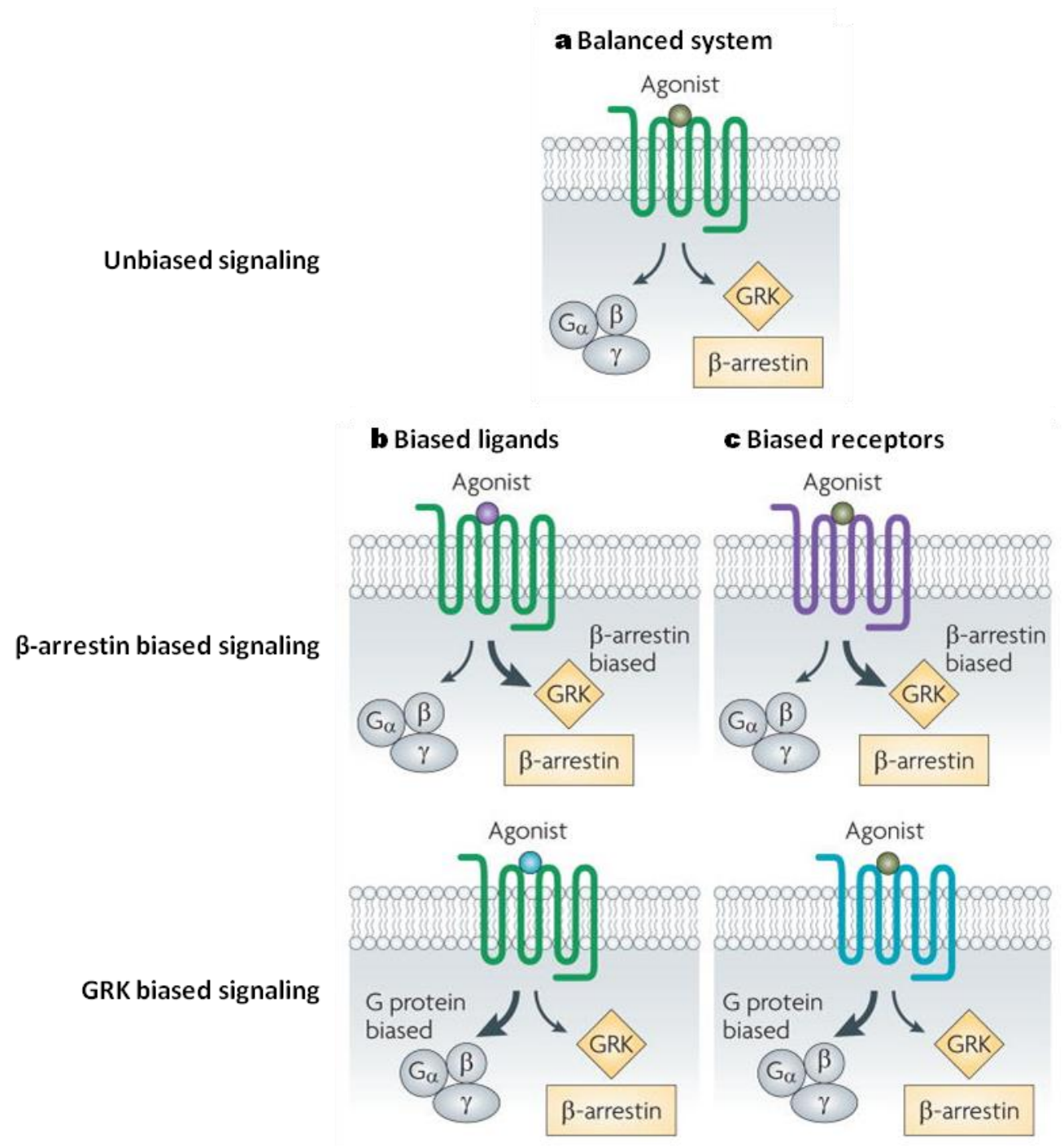

Figure 4: Biased signaling either mediated by biased ligands or biased receptors

In a balanced system (a) ligand-binding leads to activation of both $G$ protein and $\beta$-arrestin effects, followed by $\beta$-arrestin mediated desensitization and internalization of the receptor. If a biased ligand binds to an unbiased receptor (b) signaling is preferentially mediated by either $G$ proteins ( $G$ protein-biased ligand; light blue) or $\beta$-arrestins ( $\beta$-arrestin-biased ligand; purple). Alternatively, binding of an unbiased ligand to a biased receptor (c) also results in biased signaling (purple: arrestin-biased; light blue: G protein-biased). Figure modified from Rajagopal et al. 2010.

biased ligands the existence of biased receptors is also proposed within this model. Here, binding of an unbiased ligand promotes signaling via preferred signaling pathways (Rajagopal et al., 2010). Currently the concept of biased signaling is a field of intense research since the possibility of activating specific pathways within a cell by using distinct ligands is potentially of high interest to the pharmaceutical industry (Bosier \& Hermans, 2014). Although the importance of arrestin-mediated effects and biased signaling is more and more revealed it is still not fully understood which of the known arrestin-mediated effects are supported by $G$ protein activated pathways, since arrestin binding to the receptor is inevitably coupled to $G$ protein activation (Miller \& Lefkowitz, 2001). Therefor a clear discrimination between arrestin- and $G$ protein-mediated effects would be desireable. One possibility to achieve a separation of both effects would be an inducible system which directly recruits arrestin to the receptor without previous ligand binding. 


\subsection{Analysis of protein protein interactions by chemical induced dimerization}

Since the understanding of biological processes constantly progresses it becomes more and more important to understand and comprehend biological consequences of interactions of different partners on protein or DNA level (Brent, 2004). The significance of protein protein interactions is in many cases not well understood, although these interactions directly influence the phenotype of an organism (Fegan et al., 2010). The possibility to induce protein protein interactions or to block them in a targeted manner is a useful tool for the analysis of different cellular functions. During recent years chemical-induced dimerization (CID) of proteins has evolved as one of the favored methods for the investigation of protein interactions (Fegan et al., 2010). In this approach two proteins or functional domains thereof are attached to the protein of interest and are brought in close proximity by addition of a dimerizing agent (DeRose et al., 2013). Depending on the symmetry of the dimerizer two identical proteins (symmetric dimerizer) can be brought together as a homodimer or two different proteins are brought together as a heterodimer (asymmetric dimerizer) (Figure 5).

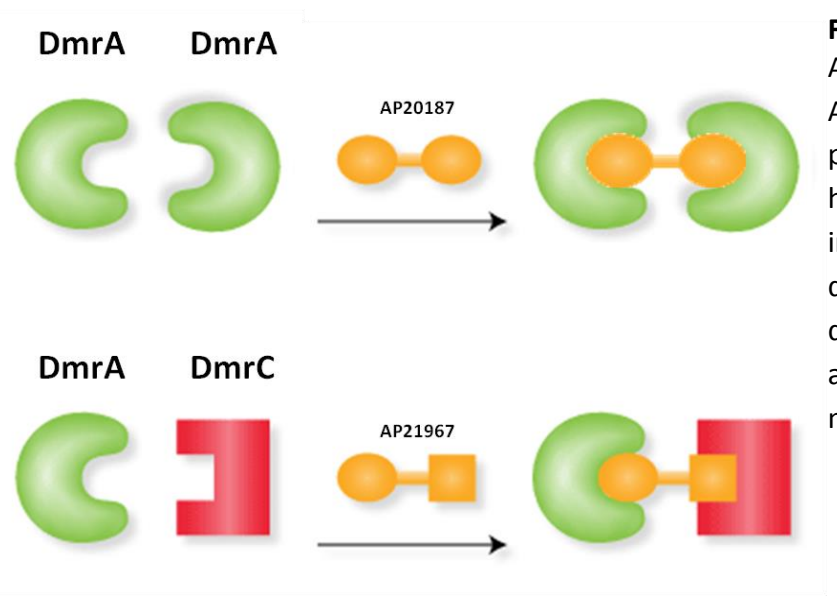

Figure 5: Principle of homo-.and heterodimerization After entering the cell a symmetric dimerizer (e.g. AP20187; top) binds to two identical proteins/ protein domains (DmrA; green) inducing a homodimerization where both proteins are located in close proximity to each other. If an asymmetric dimerizer (e.g. AP21967; bottom) is used two different proteins/ protein domains (DmrA; green and DmrC; red) are recruited to each other. Figure modified from Clontech Laboratories 2008.

In the first example of chemical-induced dimerization of proteins described in the literature the immunsuppresive drug FK506 was used to reversibly homodimerize the FK506 binding protein (FKBP12) (Spencer et al., 1993). Furthermore, it was demonstrated that fusion of FKBP12 to the $\zeta$ chain of the $T$ cell receptor was sufficient to activate endogenous signaling pathways when dimerization was triggered by FK1012 (Spencer et al., 1993). Since this pioneering study several other dimerization systems have been established which follow more or less the same principle. One of the recently most used systems is the FKBP12-FRB system as marketed by the company Clontech (Figure 6). Besides binding to known dimerizing agents such as FK1012, FKBP12 can also bind to the immunosuppressant rapamycin. In this combination and not in an unbound state the complex can interact with FKBP12-rapamycin associated protein (FRAP) also known as mammalian target of rapamycin (mTOR) (Banaszynski et al., 2005). Problematic is the size (289 kDa) of mTOR which will quite likely interfere with biological functions of the protein of interest when present as a mTOR fusion protein (Fegan et al., 2010). However, the site of binding to rapamycin could be narrowed down to a specific rapamaycin binding domain (FRB) of only 90 amino acids (11 kDa) (Chen et al., 1995). The complex consisting of FKBP12, FRB and rapamycin is, in principle, suitable as a dimerizing system since both domains bind tightly to rapamycin (Banaszynski et al., 2005). However, rapamycin will interact with endogenous mTOR in addition to fusion proteins, thus initiating unwanted cellular effects (Ballou \& Lin, 2008). Rapamycin analogs (rapalogs) were designed which specifically bind to a slightly modified version of the FRB domain, but not to endogenous mTOR, with nanomolar affinity (Clackson, 1998; Bayle et al., 2006). Dimerizing systems which consist of the three components 


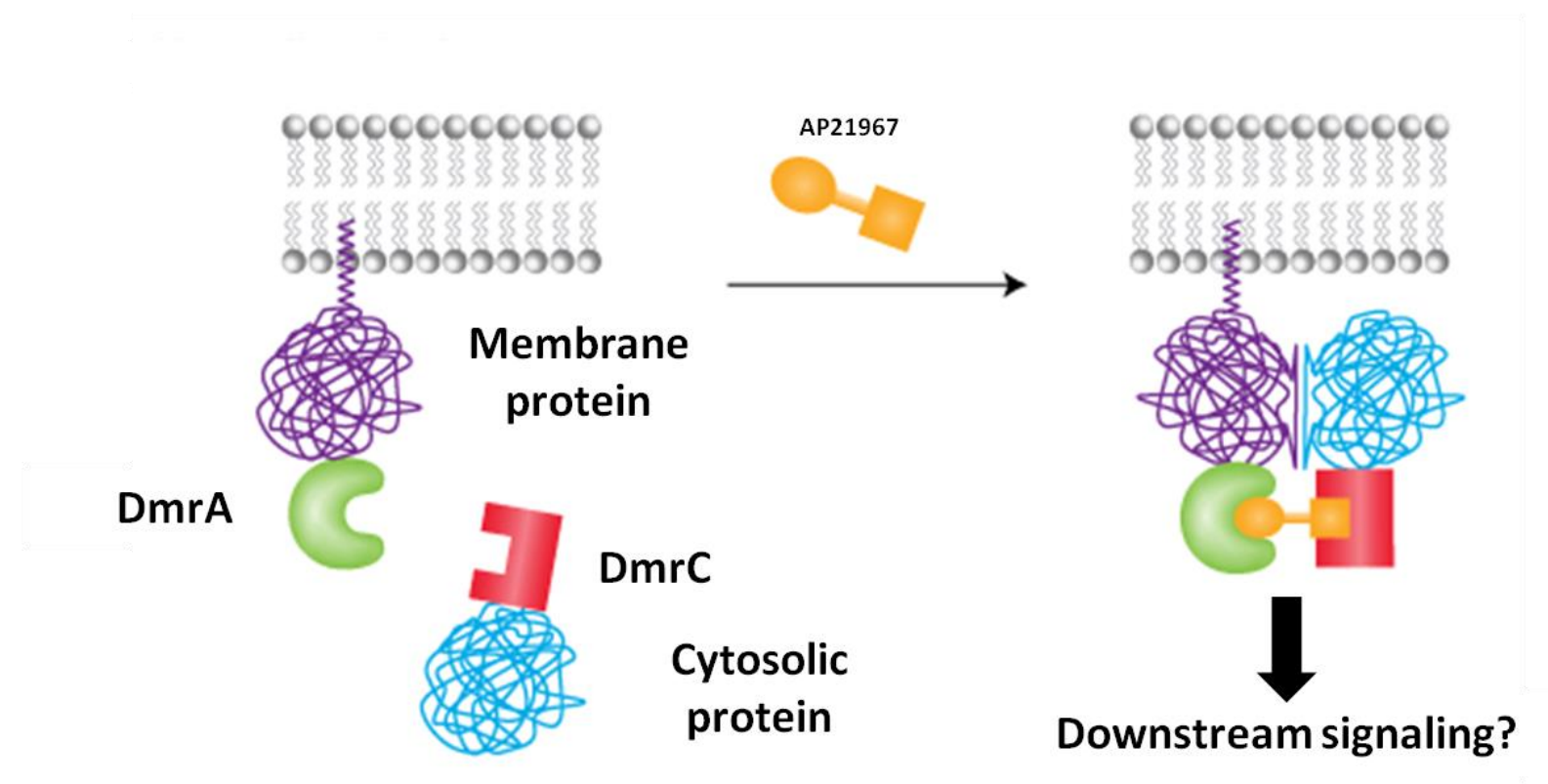

Figure 6: Heterodimerization system consisting of an DmrA/C domain and an A/C heterodimerizer Both Dmr domains A (green; FKBP12) and C (red; FRB) are fused to the C-terminus of proteins of interest (purple and light blue). Addition of the heterodimerizer AP21967 leads to the translocation of both proteins into close proximity which potentially triggers downstream cellular effects. Figure modified from Clontech Laboratories 2008.

FKBP12, FRB and AP21967 are commercially available and are used for interaction analysis between the vasopressin receptors V1a and V2 and $\beta$-arrestin 2 in the absence of ligand binding (Terrillon \& Bouvier, 2004a). Since the dimer system is universally useable it was also used for several other studies including including protein protein interactions studies of the axon survival factor Nmnat2, specific SUMOylation of the transcription factor STAT1, induced cell apoptosis after induced dimerization of the Epstein-Barr virus latent membrane protein 1 (LMP1) with caspase-8 or the AP21967-induced targeting of the $\mathrm{GABA}_{B 2}$ receptor to the cell membrane (Hatzivassiliou et al., 2005; Zimnik et al., 2009; Comps-Agrar et al., 2012; Milde et al., 2013).

\subsection{Aims of this work}

One of the aims of this work was to refine an antibody-independent, biotin acceptor peptide (AP) based internalization and recycling assay to make the assay applicable for the analysis of a large variety of transmembrane proteins. Thereby the assay should be more sensitive than conventional antibody-based detection systems and should not interfere with constitutive endocytosis and translocation of newly synthesized proteins to the cell surface. In addition, the assay should be capable to tag a specific protein population for the quantification of constitutive endocytosis and also to discriminate between ligand-stimulated receptors and new receptors during immunofluorescence microcopy. The established assay should be used to quantify ligand-dependent and -independent internalization and recycling of the chemokine receptors CXCR4, CCR5 and CXCR4-CCR5 ${ }_{\mathrm{CT}}$ using flow cytometry. Furthermore the intracellular localization of biotinylated and newly expressed receptors, after ligand-stimulation, should be described. Therefore a combination of the biotin-based detection system and a newly created anti-AP antibody, which can be used for the detection of the whole receptor population, was used.

Furthermore it was the aim to establish an AP21967/AP20187 inducible dimerization system for the translocation of $\beta$-arrestin 2 to the chemokine receptors CXCR4/CCR5 or a homodimerization of those receptors. In contrast to the classical model of GPCR signaling the translocation of $\beta$-arrestin to the receptor should be ligand-indepdendent to allow discrimination between $\mathrm{G}$ protein-mediated 
effects and $\beta$-arrestin 2-mediated effects. Cellular consequence of $\beta$-arrestin 2 translocation to the receptor should be determined by analyzing the capacity of $\beta$-arrestin 2 to dampen ligand-induced and $\mathrm{G}$ protein-mediated calcium release. Furthermore, the question should be addressed whether $\beta$-arrestin binding is sufficient to induce ligand-independent receptor internalization. In case that $\beta$-arrestin is capable to induce receptor internalization ligand- and AP21967-triggered receptor internalization should be compared using flow cytometry and immunofluorescence microscopy. Finally, the signaling potential of $\beta$-arrestin was analyzed by monitoring the phosphorylation level of the MAP kinases ERK 1/2. Regarding receptor homodimerization the aim was to comprehend different hypotheses which postulated a crucial role of receptor homodimerization for the initiation of downstream signaling. 


\section{Materials and Methods}

\subsection{Materials}

\subsubsection{Laboratory equipment}

Table 2: Laboratory equipment

\begin{tabular}{|c|c|c|}
\hline Name & Type & Company \\
\hline Autoclave & Fedegari Autoclavi Spa & Technomara (Fernwald, GER) \\
\hline Blotting device & $\begin{array}{l}\text { Pierce Fast Semi Dry } \\
\text { Blotter }\end{array}$ & $\begin{array}{l}\text { Thermo Scientific } \\
\text { (Waltham, USA) }\end{array}$ \\
\hline Centrifuges & $\begin{array}{l}5415 D \\
5417 R \\
\text { Multifuge } 3 \text { S-R Heraeus } \\
\text { Megafuge 1.0 R }\end{array}$ & $\begin{array}{l}\text { Eppendorf (Hamburg, GER) } \\
\text { Eppendorf } \\
\text { Schütt (Göttingen, GER) } \\
\text { Schütt }\end{array}$ \\
\hline Chemilux imager & ChemoCam & Intas (Göttingen, GER) \\
\hline Cooling units & $\begin{array}{l}\text { Gastro line }\left(4^{\circ} \mathrm{C}\right) \\
\text { Comfort }\left(-20^{\circ} \mathrm{C}\right) \\
\text { VIP series }\left(-86^{\circ} \mathrm{C}\right)\end{array}$ & $\begin{array}{l}\text { Liebherr (Ochsenhausen, GER) } \\
\text { Liebherr } \\
\text { Sanyo (München, GER) }\end{array}$ \\
\hline Counting chamber & Neubauer Improved & Brand (Wertheim, GER) \\
\hline Electrophoresis device & $\begin{array}{l}\text { Agagel Maxi } \\
\text { SE600 }\end{array}$ & $\begin{array}{l}\text { Biometra (Göttingen, GER) } \\
\text { Hoefer (San Francisco, USA) }\end{array}$ \\
\hline Electroporation device & $\begin{array}{l}\text { Gene pulser II with capacity } \\
\text { extender }\end{array}$ & Bio-Rad (Hercules, USA) \\
\hline Flow Cytometer & $\begin{array}{l}\text { FACSCalibur } \\
\text { LSR II }\end{array}$ & $\begin{array}{l}\text { Becton Dickinson } \\
\text { (San Francisco, USA) } \\
\text { Becton Dickinson }\end{array}$ \\
\hline Homogenizer & Homogenizer & Satorius (Göttingen, GER) \\
\hline Ice machine & Ziegra Ice maker & Ziegra (Hannover, GER) \\
\hline Incubator & $\begin{array}{l}\text { HERAcell } 150 \text { Heraeus } \\
\text { T6060 Heraeus Unitron }\end{array}$ & $\begin{array}{l}\text { Thermo Scientific } \\
\text { Thermo Scientific }\end{array}$ \\
\hline Magnetic stirrer & Combimag Reo & IKA (Staufen, GER) \\
\hline Microscope & $\begin{array}{l}\text { Confocal microscope } \\
\text { TCS SP2 } \\
\text { Axiovert } 40\end{array}$ & $\begin{array}{l}\text { Leica Microsystems } \\
\text { (Heidelberg, GER) } \\
\text { Carl Zeiss (Jena, GER) }\end{array}$ \\
\hline PCR cycler & Mastercycler epGradient & Eppendorf \\
\hline pH meter & pH Level 1 & Inolab (Weilheim, GER) \\
\hline Photometer & $\begin{array}{l}\text { Biophotometer } \\
\text { ThermalPrinter Typ DPU-414 } \\
\text { Nanodrop } 2000 \text { c } \\
\text { Microplate Reader } \\
\text { Powerwave } 340\end{array}$ & $\begin{array}{l}\text { Eppendorf } \\
\text { Eppendorf } \\
\text { Thermo Scientific } \\
\text { Biotek (Winooski, USA) }\end{array}$ \\
\hline Pipettes & $\begin{array}{l}\text { Pipetboy accu } \\
\text { Reference }(10-1000 \mu \mathrm{l}) \\
\text { Research }(10-1000 \mu \mathrm{l})\end{array}$ & $\begin{array}{l}\text { Integra (Fernwald, GER) } \\
\text { Eppendorf } \\
\text { Eppendorf }\end{array}$ \\
\hline Power supply & $\begin{array}{l}\text { ECPS } 2000 / 300 \\
\text { EPS } 301\end{array}$ & $\begin{array}{l}\text { Pfizer (New York, USA) } \\
\text { Amersham (Uppsala, Swe) }\end{array}$ \\
\hline Scale & $\begin{array}{l}\text { M-Prove Type ED } 153 \\
\text { M-Prove Type AZ124 }\end{array}$ & $\begin{array}{l}\text { Satorius } \\
\text { Satorius }\end{array}$ \\
\hline Shaker & $\begin{array}{l}\text { Vortex Genie } 2 \\
\text { Celloshaker Variospeed }\end{array}$ & $\begin{array}{l}\text { Scientific Industries } \\
\text { (New York, USA) } \\
\text { Schütt }\end{array}$ \\
\hline
\end{tabular}




\begin{tabular}{|c|c|c|}
\hline & $\begin{array}{l}\text { Duomax } 1030 \\
\text { Polymax } 1040 \\
\text { GFL } 3005\end{array}$ & $\begin{array}{l}\text { Heidolph (Schwabach, GER) } \\
\text { Heidolph } \\
\text { GFL (Burgwedel, GER) }\end{array}$ \\
\hline Syringe & $\begin{array}{l}\text { Microliter } \\
\text { Syringes }(50 \mu \mathrm{l}, 100 \mu \mathrm{l})\end{array}$ & Hamilton \\
\hline Thermomixer & $\begin{array}{l}\text { Thermomixer compact } \\
\text { Thermomixer comfort }\end{array}$ & $\begin{array}{l}\text { Eppendorf } \\
\text { Eppendorf }\end{array}$ \\
\hline Ultracentrifuge & $\begin{array}{l}\text { Beckman Optima LE-80K } \\
\text { Ultracentrifuge } \\
\text { Rotor Model SW50.1 } \\
\text { Rotor Model SW65 Ti }\end{array}$ & $\begin{array}{l}\text { Beckman Coulter } \\
\text { (Pasadena, USA) } \\
\text { Beckman Coulter } \\
\text { Beckman Coulter }\end{array}$ \\
\hline Ultrasonic probe & UW 2070 & $\begin{array}{l}\text { Bandelin electronics } \\
\text { (Berlin, GER) }\end{array}$ \\
\hline UV transilluminator & $\begin{array}{l}\text { Gellmager } \\
\text { Digital graphik printer UP-D890 }\end{array}$ & $\begin{array}{l}\text { Intas } \\
\text { Sony (Minato, Japan) }\end{array}$ \\
\hline Water bath & $\begin{array}{l}\text { W13 } \\
\text { W6 }\end{array}$ & $\begin{array}{l}\text { Schütt } \\
\text { Schütt }\end{array}$ \\
\hline Water purification system & Milli-Q & Satorius \\
\hline Work bench & $\begin{array}{l}\text { CleanAir DLF BSS4 } \\
\text { Typ HeraSafe KS } 12\end{array}$ & $\begin{array}{l}\text { Schrader (Göttingen, GER) } \\
\text { Thermo Scientific }\end{array}$ \\
\hline
\end{tabular}

\subsubsection{Chemicals and reagents}

Table 3: List of chemicals and reagents

\begin{tabular}{ll}
\hline Name & \\
\hline $\begin{array}{l}\text { 4-(2-hydroxyethyl)-1-piperazineethanesulfonic } \\
\text { acid }\end{array}$ & Roth (Karlsruhe, GER) \\
$\begin{array}{l}\text { A/A Homodimerizer (AP20187) } \\
\text { A/C Heterodimerizer (AP21967) }\end{array}$ & Clontech (Mountain View, USA) \\
\hline Acrylamide, 2x & Clontech \\
\hline $\begin{array}{l}\text { Adenosine 5' triphosphate dipotassium salt } \\
\text { dihydrate }\end{array}$ & Serva Electrophoresis (Heidelberg, GER) /Roth \\
\hline Agar-Agar & Sigma Aldrich (Taufkirchen, GER) \\
\hline AMD3100 octahydrochloride hydrate & Roth \\
\hline Ammonium chloride & Sigma Aldrich \\
\hline Ammonium persulfate & Roth \\
Ampicillin sodium salt & Roth \\
\hline Bicine & Roth \\
Biotin & Sigma Aldrich \\
Biotin-X-NHS & Sigma Aldrich \\
Bromphenol blue & Calbiochem (Darmstadt, GER) \\
Calcium chloride & Roth \\
Complete mini protease inhibitor cocktail & Roth \\
\hline Desoxynucleotides solution mix & Roche \\
Dimethyl sulfoxide & Sigma Aldrich/Roth \\
\hline Disodium hydrogen phosphate & Roth \\
Ethanol & Roth \\
\hline Ethidium bromide & Sigma Aldrich \\
Ethylenediaminetetraacetic acid & Roth \\
\hline FACSflow & Roth \\
Fetal calf serum & Becton Dickinson \\
\hline G418 sulfate & GE Healthcare (Fairfield, USA) \\
\hline Gelatin & Calbiochem \\
\hline & Becton Dickinson \\
\hline
\end{tabular}




\begin{tabular}{|c|c|}
\hline Glycerol & Roth \\
\hline Glycine & Roth \\
\hline H.A.T. supplement $50 \mathrm{X}$ & Life technologies (Carlsbad, USA) \\
\hline HEPES & Roth \\
\hline H.T. supplement $50 \mathrm{X}$ & Life technologies \\
\hline Human Interleukin 6 & Roche (Basel, CH) \\
\hline Igepal & Sigma Aldrich \\
\hline Isopropanol & Roth \\
\hline KLH & Thermo Scientific \\
\hline L-Glutamic acid potassium salt monohydrate & Sigma Aldrich \\
\hline Luminol sodium salt & Sigma Aldrich \\
\hline Magnesium chloride & Roth \\
\hline Magnesiumacetate tetrahydrate & Sigma Aldrich \\
\hline Methanol & Roth \\
\hline Mowiol 4-88 reagent & Calbiochem \\
\hline $\mathrm{N}, \mathrm{N}^{\prime}$-Methylenbisacrylamid $2 \mathrm{X}$ & Serva Electrophoresis/Roth \\
\hline Ni-NTA agarose & Qiagen (Venlo, NL) \\
\hline Paraformaldehyde & Sigma Aldrich \\
\hline P-coumaric acid & Sigma Aldrich \\
\hline Phenol-chloroform-isoamyl alcohol & Biomol (Hamburg, GER) \\
\hline Phenylmethansulfonylfluorid & Sigma Aldrich/Applichem (Darmstadt, GER) \\
\hline Phorbol-12-myristate-13-acetate & Calbiochem \\
\hline Pierce fast semi-dry transfer buffer, 10x & Thermo Scientific \\
\hline Piperazine-N,N'-bis(2-ethanesulfonic acid) & Sigma Aldrich \\
\hline Poly-L-lysine solution & Sigma Aldrich \\
\hline Potassium chloride & Roth \\
\hline Saponin & KN Biomedicals (Aurora, USA) \\
\hline Sodium azide & Roth \\
\hline Sodium chloride & Roth \\
\hline Sodium dihydrogen phosphate & Roth \\
\hline Sodium dodecyl sulfate & Roth \\
\hline $\begin{array}{l}\text { Succinimidyl-4-(N- } \\
\text { maleimidomethyl)cyclohexane-1 carboxylate }\end{array}$ & Sigma Aldrich/Thermo Scientific \\
\hline Sucrose & Sigma Aldrich \\
\hline TAK779 & Merck (Darmstadt, GER) \\
\hline Tetramethylethylenediamine & Roth \\
\hline TiterMax Gold adjuvant & Sigma Aldrich \\
\hline Tris & Roth \\
\hline Trypan blue & Roth \\
\hline Trypsin solution, $10 \mathrm{x}$ & Biochrom (Berlin, GER) \\
\hline Tryptone & Roth \\
\hline Tween 20 & Roth \\
\hline Ultrapure agarose & Invitrogen (Carlsbad, USA) \\
\hline Yeast extract & Roth \\
\hline$\beta$-Mercaptoethanol & Merck \\
\hline
\end{tabular}


3.1.3 Disposable items

Table 4: List of disposable items

\begin{tabular}{|c|c|c|}
\hline Name & Type & Company \\
\hline Bioreactor & miniPERM classic & Sarstedt (Nümbrecht, GER) \\
\hline Cell culture flask & 250 and $550 \mathrm{ml}$ & $\begin{array}{l}\text { Greiner Bio-One } \\
\text { (Frickenhausen, GER) }\end{array}$ \\
\hline Cell culture plate & $\begin{array}{l}96 \text {-well plate, flat-, v-bottom, } \\
\text { tissue culture } \\
24 \text {-well plate, tissue culture } \\
6 \text {-well plate, tissue culture } \\
\text { Round } 10 \mathrm{~cm}, 14 \mathrm{~cm}\end{array}$ & $\begin{array}{l}\text { Greiner Bio-One/Sarstedt } \\
\text { Greiner Bio-One/Sarstedt } \\
\text { Greiner Bio-One/Sarstedt } \\
\text { Greiner Bio-One }\end{array}$ \\
\hline Cell scraper & 99002 & TPP (Trasadingen, $\mathrm{CH}$ ) \\
\hline Centrifuge tubes & $\begin{array}{l}\text { Ultra Clear } 14 \times 95 \mathrm{~mm} \\
\text { Ultra Clear SW65 13×51 mm } \\
\text { Falcon tubes } 15 \text { and } 50 \mathrm{ml}\end{array}$ & $\begin{array}{l}\text { Beckman Coulter } \\
\text { Greiner Bio-One }\end{array}$ \\
\hline Columns & PD-10 & GE Healthcare \\
\hline Cryo tubes & 121789 & Greiner Bio-One \\
\hline Cuvettes & Uvette $220-1600 \mathrm{~nm}$ & Eppendorf \\
\hline Dialysis tube & $\begin{array}{l}\text { Servapor MWCO } 12-14000 \\
16 \text { and } 29 \mathrm{~mm} \text { diameter }\end{array}$ & Serva Electrophoresis \\
\hline Electroporation cuvette & $0,4 \mathrm{~cm}$ & Bio-Rad \\
\hline Flow cytometry tube & Polystyrene tube, $5 \mathrm{ml}$ & Sarstedt \\
\hline Nitrocellulose membrane & $\begin{array}{l}\text { Whatman Protran } \\
\text { BA } 830.2 \mu \mathrm{m}\end{array}$ & GE Healthcare \\
\hline Pasteur capillary pipettes & 747715 & Brand \\
\hline PCR tubes & $0,2 \mathrm{ml}$ & Sarstedt \\
\hline Pipette tips & $1-1000 \mu \mathrm{l}$ & Greiner Bio-One \\
\hline Safe-lock tubes & $0,5-2 \mathrm{ml}$ & Greiner Bio-One/Sarstedt \\
\hline Slide and cover slip & $76 \times 26 \mathrm{~mm}$ & Thermo Scientific \\
\hline Sterile filters & Pore size $(0,25 \mu \mathrm{m})$ & Satorius \\
\hline Syringes & $1-50 \mathrm{ml}$ & Becton Dickinson \\
\hline Western blotting filter paper & MN 440 B & $\begin{array}{l}\text { Macherey \& Nagel } \\
\text { (Düren, GER) }\end{array}$ \\
\hline
\end{tabular}

\subsubsection{Kits}

- Macherey \& Nagel NucleoBond PC 500

- Macherey \& Nagel NucleoSpin Plasmid

- Macherey \& Nagel NucleoSpin Gel and PCR Clean-up

- Thermo Scientific Rapid DNA Ligation Kit

- R\&D Systems Human Phospho-MAPK Array Kit

\subsubsection{DNA and protein markers}

As molecular weight standard for agarose gels the GeneRuler $1 \mathrm{~kb}$ Plus DNA Ladder was used. The molecular weight standard for SDS protein gels was the Pierce Prestained Protein Molecular Weight Marker. Both markers were obtained from Thermo Scientific. 


\subsubsection{Peptides and enzymes}

Table 5: List of peptides and enzymes

\begin{tabular}{ll}
\hline Name & Company \\
\hline AccuTaq DNA polymerase & Sigma Aldrich \\
Antartic phosphatase & New England Biolabs (Frankfurt Main, GER) \\
\hline AP-biotin-peptide & Synthesized by JPT (Berlin, GER) \\
AP-peptide & Synthesized by JPT \\
\hline Avrll & New England Biolabs \\
BamHI-HF & New England Biolabs \\
EcoRV-HF & New England Biolabs \\
HindIII-HF & New England Biolabs \\
Kpnl-HF & New England Biolabs \\
Mlul & New England Biolabs \\
Notl-HF & New England Biolabs \\
Phusion DNA polymerase & New England Biolabs \\
RedTaq DNA polymerase & Sigma Aldrich \\
Scal-HF & New England Biolabs \\
Spel & New England Biolabs \\
Taq DNA polymerase & New England Biolabs \\
Xbal & New England Biolabs \\
\hline
\end{tabular}

\subsubsection{Antibodies}

\subsubsection{Primary antibodies}

Table 6: List of primary antibodies

\begin{tabular}{|c|c|c|c|c|c|}
\hline Antigen & Source & Clone & $\begin{array}{l}\text { Working } \\
\text { concentration }\end{array}$ & Application & Company \\
\hline Anti-AP epitope TAG & Rabbit & Polyclonal & $1: 100$ & FACS & $\begin{array}{l}\text { USBiological } \\
\text { (Swampscott, USA) }\end{array}$ \\
\hline Anti-GRK2/3 & Mouse & C5/1 & $5 \mu \mathrm{g} / \mathrm{ml}$ & WB & RG Oppermann \\
\hline Anti-HA & Rat & $3 F 10$ & 100 ng/ml & WB & Roche \\
\hline Anti-HA (biotin) & Rat & $3 F 10$ & $\begin{array}{l}100 \mathrm{ng} / \mathrm{ml} \\
700 \mathrm{ng} / \mathrm{ml}\end{array}$ & $\begin{array}{l}\text { WB } \\
\text { IF }\end{array}$ & Roche \\
\hline $\begin{array}{l}\text { Anti-human-CCR5 } \\
\text { (unconjucated, FITC, } \\
\text { PE) }\end{array}$ & Mouse & $\mathrm{T} 21 / 8$ & $\begin{array}{l}10 \mu \mathrm{g} / \mathrm{ml} \\
5 \mu \mathrm{g} / \mathrm{ml} \\
1: 10 / 1: 40\end{array}$ & $\begin{array}{l}\text { WB } \\
\text { IF } \\
\text { FACS }\end{array}$ & $\begin{array}{l}\text { Biolegend (San } \\
\text { Diego, USA) / } \\
\text { Santa Cruz (Dallas, } \\
\text { USA) / } \\
\text { RG Oppermann }\end{array}$ \\
\hline $\begin{array}{l}\text { Anti-human-CXCR4 } \\
\text { (unconjucated, FITC, } \\
\text { PE) }\end{array}$ & Mouse & $12 \mathrm{G} 5$ & $\begin{array}{l}5 \mu \mathrm{g} / \mathrm{ml} \\
1: 10\end{array}$ & $\begin{array}{l}\text { IF } \\
\text { FACS }\end{array}$ & $\begin{array}{l}\text { R\&D Systems } \\
\text { (Minneapolis, USA) }\end{array}$ \\
\hline $\begin{array}{l}\text { Anti-mTOR (human } \\
\text { FRB domain) [DmrC] }\end{array}$ & Rabbit & Polyclonal & $1: 2000$ & WB & $\begin{array}{l}\text { Enzo Life Science } \\
\text { (Farmingdale, USA) }\end{array}$ \\
\hline Anti-p44/p42 MAPk & Rabbit & 137F5 & 1:1000 & WB & Cell Signalling \\
\hline Anti-pan-cadherin & Mouse & $\mathrm{CH}-19$ & $1: 20$ & WB & Santa Cruz \\
\hline $\begin{array}{l}\text { Anti-phospho-p44/p42 } \\
\text { MAPK }\end{array}$ & Rabbit & D13.14.4E & $1: 2000$ & WB & Cell Signalling \\
\hline $\begin{array}{l}\text { Anti-rat- } \beta \text {-arrestin } 1 / 2 \\
\text { (unconjugated, biotin) }\end{array}$ & Mouse & 21B1 & $5 \mu \mathrm{g} / \mathrm{ml}$ & WB & RG Oppermann \\
\hline Anti- $\beta$-Actin & Rabbit & $13 \mathrm{E} 5$ & 1:1000 & WB & $\begin{array}{l}\text { Cell Signalling } \\
\text { (Cambridge, UK) }\end{array}$ \\
\hline Anti- $\beta$-arrestin 2 & Mouse & $\mathrm{H}-9$ & $1: 200$ & WB & Santa Cruz \\
\hline
\end{tabular}




\subsubsection{Secondary antibodies}

Table 7: List of secondary antibodies and conjugates

\begin{tabular}{lllll}
\hline Antigen & Source & Working concentration & Application & Company \\
\hline Anti-mouse IgG (FITC) & Goat & $1: 40$ & FACS & $\begin{array}{l}\text { Dako } \\
\text { (Glostrup, DK) / } \\
\end{array}$ \\
& & $\begin{array}{l}1: 100 \\
1: 1000\end{array}$ & $\begin{array}{l}\text { IF } \\
\text { ELISA }\end{array}$ & $\begin{array}{l}\text { Jackson Immunoresearch } \\
\text { (West Grove, USA) }\end{array}$ \\
Anti-mouse IgG (HRP) & Rabbit & $1: 1000$ & WB & Dako \\
Anti-Rabbit IgG (HRP) & Swine & $1: 1000$ & WB & Dako \\
Anti-Rabbit IgG (HRP) & Goat & $1: 10000$ & WB & Jackson Immunoresearch \\
Anti-Rat IgG (HRP) & Goat & $1: 10000$ & WB & Jackson Immunoresearch \\
Streptavidin & & $50 \mu \mathrm{m} / \mathrm{ml}$ & ELISA & Jackson Immunoresearch \\
Streptavidin (Alexa647) & & $2 \mu \mathrm{g} / \mathrm{ml}$ & IF & Jackson Immunoresarch \\
\hline Streptavidin (HRP) & $1: 1000$ & WB & Jackson Immunoresearch \\
& & $1: 1000$ & ELISA & \\
Streptavidin (PE) & $1: 40$ & FACS & Jackson Immunoresearch \\
\hline
\end{tabular}

3.1.8 Plasmids

Table 8: List of plasmids

\begin{tabular}{|c|c|c|c|c|}
\hline Name & $\begin{array}{l}\text { Size } \\
\text { (bp) }\end{array}$ & Resistance & Insert & Source \\
\hline pEF1/Myc-HisA & 6165 & Ampicillin/Geneticin & $\begin{array}{l}\text { CXCR4-CCR5 }{ }_{\text {CT }}, \text { CCR5, } \\
\text { CXCR4, } \\
\text { CCR5-DmrA, CXCR4- } \\
\text { DmrA }\end{array}$ & Invitrogen \\
\hline pHet-1 & 5329 & Ampicillin & Rat $\beta$-Arrestin 2 & Clontech \\
\hline pHet-Nuc1 & 5410 & Ampicillin & CCR5, CXCR4 & Clontech \\
\hline pMaxKS-IE & 4400 & Kanamycine & $\mathrm{G}_{\mathrm{qi5}}, \mathrm{G}_{\mathrm{qo5}}$ & $\begin{array}{l}\text { N. Engels (Immunology, } \\
\text { Göttingen) }\end{array}$ \\
\hline
\end{tabular}

\subsubsection{Oligonucleotides}

All oligonucleotides were synthesized from the company IBA (Göttingen, GER).

Table 9: List of oligonucleotides

\begin{tabular}{|c|c|c|}
\hline Name & Sequence (5' to $3^{\prime}$ ) & Purpose \\
\hline CXCR4-CCR5 Notl rev & $\begin{array}{l}\text { TGTCTGAACCCCATCCTCTATGCCTTTGTCGGGGAGAAGTT } \\
\text { CAGAAACTACCTCTTAGTCTTCTTCCAAAAGCACATTGCCA } \\
\text { AACGCTTCTGCAAATGCTGTTCTATTTTCCAGCAAGAGGCT } \\
\text { CCCGAGCGAGCAAGCTCAGTTTACACCCGATCCACTGGGG } \\
\text { AGCAGGAAATATCTGTGGGCTTGTGAGCGGCCGCCCGGC } \\
\text { G }\end{array}$ & $\begin{array}{l}\text { Cloning of a } \\
\text { CXCR4-CCR5 } 5_{\text {CT }} \\
\text { chimera in } \\
\text { pEF1/Myc-HisA }\end{array}$ \\
\hline $\begin{array}{l}\text { EcoRI-AP-CXCR4 } \\
\text { forward }\end{array}$ & $\begin{array}{l}\text { CGGGCGGAATTCATGGGCCTGAACGACATCTTCGAGGCCC } \\
\text { AGAAGATCGAGTGGCACGAGGAGGGGATCAGTATATACA } \\
\text { CT }\end{array}$ & $\begin{array}{l}\text { Cloning of a } \\
\text { CXCR4-CCR5 } 5_{\mathrm{CT}} \\
\text { chimera in } \\
\text { pEF1/ } \\
\text { Myc-HisA } \\
\end{array}$ \\
\hline $\mathrm{G}_{\mathrm{q}}$ forward BamHI & CCGCGCGGATCCATGACTCTGGAGTCCATCATGG & $\begin{array}{l}\text { Cloning of } \\
\mathrm{G}_{\mathrm{q}} \text {-protein in } \\
\text { pMaxKS-IE }\end{array}$ \\
\hline $\mathrm{G}_{\mathrm{q}}$ forward + HA BamHI & $\begin{array}{l}\text { CCGCGCGGATCCATGTACCCATACGATGTTCCAGATTACGC } \\
\text { TACTCTGGAGTCCATCATGG }\end{array}$ & $\begin{array}{l}\text { Cloning of } \\
\mathrm{G}_{\mathrm{q}} \text {-protein in } \\
\text { pMaxKS-IE }\end{array}$ \\
\hline
\end{tabular}




\begin{tabular}{|c|c|c|}
\hline $\mathrm{G}_{\mathrm{qi}}$ reverse Notl & GCCGCGGCGGCCGCTCAGAAGAGGCCACAGTCCTTAAG & $\begin{array}{l}\text { Cloning of } \\
\mathrm{G}_{\mathrm{qi}} \text {-protein in } \\
\text { pMaxKS-IE }\end{array}$ \\
\hline $\mathbf{G}_{\mathrm{qo}}$ reverse Notl & GCCGCGGCGGCCGCTTAGTACAAGCCACAGCCCTTCAG & $\begin{array}{l}\text { Cloning of } \\
\mathrm{G}_{\mathrm{qo}} \text {-protein in } \\
\text { pMaxKS-IE }\end{array}$ \\
\hline BamHI-CCR5 for & CCCGCGCGGATCCATGGATTATCAAGTGTCAAGTCCA & $\begin{array}{l}\text { Cloning of a } \\
\text { CCR5-DmrA in } \\
\text { pEF1/Myc-HisA }\end{array}$ \\
\hline beta-Arrestin2-Spel rev & CGGCGCACTAGTGCAGAACTGGTCATCACAGTC & $\begin{array}{l}\text { Cloning of } \\
\beta \text {-Arrestin2 in } \\
\text { pHet-1 }\end{array}$ \\
\hline CCR5-Spel rev & CGGCGCACTAGTCAAGCCCACAGATATTTCCTGCTC & $\begin{array}{l}\text { Cloning of CCR5 } \\
\text { in pHet-Nuc1 }\end{array}$ \\
\hline CXCR4-Spel rev & CGGCGCACTAGTGCTGGAGTGAAAACTTGAAGACTC & $\begin{array}{l}\text { Cloning of } \\
\text { CXCR4 in } \\
\text { pHet-Nuc1 }\end{array}$ \\
\hline Kpnl-CXCR4 for & CCGCGCGGTACCATGGAGGGGATCAGTATATACACT & $\begin{array}{l}\text { Cloning of } \\
\text { CXCR4-DmrA in } \\
\text { pEF1/Myc-HisA }\end{array}$ \\
\hline Notl-DmrA rev & GCGGCGCGCGGCCGCTCATTCCAGTTTTAGAAGCTCCAC & $\begin{array}{l}\text { Cloning of a } \\
\text { recetpro-DmrA } \\
\text { in } \\
\text { pEF1/Myc-HisA }\end{array}$ \\
\hline Xbal-betaArrestin2 for & CCGCGCTCTAGAATGGGTGAAAAACCCGGGACC & $\begin{array}{l}\text { Cloning of } \\
\beta \text {-Arrestin2 in } \\
\text { pHet-1 }\end{array}$ \\
\hline Xbal-CCR5 for & CCGCGCTCTAGAATGGATTATCAAGTGTCAAGTCCA & $\begin{array}{l}\text { Cloning of CCR5 } \\
\text { in pHet-Nuc1 }\end{array}$ \\
\hline Xbal-CXCR4 for & CCGCGCTCTAGAATGGAGGGGATCAGTATATAC & $\begin{array}{l}\text { Cloning of } \\
\text { CXCR4 in } \\
\text { pHet-Nuc1 }\end{array}$ \\
\hline BGH rev & TAGAAGGCACAGTCGAGG & Sequencing \\
\hline T7 for & TAATACGACTCACTATAGGG & Sequencing \\
\hline UTR for & GGATCTTGGTGGCGTGAAACTC & Sequencing \\
\hline
\end{tabular}

\subsubsection{Antibiotics}

Table 10: List of antibiotics

\begin{tabular}{ll}
\hline Name & $\begin{array}{l}\text { Concentration } \\
{[\mu \mathrm{g} / \mathrm{ml}]}\end{array}$ \\
\hline Ampicillin & 100 \\
Kanamycin & 50 \\
Geneticin & 600 \\
Penicillin/Streptomycin & 100 \\
\hline
\end{tabular}




\subsubsection{Buffers and solutions}

3.1.11.1.1 Molecular biology

\section{$50 \mathrm{mM}$ Phosphate buffer}

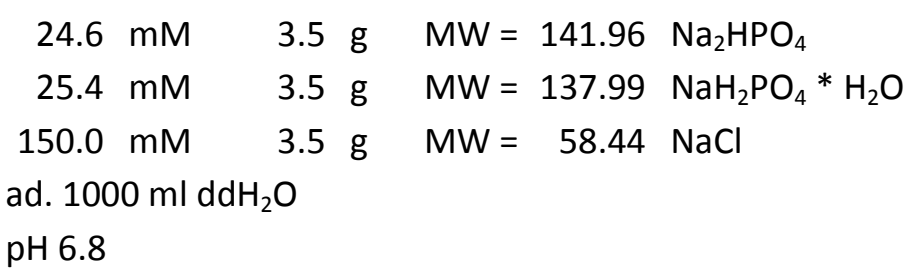

$3 \mathrm{M}$ Sodium acetate

$3.0 \mathrm{M} \quad 20.4 \mathrm{~g} \quad \mathrm{MW}=136.08$ TRIS

ad. $50 \mathrm{ml} \mathrm{ddH} \mathrm{H}_{2} \mathrm{O}$

TAE-buffer, 50x

$\begin{array}{llrlll}2.0 & \mathrm{M} & 242.0 \mathrm{~g} & \mathrm{MW}=121.14 & \text { TRIS } \\ 1.0 & \mathrm{M} & 57.1 \mathrm{ml} & \mathrm{MW}= & 60.05 & \text { Glacial acetic acid } \\ 0.05 & \mathrm{M} & 18.6 \mathrm{~g} & \mathrm{MW}=372.24 & \text { EDTA dipotassium salt } * 2 \mathrm{H}_{2} \mathrm{O}\end{array}$

ad. $1000 \mathrm{ml} \mathrm{ddH}_{2} \mathrm{O}$

$\mathrm{pH} 8.2-8.4$

Before usage the 50x TAE-buffer was diluted with $\mathrm{ddH}_{2} \mathrm{O}$ to $1 \times$ TAE-buffer.

3.1.11.1.2 Cell culture

$2,5 \mathrm{M} \mathrm{CaCl}_{2}$

$2.5 \mathrm{M} \quad 18.38$ g $\mathrm{MW}=147.02 \mathrm{CaCl}_{2} * 2 \mathrm{H}_{2} \mathrm{O}$

ad. $50 \mathrm{ml} \mathrm{ddH} \mathrm{H}_{2} \mathrm{O}$

Store at $4^{\circ} \mathrm{C}$ or $-20^{\circ} \mathrm{C}$

Freezing-medium

$\begin{aligned} 45.0 \mathrm{ml} & \text { FCS } \\ 5.0 \mathrm{ml} & \text { DMSO }\end{aligned}$

Storage at $4^{\circ} \mathrm{C}$

$10 \%$ glycerol ( $v / v)$

$\begin{array}{ll}10.0 \mathrm{ml} & \text { Glycerol } 100 \% \\ 90.0 \mathrm{ml} & \text { Autoclaved PBS solution, 1x }\end{array}$

Sterile-filtered; Storage at rt

\section{2x HBS solution}

$\begin{array}{rrrll}280.0 & \mathrm{mM} & 2.8 \mathrm{ml} & \mathrm{NaCl}(2.0 \mathrm{M}) \\ 50.0 & \mathrm{mM} & 2.0 \mathrm{ml} & \operatorname{HEPES}(0.5 \mathrm{M}) \\ 0.15 & \mathrm{mM} & 30.0 \mathrm{\mu l} & \mathrm{Na}_{2} \mathrm{HPO}_{4}(1.0 \mathrm{M})\end{array}$

ad. $20 \mathrm{ml} \mathrm{ddH_{2 } \mathrm { O }}$

pH 7.1 (important); Storage at rt 


\section{0,5 M HEPES}

$0.5 \mathrm{M} \quad 6.0 \mathrm{~g} \quad \mathrm{MW}=238.3$ HEPES

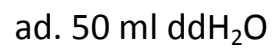

Autoclave $121^{\circ} \mathrm{C}$ for 20 minutes; Store at $4^{\circ} \mathrm{C}$

\section{$2 \mathrm{M} \mathrm{NaCl}$}

$2.0 \mathrm{M} \quad 5.8 \mathrm{~g} \quad \mathrm{MW}=58.44 \mathrm{NaCl}$

ad. $50 \mathrm{ml} \mathrm{ddH_{2 } \mathrm { O }}$

Autoclave $121^{\circ} \mathrm{C}$ for 20 minutes; Store at $4^{\circ} \mathrm{C}$

$1 \mathrm{M} \mathrm{Na}_{2} \mathrm{HPO}_{4}$

$1.0 \mathrm{M} \quad 1.8 \mathrm{~g} \quad \mathrm{MW}=178.01 \quad \mathrm{Na}_{2} \mathrm{HPO}_{4} * 2 \mathrm{H}_{2} \mathrm{O}$

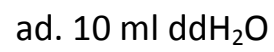

Autoclave $121^{\circ} \mathrm{C}$ for 20 minutes; Store at $4^{\circ} \mathrm{C}$

PBS stock solution, $10 \mathrm{x}$

$0.4 \mathrm{M} \quad 323.2$ g $\quad M W=358.14 \quad \mathrm{Na}_{2} \mathrm{HPO}_{4} * 12 \mathrm{H}_{2} \mathrm{O}$

$0.1 \mathrm{M} \quad 48.0 \mathrm{ml} \quad \mathrm{MW}=137.99 \quad \mathrm{NaH}_{2} \mathrm{PO}_{4} * \mathrm{H}_{2} \mathrm{O}$

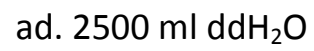

$\mathrm{pH} 7.2-7.4$

\section{PBS solution, $1 x$}

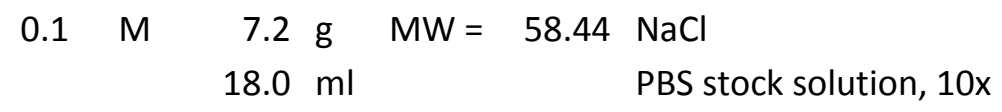

ad. $1000 \mathrm{ml} \mathrm{ddH} \mathrm{H}_{2} \mathrm{O}$

$\mathrm{pH} 7.3$

Autoclave at $121^{\circ} \mathrm{C}$ for 20 minutes; Storage at $4^{\circ} \mathrm{C}$

0,5 \% Trypan blue-solution

5.7 $\mathrm{mM} \quad 0.5 \mathrm{~g} \quad \mathrm{MW}=872.88$ Trypan blue

ad. $100 \mathrm{ml}$ PBS solution, $1 \mathrm{x}$

Boil to dissolve Trypan blue completely

\section{Trypsin-EDTA solution}

$\begin{array}{ll}100.0 \mathrm{ml} & \text { Trypsin-EDTA }(0,05 \% / 0,02 \%) \\ 400.0 \mathrm{ml} & \text { Autoclaved } \mathrm{ddH}_{2} \mathrm{O}\end{array}$

Storage at $4^{\circ} \mathrm{C}$ 
3.1.11.1.3 Protein biology

Acryl bisacrylamide solution

$4.1 \mathrm{M} \quad 58.4 \mathrm{~g} \quad \mathrm{MW}=71.10 \quad 2 \mathrm{x}$, Acrylamide

$0.05 \mathrm{M} \quad 1.6 \mathrm{~g} \quad \mathrm{MW}=154.20 \quad 2 \mathrm{x}, \mathrm{N}, \mathrm{N}^{\prime}$-methylene-bisacrylamide

ad. $200 \mathrm{ml} \mathrm{ddH_{2 } \mathrm { O }}$

2,2'-azino-bis(3-ethylbenzothiazoline-6-sulphonic acid) (ABTS)

$\begin{array}{rlrlll}2.0 & \mathrm{mM} & 1.1 \mathrm{~g} & \mathrm{MW}=514.62 & \text { ABTS } \\ 50.0 & \mathrm{mM} & 6.9 \mathrm{~g} & \mathrm{MW}=137.99 & \mathrm{NaH}_{2} \mathrm{PO}_{4} * \mathrm{H}_{2} \mathrm{O} \\ 100.0 & \mathrm{mM} & 13.61 \mathrm{~g} & \mathrm{MW}=136.08 & \text { Natriumacetat } * 3 \mathrm{H}_{2} \mathrm{O}\end{array}$

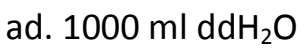

$\mathrm{pH} 4.2$; store in aliquots at $-20^{\circ} \mathrm{C}$

\section{Biomix A}

$0.5 \mathrm{M} \quad 8.2 \mathrm{~g} \quad \mathrm{MW}=163.17$ Bicine

ad. $200 \mathrm{ml} \mathrm{ddH_{2 } \mathrm { O }}$

$\mathrm{pH} 8.3$; Storage at $4^{\circ} \mathrm{C}$

\section{Biomix B}

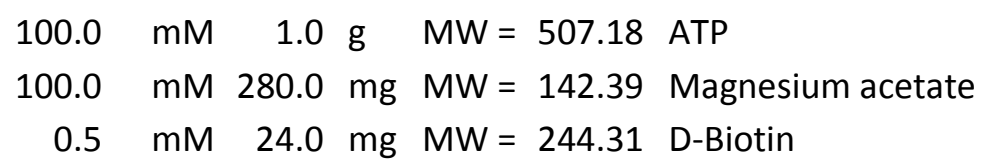

ad. $20 \mathrm{ml} \mathrm{ddH}_{2} \mathrm{O}$

Storage at $-20^{\circ} \mathrm{C}$

BM-medium

$$
\begin{array}{ll}
0.1 \mathrm{~g} & \text { BSA } \\
0.5 \mathrm{ml} & \text { Hepes buffer (1 M) }
\end{array}
$$

ad. $50 \mathrm{ml} \mathrm{RPMI} 1640$ or DMEM medium

$\mathrm{pH} 7.4$

\section{Coating-buffer}

$\begin{aligned} 170.0 \mathrm{ml} & \text { Solution A ELISA } \\ 80.0 \mathrm{ml} & \text { Solution B ELISA }\end{aligned}$

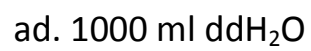

$\mathrm{pH} 10.6$

Coomassie blue staining solution
$1.2 \mathrm{mM} \quad 1.0 \mathrm{~g} \quad \mathrm{MW}=825.97$ Coomassie R250
$1.2 \mathrm{M} \quad 70.0 \mathrm{ml} \mathrm{MW}=60.05$ Glacial acetic acid
$8.0 \mathrm{M} \quad 250.0 \mathrm{ml} \mathrm{MW}=32.04$ Methanol

ad. $1000 \mathrm{ml} \mathrm{ddH_{2 } \mathrm { O }}$ 


\section{Coomassie destaining solution}

$1.1 \mathrm{M} \quad 125.0 \mathrm{~g} \quad \mathrm{MW}=60.05$ Glacial acetic acid

$12.0 \mathrm{M} 750.0 \mathrm{ml} \mathrm{MW}=32.04$ Methanol ad. $2000 \mathrm{ml} \mathrm{ddH_{2 } \mathrm { O }}$

\section{Cytochalasin B}

$0.5 \mathrm{mM} \quad 1.0 \mathrm{mg} \quad \mathrm{MW}=479.60$ Cytochalasin B ad. $1 \mathrm{ml}$ DMSO

\section{EM-medium}

$$
\begin{array}{ll}
0.1 \mathrm{~g} & \text { BSA } \\
0.5 \mathrm{ml} & \text { MES buffer (1 M) }
\end{array}
$$

ad. $50 \mathrm{ml} \mathrm{RPMI} 1640$ or DMEM medium $\mathrm{pH} 2.4$

\section{Facs-buffer}

$$
\begin{array}{rl}
490.0 \mathrm{ml} & \text { PBS solution, 1x } \\
2.5 \mathrm{ml} & \mathrm{NaN}_{3}(20 \%) \\
7.5 \mathrm{ml} & \mathrm{FCS}
\end{array}
$$

\begin{tabular}{|c|c|c|c|c|c|c|}
\hline 20.0 & $\mathrm{mM}$ & 2.8 & g & $\mathrm{MW}=$ & 238.30 & HEPES \\
\hline 25.0 & $\mathrm{mM}$ & 3.7 & g & $\mathrm{MW}=$ & 58.44 & $\mathrm{NaCl}$ \\
\hline 5.0 & $\mathrm{mM}$ & 0.2 & g & $\mathrm{MW}=$ & 74.56 & $\mathrm{KCl}$ \\
\hline 1.0 & $\mathrm{mM}$ & 74.0 & $\mathrm{mg}$ & $\mathrm{MW}=$ & 147.02 & $\mathrm{CaCl}_{2} * 2 \mathrm{H}_{2} \mathrm{O}$ \\
\hline 1.0 & $\mathrm{mM}$ & 101.0 & $\mathrm{mg}$ & $\mathrm{MW}=$ & 203.30 & $\mathrm{MgCl}_{2} * 6 \mathrm{H}_{2} \mathrm{O}$ \\
\hline 0.5 & $\mathrm{mM}$ & 45.0 & $\mathrm{mg}$ & $\mathrm{MW}=$ & 180.15 & Glucose \\
\hline
\end{tabular}

Store at $4^{\circ} \mathrm{C}$

\section{M Glycerol buffer}

$\begin{array}{llll}1.0 \mathrm{M} & 2.7 \mathrm{~g} \quad \mathrm{MW}=92.09 \text { Glycerol }\end{array}$ ad. $500 \mathrm{ml} \mathrm{ddH_{2 } \mathrm { O }}$

\section{HAG-CM buffer}

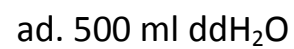

pH 7.4 with $\mathrm{NaOH}$; Store at $4^{\circ} \mathrm{C}$

\section{HEPES-buffer}

$$
1.0 \mathrm{M} \quad 11.9 \mathrm{~g} \quad \mathrm{MW}=238.30 \text { HEPES }
$$

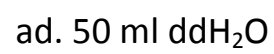

$\mathrm{pH} 7.0$

Storage at RT in the dark

HRP blocking solution

$$
\begin{array}{rr}
1.0 \mathrm{\mu l} & \mathrm{NaN}_{3}(20 \%) \\
10.0 \mathrm{ml} & \mathrm{H}_{2} \mathrm{O}_{2}(35 \%)
\end{array}
$$

ad. $1000 \mathrm{ml} \mathrm{TBST}$ 
Indo-1-AM solution

$1.0 \mathrm{mM} \quad 50.0 \mu \mathrm{g} \quad \mathrm{MW}=1009.9$ Indo-1-AM

ad. $50 \mu \mathrm{l} \mathrm{H} \mathrm{H}_{2}$-free DMSO

Storage at rt

Indo-1-AM pluronic acid F127 mix
$0.7 \mu \mathrm{l}$
Indo-1-AM (1 mM)
$2.1 \mu \mathrm{l}$
Pluronic-acid F127 (5\%)

\section{Krebs-Ringer solution}

$$
\begin{aligned}
& 140.0 \mathrm{mM} \quad 4.1 \mathrm{~g} \quad \mathrm{MW}=58.40 \mathrm{NaCl} \\
& 4.0 \mathrm{mM} 150.0 \mathrm{mg} \mathrm{MW}=74.56 \mathrm{KCl} \\
& 1.0 \mathrm{mM} 100.0 \mathrm{mg} \mathrm{MW}=203.30 \mathrm{MgCl}_{2} * 6 \mathrm{H}_{2} \mathrm{O} \\
& 1.0 \mathrm{mM} \quad 0.9 \mathrm{~g} \quad \mathrm{MW}=180.16 \quad \mathrm{D} \text {-Glucose } \\
& 10.0 \mathrm{mM} \quad 1.2 \mathrm{~g} \quad \mathrm{MW}=238.30 \text { Hepes } \\
& 1.0 \mathrm{mM} 74.0 \mathrm{mg} \mathrm{MW}=147.02 \mathrm{CaCl}_{2} * 2 \mathrm{H}_{2} \mathrm{O}
\end{aligned}
$$

\begin{tabular}{|c|c|c|c|c|}
\hline$M$ & 864.0 & $\mathrm{~g}$ & 75.07 & \\
\hline $\mathrm{mM}$ & 60.0 & & $\mathrm{MW}=$ & \\
\hline M & 180.0 & & 21.14 & \\
\hline
\end{tabular}

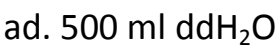

$\mathrm{pH} 7.4$; Storage at $-4^{\circ} \mathrm{C}$

\begin{tabular}{|c|c|c|c|c|c|c|}
\hline 10.0 & $\mathrm{mM}$ & 1.5 & g & $\mathrm{MW}=$ & 302.37 & PIPES \\
\hline 0.0 & $\mathrm{mM}$ & 3.7 & g & $\mathrm{MW}=$ & 74.55 & $\mathrm{KCl}$ \\
\hline 3.0 & $\mathrm{mM}$ & 90.0 & $\mathrm{mg}$ & $\mathrm{MW}=$ & 58.44 & $\mathrm{NaCl}$ \\
\hline 3.5 & $\mathrm{mM}$ & 360.0 & $\mathrm{mg}$ & $\mathrm{MW}=$ & 203.3 & $\mathrm{MgCl}_{2} * 6 \mathrm{H}_{2} \mathrm{O}$ \\
\hline
\end{tabular}

\section{Laemmli buffer, $10 \mathrm{x}$}

ad. $6000 \mathrm{ml} \mathrm{ddH_{2 } \mathrm { O }}$

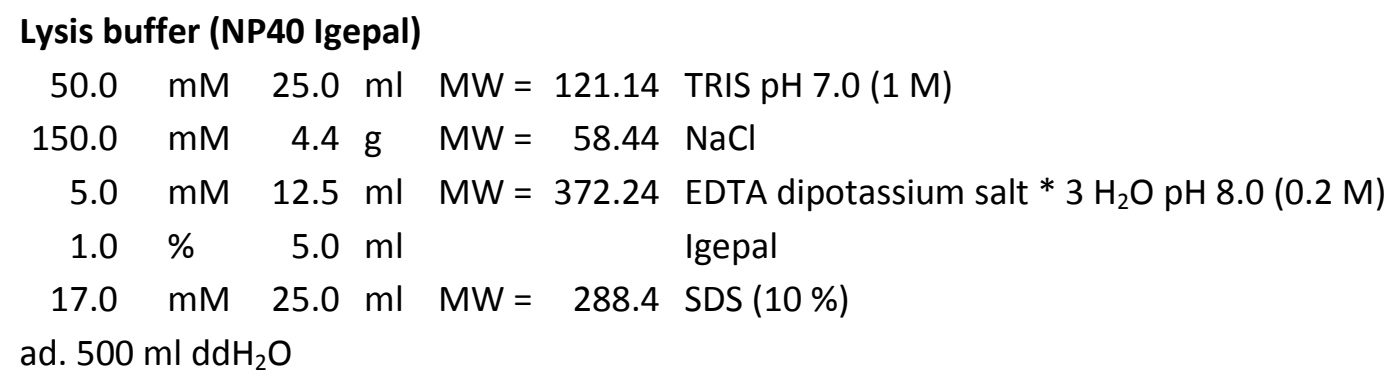

\section{Membrane buffer}

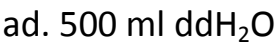

$\mathrm{pH} 7.0$

\section{MES-buffer}

$$
\text { 1.0 M } 10.7 \text { g } M W=213.25 \text { MES * } \mathrm{H}_{2} \mathrm{O}
$$

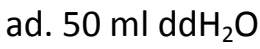

Storage at $r t$ in the dark 


\section{Mounting medium (with antifading reagent)}

$$
\begin{aligned}
& 2.4 \mathrm{~g} \quad \text { Mowiol 4-88 } \\
& \text { 3.2 M } 6.0 \mathrm{~g} \quad \mathrm{MW}=92.09 \text { Glycerol } \\
& 6 \mathrm{ml} \quad \mathrm{ddH}_{2} \mathrm{O} \\
& 0.1 \mathrm{M} \quad 12.0 \mathrm{ml} \quad \mathrm{MW}=121.14 \quad 0,2 \mathrm{M} \text { TRIS pH } 8.5
\end{aligned}
$$

Mowiol and glycerol are mixed and stirred for 1 hour at rt. The $\mathrm{dd}_{2} \mathrm{O}$ is added and the mixture stirred for additional 2 hours at rt. Tris buffer is added and the solution is incubated up to 2 hours at $50^{\circ} \mathrm{C}$ in the water bath under occasional stirring. To remove non dissolved mowiol the mixture is centrifuged at $5000 \mathrm{xg}$ for 15 minutes. The aliquots are stored in $1.5 \mathrm{ml}$ tubes at $-20^{\circ} \mathrm{C}$.

\section{$\mathrm{NH}_{4} \mathrm{Cl}$ solution}

$$
50.0 \mathrm{mM} \quad 1.3 \mathrm{~g} \quad \mathrm{MW}=53.49 \mathrm{NH}_{4} \mathrm{Cl}
$$

\begin{tabular}{|c|c|c|c|c|c|}
\hline 10.0 & $\mathrm{mM}$ & $0.3 g$ & $\mathrm{MW}=$ & 68.08 & Imidazol \\
\hline 0 & $\mathrm{mN}$ & 8.7 & $\mathrm{MW}=$ & 58.44 & $\mathrm{NaCl}$ \\
\hline 50. & $\mathrm{nN}$ & 3.5 & $\mathrm{MW}=$ & 137.99 & $\mathrm{NaH}_{2} \mathrm{PO}_{4}$ \\
\hline
\end{tabular}

ad. $500 \mathrm{ml} \mathrm{ddH} \mathrm{H}_{2} \mathrm{O}$

Sterile filtered

\section{NiNTA binding buffer}

ad. $500 \mathrm{ml} \mathrm{ddH_{2 } \mathrm { O }}$

$\mathrm{pH} 8.0$

\section{NiNTA clearing buffer}

\begin{tabular}{|c|c|c|c|c|c|}
\hline 50.0 & $\mathrm{mM}$ & $8.5 g$ & $\mathrm{MW}=$ & 68.08 & Imidazol \\
\hline & $\mathrm{mM}$ & 8.7 & $\mathrm{MW}=$ & 58.44 & $\mathrm{NaCl}$ \\
\hline 0 & $\mathrm{~N}$ & 3.5 & $\mathrm{MW}=$ & 7.99 & $\mathrm{NaH}_{2} \mathrm{PO}_{4}$ \\
\hline
\end{tabular}

$\begin{array}{llllll}3.5 & \mathrm{M} & 20.0 \mathrm{ml} & \mathrm{MW}= & 68.05 & \text { Glacial acetic acid } \\ 6.0 & \mathrm{M} & 57.3 \mathrm{~g} & \mathrm{MW}= & 95.53 & \text { Guanidium chloride }\end{array}$

ad. $100 \mathrm{ml} \mathrm{ddH} \mathrm{H}_{2} \mathrm{O}$

$\mathrm{pH} 8.0$

\section{NiNTA elution buffer}

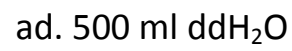

$\mathrm{pH} 8.0$

\section{NiNTA washing buffer}

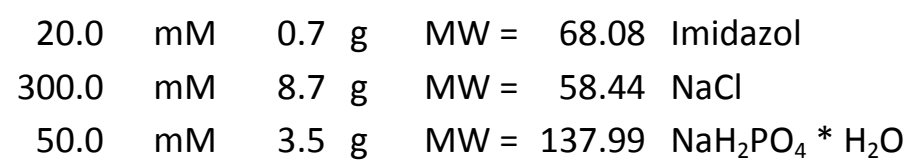

ad. $500 \mathrm{ml} \mathrm{ddH} \mathrm{H}_{2} \mathrm{O}$

$\mathrm{pH} 8.0$

\section{Nitrophenyl $\mathbf{N}$-acetyl- $\beta$-D-glucosaminide (NAGA substrate)}

$8.0 \mathrm{mM} 27.4 \mathrm{mg} \mathrm{MW}=342.30$ NAGA substrate ad. $10 \mathrm{ml}$ Sodium acetate buffer

Warm up to completely dissolve the NAGA substrate; storage at $4^{\circ} \mathrm{C}$ 
PBS-Tween
$0.5 \mathrm{ml}$
Tween 20

ad. $1000 \mathrm{ml}$ PBS solution, 1x

\section{Saponin-Gelatine solution}
$0.1 \%$
$0.1 \mathrm{~g}$
Saponin
$0.2 \%$
$0.2 \mathrm{~g}$
Gelatin

ad. $100 \mathrm{ml}$ PBS

Heat up for total dissolution of gelatin. Has to be prepared fresh before each staining.

\section{Separation gel buffer}

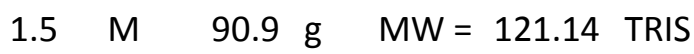

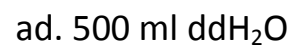

$\mathrm{pH} 8.8$

\section{Sodium acetate buffer}

40.0 mM $46.1 \mathrm{~g} \quad \mathrm{MW}=136.08$ Sodium acetate $* 3 \mathrm{H}_{2} \mathrm{O}$

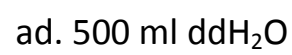

$\mathrm{pH} 4.5$ with $\mathrm{HCl}$

\section{Solution A (ECL)}

$1.4 \mathrm{mM} 250.0 \mathrm{mg} \mathrm{MW}=177.16$ Luminol

ad. $1000 \mathrm{ml}$ TRIS $(0,1 \mathrm{M})$

$\mathrm{pH} 8.6$; storage at $4^{\circ} \mathrm{C}$

\section{Solution A ELISA}

$0.2 \mathrm{M} \quad 10.99 \mathrm{~g} \quad \mathrm{MW}=105.99 \quad \mathrm{Na}_{2} \mathrm{CO}_{3}$

ad. $500 \mathrm{ml} \mathrm{ddH_{2 }} \mathrm{O}$

\section{Solution B (ECL)}

$3.4 \mathrm{mM} 55.0 \mathrm{mg} \mathrm{MW}=164.16$ Para-coumaric-acid ad. $50 \mathrm{ml}$ DMSO

Storage at rt without incidence of light

\section{Solution B ELISA}

$0.2 \mathrm{M} \quad 8.4 \mathrm{~g} \quad \mathrm{MW}=84.01 \mathrm{NaHCO}_{3}$

ad. $500 \mathrm{ml} \mathrm{ddH} \mathrm{H}_{2} \mathrm{O}$

\section{Stacking gel buffer}

$0.5 \mathrm{M} \quad 30.3 \mathrm{~g} \quad \mathrm{MW}=121.14$ TRIS

ad. $500 \mathrm{ml} \mathrm{ddH_{2 }} \mathrm{O}$

$\mathrm{pH} 6.8$ 
Stripping solution

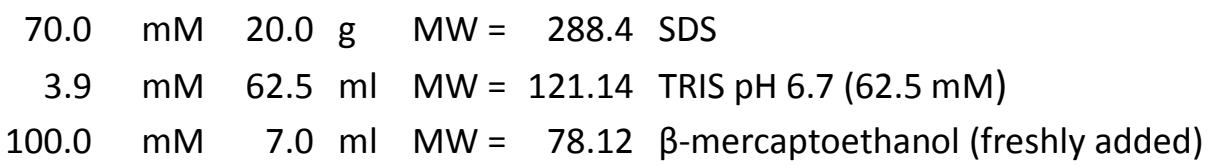

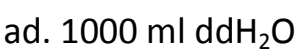

\section{TBS, $10 x$ solution}

$1.4 \mathrm{M} \quad 80.0 \mathrm{~g} \quad \mathrm{MW}=58.44 \mathrm{NaCl}$

$0.2 \mathrm{M} \quad 24.0 \mathrm{~g} \quad \mathrm{MW}=121.14 \mathrm{TRIS}$

ad. $1000 \mathrm{ml} \mathrm{ddH_{2 } \mathrm { O }}$

$\mathrm{pH} 7.6$

TBST solution, $\mathbf{1 x}$

$$
\begin{aligned}
100.0 \mathrm{ml} & \text { TBS, } 10 x \text { solution } \\
1.0 \mathrm{ml} & \text { Tween } 20
\end{aligned}
$$

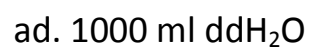

\section{Treatment buffer, $\mathbf{2 x}$}

$$
\begin{aligned}
12.5 \mathrm{ml} & \text { Stacking gel buffer } \\
20.0 \mathrm{ml} & \text { SDS }(10 \%) \\
10.0 \mathrm{ml} & \text { Glycerol }(100 \%) \\
5.0 \mathrm{ml} & \text { Bromphenol blue }(10 \mathrm{mg} / \mathrm{ml})
\end{aligned}
$$

Treatment buffer with $\beta$-mercaptoethanol, 1x

$\begin{array}{ll}450.0 \mu \mathrm{l} & \text { Treatment buffer, } 2 \mathrm{x} \\ 450.0 \mu \mathrm{l} & \mathrm{ddH}_{2} \mathrm{O} \\ 100.0 \mu \mathrm{l} & \beta \text {-mercaptoethanol }\end{array}$

TRIS-buffer with potassiumglutamate

$\begin{array}{llllll}10.0 & \mathrm{mM} & 1.2 & \mathrm{~g} & \mathrm{MW}=121.14 & \text { TRIS } \\ 30.0 & \mathrm{mM} & 6.1 & \mathrm{~g} & \mathrm{MW}=203.23 & \text { L-glutamic acid potassium salt monohydrate }\end{array}$

\begin{tabular}{|c|c|c|}
\hline Name & Genotype & Company \\
\hline $\begin{array}{l}\text { E. coli BL21 } \\
\text { (DE3) }\end{array}$ & $\begin{array}{l}\text { fhuA2 [lon] ompT gal }(\lambda \mathrm{DE} 3)[\mathrm{dcm}] \Delta \text { hsdS } \\
\lambda \text { DE3 }=\lambda \text { sBamHlo } \Delta \text { EcoRI-B int::(lacl::PlacUV5::T7 gene1) i } 21 \Delta \text { nin5 }\end{array}$ & $\begin{array}{l}\text { New England } \\
\text { Biolabs }\end{array}$ \\
\hline E.coli & $\mathrm{F}^{\prime}\{$ laclq, Tn10(TetR)\} mcrA $\Delta($ mrr-hsdRMS-mcrBC) $Ф 80$ lacZ $\Delta \mathrm{M} 15$ & Invitrogen \\
\hline Top10F- & $\begin{array}{l}\text { \lacX74 recA1 araD139 } \Delta \text { (ara leu) } 7697 \text { galU galK rpsL (StrR) endA1 } \\
\text { nupG }\end{array}$ & \\
\hline
\end{tabular}

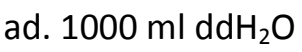

$\mathrm{pH} 8.0$ with $\mathrm{HCl}$

\subsubsection{Cell lines}

\subsubsection{Prokaryotic cell lines}

Table 11: List of prokaryotic cell lines 


\subsubsection{Eukaryotic cell lines}

Cell line were established in collaboration with C. Schläger (RBL CCR5-AP), S. Tjaden (RBL CXCR4-AP) and S. Henze (HEK CXCR4-/CCR5-DmrA with $\beta$-Arrestin 2-DmrC).

Table 12: List of eukaryotic cell lines

\begin{tabular}{lll}
\hline Name & Purpose & Source \\
\hline X63.Ag8.653 & $\begin{array}{l}\text { Fusion with spleen cells from } \\
\text { immunized mice }\end{array}$ & Own laboratory \\
HEK293 & $\begin{array}{l}\text { Expression of receptor-DmrA } \\
\text { alone and receptor-DmrA in } \\
\text { combination with rat } \\
\beta \text { B-Arrestin 2 }\end{array}$ & $\begin{array}{l}\text { German collection of } \\
\text { microorganisms and cell } \\
\text { cultures (Braunschweig, GER) }\end{array}$ \\
& $\begin{array}{l}\text { Transient expression of diverse } \\
\text { constructs }\end{array}$ & Own laboratory \\
HEK293T & $\begin{array}{l}\text { Expression of AP-tagged CCR5, } \\
\text { CXCR4 and CXCR4-CCR5 } \\
\text { CT } \\
\text { chimera }\end{array}$ & Own laboratory \\
\hline
\end{tabular}

\subsubsection{Cell culture media}

\subsubsection{LB-medium}

LB-medum

$\begin{array}{lll}10 & \mathrm{~g} & \text { Tryptone } \\ 5 & \mathrm{~g} & \text { Yeast extract } \\ 5 & \mathrm{~g} & \mathrm{NaCl} \\ 1 & \mathrm{I} & \mathrm{ddH}_{2} \mathrm{O} \\ 7,0 & \mathrm{pH} & \end{array}$

The medium was autoclaved at $121^{\circ} \mathrm{C}$ for 20 minutes and antibiotics added after the medium has cooled down. For agar-plates $15 \mathrm{~g}$ agar was added. After the medium was autoclaved it was placed on a magnetic-stirrer to cool down faster. Antibiotics were added and the medium was poured into petri dishs.

\subsubsection{Media for mammalian cell culture}

Table 13: List of media for mammalian cell culture

\begin{tabular}{llll}
\hline Name & Ingredients & $\begin{array}{l}\text { Supplements } \\
\text { (if needed) }\end{array}$ & Company \\
\hline DMEM & Glutamin & $\begin{array}{l}5 \% \text { or } 10 \% \mathrm{FCS} \\
\text { Pen/Strep }\end{array}$ & Merck/Invitrogen \\
& $4.5 \mathrm{~g} / \mathrm{l} \mathrm{Glucose}$ & Geneticin & \\
RPMI 1640 & $3,7 \mathrm{~g} / \mathrm{NaHCO}_{3}$ & $\begin{array}{l}5 \% \text { or } 10 \% \mathrm{FCS} \\
\text { Plutamin }\end{array}$ & Merck/Invitrogen \\
& $2,0 \mathrm{~g} / \mathrm{NaHCO}_{3}$ & Geneticin & \\
\hline
\end{tabular}




\subsubsection{Software}

Table 14: List of software

\begin{tabular}{|c|c|c|}
\hline Name & Purpose & Author/Company \\
\hline Adobe Photoshop CS 5 & Image processing & Adobe (San Jose, USA) \\
\hline CellQuestPro & Recoding of flow cytometry data & Becton Dickinson \\
\hline $\begin{array}{l}\text { Clone Manager } \\
\text { Professional } 8\end{array}$ & DNA analysis & Sci-Ed (Cary, USA) \\
\hline FlowJo 7.6.5 & Flow cytometry data analysis & Treestar (Ashland, USA) \\
\hline GENtle & Primer design and DNA analysis & Markus Manske (GER) \\
\hline ImageJ & $\begin{array}{l}\text { Quantification and data analysis of } \\
\text { digital images }\end{array}$ & $\begin{array}{l}\text { National Institutes of Health } \\
\text { (USA) }\end{array}$ \\
\hline $\begin{array}{l}\text { Leica microscope } \\
\text { software }\end{array}$ & Immunofluorescence images & Leica Microsystems \\
\hline Mendeley & Bibliography & Mendeley (New York, USA) \\
\hline Paint.net 3.5 & Image processing & Rick Brewster (USA) \\
\hline PhotoFiltre 6.4 & Image processing & Antonio Da Cruz (FR) \\
\hline Sigma Plot 8 and 12 & Statistical data analysis and graph design & $\begin{array}{l}\text { Systat Software (San Jose, } \\
\text { USA) }\end{array}$ \\
\hline
\end{tabular}




\subsection{Methods}

\subsubsection{Molecular biology}

\subsubsection{Agarose gel electrophoresis}

To separate DNA-fragments according to their size agarose-gel-electrophoresis was performed. Agarose $(0,7$ to $2 \% \mathrm{w} / \mathrm{v})$ was resuspendend in $1 \mathrm{x}$ TAE buffer and to visualize the DNA-fragments $0,5 \mu \mathrm{g} / \mathrm{ml}$ ethidium-bromide was added directly into the buffer. This solution was poured on to a tray and an appropriate comb was inserted. At $r$ the agarose polymerized after approx. 30 min and was transferred into a gel-chamber. The chamber was filled with 1x TAE-buffer and the samples were loaded onto the gel. If necessary the samples were mixed with loading-dye $(6 \mathrm{x})$. The electrophoresis was performed at $120 \mathrm{~V}, 220 \mathrm{~mA}$ for approx. $60 \mathrm{~min}$. Afterwards the gel was taken from the tray and the DNA could be visualized with UV-light.

\subsubsection{Polymerase chain reaction}

DNA amplification was done via polymerase chain reaction. Because of their proofreading ability these reactions were catalyzed by Phusion DNA-polymerase. A PCR reaction catalyzed by Phusion DNA-polymerase contained the following:

$10 \mu$ HF Phusion Buffer, $5 x$

$1 \mu \mathrm{ldNTP} \operatorname{mix}(10 \mathrm{mM})$

$2.5 \mu \mathrm{l}$ forward primer $(0.05 \mu \mathrm{M})$

$2.5 \mu \mathrm{l}$ reverse primer $(0.05 \mu \mathrm{M})$

$\mathrm{x} \quad \mu$ l DNA template $(5$ to $15 \mathrm{ng} / \mu \mathrm{l}$ )

$0.5 \mu$ l Phusion DNA-polymerase

ad. to $50 \mu \mathrm{l} \quad \mathrm{ddH}_{2} \mathrm{O}$

The reaction mix was filled into a $0.5 \mathrm{ml} \mathrm{PCR} \mathrm{cup} \mathrm{and} \mathrm{put} \mathrm{into} \mathrm{a} \mathrm{PCR-cycler} \mathrm{which} \mathrm{was} \mathrm{running} \mathrm{the}$ following program:

$\left.\begin{array}{lrl}\text { Lid } & 100^{\circ} \mathrm{C} & \\ \text { Initial denaturation } & 98^{\circ} \mathrm{C} & 30 \mathrm{sec} \\ \text { Denaturation } & 98^{\circ} \mathrm{C} & 10 \mathrm{sec} \\ \text { Annealing } & 59^{\circ} \mathrm{C} & 30 \mathrm{sec} \\ \text { Extension } & 72^{\circ} \mathrm{C} & 30 \mathrm{sec} / \mathrm{kb}\end{array}\right\}$ approx. 30 cycles

To check the success of the PCR a sample of the reaction was mixed with loading-dye, loaded on a $1.5 \%$ agarose gel and separated by electrophoresis (3.2.1.1). The PCR was successful if a DNA signal with the expected size was visible.

\subsubsection{Purification of DNA fragments from PCR}

The amplified DNA-fragments were purified directly from the PCR reaction using the NucleoSpin Gel and PCR Clean-up kit from Macherey \& Nagel. The purification was done following the manufacturer's guideline. At the end of the purification the DNA was dissolved in approx. $30 \mu \mathrm{l}$ $\mathrm{ddH}_{2} \mathrm{O}$. 


\subsubsection{Digestion and dephosphorylation of DNA}

For site-directed ligation of DNA and vector restriction digestion was done. Digestion with restriction enzymes creates DNA fragments with a phosphate-group on one and an $\mathrm{OH}$-group on the other side. $1 \mu \mathrm{g}$ DNA was digested for 1 to 3 hours at $37^{\circ} \mathrm{C}$ following the manufacturer's guidelines for buffer-conditions and enzyme concentration. To check if the digestion was successful digested and undigested DNA was loaded on an agarose gel and separated by electrophoresis. If DNA is cut with only one restriction enzyme the chance for the DNA to religate is high. To prevent DNA-religation $1 \mu \mathrm{l}$ alkaline phosphatase was added to the digestion mix and incubated for additional $1 \mathrm{~h}$. Purification was done using the NucleoSpin Gel and PCR Clean-up kit from Macherey \& Nagel (3.2.1.3).

\subsubsection{Ligation of DNA fragments}

For DNA replication in E. coli and expression of the gene in a mammalian cell line it is necessary to ligate the DNA of the gene with a suitable vector. Vector-DNA and DNA-fragment were mixed at a molar ratio of 1:3. The ligation reaction was catalyzed by T4-ligase up to 3 hours at $r$ in a total volume of $20 \mu \mathrm{l}$ under buffer conditions following the guidelines of the manufacturer. To check the religation-rate of the vector a second reaction mix without the insert-DNA was prepared. $10 \mu$ of the reaction mix was used for the transformation of competent $\mathrm{E}$. coli Top10F cells.

\subsubsection{Heat-shock transformation of chemo-competent E.coli}

For protein expression (E.coli BL21 (DE3)) or plasmid-replication (E. coli Top10F-) plasmid-DNA was transformed into the appropriate E.coli strain. To this end competent E.coli were thawed on ice and mixed with $10 \mu \mathrm{l}$ of ligation mix or $2 \mu \mathrm{g}$ plasmid-DNA. Cells were gently mixed by vortexing and chilled for $20 \mathrm{~min}$ on ice. The following heat-shock was performed at $42^{\circ} \mathrm{C}$ for $90 \mathrm{sec}$ in a thermomixer. Afterwards the cells were incubated on ice for additional $2 \mathrm{~min}$ and resuspendend in $500 \mu \mathrm{l} \mathrm{LB}$-medium (without antibiotics) and incubated for $60 \mathrm{~min}$ at $37^{\circ} \mathrm{C}$ in a thermomixer. 50 and $100 \mu \mathrm{l}$ of the cell suspension was directly plated on LB-agar plates with the appropriate antibiotic. The rest of the cell-suspension was centrifuged at $1400 \times$ g, resuspendend in $200 \mu \mathrm{l} \mathrm{LB}$-medium and plated on LB-agar plates as well. The plates were incubated at $37^{\circ} \mathrm{C}$ overnight.

\subsubsection{Colony-PCR of transformed E.coli}

To check whether the transformed plasmid is expressed grown colonies were taken to perfom colony PCR. Colonies were picked from the agar-plate with a pipette-tip and transferred to a LB-agar master-plate, which was incubated at least for 8 hours at $37^{\circ} \mathrm{C}$. The rest of the cell material was

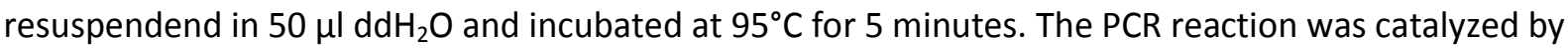
TAQ DNA-polymerase. The corresponding reaction mix consisted of the following:

$2.5 \mu$ l RedTaq Buffer, 10x

$0.5 \mu \mathrm{l}$ dNTP mix (10 mM)

$1.25 \mu \mathrm{l}$ forward primer $(0.05 \mu \mathrm{M})$

$1.25 \mu$ l reverse primer $(0.05 \mu \mathrm{M})$

$10 \mu$ DNA suspension

$1.25 \mu \mathrm{l}$ Phusion DNA-polymerase

$7.25 \mu \mathrm{ldd} \mathrm{dd}_{2} \mathrm{O}$

$\Sigma 25 \mu \mathrm{l}$ 
The PCR-cycler program for TAQ DNA-polymerase was:

$\left.\begin{array}{lll}\text { Lid } & 100^{\circ} \mathrm{C} & \\ \text { Initial denaturation } & 94^{\circ} \mathrm{C} & 1 \mathrm{~min} \\ \text { Denaturation } & 94^{\circ} \mathrm{C} & 1 \mathrm{~min} \\ \text { Annealing } & 59^{\circ} \mathrm{C} & 2 \mathrm{~min} \\ \text { Extension } & 72^{\circ} \mathrm{C} & 1 \mathrm{~min} / \mathrm{kb}\end{array}\right\}$ approx. 30 cycles

At the end of the cycler program $10 \mu \mathrm{l}$ of the PCR-mix was loaded directly on a $1.5 \%$ agarose gel (3.2.1.1). After electrophoresis the positive clones could be identified by a DNA-signal with an expected size.

The positive clones were inoculated in $6 \mathrm{ml} \mathrm{LB}$-medium with antibiotics and cultured overnight at $37^{\circ} \mathrm{C}$ and $200 \mathrm{rpm}$. On the following day the plasmid-DNA was purified and digested with the same enzymes which were used to prepare vector-DNA and insert-DNA for ligation.

\subsubsection{Plasmid purification from E. coli cultures}

E. coli Top10F cells were transformed with the plasmid of interest and cultured in LB-medium with antibiotics overnight at $37^{\circ} \mathrm{C}$ and $200 \mathrm{rpm}$. For long-term storage $800 \mu \mathrm{l}$ cells suspension and $200 \mu \mathrm{l}$ glycerol (99\%) was mixed and stored at $-80^{\circ} \mathrm{C}$. DNA purification from E.coli was done using commercial kits (NucleoBond PC 500 and NucleoSpin plasmid) according to the manufacturer's

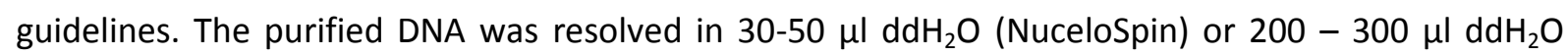
(NucleoBond) and the DNA content was measured photometrically.

\subsubsection{Phenol-Chloroform extraction and ethanol precipitation of DNA}

To remove buffer components and proteins from DNA a mixture of phenol-chloroform-isoamylalkohol $(25: 24: 1(\mathrm{v} / \mathrm{v}))$ was added to the DNA and the sample was centrifuged for 15 seconds at $12600 \mathrm{x}$. The upper phase was transferred into a new $1.5 \mathrm{ml}$ tube.

For DNA extraction $3 \mathrm{M}$ sodium acetate was added in the same volume as the sample. $96 \%$ pre-cooled ethanol was added ( 2.5 volumes of the starting sample volume) and the sample was incubated for 20 minutes on ice. Subsequently the sample was centrifuged for $5 \mathrm{~min}$ at $12600 \mathrm{xg}$ at $4^{\circ} \mathrm{C}$, the supernatant was removed and the pellet washed with $1 \mathrm{ml}$ of $70 \%$ ethanol. Ethanol was

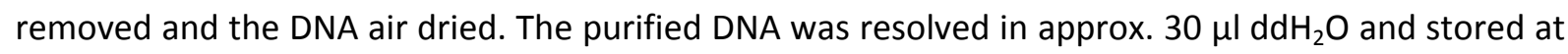
$-20^{\circ} \mathrm{C}$.

\subsubsection{DNA sequencing}

Sequencing of plasmid-DNA was done by SeqLab (Göttingen, GER). To this end, $80 \mathrm{ng} / \mu \mathrm{l}$ DNA was mixed with $30 \mathrm{pmol}$ of the sequencing-primer and adjusted to a total volume of $15 \mu$ with $\mathrm{dd}_{2} \mathrm{O}$. 


\subsection{Cell culture and functional assays}

\subsubsection{Culture conditions}

All cell lines were incubated in a water-saturated atmosphere with $5 \% \mathrm{CO}_{2}$ at $37^{\circ} \mathrm{C}$. Rat basophilic leukemia (RBL) cells were cultured in RPMI 1640 medium supplemented with $10 \%$ heat inactivated FCS and $100 \mu \mathrm{g} / \mathrm{ml}$ mixture of penicillin/streptomycin. For the selection of transfected cells $600 \mu \mathrm{g} / \mathrm{ml}$ geneticin was added. To thin out the cells they were washed with PBS and subsequently trypsinized with trypsin-EDTA for up to 25 minutes. All other cell lines (Ag8, peritoneal macrophages, hybridoma cells) were kept in RPMI 1640 medium without geneticin.

Human embryonic kidney cells (HEK293) cells were incubated in DMEM medium supplemented with the same ingredients as the RPMI 1640 medium. For cell selection a concentration of $1200 \mu \mathrm{g} / \mathrm{ml}$ geneticin was used. For maintenance cultures the concentration was lowered to $600 \mu \mathrm{g} / \mathrm{ml}$. For the detachment of HEK293 cells the cells were washed gently with PBS and trypsinized with trypsin-EDTA for 2 minutes.

Centrifugation of all cell lines was done at $270 \mathrm{xg}$ at $\mathrm{rt}$ for 5 minutes. All working steps which were relevant for cell culturing were done under sterile conditions with sterile solutions and sterile equipment.

\subsubsection{Freezing and thawing of cells}

For cell-storage cells were washed with PBS, trypsinized and centrifuged for 5 minutes at $270 \times \mathrm{g}$ at rt. The supernatant was decanted and the cell-pellet was gently resuspend in freezing-medium. Afterwards the cell-suspension was transferred into pre-cooled $2 \mathrm{ml}$ cryo-tubes and stored at $-80^{\circ} \mathrm{C}$. For long term storage the cells were frozen in liquid nitrogen. Cell thawing was done in a water bath at $37^{\circ} \mathrm{C}$. The cryo-tube was removed from the water bath after nearly the whole cell-suspension was molten and transferred into $10 \mathrm{ml}$ of cell-culture medium. The cells were centrifuged at $270 \times \mathrm{g}$ for 5 minutes at $\mathrm{rt}$ and the supernatant was removed. The cell pellet was gently resuspended in cell culture medium and seeded in new culture dishes.

\subsubsection{Cell counting}

Adherent cells were washed with PBS, trypsinized and centrifuged at $270 \times \mathrm{g}$ for 5 minutes at rt. Afterwards the cell pellet was resuspended in a suitable volume of cell culture medium. $10 \mu \mathrm{l}$ of the cell-suspension was mixed with $90 \mu \mathrm{l}$ of $0.5 \%$ trypan blue-solution and pipetted onto a Neubauer counting chamber.

\subsubsection{Cell transfection}

\subsubsection{Transfection of RBL-cells using electroporation}

To express foreign DNA in a cell line it is necessary to clone the DNA into a suitable expression vector. For our purpose we cloned the receptor DNA into the expression vector pEF1/Myc-HisA which contained a geneticin resistance cassette for the selection of positively transfected cells. The plasmid was linearised with the restriction enzyme Scal (3.2.1.4) and extracted with phenol/chloroform (3.2.1.9). The cells were washed with PBS, trypsinized and $1^{*} 10^{7}$ cells were resuspended in $250 \mu \mathrm{l}$ PBS. $18 \mu \mathrm{g}$ of the linearised expression vector was pipetted into a pre-cooled electroporation cuvette. The cell suspension was added, gently mixed with DNA and incubated for 10 minutes on ice. The electroporation was done at $960 \mu \mathrm{F}$ and $260 \mathrm{~V}$ at $\mathrm{rt}$. After the electroporation the cells were again cooled on ice for 10 minutes. Afterwards the cell suspension was transferred into $10 \mathrm{ml}$ of culture medium and centrifuged at $270 \times \mathrm{g}$ for 5 minutes at $\mathrm{rt}$. The supernatant was decanted and the cell pellet was resuspended in $1 \mathrm{ml}$ of culture medium. The $1 \mathrm{ml}$ cell suspension was added to 
$36 \mathrm{ml}$ of culture medium and distributed in $0.5 \mathrm{ml}$ aliquots on 24 well culture plates. To select the positively transfected cells the culture medium was exchanged for culture medium with $600 \mu \mathrm{g} / \mathrm{ml}$ geneticin. Visible colonies were transferred into 96 well plates and the expression level of receptors at the cell surface was checked using flow-cytometry (3.3.6.1).

\subsubsection{Co-transfection of HEK293-cells using calcium-phosphate}

HEK293 cells are susceptible for transfection by calcium-phosphate precipitates. The DNA is enclosed in the calcium-phosphate precipitates and is taken up by the cells over the cell membrane. The pEF1/Myc-HisA vector which contained the receptor-DmrA DNA was linearized using the restriction enzyme Scal. $\beta$-Arrestin $2-D m r C$ was cloned into pHet1 which was linearized with Mlul 3.2.1.4). Both plasmids were purified using phenol/chloroform extraction (3.2.1.9).

One day before the transfection $6 * 10^{5}$ were seeded on multiple $10 \mathrm{~cm}$ culture dishes. 4 hours before the cells were transfected the medium was exchanged with DMEM medium from Invitrogen. $5 \mu \mathrm{g}$ DNA from each construct was added to $50 \mu \mathrm{l} 2.5 \mathrm{M} \mathrm{CaCl}_{2}$ and with $\mathrm{ddH}_{2} \mathrm{O}$ adjusted to a final volume of $500 \mu \mathrm{l}$. Afterwards $500 \mu \mathrm{l}$ of $2 x$ HBS-solution was added dropwise with additional snapping of the tube. Immediately afterwards the mixture was added to the cells. 24 hours post transfection the medium was removed and $900 \mu \mathrm{l}$ of pre-warmed $10 \%$ glycerol $(\mathrm{v} / \mathrm{v})$ was added to the cells and removed shortly afterwards. For selection purposes $1200 \mu \mathrm{g} / \mathrm{ml}$ genetecin was added to the medium. Effect of cell selection was visible after 14 days. Further treatment of positive cell clones was identical to RBL-cells.

The calcium-phosphate transfection method could also be used for transient transfections. In contrast to the stable transfection the transient transfection of cells is not permanent and the transfected plasmids must not be linearized. For the transient transfection $3 * 10^{5}$ cells were seeded in a well of a 6 well plate one day before transfection. For the transfection $3.3 \mu \mathrm{g}$ DNA was added to $16.6 \mu \mathrm{l} 2.5 \mathrm{M} \mathrm{CaCl}_{2}$ and adjusted with $\mathrm{ddH}_{2} \mathrm{O}$ to a final volume of $166 \mu \mathrm{l}$. Afterwards $166 \mu \mathrm{l} 2 \mathrm{x}$ HBS-solution was added dropwise. The remainder of the transfection protocol was identical to the stable transfection.

\subsubsection{Subcloning of positively selected cell-clones}

To ensure that the positively selected cell clones did not contain any contaminants the cells were subcloned. Cells were adjusted to $1.3 * 10^{4}$ cells per $\mathrm{ml}$ and were diluted threefold (260/62/20 cells per $\mathrm{ml}$ ) in a total medium volume of $25 \mathrm{ml}$. One drop of this cell-suspension was added to $100 \mu \mathrm{l}$ medium per well of a 96 well plate resulting in a minimal cellular concentration of 0.8 cells per well. Separately grown colonies were analyzed using flow-cytometry (3.3.6.1).

\subsubsection{Functional assays}

\subsubsection{Ca ${ }^{2+-m o b i l i z a t i o n ~ a s s a y ~}$}

To measure the cytosolic $\mathrm{Ca}^{2+}$-shift after cellular stimulation the membrane permeable dye Indo-1-AM was used. In the presence of $\mathrm{Ca}^{2+}$ the emission spectrum changed ( 475 to $400 \mathrm{~nm}$ ), which was used to detect the intracellular calcium mobilization. Cells were adjusted to $1.5^{*} 10^{6}$ and resuspended in $700 \mu \mathrm{l}$ RPMI 1640 medium with $5 \%$ FCS. $1 \mu \mathrm{M}$ Indo-1-AM mixed with pluronic-acid F127 $(0.015 \% \mathrm{v} / \mathrm{v})$ was carefully added to the cell suspension $\left(25^{\prime} / 30^{\circ} \mathrm{C} / 350 \mathrm{rpm}\right)$ in darkened tubes. $700 \mu \mathrm{l}$ of RPMI 1640 medium with $10 \% \mathrm{FCS}$ was added $\left(10^{\prime} / 30^{\circ} \mathrm{C} / 350 \mathrm{rpm}\right)$. Cells were washed and resuspended in Krebs-Ringer-solution. The $400 \mathrm{~nm} / 475 \mathrm{~nm}$ ratio was recorded for 25 seconds by flow cytometry and resulting data were normalized. 


\subsubsection{N-acetyl- $\beta$-D-glucosaminidase (NAGA) release}

To test the functional integrity of receptors expressed by RBL cells the ligand-induced and $G$ protein-mediated NAGA release from transfected cells was measured. RBL cells are myeloid cells which contain NAGA within prestored vesicles.

RBL cells were adjusted to $4 * 10^{6}$ cells in $1 \mathrm{ml} \mathrm{HAG-CM}$ buffer containing $0.25 \%$ BSA and $5 \mu \mathrm{l} 100 \%$ cytochalasin $(\mathrm{w} / \mathrm{v})$ and were incubated for 20 minutes at $37^{\circ} \mathrm{C}$. In parallel, $10 \mu \mathrm{l}$ of $1 \%$ triton-X $(\mathrm{v} / \mathrm{v})$ was added to $90 \mu \mathrm{l}$ of the cell suspension and incubated for 4 minutes at $37^{\circ} \mathrm{C}$ to obtain maximal cell lysis (positive control). The sample was centrifuged $\left(3200 \mathrm{x} \mathrm{g} / 5^{\prime}\right.$ at $\left.4^{\circ} \mathrm{C}\right)$ and the cell-free supernatant was used for calibration purposes with samples diluted 1:2 ratio in HAG-CM buffer. The ligand $(0.5-250 \mathrm{nM})$ in $10 \mu \mathrm{l} \mathrm{HAG-CM}$ buffer was added to $90 \mu \mathrm{l}$ of cell-suspension and incubated at $37^{\circ} \mathrm{C}$ for 4 minutes and centrifuged $\left(3200 \times \mathrm{g} / 5^{\prime}\right.$ at $\left.4^{\circ} \mathrm{C}\right)$. Supernatant $(25 \mu \mathrm{l})$ of the triton lysate and of the ligand-stimulated cells were incubated $\left(2\right.$ hours $\left./ 37^{\circ} \mathrm{C}\right)$ in a microtiter plate with $125 \mu \mathrm{l}$ of 4 Nitrophenyl $\mathrm{N}$-acetyl- $\beta$-D-glucosaminide. The reaction was stopped by adding $50 \mu \mathrm{l}$ of $1 \mathrm{M}$ glycerol-buffer and the optical density at $450 \mathrm{~nm}$ was determined in a plate photometer. The standard curve was used to calculate the NAGA release (\% of total cellular NAGA content).

\subsubsection{Phosphorylation/activation of ERK1/2 MAP-kinases after ligand and AP21967/AP20187 stimulation}

$6 * 10^{5}$ HEK293-cells were seeded onto lysine-coated 6 well plates and cultivated overnight in FCS-free DMEM medium containing $0.02 \%$ BSA. The next day cells were incubated $\left(60^{\prime} / 37^{\circ} \mathrm{C}\right)$ in fresh DMEM medium without serum. After cellular stimulation the plates were chilled on ice and were detached with treatment buffer and lysed $\left(5^{\prime} / 95^{\circ} \mathrm{C} /\right.$ sonication). The lysates were used for immunoblotting (3.5.2) with anti-phospho-ERK1/2 detection antibodies. As a loading control the immunoblot was reprobed using anti-pan-ERK1/2-antibody.

A similar protocol was followed to probe a diverse range of signaling pathways using human phospho-MAPK array kit from R\&D system. Cells were prepared as described and the kit was used following the manufacturer's guidelines.

\subsubsection{Quantification and visualization of internalization-and recycling processes of CXCR4- and CCR5-receptors}

In the presence or absence of receptor agonists and antagonists the expression of CXCR4- and CCR5-receptors on the cell surface is a subject of constant changes. These changes can be either detected by biotin-streptavidin (3.6) or direct receptor staining. If necessary, the cells were biotinylated (3.6) and adjusted to $6 * 10^{6}$ cells. The cells were resuspended in $2 \mathrm{ml} \mathrm{BM}$ medium and stimulated with receptor-agonist/-antagonist or AP21967/AP20187 $\left(30^{\prime} / 37^{\circ} \mathrm{C}\right)$. To measure the recycling rate of the receptor the samples were acid washed to remove the ligand and resuspended in ligand-free BM medium $\left(30^{\prime} / 37^{\circ} \mathrm{C}\right)$. Through the whole process samples were taken, washed with EM-, BM-medium and FACS-buffer and transferred into wells of a 96 well plate $\left(4^{\circ} \mathrm{C}\right)$. Quantification was performed by flow cytometry (3.3.6.1). The percentage of expressed receptors on the cell surface was calculated on the base of unstimulated control cells. For the visualization of internalized receptors immunfluorescence microscopy (3.3.6.2) was done. The procedure was identical to the quantification with the exception that all steps were done with adherent cells. 


\subsubsection{Fluorescence-based assays}

\subsubsection{Flow-cytometry}

To detect the amount of CXCR4 and CCR5 on the cell surface the cells were stained with fluorophor-labeled antibodies or streptavidin. Cells were adjusted to a defined cell density of cells per $\mathrm{ml}$. The staining was done in a 96 -well plate $\left(60^{\prime} / 4^{\circ} \mathrm{C} /\right.$ dark). In between the cells were washed with FACS-buffer. The samples were resuspended in FACS-buffer and transferred into tubes. For the calibration of the flow cytometer non labeled cells were used. Routinely, 10,000 cells were measured per sample.

\subsubsection{Immunfluorescence miscroscopy}

Prior to the staining $1 * 10^{5}$ cells were seeded on sterile round cover slips, which were placed in 24 well plates (overnight at $37^{\circ} \mathrm{C}$ ). If necessary the cells were biotinylated (3.6) and stimulated with the corresponding ligand or AP21967/AP20187. Cells were fixed with paraformaldehyd (PFA) $\left(20^{\prime} / 37^{\circ} \mathrm{C}\right)$ and quenched with a $50 \mathrm{mM} \mathrm{NH}{ }_{4} \mathrm{Cl}$ solution $\left(30^{\prime} / 37^{\circ} \mathrm{C}\right)$. To permeabilize the cell membrane, the cells were incubated with a gelatin-saponin solution $\left(15^{\prime} / 37^{\circ} \mathrm{C}\right)$. For the staining the primary antibody was added ( $60^{\prime} /$ on ice) followed by the detection antibody or streptavidin $\left(60^{\prime} /\right.$ on ice/dark). Between all steps the samples were washed either with sterile PBS or gelatin-saponin solution. The cover slips were sealed with mounting medium and placed on a microscope slide and subsequently dried (overnight/rt/dark). Cells were analyzed by confocal laser microscopy using a $63 \times 1.3$ objective and the oil immersion technique.

\subsection{Generation of a monoclonal antibody against the acceptor-peptide (AP)}

Monoclonal antibodies were generated according to the Köhler-Milstein-protocol with modifications described elsewhere in (Peters \& Baumgarten, 1992).

\subsubsection{Preparation of a KLH-peptide conjugate for immunization}

The AP-peptide sequence was taken from the biotin carboxyl carrier protein, a subunit of the acetyl-CoA carboxylase (Beckett et al., 1999). Furthermore, it has been determined that a minimal length of approx. 15 amino acids is crucial for a successful biotinylation reaction (Chen et al., 2005). For the immunization of mice an AP-peptide with an aminohexanoic acid (Ahx) spacer and an additional c-terminal cysteine residue for conjugation purposes was generated by JPT. Because of the short sequence of the peptide the immunogenicity is very low. To increase the immunogenicity the peptide was coupled to a pre activated form of the keyhole limpet hemocyanin (KLH-NHS). In combination with the c-terminal cysteine residue of the AP-peptide the KLH could easily coupled to the peptide without using a crosslinking reagent.

We resuspended $2 \mathrm{mg}$ of $\mathrm{KLH}$ and $2 \mathrm{mg}$ of the AP-peptide into $200 \mu \mathrm{l}$ of $50 \mathrm{mM}$ phosphate-buffer. Both solutions were mixed and incubated for 2 hours at $\mathrm{rt}$ in an overhead-stirrer. To saturate remaining reactive amino- and SH-groups $50 \mu \mathrm{l}$ of $2 \%(\mathrm{w} / \mathrm{v})$ cysteine-phosphate-buffer solution was added and incubated for an additional hour under same conditions. Afterwards the suspension was dialyzed against PBS overnight to remove uncoupled AP-peptide. The coupling efficiency was tested by ELISA (3.5.3). 
Prior to immunization of mice $350 \mu \mathrm{l}$ of the AP-KLH peptide was mixed with $350 \mu \mathrm{l}$ of the adjuvant TiterMax by sonication. The resulting water-oil emulsion was used for the immunization and guaranteed a slow release of the AP-KLH antigen to the organism. To increase the number of antibody producing B-cells and their specificity immunization with $50 \mu \mathrm{g} \mathrm{AP-KLH}$ peptide with adjuvant was injected at 3 monthly intervals into a skin fold. 3 days

Table 15: Time schedule for mice immunization

\begin{tabular}{ccc}
\hline Day & Step & KLH-AP $[\mu \mathrm{g}]$ \\
\hline $\mathbf{1}$ & Priming & 50 \\
$\mathbf{3 0}$ & $1^{\text {st }}$ refreshment & 50 \\
$\mathbf{6 0}$ & $2^{\text {nd }}$ refreshment & 50 \\
$\mathbf{9 0}$ & $3^{\text {rd }}$ refreshment & 50 \\
$\mathbf{1 2 0}$ & $1^{\text {st }}$ boost & 50 \\
$\mathbf{1 2 1}$ & $2^{\text {nd }}$ boost & 75 \\
$\mathbf{1 2 2}$ & $3^{\text {rd }}$ boost & 100 \\
\hline
\end{tabular}
before cell-fusion the successive boosting injections were made with an increasing amount of antigen (Table 15) in the absence of adjuvant.

\subsubsection{Fusion of splenocytes with Ag8 cells and identification of positive hybridoma cell-clones}

To guarantee optimal growth-conditions for the freshly fused cells (hybridoma-cells) a few days before the cell-fusion mouse peritoneal-macrophages (feeder-cells) were seeded in 96 -well plates.

The macrophages produced both the cytokine IL-6 and several other growth factors. They also remove cell debris from non fused cells. For the feeder-cell preparation a Balb/c mouse was killed, the abdomen opened and flushed with PBS. The resulting cell-suspension was given into $400 \mathrm{ml}$ of RPMI 1640 medium and distributed on 96 well plates.

For the cell-fusion an immunized mice was killed and the abdomen opened. The spleen was removed and transferred into a petri-dish with $10 \mathrm{ml}$ RPMI 1640 medium. The spleen was finely chopped and extensively flushed with medium. To allow bigger spleen-parts to settle down the suspension stood still for a couple of minutes. In the meantime Ag8 cells were counted and adjusted to $1 * 10^{8}$ cells per $20 \mathrm{ml}$ medium. The spleen supernatant was given to the Ag8 cell suspension and centrifuged at $\mathrm{rt}$ and $200 \times \mathrm{g}$ for 5 minutes. The supernatant was removed and $100 \%$ PEG-medium (w/v) and PBS was added (Table 16).

Table 16: Pipetting scheme for PEG-medium and PBS during cell-fusion

\begin{tabular}{ccc}
\hline Step & Volume & Duration \\
\hline $\mathbf{1}$ & $0.25 \mathrm{ml}$ PEG-medium & 10 seconds \\
$\mathbf{2}$ & $1.5 \mathrm{ml}$ PEG-medium & 1 minute \\
$\mathbf{3}$ & $1 \mathrm{ml} \mathrm{PBS}$ & 30 seconds \\
$\mathbf{4}$ & $3 \mathrm{ml} \mathrm{PBS}$ & 30 seconds \\
$\mathbf{5}$ & $16 \mathrm{ml} \mathrm{PBS}$ & 1 minute \\
\hline
\end{tabular}

Afterwards the suspension was centrifuged for 5 minutes at $300 \times \mathrm{g}$ and RT and allowed to stand still for 5 minutes. Then the supernatant was removed and the pellet resuspended in $450 \mathrm{ml}$ RPMI 1640 medium with $1 \times$ HAT supplemented. The HAT was required to inhibit the growth of non- and self-fused Ag8-cells. The cell suspension was evenly distributed on the previously prepared feeder-cell plates. After undesired fusion products died because of the HAT selection, the medium was supplemented with $1 \mathrm{x} \mathrm{HT}$ to allow the cells to adapt to medium conditions in the absence of aminopterin.

To identify wells with colonies which produce AP-specific antibodies ELISA assays were done. The plates were coated with AP-peptide and $100 \mu$ l of the supernatant of each well was directly applied for the detection. Colonies from positive wells were separated and again checked by ELISA. To ensure 
homogenecity of the resulting hybridomas the positively identified cell-colonies were subcloned. To this end cells were aspirated, transferred into $6 \mathrm{ml}$ medium and diluted in 3 dilution steps to obtain a wiede range of concentrations. Cells were seeded onto feeder-plates and the antibody of single grown colonies was again checked for its antigen-specificity. If necessary the subcloning step was repeated several fold. Positive cell-clones were cultivated in flasks with IL-6 medium $(0.1 \mathrm{ng} / \mathrm{ml})$ and the antibody-containing supernatant was used for further experiments.

\subsection{Protein analysis}

\subsubsection{Sodium dodecyl sulfate polyacrylamide gel electrophoresis (SDS-PAGE)}

By SDS-PAGE charged proteins are separated according to their molecular weight. The separation-gel was mixed according to Table 17 and poured between two glass-plates separated by spacers and fixed with clamps. Acrylamide was covered with a thin layer of isopropanol. After polymerization the isopropanol was decanted, a stacking-gel was poured on top and a comb was inserted. After the polymerization of the stacking gel the whole gel was attached to an electrophoresis chamber and filled with $1 x$ Laemmli buffer. The samples were incubated $\left(5^{\prime} / 95^{\circ} \mathrm{C}\right)$ with treatment buffer and were loaded together with a prestained molecular weight marker onto the gel using a glass syringe. Electrophoresis was performed at $70 \mathrm{~V}$ for 15 minutes and was increased to $120 \mathrm{~V}$ and a constant current of $300 \mathrm{~mA}$. To visualize the separated proteins the gels were either stained with coomassie dye or further processed by immunoblotting (3.5.2).

\begin{tabular}{|c|c|c|}
\hline Separation gel & Reagent & Stacking gel \\
\hline $10.0 \mathrm{ml}$ & Acryl bisacrylamide solution & $1.3 \mathrm{ml}$ \\
\hline \multirow[t]{2}{*}{$7.5 \mathrm{ml}$} & Separation gel buffer & \\
\hline & Stacking gel buffer & $2.5 \mathrm{ml}$ \\
\hline $0.3 \mathrm{ml}$ & $10 \%$ SDS (w/v) & $0.1 \mathrm{ml}$ \\
\hline $12.0 \mathrm{ml}$ & $\mathrm{ddH}_{2} \mathrm{O}$ & $6.1 \mathrm{ml}$ \\
\hline $5.0 \mathrm{mg}$ & Ammonium persulfate & $2.5 \mathrm{mg}$ \\
\hline $20.0 \mu \mathrm{l}$ & TEMED & $10.0 \mu \mathrm{l}$ \\
\hline
\end{tabular}

\subsubsection{Immunoblot (Western Blotting)}

Proteins previously separated by SDS gel electrophoresis (3.5.1) were transferred to nitrocellulose membranes where they are accessible for detecting antibodies. Four filter-papers and the nitrocellulose-membrane were soaked in semi-dry transfer buffer. Two filter-papers were placed on the anode and the SDS gel was placed on top followed by the nitrocellulose membrane and two additional filter-papers. The stack was turned on the back thereby orientating the gel towards the anode. Air bubbles were removed by rolling a pipette over the stack. The protein transfer was performed for 60 minutes at $200 \mathrm{~mA}$ and $25 \mathrm{~V}$, at maximum.

Free binding sites on the nitrocellulose membrane were blocked $\left(60^{\prime} / \mathrm{rt}\right)$ with $1-5 \%$ BSA-TBST and immunostaining was performed by incubation with primary antibodies overnight at $4^{\circ} \mathrm{C}$, followed by secondary detecting antibodies in $0.5 \%$ BSA-TBST for at least 60 minutes. In between, the membrane was extensively washed 3-times with TBST. Antigens of interest were detected by adding $\mathrm{ECL}$ reagents ( $4 \mathrm{ml}$ solution $A+0.4 \mathrm{ml}$ solution $B+1.2 \mu \mathrm{l} \mathrm{H} \mathrm{O}_{2}, 35 \%$ ) and the result was documented with a LCD camera. 
For re-probing of immunoblots membranes were incubated $\left(30^{\prime} / \mathrm{rt}\right)$ with a HRP-blocking solution which inactivated the enzymatic activity of HRP. Alternatively, antibodies were removed from the nitrocellulose membrane by incubation $\left(30^{\prime} / 56^{\circ} \mathrm{C} /\right.$ shaking) with stripping buffer. In both cases membranes were afterwards washed extensively with TBST followed by 1-5 \% BSA-TBST blockade.

\subsubsection{Enzyme-linked immunoabsorbent assay (ELISA)}

ELISA assays were used to quantify various proteins of interest. For an indirect ELISA the antigen was used for coating $(1-5 \mu \mathrm{g} / \mu \mathrm{l})$ and detected by antibody-containing solutions (e.g. hybridoma supernatans). For a direct ELISA a capture antibody was used for coating and a solution containing the corresponding antigen was added afterwards. In both cases the supernatant was discarded and exchanged with a HRP coupled reporter-antibody (or conjugate) (1 hour/rt/wet chamber). Between all steps the plate was thoroughly washed with PBST. For the evaluation the HRP substrate ABTS with $0.44 \% 3.5 \% \mathrm{H}_{2} \mathrm{O}_{2}$ was added. The optical density of the supernatant was measured at 405 and $490 \mathrm{~nm}$ wavelength in a plate photometer.

\subsubsection{Purification of membrane fractions from whole cell extracts using ultracentrifugation}

For membrane purification cell lysates were ultracentrifuged on a sucrose gradient.

Prior to the purification cells were seeded and incubated on cell culture plates till they reached confluency. Cells were treated with AP21967 or ligand and the reaction was stopped by transferring culture plates on ice. Membrane buffer was added and the cells scraped from the culture plate. The cells were dounce homogenized and sonicated (20"/50 \% amplitude). The sucrose gradient (50\%; $35 \% ; 20 \%$ ) was prepared in centrifugation tubes and cell lysates were loaded on top. Samples were centrifuged at $217000 \times \mathrm{g}\left(2\right.$ hours $\left./ 4^{\circ} \mathrm{C}\right)$. The membrane phase $(50 \% / 35 \%$ interphase) was aspirated and centrifuged again at $248000 \times \mathrm{g}\left(15^{\prime} / 4^{\circ} \mathrm{C}\right)$. The pellet was resuspended in $50 \mu \mathrm{l}$ of lysis buffer and probed by immunoblotting (3.5.2).

\subsubsection{Expression and purification of biotin ligase A from E. coli BL21 (DE3)}

E.coli BL21 (DE3) bacteria were transformed with plasmid BirA-pET 21a (3.2.1.6) which was kindly provided by Alice Ting (Massachusetts Institute of Technology, Cambridge, USA). Single colonies were picked and transferred into LB-medium with ampicillin ( 16 hours $/ 37^{\circ} \mathrm{C} / 200 \mathrm{rpm}$ ). The starter culture was used to inoculate the culture for protein expression. $\mathrm{OD}_{600 \mathrm{~nm}}$ was measured to determine the optimal time point to induce the protein expression with $1 \mathrm{M}$ IPTG $\left(3\right.$ hours $\left./ 25^{\circ} \mathrm{C} / 200 \mathrm{rpm}\right)$. The samples were centrifuged, the supernatant decanted and stored overnight at $-80^{\circ} \mathrm{C}$. The pellets were resuspended in NiNTA binding buffer and lysed by sonication $\left(60^{\prime \prime}\right)$. In the meantime NiNTA agarose was washed with binding buffer and loaded with the supernatant of the lysed cells $\left(60^{\prime} / 4^{\circ} \mathrm{C} / \mathrm{stirring}\right)$. The mixture was poured into a PD10 column, which was emptied by gravity flow. The agarose was washed with NiNTA washing buffer and eluted with elution buffer. The flow through was collected separately. Samples were taken and probed by SDS gel electrophoresis which was subsequently dyed with coomassie blue to check the purification efficiency. In parallel, the $\mathrm{OD}_{280 \mathrm{~nm}}$ of the eluate fractions was measured and fractions with a high protein yield were pooled and dialyzed against TRIS buffer with $30 \mathrm{mM}$ potassium glutamate. The $\mathrm{OD}_{280 \mathrm{~nm}}$ of the dialyzed samples was measured and was used for calculation of the BirA concentration. 


\subsection{Enzymatic and biochemical biotinylation of the acceptor peptide (AP)}

The enzyme biotin ligase A (BirA) catalyzes a reaction which fuses biotin to a lysine residue of the AP-peptide. This reaction can be used to tag a specific protein-population (Howarth \& Ting, 2009). For the biotinylation $2 * 10^{6}$ cells were mixed with a $3 \mu \mathrm{M}$ BirA solution $(20 \mu \mathrm{l}$ biomix $\mathrm{A}$ and $\mathrm{B}$ adjusted to $200 \mu \mathrm{l}$ with TRIS-potassiumglutamate buffer) $\left(30^{\prime} / 30^{\circ} \mathrm{C} / 350 \mathrm{rpm}\right)$. The biotinylation reaction can be carried out with adherent and detached cells. After biotinylation the cells were stained with streptavidin or used for other assays (e.g. internalization assay (3.3.5.4) or immunofluorescence (3.3.6.2)).

Besides the enzymatic biotinylation a chemical biotinylation with biotin-XNHS was also performed. The XNHS-group reacted with all surface-expressed proteins. To this end a $0.1 \%$ biotin-XNHS solution was pipetted to cell suspension $\left(5^{\prime} / \mathrm{rt}\right)$ in PBS $(\mathrm{pH} 8.0)$. 


\section{Results}

\subsection{Biotin Ligase A-catalyzed biotinylation of an acceptor peptide - a new tool for internalization and recycling studies}

Classical internalization studies are most often based on receptor-specific antibodies which are used to measure receptor depletion from the cell surface by flow cytometry or immunofluorescence. This methodological approach is limited since it does not allow to discriminate between receptors which still remain on the cell-surface after ligand stimulation and those receptors which either recycle back from internal stores or translocate to the cell surface during receptor biogenesis. Another disadvantage of anti-receptor antibody-based assays is the lack of comparability of the results when internalization/recycling of two or more receptors is being analyzed. Both limitations can be overcome using AP-tagged receptors and anti-AP antibodies. With the specific biotinylation of the AP via BirA biotin ligase a whole receptor population at the cell surface can be specifically tagged for further internalization/recycling studies and analyzed separate from internal receptor stores.

Monoclonal anti-AP antibodies provide the possibility to compare the results of different receptors and allow to discriminate between biotinylated and non-biotinylated membrane proteins.

\subsubsection{Generation of RBL cell-lines which stably express CXCR4-, CCR5- and CXCR4-CCR5 chimeric-receptors with an $\mathrm{N}$-terminal acceptor peptide}

To investigate the internalization and recycling processes of distinct receptor populations RBL-cells were stably tranfected with AP-tagged versions of CXCR4, CCR5 and CXCR4-CCR5 $5_{\text {ст. }}$. To this end the DNA was ligated into the expression vector pEF1/Myc-HisA and transfected into cells by electroporation. Transfected cells were selected with geneticin. Prior to flow cytometry the cells were stained with anti-receptor antibodies to check the expression levels of the receptors. The cell lines with the highest mean channel of fluorescence (MCF) were subcloned at least once in order to ensure homogenous cell populations. Expression of the AP-tag was tested separately with an anti-AP antibody. The MCF values in Table 18 demonstrate that both the receptor and the AP-TAG are expressed in a sufficient manner. To exclude clonal artefacts two cell lines with high receptor expression were used for all subsequent

Table 18: $\mathrm{MCF}$ and $\mathrm{EC}_{50} / \mathrm{E}_{\max }$ values of receptor-expressing RBL-cells RBL cells were transfected with the plasmid pEF1/Myc-HisA-CXCR4, -CCR5 or experiments (data not shown).

The functional integrity of the APtagged receptors was tested with NAGA-release assays after ligand stimulation. RBL-cells are myeloid cells which release in a G-protein-dependent reaction prestored NAGA. The calculated CXCR4-CCR5 $5_{\text {CT }}$ using electroporation and stable cell lines were generated (CXCR4 \#4/13; CCR5 \#5/11; CXCR4-CCR5 $\left.{ }_{\mathrm{CT}} \# 7 / 15\right)$. Receptor expression levels were determined by flow using anti-receptor antibodies or YC8 anti-AP antibodies $\left(60^{\prime} / 4^{\circ} \mathrm{C} /\right.$ dark). Unstained cells were used for the calibration. The MCF-value was calculated from three independent measurements. Functional integrity of the transfected receptors was checked by NAGA release after stimulation with $250 \mathrm{nM}$ ligand (CCL5; CXCL12). For the calculation of the $\mathrm{EC}_{50}$ and $\mathrm{E}_{\max }$ values standard-curves with triton lysed cells were created. $\mathrm{EC}_{50}$ and $\mathrm{E}_{\max }$ represent the mean-value of 3 independent experiments.

\begin{tabular}{|l|r|r|r|r|r|}
\hline \multirow{2}{*}{ RBL cell line } & \multicolumn{3}{|c|}{ MCF } & \multicolumn{2}{c|}{ NAGA-release } \\
\cline { 2 - 6 } & anti CCR5 & anti CXCR4 & anti AP & EC $_{50}$ [nM] & $\mathbf{E}_{\max }$ [\%] \\
\hline CCR5 & 1310 & n.a. & 670 & 32 & 20 \\
\hline CXCR4 & na. & 4550 & 735 & 2 & 17 \\
\hline CXCR4-CCR5 $_{\mathrm{CT}}$ & n.a. & 6433 & 344 & 29 & 20 \\
\hline WT & 9 & 26 & 7 & n.a. & n.a. \\
\hline
\end{tabular}


$\mathrm{EC}_{50}$-values are within the range of 2 to $32 \mathrm{nM}$ which corresponds to values obtained with non-modified receptors. This result indicates that the $\mathrm{N}$-terminal AP-tag does not interfere with ligand binding and receptor signaling in all these cell lines.

\subsubsection{Generation of an AP-tag-specific antibody which enables detection of biotinylated or non-biotinylated forms}

Apart from the biotin-streptavidin detection system a universal method for the detection of biotinylated receptors is desirable. Monoclonal in contrast to polyclonal antibody preparations offer the advantage of defined antigen specificity and unlimited supply.

For the generation of monoclonal anti-AP antibodies BALB/c mice were immunized with an emulsion of an AP-KLH peptide and the adjuvant TiterMax. To obtain high specific anti-AP antibodies the mice were immunized every four weeks with $50 \mu \mathrm{g}$ of AP-KLH over a period of five months. To immortalize the antibody producing B-lymphocytes the cells were fused with the myeloma cell-line Ag8. For the subsequent cell selection the medium was supplemented with $1 x$ hypoxanthine aminopterin thymidine (HAT) to eliminate non-fused Ag8 cells. To detect hybridomas which produce anti-AP antibodies the supernatant of the different cell clones were tested by ELISA. Positive clones were subcloned and again tested for binding to the AP-peptide using flow cytometry and immunofluorescence microscopy. The isotype of resulting monoclonal antibodies from hybridoma supernatants was determined by ELISA. Three hybridoma clones (E7A: $\lg \mathrm{G}_{1} / \mathrm{K} ; \mathrm{R} 8 \mathrm{G} \lg \mathrm{G}_{1} / \mathrm{K} ; \mathrm{YC} 8$ $\left.\lg G_{2 a} / K\right)$ were selected for mass production. To this end hybridoma clones were expanded and cultivated in cell culture flasks. The supernatants were periodically harvested and stored at $-20^{\circ} \mathrm{C}$.

\subsubsection{Mutual interference of ligand and YC8 antibody-binding to AP-tagged receptors}

We tested whether ligand-binding to the receptor interferes with YC8 binding to the AP-tagged receptor. To this end, cells were stimulated with ligand (10\% /on ice) prior to cell staining. In order to confirm the epitope specificity of YC8 the antibody was pre-absorbed with an excess $(1 \mu \mathrm{g} / \mu \mathrm{l})$ of AP-peptide $\left(30^{\prime} / \mathrm{rt}\right)$ before cell staining.

The results as obtained by flow cytometry are shown in Figure 7. Preabsorption of YC8 with AP-peptide fully abrogated staining of the cells (top panel, violet graph). In contrast, pretreatment with AP-peptide did not affect the binding of anti-receptor antibodies (bottom panel, orange graph). Prior ligand stimulation had neither an effect on the binding of YC8 nor of anti-receptor antibodies (yellow and green graph). These results show that YC8 specifically binds an epitope on the AP-peptide and ligand binding to the receptor does not interfere antibody binding. Therefore, YC8 staining may be used for the faithful detection of membrane-bound or intracellular receptors in their native or ligand-activated state. 


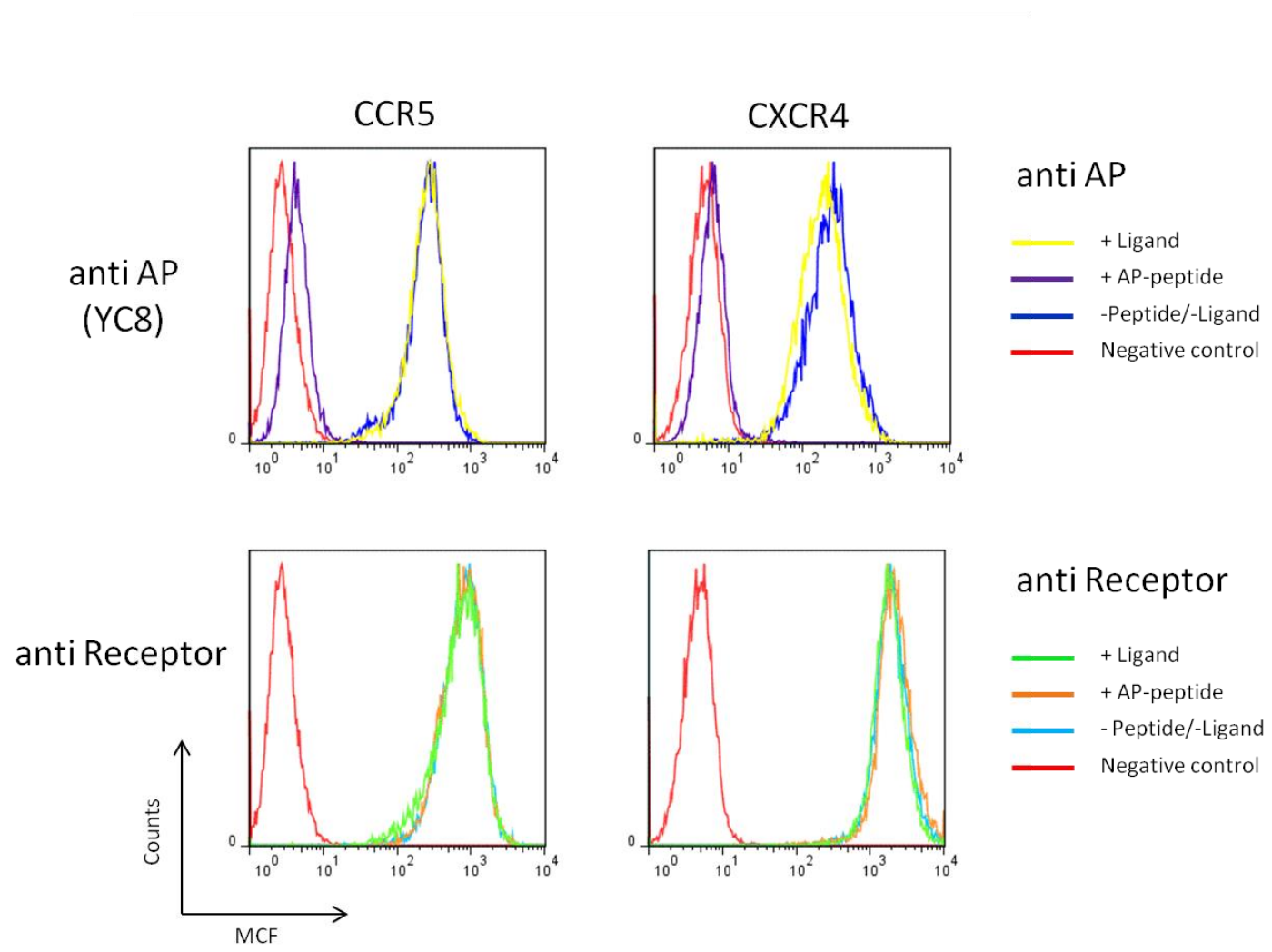

Figure 7: Binding of the YC8 anti-AP antibodies and anti-receptor antibodies to CXCR4/CCR5 after preincubation with AP-peptide or ligand (flow cytometry)

RBL-CXCR4 (right) or -CCR5 (left) cells were stained $\left(60^{\prime} / 4^{\circ} \mathrm{C}\right.$ ) with $10 \mu \mathrm{g}$ YC8 (upper panels) or $1.5 \mu \mathrm{g}$ PE-labeled anti-receptor antibody (anti CXCR4 12G5, anti-CCR5 T21/8) (lower panels) after preabsorbation of antibodies with $15 \mu \mathrm{g}$ AP-peptide (30\% / rt) or pretreatment of receptor-bearing cells with $50 \mathrm{nM}$ ligand (CCL5/CXCL12) $\left(10^{\prime} / 4^{\circ} \mathrm{C}\right)$. Receptor-bound YC8 was detected with FITC-labeled anti-mouse IgG antibodies. RBL-2H3 cells served as negative control. Per sample 10.000 cells were measured. The diagrams show the mean channel of fluorescence in relation to the cell count.

\subsubsection{Binding of YC8 to a synthetic acceptor peptide and its modulation by peptide biotinylation and streptavidin binding}

The binding of YC8 antibodies to AP-tagged receptors may not only be impaired by ligand binding (4.1.2.1), but also by modifications of the AP tag through biotin in combination with streptavidin. Elimination of YC8 binding after streptavidin binding may allow to discriminate between previously biotinylated and newly synthesized receptors. To check if the binding of biotin in combination with streptavidin interferes with YC8 binding, ELISA assays with synthetic non-/biotinylated AP-peptide was performed. Prior to the addition of hybridoma supernatant the peptide was incubated in the presence of streptavidin. Figure 8 shows that biotinylated AP-peptide, which was treated with streptavidin was bound by anti-AP antibodies as efficient as compared to peptides which were not pretreated with streptavidin. Binding affinity of anti-AP antibodies was not affected by peptide biotinylation alone, as well. The potential of streptavidin to prevent binding to the biotinylated form of the AP-peptide is evident from the reduced signal of streptavidin-HRP after streptavidin pretreatment. In summary the results show that antibody binding to the AP tag is not affected by biotinylation or streptavidin binding. Overall, YC8 was found to bind to the AP tag with highest affinity among all anti-AP antibodies tested and was therefore chosen in all subsequent experiments. 


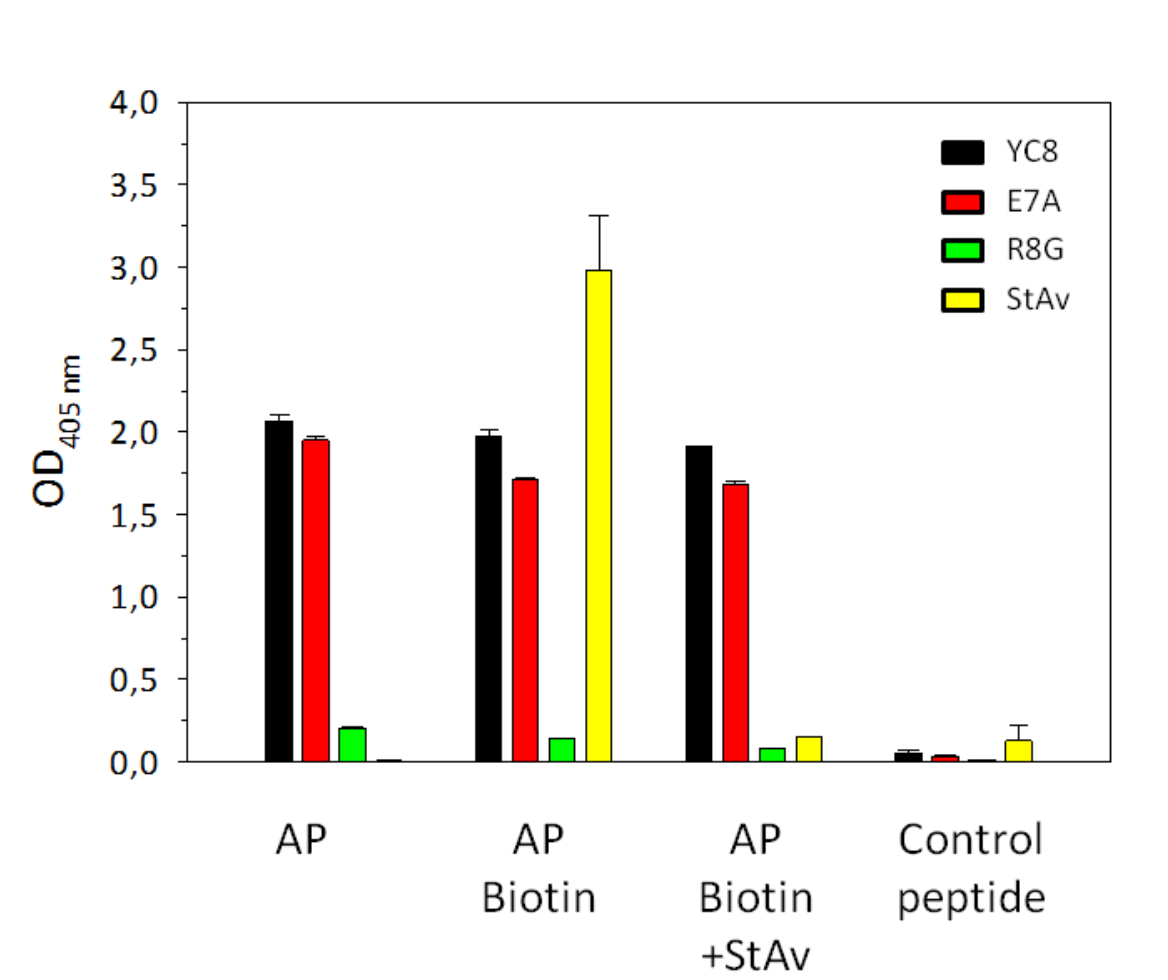

\begin{abstract}
Figure 8: Binding of anti-AP antibodies to the AP peptide and its modulation by peptide biotinylation and streptavidin binding

$5 \mu \mathrm{g} / \mathrm{ml}$ AP- or AP-biotin-peptide and an AP-unrelated peptide was directly coated to wells of an ELISA plate. AP-biotin peptide was pretreated with 0 or $50 \mu \mathrm{g} / \mathrm{ml}$ streptavidin $\left(5^{\prime} / \mathrm{rt}\right)$. Supernatant of hybridoma cells was added $\left(60^{\prime} / \mathrm{rt}\right)$. HRP labeled anti-mouse IgG antibody or streptavidin-HRP was used for detection. Results were obtained photometrically. Bars represent the $\Delta \mathrm{OD}_{405 \mathrm{~nm} / 490 \mathrm{~nm}}$ from two independent experiments (mean $+/$ - s.d.).
\end{abstract}

\title{
4.1.3 Biotin ligase $\mathrm{A}$ - a tool for specific biotinylation-of membrane proteins
}

A large variety of different labeling methods for membrane proteins have been devised, but all those methods have certain limitations. These limitations result either from the large size of the labeling protein which may alter structural and functional properties of the labeled protein (Marks et al., 2004) or the tendency to produce a high signal background (Marks \& Nolan, 2006).

To avoid these potential problems we used the enzyme biotin-ligase $A$, from E.coli to specifically biotinylate a lysine residue in a 15 amino acid long acceptor peptide (Chen et al., 2005) which was added to the CXCR4/CCR5 aminoterminus.

\subsubsection{Purification of biotin ligase from E. coli lysates by nickel chelate chromatography}

We purified BirA biotin ligase from E.coli BL21 (DE3) which were transformed with BirA-pET 21a. Transformed E.coli were cultivated in a liquid LB culture and the BirA expression was induced with $0.1 \mathrm{mM}$ IPTG during the linear growth phase of the bacteria. BirA was purified from cell lysates using a NiNTA agarose column and increasing concentrations of imidazole were used for washing and elution of the protein. The success of BirA purification was monitored by a Coomassie-stained SDS gel (Figure 9). BirA runs at the expected MW of $36 \mathrm{kDa}$ (lane E1 - E3). The overall purity of the eluted BirA biotin ligase preparation regularly exceeded $95 \%$. 


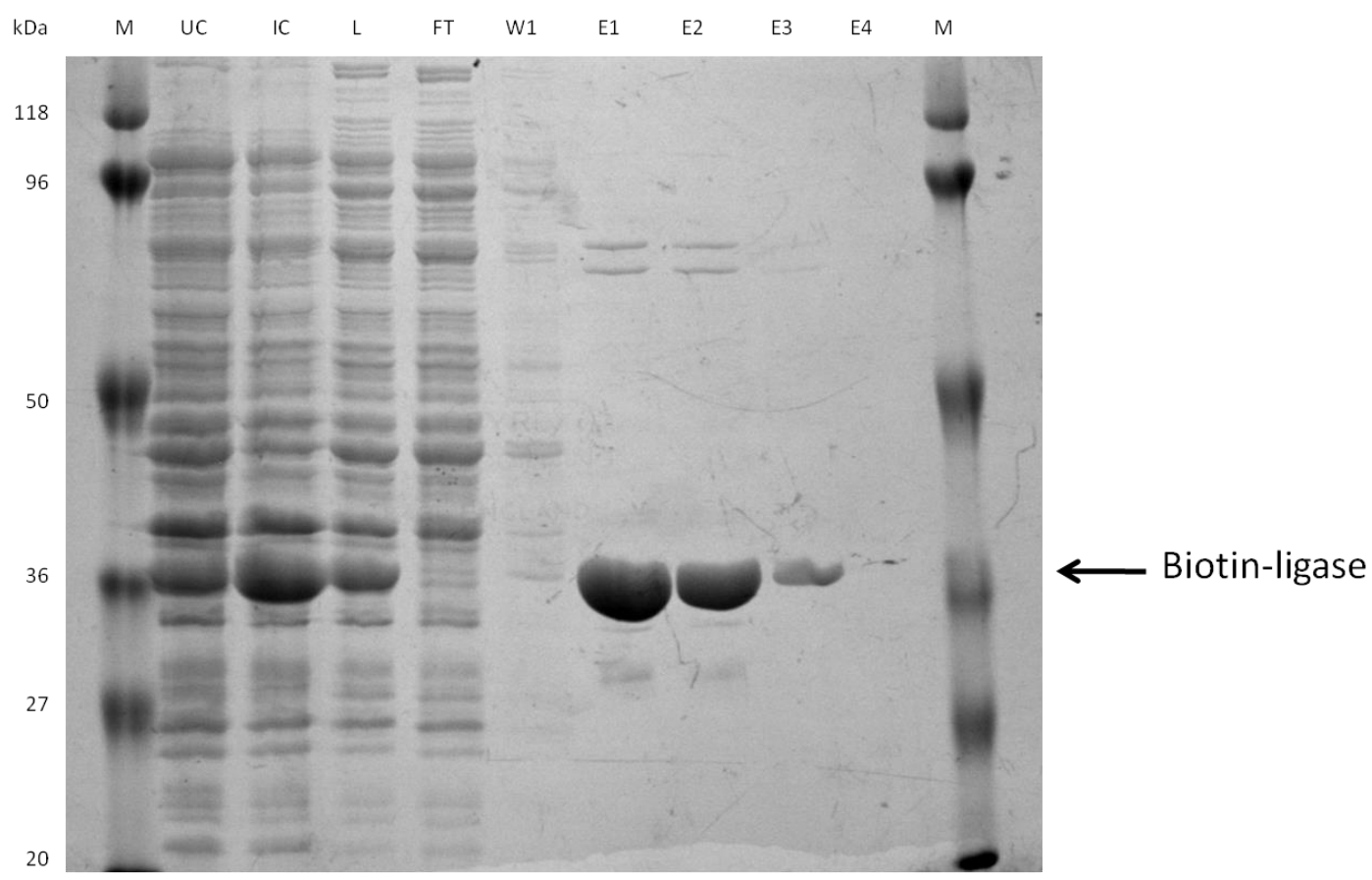

Figure 9: Affinity purification of biotin ligase $A$ from E.coli lysates with NiNTA-agarose E. coli BL21 (DE3) were transformed with $250 \mathrm{ng}$ of the plasmid BirA-pET 21a. Bacteria from a single colony were expanded and transferred into liquid LB medium. The BirA expression was induced with 0.1 mM IPTG in the linear growth phase $\left(3\right.$ hours $\left./ 25^{\circ} \mathrm{C} / 200 \mathrm{rpm}\right)$. For lysis bacteria were harvested, frozen (overnight $/-80^{\circ} \mathrm{C}$ ) and sonicated $\left(60^{\prime \prime} / 50 \%\right.$ amplitude). Purification of BirA was achieved using NiNTA agarose and increasing concentrations of imidazole for washing $(20 \mathrm{mM})$ and elution $(250 \mathrm{mM})$. Samples were loaded onto a SDS gel which was stained with Coomassie blue. ( $M=$ marker; $U C=$ uninduced control; IC = IPTG-induced control; L = lysate; FT = flow through; $W 1$ = wash step 1; E1-E4 = elution step 1 to 4 )

\subsubsection{Time and temperature-dependent biotinylation of a synthetic AP by BirA biotin ligase}

To determine optimal reaction conditions and in order to ensure constant quality of different BirA preparations we established an in-vitro assay for the biotinylation of synthetic AP peptide by purified BirA in an ELISA format. This assay allowed detailed kinetic and temperature analyses of the biotinylation reaction. AP peptide was coated to wells of a 96-well-plate and biotinylated with $3 \mu \mathrm{M}$ BirA (3.6) for different time intervals and temperatures. The binding of streptavidin-HRP was measured by adding a chromogenic substrate and substrate turnover was determined at $\mathrm{OD}_{405 \mathrm{nM}}$ (Figure 10). The most efficient biotinylation was observed by incubation at $37^{\circ} \mathrm{C}$ or $25^{\circ} \mathrm{C}$ and this reaction was completed after 30 minutes. The reaction proceeds much slower and less efficient at $4^{\circ} \mathrm{C}$. In summary, the results indicate that optimal biotinylation can be achieved at $25^{\circ} \mathrm{C}$ or $37^{\circ} \mathrm{C}$ after 30 minutes of incubation. 


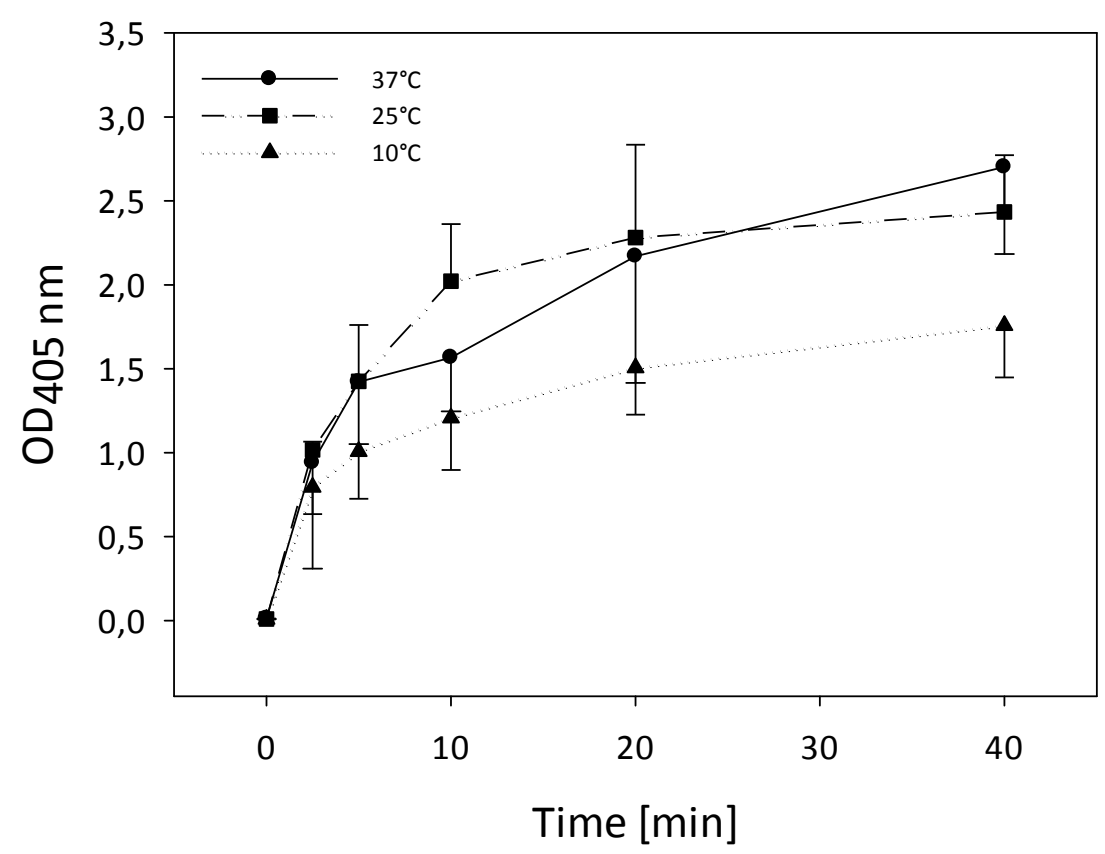

Figure 10: Time and temperature dependent biotinylation of the AP peptide by BirA

AP-peptide $(8 \mu \mathrm{g} / \mathrm{ml})$ was coated to wells of a 96-well microtiter plate and biotinylated by $3 \mu \mathrm{M}$ BirA solution for $0-40$ minutes at $10^{\circ} \mathrm{C}, 25^{\circ} \mathrm{C}$ or $37^{\circ} \mathrm{C}$. Reactions were stopped by washing and transfer on ice and streptavidin-HRP was added. After incubation with a chromogenic substrate the absorbance was measured photometrically at $\mathrm{OD}_{405 \mathrm{~nm}}$. Results represent mean $+/-$ s.d. of at least three indendent experiments.

\subsubsection{Constitutive internalization of CXCR4 ,CCR5 and chimeric receptors and it's modulation by receptor agonists and antagonists}

Chemokine receptors undergo a constant ligand-independent or constitutive internalization. To measure the kinetics of constitutive receptor internalization cells were biotinylated (3.6) and incubated in BM medium in the absence of any stimulants for up to four hours at $37^{\circ} \mathrm{C}$. Cells were then stained with YC8 anti-AP (dashed lines) or streptavidin (straight lines) and analyzed by flow cytometry (Figure 11). The percentage of receptor expression on the cell surface as compared to cells at time point 0 was calculated. Using linear regression analysis the depletion of biotinylated or of YC8 (anti-AP) binding sites of receptors from the cell surface per hour was calculated. Biotinylated CXCR4 receptors in their wildtype confirmation and as CXCR4-CCR5 ${ }_{C T}$ chimeras underwent spontaneous internalization from the cell surface with exactly the same kinetics (12.1\% per hour), and CCR5 internalization proceeded only slightly faster ( $13.7 \%$ per hour). In contrast YC8 anti-AP staining did not reveal significant alterations in cell surface expression of any of these receptors.

In summary constitutive internalization of CXCR4 and CCR5 was described in quantitative terms for the first time in-vivo using biotinylated receptors. Since all three receptors were internalized with identical kinetics, this may suggest passive receptor uptake by membrane flow rather than a receptor-driven mechanism. 


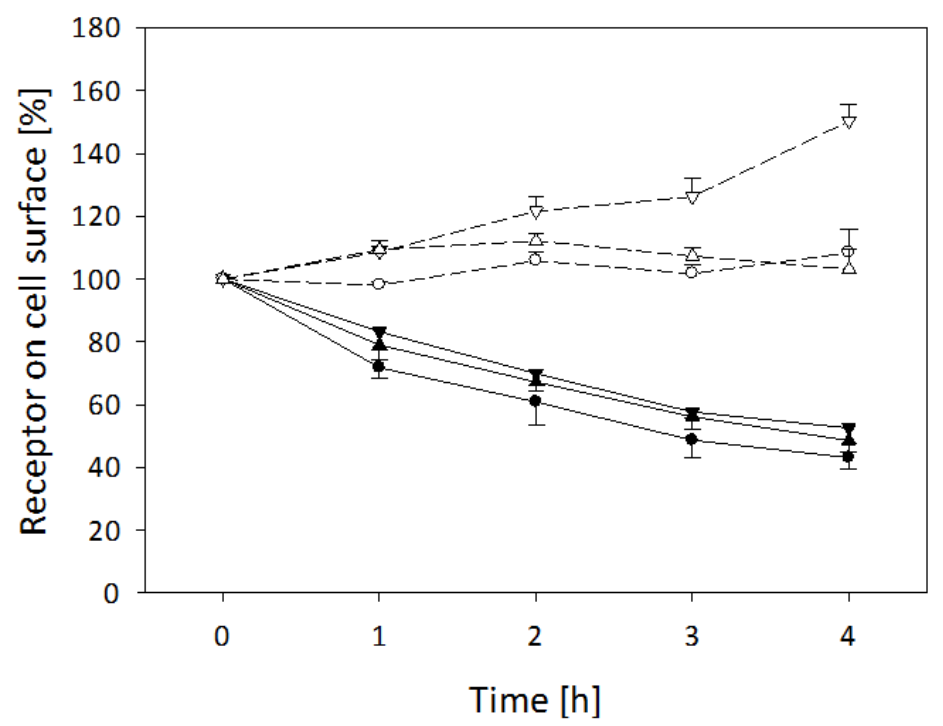

\section{Biotin-Streptavidin}

$\longrightarrow$ CCR5

$\rightarrow$ CXCR4

$\simeq$ CXCR4-CCR5

YC8 (anti AP)

$-0-$ CCR5

$-\nabla-\quad$ CXCR4

$-\triangle-\quad$ CXCR4-CCR5

Figure 11: Constitutive receptor internalization in the absence of receptor agonists

Cells were biotinylated and incubated in BM medium up to four hours at $37^{\circ} \mathrm{C}$. Cells were stained with YC8 anti-AP (dashed lines) or streptavidin (straight lines) and analyzed by flow cytometry. Results represent the mean value +/- s.d. of three independent experiments.

\subsubsection{Modulation of CCR5 internalization by receptor ant-/agonists}

Apart from the classical CCR5 agonist CCL5 a modified version of this ligand (Met-CCL5) with an additional aminoterminal methionine was reported to act as a neutral antagonist, and the synthetic CCR5 antagonist TAK779 even exerts inverse agonism.

To determine the effect of these three CCR5 ligands which together represent a wide spectrum of receptor ant-/agonism on CCR5 cell surface expression we employed the new internalization method on CCR5-expressing cells which were incubated with TAK779 (circle), Met-CCL5 (triangle down) and CCL5 (triangle up) up to four hours at $37^{\circ} \mathrm{C}$ (Figure 12). Untreated cells served as a control (squares). Treatment with TAK779 significantly retarded internalization (10.9\% per hour) as compared to untreated cells (13.7\% per hour) while Met-CCL5 treatment enhanced receptor internalization (15.6\% per hour). This indicated that Met-CCL5 acts as a partial antagonist for CCR5 with regard to receptor internalization. Compared to CCL5-induced receptor internalization (9.3\% per minute during the initial phase of ligand-driven CCR5 internalization) this value still represents a slow form of CCR5 internalization. Using the more sensitive method for the qualitative analysis of receptor internalization we could show, that an inverse agonist (TAK779) further slows down receptor uptake from the cell surface as compared to constitutive internalization in the absence of ligand. Met-CCL5 turned out to exhibit partial agonistic activity with regard to receptor internalization. 


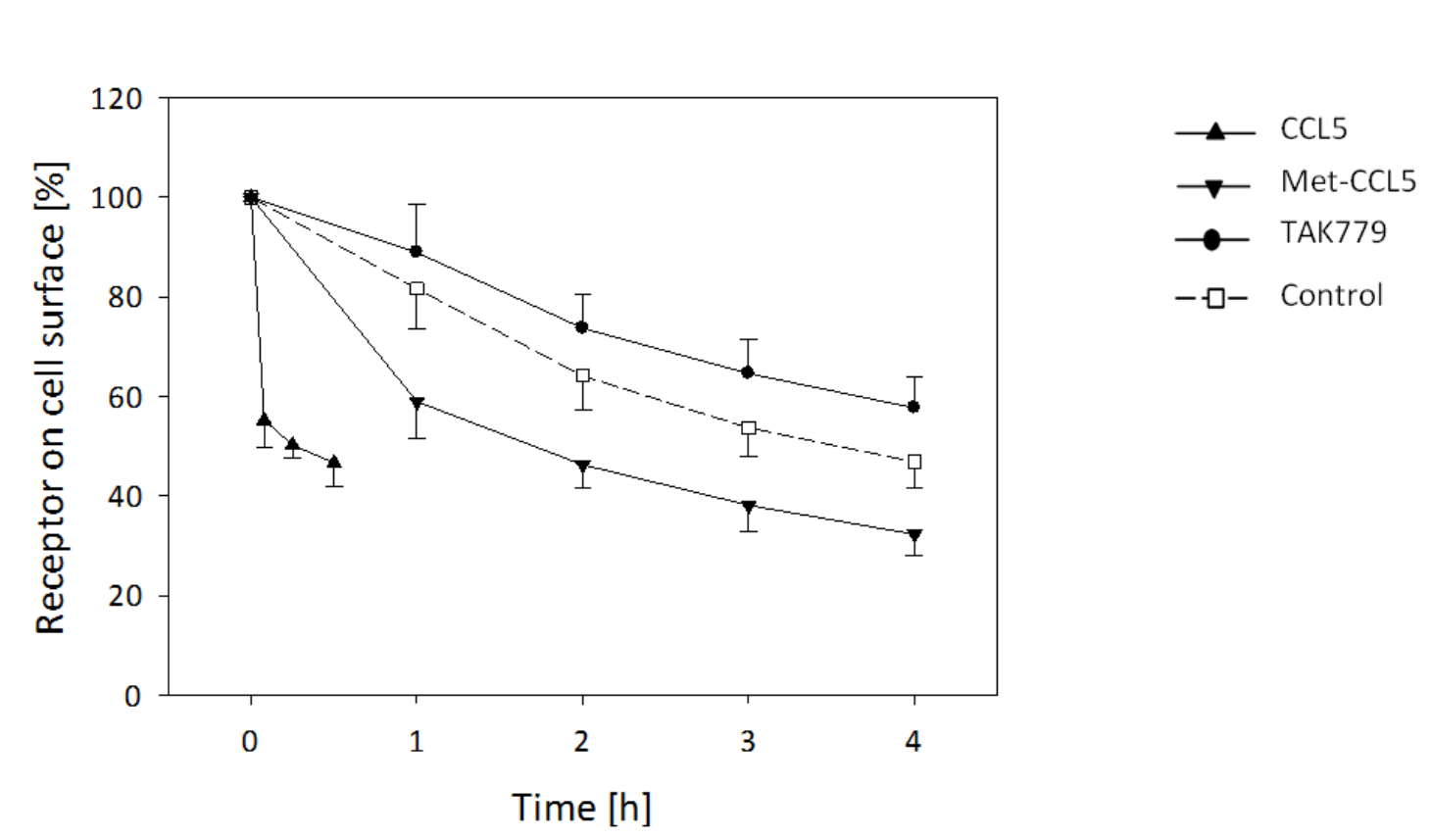

Figure 12: Influence of receptor ant-/agonists on the consitutive internalization of CCR5 Cells were biotinylated and incubated in BM medium with or without ant-/agonists (CCL5 $0.05 \mu \mathrm{M}$; Met-CCL5 0.15 $\mu \mathrm{M}$; TAK779 $3 \mu \mathrm{M}$ ) up to four hours at $37^{\circ} \mathrm{C}$. Cells were stained with streptavidin and analyzed by flow cytometry. Results represent the mean value + /- s.d. of three independent experiments.

\subsubsection{Ligand-induced internalization and receptor recycling}

Detailed quantification of ligand-induced receptor internalization and recycling was done by flow cytometry using biotinylated and YC8 anti-AP stained cells. To exclude the influence of rapid re-internalization during recycling phase cells were additionally treated with receptor antagonist. Distribution of internalized and recycled receptors was determined by immunofluorescence microscopy.

\subsubsection{Quantification of ligand-driven internalization and recycling of biotinylated and anti-AP stained receptors}

To compare the classical antibody-based and the newly established biotin-based assay during ligand driven receptor internalization and subsequent recycling cells were biotinylated with BirA and incubated in ligand containing BM medium for 30 minutes at $37^{\circ} \mathrm{C}$ degrees. Ligand was then removed by acid wash and cells were transferred into new BM medium to allow receptors to reaccumulate at the cell surface during the recycling phase. All samples were stained with YC8 anti-AP or streptavidin in parallel and analyzed by flow cytometry. The percentage of receptors remaining on the cell surface was calculated on the basis of untreated cells. The internalization and recycling of three different chemokine receptors in their biotinylated or non-biotinylated forms was analyzed (Figure 13).

CCR5 receptors undergo rapid CCL5-induced internalization (approx. $40 \%$ ) within the first five minutes after ligand stimulation. CXCL12-stimulated CXCR4 is internalized as efficient as agonist-activated CCR5, but with slower kinetics. During the recycling phase approx. $20 \%$ of the internalized CCR5 return to the cell surface, and approx. $30 \%$ of internalized CXCR4 are recycled, as determined by YC8 anti-AP staining.

Staining of biotinylated receptors with streptavidin gives the same results as obtained by YC8 anti-AP staining during the internalization phase. In contrast, whereas the classical antibody-based method indicates significant CXCR4 and CCR5 recycling back to the cell surface after ligand removal, 
biotinylated receptors do not reaccumulate at the cell surface. Although this result also applies to CXCR4-CCR5 $_{\text {CT }}$ receptors the receptor internalization is significantly reduced (approx. $20 \%$ ) in comparison to CXCR4 and CCR5 receptors.

Results obtained by the classical antibody-based and the biotin-based methods coincide during the ligand-induced internalization phase, thus, validating the new method. However, in contrast to AP staining no significant recycling of biotinylated receptors was observed in these experiments. This discrepancy could be explained by specific intracellular retention of internalized/biotinylated receptors or rapid re-internalization of recycled receptors. At the same time the increase of the anti-AP YC8 signal may be explained by translocation of newly synthesized receptors from internal stores to the plasma membrane.
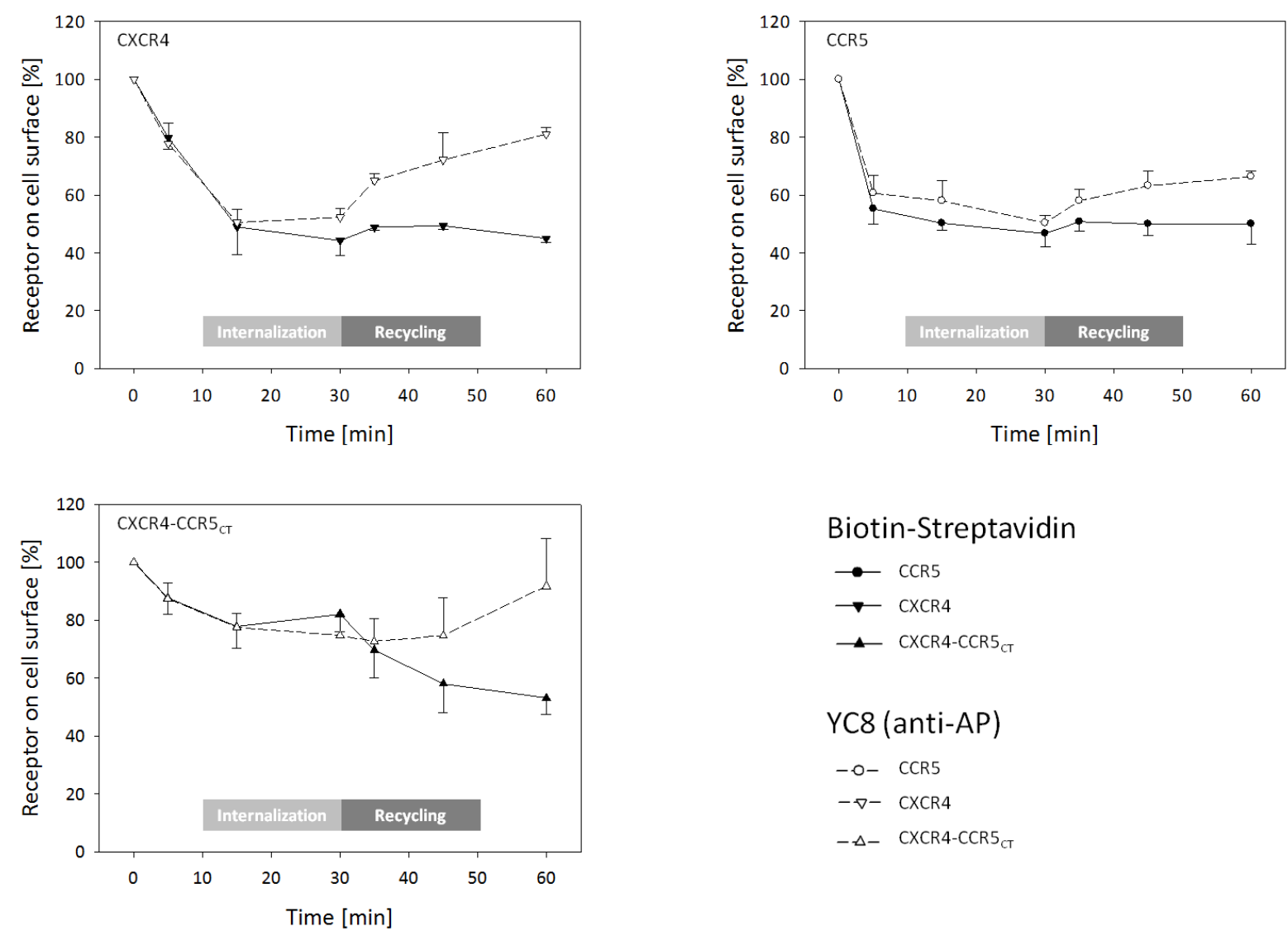

Biotin-Streptavidin

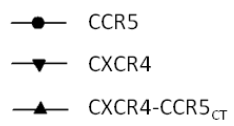

YC8 (anti-AP)

$-0-$ CCR5

$-\nabla-$ CXCR4

$-\triangle-$ CXCR4-CCR5 CT

Figure 13: Ligand-induced internalization and recycling of CXCR4, CCR5 and CXCR4-CCR5 ${ }_{\mathrm{CT}}$

Cells were biotinylated and incubated in BM medium with $125 \mathrm{nM}$ ligand (CCL5/CXCL12) for 30 minutes at $37^{\circ} \mathrm{C}$. Ligand was removed by acid wash and the cells transferred into fresh BM medium during the subsequent recycling phase $\left(30^{\prime} / 37^{\circ} \mathrm{C}\right)$. Cells were stained with YC8 (dashed line) or streptavidin (straight line) and analyzed by flow cytometry. Each curve shows the mean percentage (+/-s.d.) of expressed receptor on the cell surface normalized to the MCF value of untreated cells and is representative for three independent experiments. 


\subsubsection{Effects of the receptor antagonists TAK779 and AMD3100 on the recycling-rate after ligand-induced receptor-internalization}

To test the hypothesis that the lack of receptor recycling after ligand-induced internalization (4.1.6.1) was due to instant re-internalization of ligand-receptor complexes we repeated the experiments in a modified manner by adding high affinity receptor antagonists during the recycling phase. Excess of antagonists dissociates ligands from their receptors. Biotinylated cells were stimulated with the corresponding ligand $\left(30^{\prime} / 37^{\circ} \mathrm{C}\right)$ followed by acid wash with EM medium. Cells were transferred into fresh BM medium in the presence or absence of antagonists ( $30 \mu \mathrm{M}$ AMD3100, $3 \mu \mathrm{M}$ TAK779) $\left(30^{\prime} / 37^{\circ} \mathrm{C}\right)$, stained with YC8 (grey bars) or streptavidin (black bars) and analyzed by flow cytometry (Figure 14). The percentage of receptor recycling (\% of $\left.\Delta\left(\mathrm{MCF}_{0^{\prime}}-\mathrm{MCF}_{30^{\prime}}\right)\right)$ is shown.

In the presence of CCR5 antagonist TAK779 the recycling rate of biotinylated CCR5 receptors is significantly enhanced compared to untreated CCR5 receptors. This result was confirmed by YC8 anti-AP staining, which also showed an increased recycling rate of TAK779-treated CCR5 receptors (black and grey bars left). This result suggests that agonist-activated CCR5 rapidly re-internalize once they recycle back to the surface, unless the ligand dissociates in the presence of an excess of TAK779. The same effect was observed with CXCR4 (black and grey bars, right), although to a lower degree. Experiments where recycling of biotinylated receptors was monitored in the presence of antagonists revealed a significant difference in the recycling characteristics of CCR5 vs. CXCR4 (black bars, left vs. right): whereas CCR5 significantly recycled back to the cell surface CXCR4 is retained within the cell. Differences in the apparent recycling of biotinylated (black bars) and anti-AP antibody detected receptors (grey bars) is explained at least in part by translocation of newly synthesized receptors from intracellular stores to the plasma membrane during the recycling phase of the experiment. These results show that the biotin/streptavidin method is well suited for the quantitative analysis of the recycling rate of different transmembrane proteins as exemplified by CXCR4 and CCR5. 


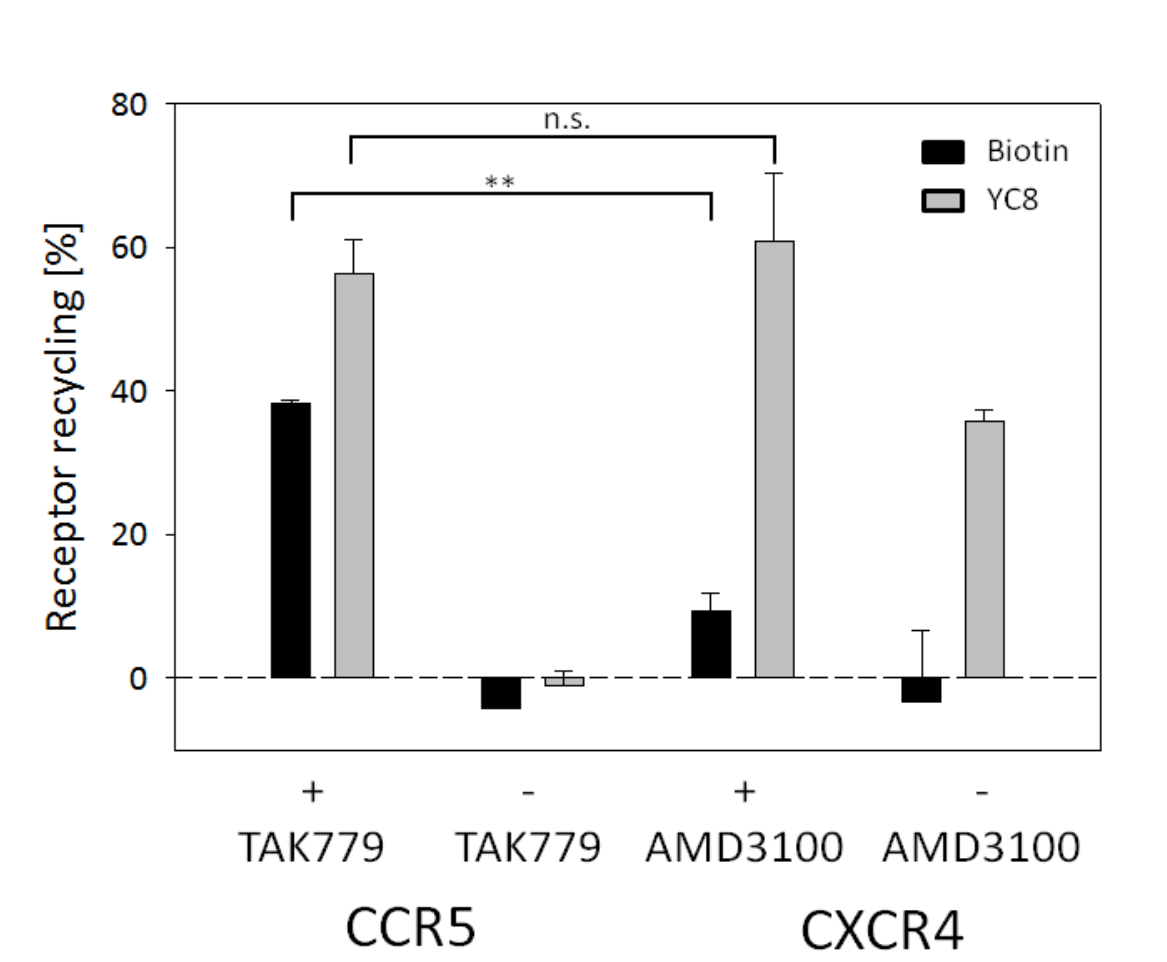

Figure 14: Recycling of CXCR4- and CCR5-receptors in the presence of receptor antagonists

RBL-CXCR4 (right) or -CCR5 cells (left) were biotinylated and stimulated with the corresponding ligand $(C C L 5 / C X C L 12)$ for 30 minutes at $37^{\circ} \mathrm{C}$. Ligand was removed by acid wash. Cells were transferred into fresh medium containing 0 or $30 \mu \mathrm{M}$ AMD3100 or $3 \mu \mathrm{M}$ TAK779 for 30 minutes at $37^{\circ} \mathrm{C}$. Cells were analyzed by flow cytometry after staining with YC8 (grey) or streptavidin (black) $\left(60^{\prime} / 4^{\circ} \mathrm{C} /\right.$ dark). Receptor recycling was calculated as percentage of the difference between cell surface expression of the receptor at time points 0 and 30 minutes Results represent mean $+/-$ s.d. of at least three independent experiments. n.s., not significant; $\left.{ }^{* *}, p<0.001\right)$.

\subsubsection{Intracellular localization of biotinylated and anti-AP stained CCR5 during receptor internalization and recycling}

To visualize the intracellular distribution of CCR5 after ligand-induced internalization and recycling (4.1.6.1) CCR5-expressing RBL cells were seeded on glass cover slips and biotinylated (3.6). Cells were stimulated with $125 \mathrm{nM}$ CCL5 which was removed after 30 minutes by acid wash. After further 30 minutes incubation in the presence of $3 \mu \mathrm{M}$ TAK779 cells were fixed with PFA and permeabilized with saponin. CCR5 receptors were stained with YC8 (green) with or without pre incubation with AP-peptide or streptavidin-Alexa 647 (red) (Figure 15). The samples were analyzed by laser confocal microscopy with two different excitation wavelengths. The resulting overlays are shown in the bottom lane of Figure 15.

Unstimulated cells (Figure 15 left panels) show a ring like fluorescence of biotinylated and non-biotinylated receptors at the cell surface. Preincubation of YC8 with an excess of AP peptide eliminates all signals, thus proving specificity of this staining (right panel). The overlay confirms that the signal for biotinylated and non-biotinylated receptors fully overlap except for the YC8-stained receptors within cytoplasmic vesicles. After 30 minutes of CCL5 stimulation biotinylated and anti-AP detected CCR5 disappear from the cell surface and accumulate in endosomal vesicles. Biotinylated receptors (red) which are also stained by anti-AP YC8 antibodies (green) are specifically concentrated 
in the perinuclear region, whereas additional receptor-containing vesicles are detected by anti-AP staining with a more dispersed distribution throughout the cytoplasm. 30 minutes after acid wash (biotinylated) receptors are no longer detected in the perinuclear region but, to some extent, recycle back to the cell surface.

Immunofluorescence confirms the results as obtained by flow cytometry (4.1.6.1) and further demonstrates that in-vivo receptor biotinylation is advantageous when distinct receptor populations are studied during agonist-induced internalization and recycling.

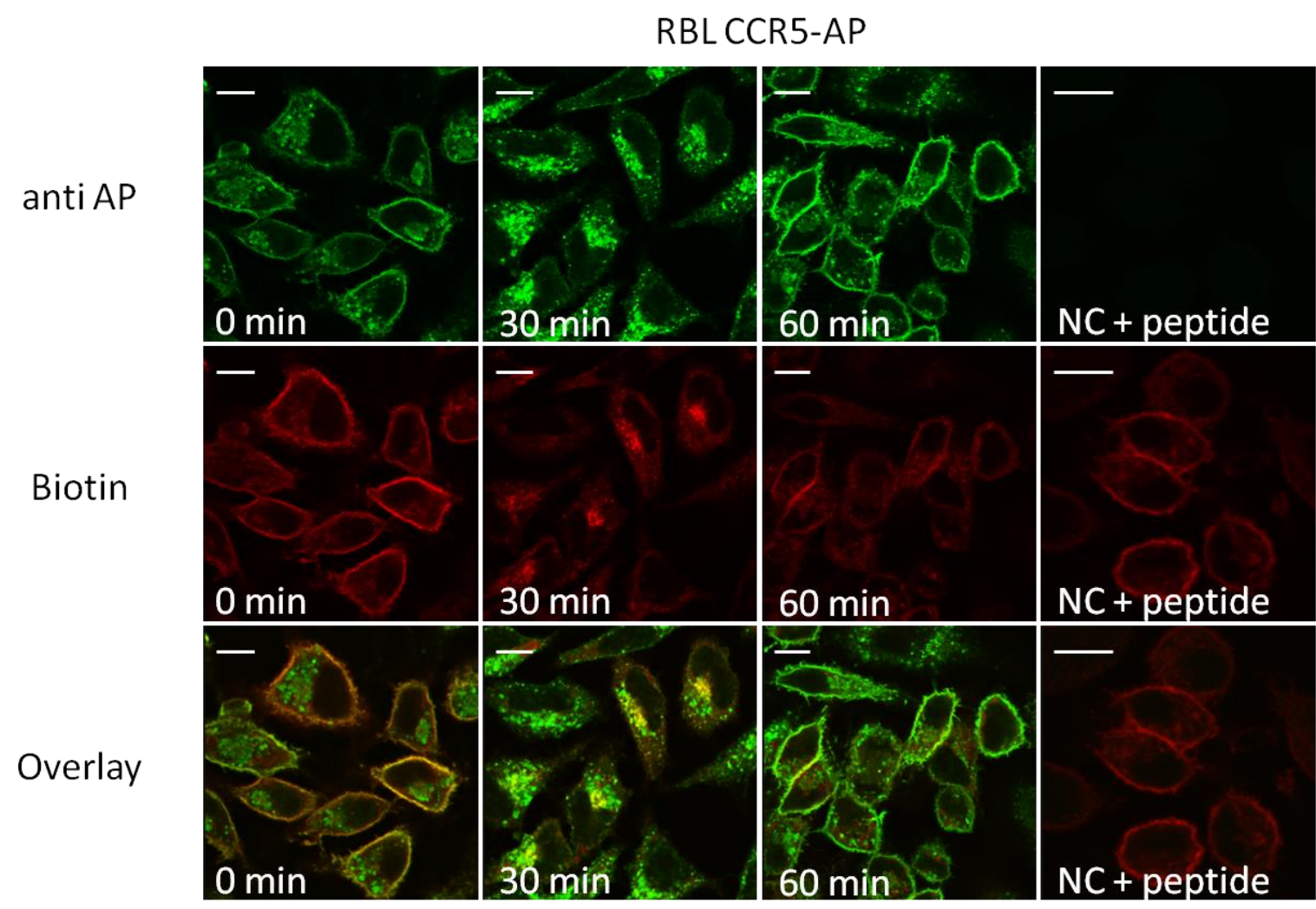

Figure 15: Double immunofluoresence staining of RBL-CCR5 cells during the internalization and recycling process

CCR5 expressing cells were seeded on lysine-coated glass cover slips and receptors were biotinylated. $125 \mathrm{~nm} \mathrm{CCL5}$ was used for stimulation $\left(30^{\prime} / 37^{\circ} \mathrm{C}\right)$ and then removed by acid wash with EM medium. Cells were transferred into fresh BM medium with $3 \mu \mathrm{M}$ TAK779 during the recycling phase $\left(30^{\prime} / 37^{\circ} \mathrm{C}\right)$. Cells were fixed with $3 \% \operatorname{PFA}\left(15^{\prime} / 37^{\circ} \mathrm{C}\right)$ and permeabilized with $0.1 \%$ saponin $\left(15^{\prime} / 37^{\circ} \mathrm{C}\right) .5 \mu \mathrm{g} / \mathrm{ml} \mathrm{YC8}$ antibody (top lane) (with or without preincubation with $2 \mathrm{mg} / \mathrm{ml}$ of the AP-peptide) and streptavidin-Alexa647 (middle lane) $(2 \mu \mathrm{g} / \mathrm{ml})$ was used for staining $\left(60^{\prime} / \mathrm{on}\right.$ ice/dark). Samples were fixed with mounting medium and analyzed by confocal laser scanning microscopy. Scale bar $10 \mu \mathrm{M}$ 


\subsection{Chemical-induced receptor homodimerization and $\beta$-Arrestin2 translocation in the absence of ligand binding}

To establish an experimental system which allows ligand-independent translocation of $\beta$-arrestin 2 to CXCR4 or CCR5 we fused the FKBP12 domain (DmrA) to the C-terminus of both receptors. The DNA sequence of this domain was provided by the vector pHet-Nuc1 and transferred to the receptor-DNA by ligation with the vector. In parallel the C-terminus of $\beta$-arrestin 2 was modified with the FRB domain (DmrC) by ligation with the vector pHet1. For expression in HEK293 cells the receptor-DmrA DNA was subcloned in the vector pEF1/Myc-His A, whereas pHet1 containing $\beta$-Arrestin 2 was directly used for transfection. The creation of stable cell lines and the establishment of the AP21976-induced system were done in collaboration with S. Henze (Henze, 2013).

\subsubsection{Cloning strategy for the modification of CXCR4-, CCR5-receptor and $\beta$-arrestin2 with Dmr-domains}

To provide cDNA of the Dmr domains for the modification of the receptor (CXCR4, CCR5) or $\beta$-arrestin 2 cDNA the DNA was ligated into the vector system pHet1 (DmrC) or pHet-Nuc1 (DmrA). pHet1 could be used directly for cells transfection, whereas pHet1-Nuc1 contained a nucleus location sequence. To allow a cytoplasmatic expression of the $\beta$-arrestin 2-DmrC peptide the cDNA was ligated with the mammalian expression vector $\mathrm{pEF} 1 / \mathrm{Myc}$ His $\mathrm{A}$ which also provided a geneticin resistance cassette (Figure 16). DNA was sequenced to exclude potential mismatches. Finally the plasmids were used for the generation of stable cell lines which either express receptor-DmrA alone or in combination with $\beta$-arrestin 2-DmrC. 
$\beta$-Arrestin 2 in pHet 1

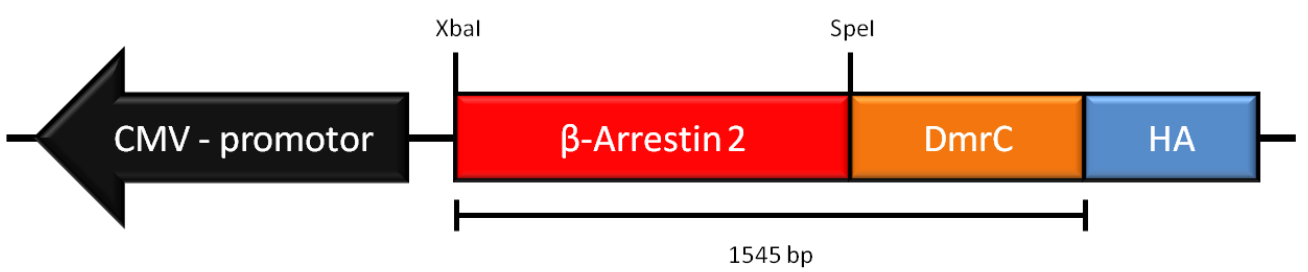

CXCR4-DmrA in pEF1/Myc His A

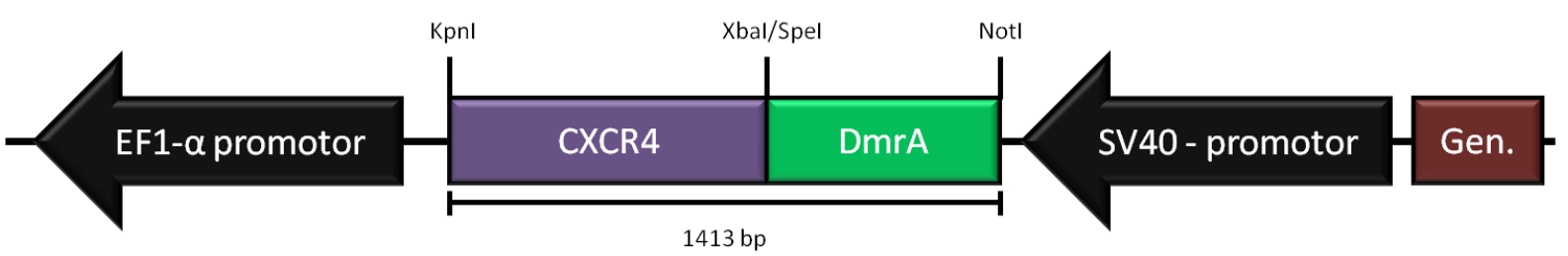

CCR5-DmrA in pEF1/Myc His A

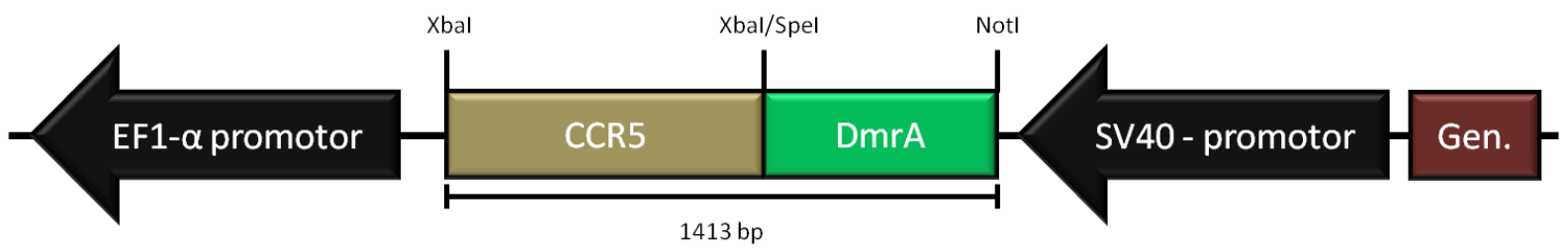

Figure 16: Cloning strategy for the generation of $\beta$-arrestin 2 and CXCR4/CCR5 DmrA/C fusion constructs $\beta$-Arrestin 2 and receptor-DNA was amplified by PCR using primers which introduces additional restriction sites for the digestion with Xbal and Spel. The vectors pHet1 and pHet-Nuc1 were single digested with Xbal and dephosphorylated using antartic phosphatase. The ligation between the DNA was catalyzed by T4 ligase. For the subcloning of the receptor-DmrA DNA into pEF1/Myc His A the pHET-Nuc1 plasmid was digested using Kpnl/Notl respectively Xbal/Notl. pEF1/Myc His A was digested using identical enzymes. For the transfection into HEK293 cells pHet1 was linearized with Mlul, pEF1/Myc HisA with Scal. Selection of positive transfectants was enabled by the geneticin resistance, which was provided by $\mathrm{pEF} 1 / \mathrm{Myc}$ His A. The expression of the modified proteins was controlled either by a CMV- (pHet1) or an EF1- $\alpha$-promotor (pEF1/Myc His A).

\subsubsection{Stable co-expression of DmrA-modified chemokine-receptors and $\beta$-arrestin2-DmrC in HEK293 cells}

HEK293 cells were transfected with either a combination of CXCR4- or CCR5-DmrA and $\beta$-Arrestin 2 -DmrC or receptor-DmrA alone in order to obtain a cell population with stable expression of the transfected proteins. The pEF1/Myc His A plasmid containing receptor-DmrA or pHet1 containing $\beta$-arrestin 2-DmrC were linearized (4.2.1) and transfected into HEK293 cells using the calcium phosphate precipitation method (3.3.4.2). Positively transfected cells were selected by DMEM medium supplemented with geneticin. The receptor-DmrA expression level on the transfectants was tested by flow cytometry with T21/8 and immunoblotting using R22 (both anti-CCR5 antibodies). To check for correct modification of $\beta$-arrestin 2 with a C-terminal DmrC domain, HEK293 cells were transiently transfected with $\beta$-arrestin 2-DmrC and the cell lysates were probed by immunoblotting with anti $\beta$-Arrestin $1 / 2$ antibodies. Overall 2 cell clones for each cell line were selected from approx. 200 initial clones. 


\subsubsection{Surface expression of DmrA-modified CXCR4- and CCR5-receptorsom HEK293 transfectants}

Figure 17 shows the fluorescence distribution of cells transfected with receptor-DmrA DNA constructs with or without $\beta$-2rrestin 2-DmrC DNA constructs together with a negative control. Cells were stained with anti.receptor-antibodies for flow cytometry. The figure shows that the MCF of the Rec-DmrA cell lines (CXCR4 773; CCR5 1986) and Rec-DmrA/ BArr-DmrC (CXCR4 285; CCR5 770) was significantly higher than in HEK293 WT cells (anti-CXCR4 22.9; anti-CCR5 10.5). During experimental series the receptor expression levels were regularly controlled to ensure that indentical experimental conditions were maintained.

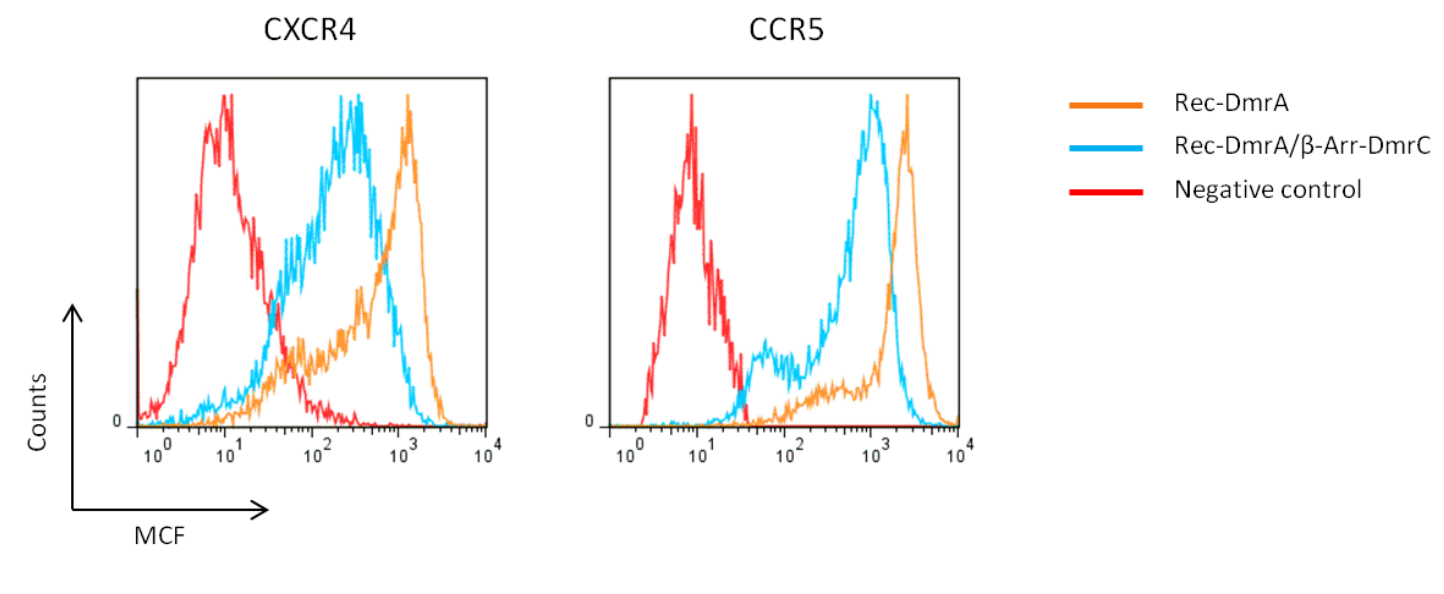

Figure 17: Expression of CXCR4- or CCR5-DmrA on transfected HEK293 cell lines HEK293 CXCR4-DmrA cells with or without $\beta$-Arrestin 2-DmrC (left panel) or HEK293 CCR5-DmrA cells with or without $\beta$-Arrestin2-DmrC (right panel) were stained $\left(60^{\prime} / 4^{\circ} \mathrm{C}\right.$ ) with PE-labeled $12 \mathrm{G} 5$ (anti-CXCR4) or T21/8 (anti-CCR5) and analyzed by flow cytometry. HEK293 WT cells were used as negative control.

\subsubsection{Structural integrity of a Dmr-A modified CCR5-receptors}

The structural integrity of the DmrA modified CCR5 fusion protein was tested by analyzing the molecular weight shift as compared to native CCR5 by immunoblotting (Figure 18). Non-transfected RBL- and HEK293-cells were used as controls. The non-modified receptor expressed by RBL cells was detected by R22 anti-CCR5 antibodies in form of two prominent bands at approx. $40 \mathrm{kDa}$. The modified receptor shows a distinct band at approx. $50 \mathrm{kDa}$. The molecular weight shift of $10 \mathrm{kDa}$ corresponds to the size of the $11 \mathrm{kDa}$ DmrA domain (Chen et al., 1995). 


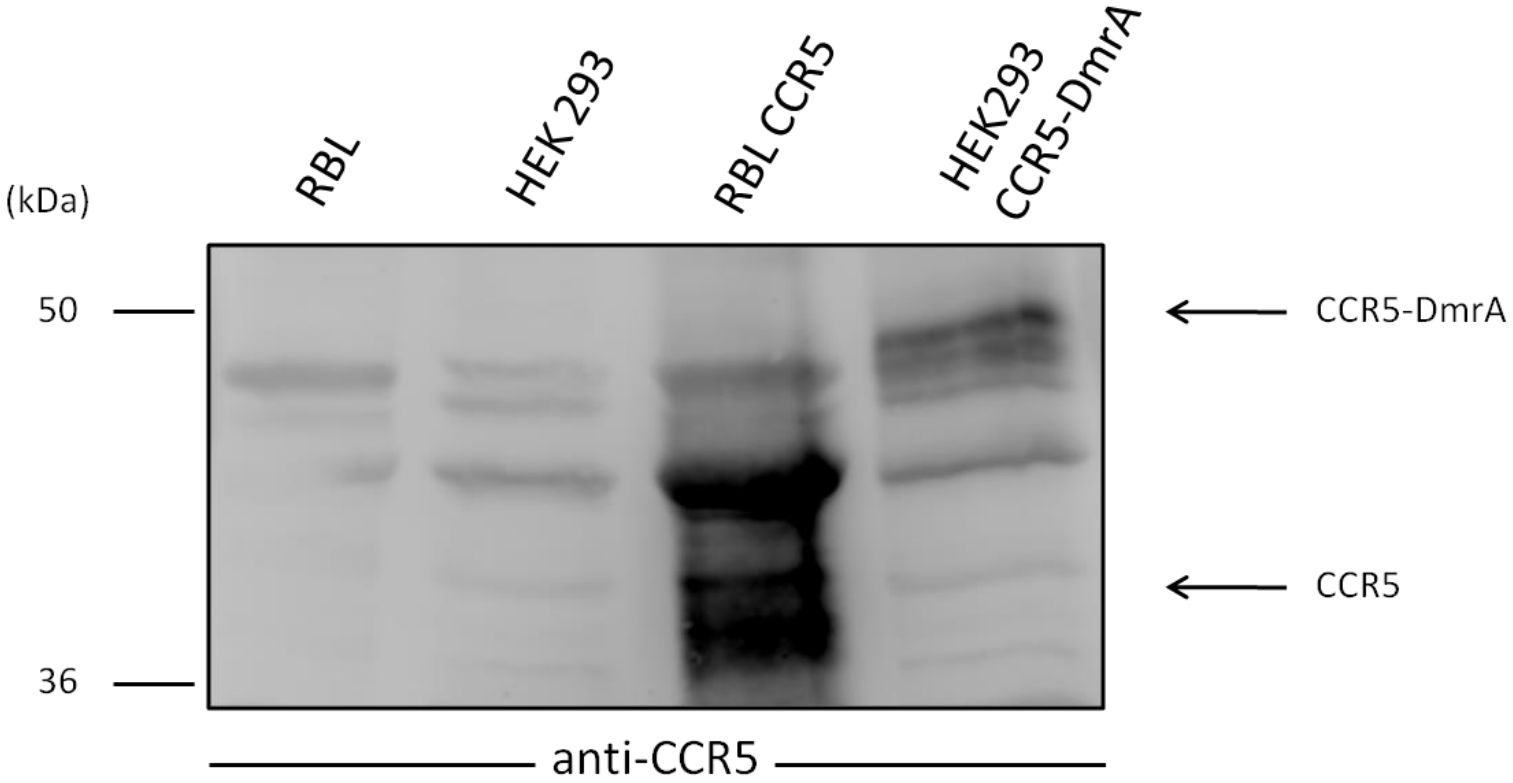

Figure 18: Expression of native vs. DmrA-modfied CCR5 in membrane fractions of HEK293 or RBL cells The membrane fraction of lysed HEK293 cells expressing CCR5-DmrA/B-Arrestin 2-DmrC was purified by ultracentrifugation over a sucrose gradient and probed by immunoblotting with anti-CCR5 (R22) antibodies. RBL-CCR5 lysate was taken as a reference, RBL and HEK293 cell lysates served as negative controls. The arrows indicate the position of modified or non modified CCR5 receptors. (Experimental procedure was done in collaboration with S. Henze)

\subsubsection{Molecular weight shift of $\beta$-arrestin2-DmrC in comparison to native $\beta$-arrestin2}

After the expression and the functional integrity of the DmrA-modified receptors was proven (4.2.2/4.2.2.2) we next tested the expression of $\beta$-arrestin 2-DmrC in transiently transfected HEK293 cells by immunoblotting with anti-arrestin antibodies (21B1) (Figure 19). The native $\beta$-Arr 2 shows a distinct band at approx. $60 \mathrm{kDa}$, which is slightly higher than calculated value of $48 \mathrm{kDa}$. All cells which were transfected with the DmrC modified version of $\beta$-Arr 2 show a prominent band at approx. $80 \mathrm{kDa}$. Even if the difference is bigger than the calculated size of the DmrC domain (11 kDa) (VilellaBach, 1999) we could thereby show that $\beta$-arrestin 2-DmrC is expressed and the shift in molecular weight indicates the $\mathrm{DmrC}$ modification. 


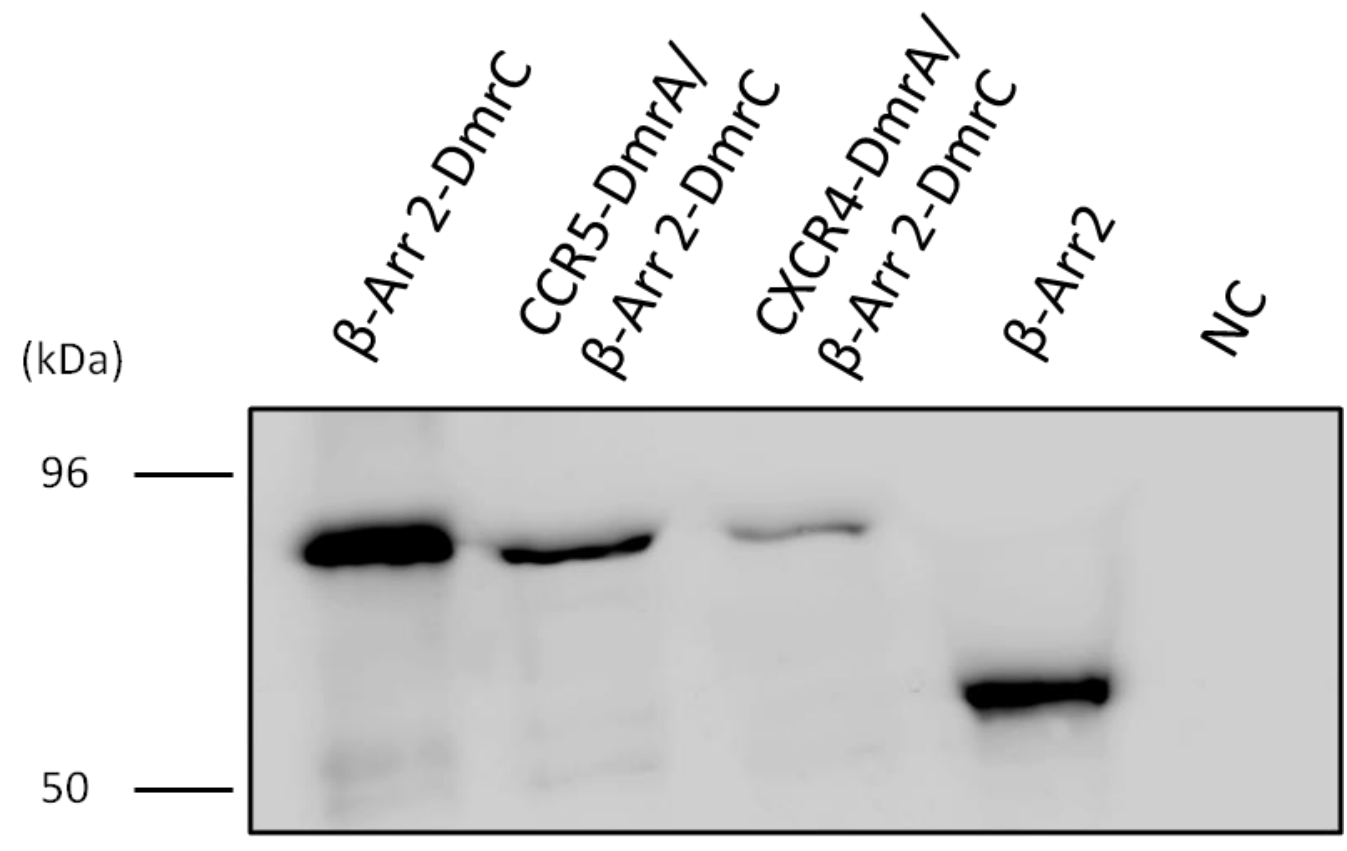

anti- $\beta$-Arrestin 2

Figure 19: Expression of native vs. DmrC modified $\beta$-arrestin 2 in lysates of transiently transfected HEK293 cells

Hek293 cells were transiently transfected with Rec-DmrA and BArr-DmrC. Untransfected HEK293 cells were used as negative control. Staining was done with anti-arrestin antibodies (21B1), whereas native $\beta$ Arr was used as a reference.

\subsubsection{Ligand independent AP21967-mediated translocation of $\beta$-arrestin2 to the plasma membrane}

After generating HEK cell lines which co express receptors modified with a DmrA domain together with $\beta$-arrestin 2-DmrC we tested whether the cell-permeable and heterodimerizing reagent AP21967 indeed induces translocation of $\beta$-arrestin 2-DmrC to the DmrA modified receptors at the plasma membrane. To this end, we determined $\beta$-arrestin 2 translocation to the membrane fraction in cellular lysates by immunoblotting, as well as by immunofluorescence microscopy.

\subsubsection{AP21967 leads to membrane translocation of $\beta$-Arrestin 2 in CXCR4-/CCR5-DmrA cell lines in a dose-dependent manner}

According to information provided by the manufacturer (Clontech), heterodimerization of DmrA/DmrC-containing fusion proteins may be induced by treatment with 0.1 to $500 \mathrm{nM} \mathrm{AP21967}$ for 30 minutes (up to 12 hours). To test whether the fusion proteins are indeed functional and in order to determine the optimal heterodimerizing effect, translocation of $\beta$-arrestin 2 to the cell membrane was determined by immunoblotting of membrane fractions from cell lysates. The results from the corresponding immunoblot are shown in Figure 20 where $\beta$-arrestin 2-DmrC is detected by anti-HA antibodies. The cytosolic fractions of CXCR4- or CCR5-expressing cells (right) show no significant alterations in the amount of $\beta$-arrestin 2 . In contrast, $\beta$-arrestin 2 in the membrane fraction (left) is clearly increased after treatment with 0.1 or $1 \mu \mathrm{M}$ P21967 for 60 minutes. The second prominent band in the membrane fraction (approx. $55 \mathrm{kDa}$ ) appears only in membrane- or cytosolic fractions after ultracentrifugation (compare Figure 24) not in untreated cell lysates (compare Figure 19). So far the origin remains unclear. The molecular weight would indicate 
$\beta$-arrestin 2 without $\mathrm{Dmr}$ domain $(48 \mathrm{kDa})$. The same blot was re-probed with an anti-pan-cadherin antibody to ensure equal loading in all lanes. Cadherins are ubiquitously expressed transmembrane proteins which specifically reside in the plasma membrane fractions of HEK cells.

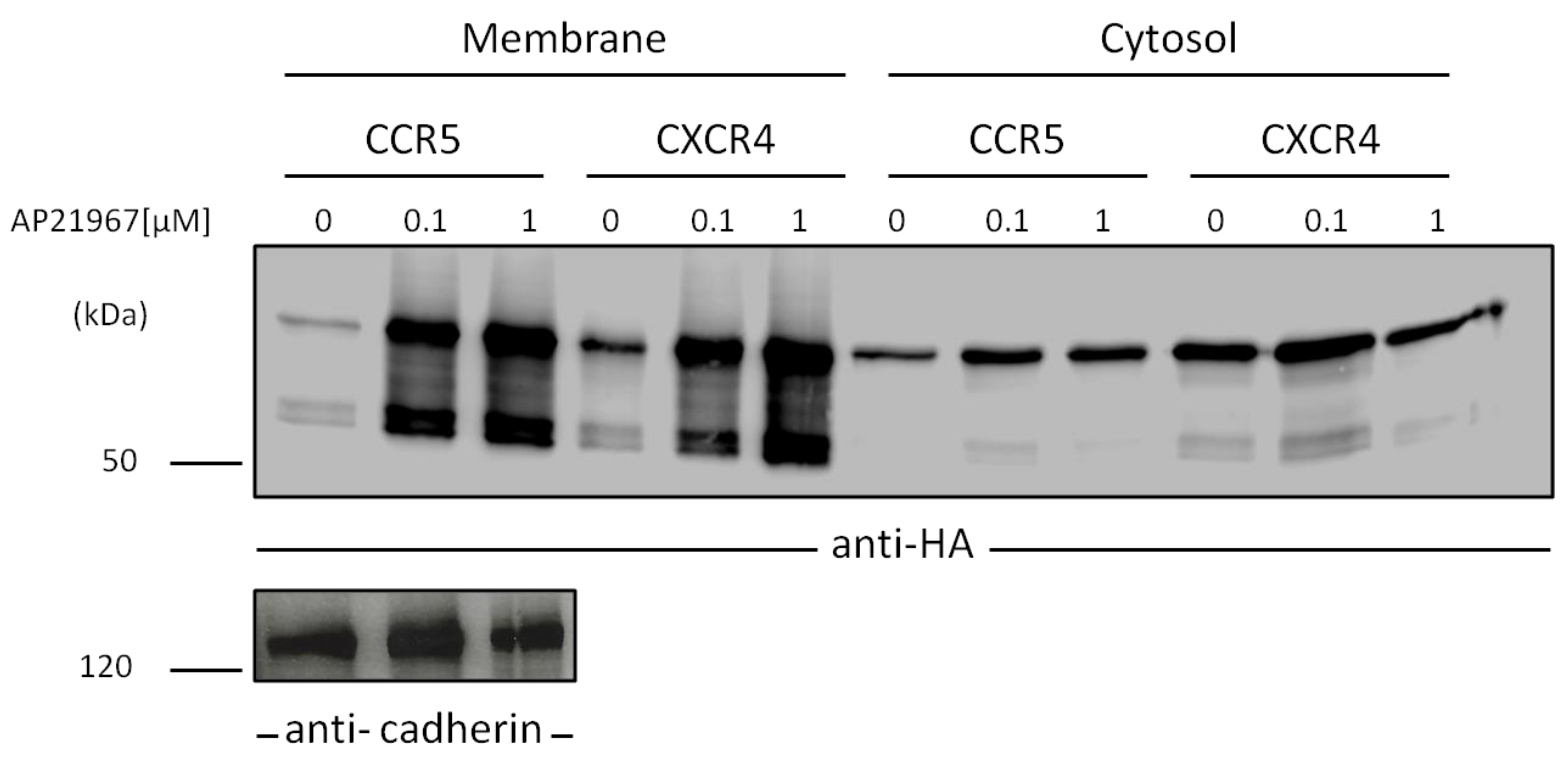

Figure 20: $\beta$-Arrestin 2-DmrC recruitment to the membrane after treatment with different doses of AP21967 (immunoblot)

Stable co transfected HEK293 cells (Rec-DmrA/BArr DmrC) were treated with two different concentrations of AP21967 (0.1 and $1 \mu \mathrm{M})$, lysed and centrifuged over a sucrose gradient to purify the membrane fraction (3.5.4). Untreated cells were used as a negative control. The samples from the membrane (left) respectively cytosol phase (right) were loaded onto a SDS gel (3.5.1) which was subsequently used for immuno blotting (3.5.2) with anti-HA antibody (3F10) detection antibody. Cadherin in combination with an anti-pan-cadherin antibody was used to guarantee an equivalent protein loading. For the blots a prestained molecular weight marker was used and both were evaluated with a lcd camera.

The effect of $\beta$-arrestin 2 translocation after AP21967 treatment was also shown by immunofluorescence microscopy (3.3.6.2). To this end, CCR5-DmrA/ $\beta$-Arrestin 2-DmrC cells were treated with 0 (NC) up to $1 \mu \mathrm{M}\left(60^{\prime}\right)$ with AP21967. $\beta$-arrestin 2 was detected by anti-HA biotin in combination with streptavidin-Alexa 647 (red emission). Figure 21 shows a representative selection of the microscopic images from three different experiments. While $\beta$-arrestin 2 is homogeneously spread in the cytoplasm of untreated cells, the $\beta$-arrestin 2 distribution changes at AP21967 concentration of $100 \mathrm{nM}$ and above (A, bottom lane). At those concentration levels of AP21967 a part of $\beta$-arrestin 2 translocates to the plasma membrane, whereas the rest remains spread in the cytoplasm. In order to validate these minor changes in the cellular distribution of $\beta$-arrestin 2 , we applied quantitative image analysis $\left(\right.$ Image $\left.^{\circledR}\right)$. Cross sections of individual cells $(n=7)$, which were treated with 0 or 316 nM AP21967 were defined and the corresponding immunofluorescence intensity was calculated. The cell diameter was normalized to 100 units and background fluorescence was defined as 1.0. In the AP-treated cells (B, red graph) fluorescence intensity in the inner and outer area, which corresponds to the plasma membrane was significantly more enhanced as compared to untreated cells. Yet the cells still showed high cytoplasmic $\beta$-arrestin 2 expression levels in both untreated and stimulated cells. These results correspond to the findings by imunnoblotting that cytoplasmic $\beta$-arrestin 2 levels do not significantly change upon AP21967-induced heterodimerization (Figure 20, right). These results show, that upon AP21967 treatment only a minor fraction of 
overexpressed $\beta$-arrestins translocate to the plasma membrane, while the majority of these proteins remain cytosolic.

In summary the immunoblots and immunofluorescence microscopy confirm that low concentrations $(0.1-1 \mu \mathrm{M})$ of AP2167 are sufficient to induce hetero-dimerization of DmrA and DmrC-containing fusion proteins as demonstrated by translocation of $\beta$-arrestin 2 to the cell membrane. 

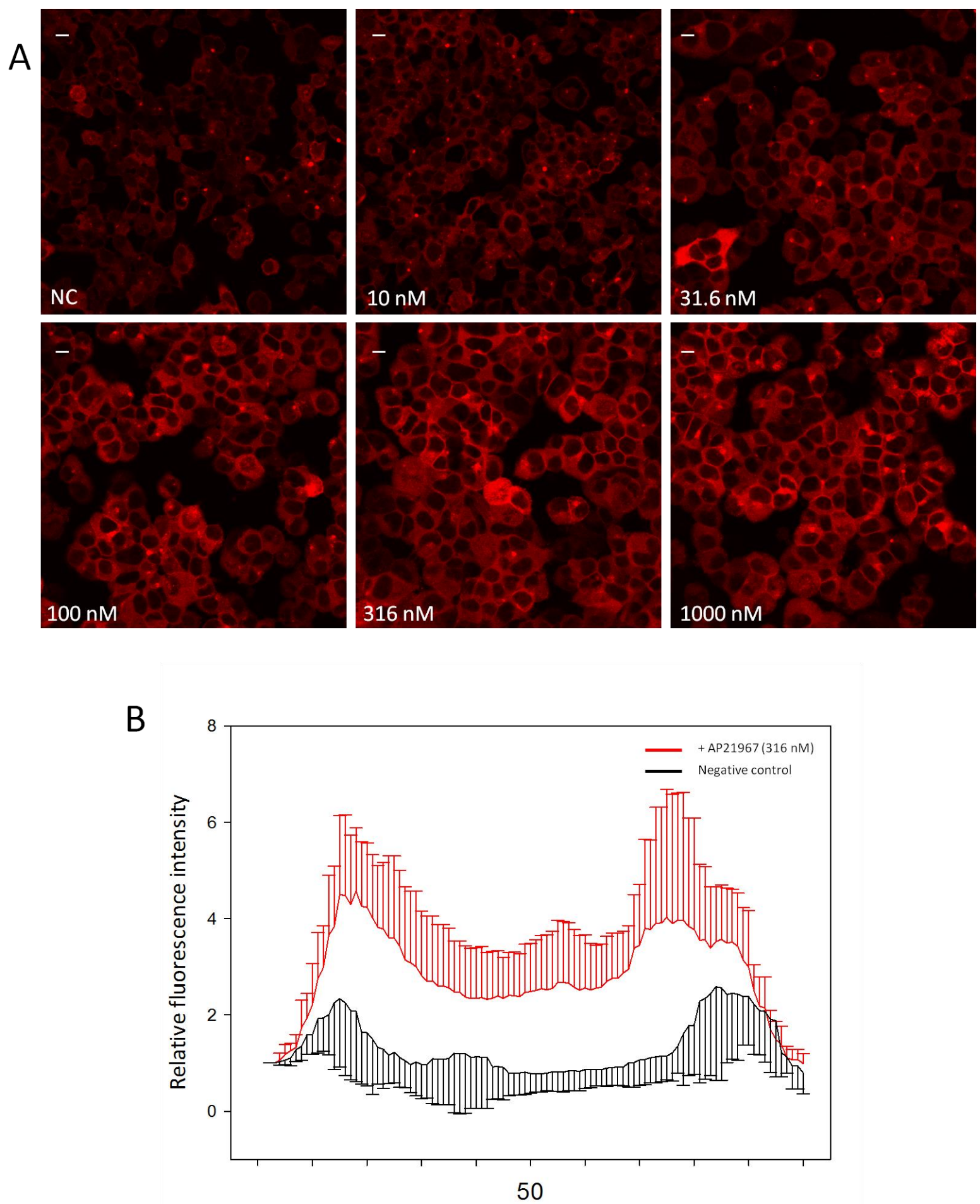

Figure 21: $\beta$-Arrestin 2-DmrC recruitment to the plasma membrane after treatment with 0 to $1000 \mathrm{nM}$ AP21967 (immunofluorescence)

A) Stable co-transfected HEK293 cells (CCR5-DmrA/ $\beta$-Arrestin 2-DmrC) were incubated with DMEM medium containing 0 to $1000 \mathrm{nM}$ AP21967 (1 hour $\left./ 37^{\circ} \mathrm{C}\right)$. The samples were prepared for immunofluorescence microscopy using the detection antibody anti-HA (3F10) in combination with streptavidin-Alexa 647 and evaluated with confocal laser microscopy. Scale bar $10 \mu \mathrm{m}$. B) Quantitative image analysis of CCR5-DmrA/ $\beta$-Arrestin 2-DmrC cells $(n=7)$ which were treated with 0 or $316 \mathrm{nM}$ AP21967. Cross sections of treated (red) and untreated (black) cells were determined and the relative fluorescence intensity (+/- s.d.) was calculated by ImageJ ${ }^{\circledR}$ setting the background fluorescence to 1.0 The cellular diameters were normalized to 100 units. 


\subsubsection{Kinetics of membrane translocation of $\beta$-Arrestin 2-DmrC}

To test the kinetic of the translocation stably co transfected HEK293 cells were stimulated with $500 \mathrm{nM}$ AP21967 for 0 to 240 minutes and the membrane fractions were purified by ultracentrifugation of cellular lysates (3.5.4). $\beta$-arrestin in membrane and cytosolic fractions were detected by 3F10 antibodies(Figure 22). In the membrane fractions of CXCR4- (left) and CCR5 cells (right) the amount of $\beta$-arrestin 2-DmrC (left) increases over time and reaches maximal levels after 2 hours of treatment. As we previously observed in the dose-response experiments (4.2.3.1) translocation of $\beta$-arrestin 2 to the plasma membrane fraction does not noticeably alter cytosolic $\beta$-arrestin levels. Reprobing with anti-pan-cadherin antibodies confirms equal protein load in all lanes of the SDS gel.

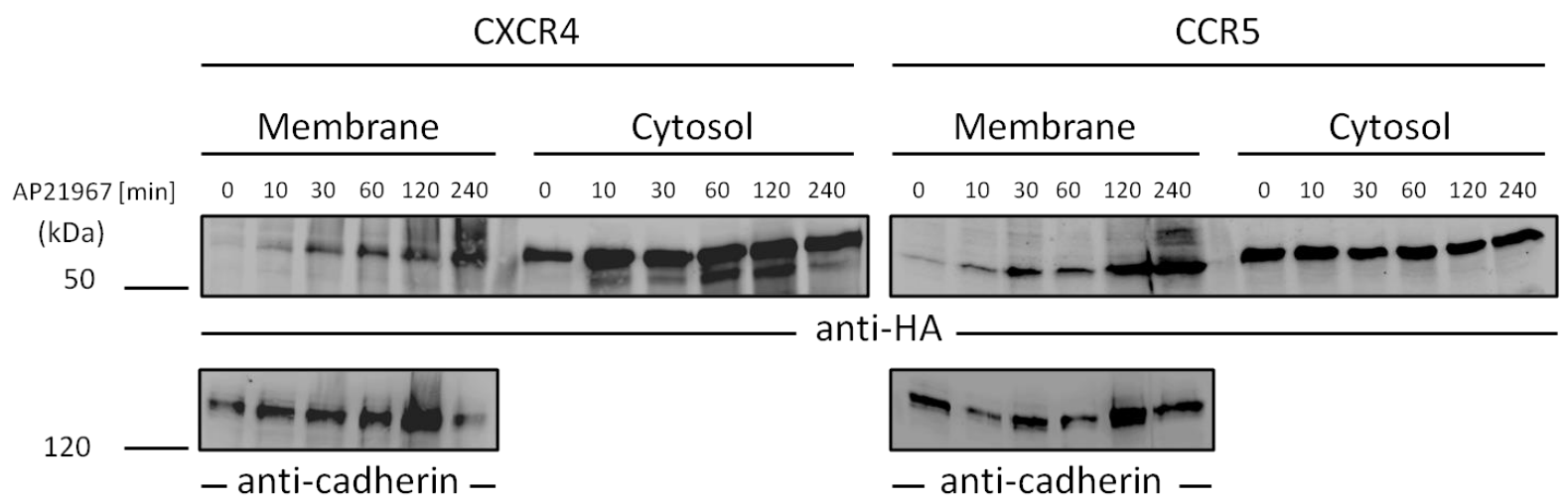

Figure 22: Kinetic of AP21967 induced $\beta$-Arrestin 2-DmrC translocation to the cell membrane (immunoblot)

Stable co transfected HEK293 cells (CXCR4-(left)/CCR5-DmrA (right) with $\beta$-Arrestin 2-DmrC) were treated with $500 \mathrm{~nm}$ AP21967 for different durations. The membrane fraction (left side) was separated from the cytsosl fraction (right side) with ultra centrifugation over a sucrose gradient (3.5.4). The samples were loaded onto an SDS gel (3.5.1) which was subsequently used for an immunoblot (3.5.2) with an anti-HA detection antibody (3F10). To guarantee a constant protein amount in all samples the blot was also probed with an anti-pan-cadherin antibody. For weight comparison a prestained molcecular weight marker was used. The blot was evaluated using an Icd camera.

To confirm these results by immunofluorescence microscopy CCR5 cells were treated with $0.5 \mu \mathrm{M}$ AP21967 for 0 to 240 minutes and stained with biotin coupled anti-HA antibody (3F10) in combination with streptavidin-alexa 647. Cells were analyzed by confocal microscopy. A representative compilation of images is shown in Figure 23. In unstimulated cells $\beta$-arrestin 2 is homogeneously distributed throughout the cells, whereas upon stimulation it is targeted towards the cell membrane in a time-dependent manner. A maximum of $\beta$-arrestin 2-DmrC translocation is visible after 60 minutes of AP21967 treatment. 

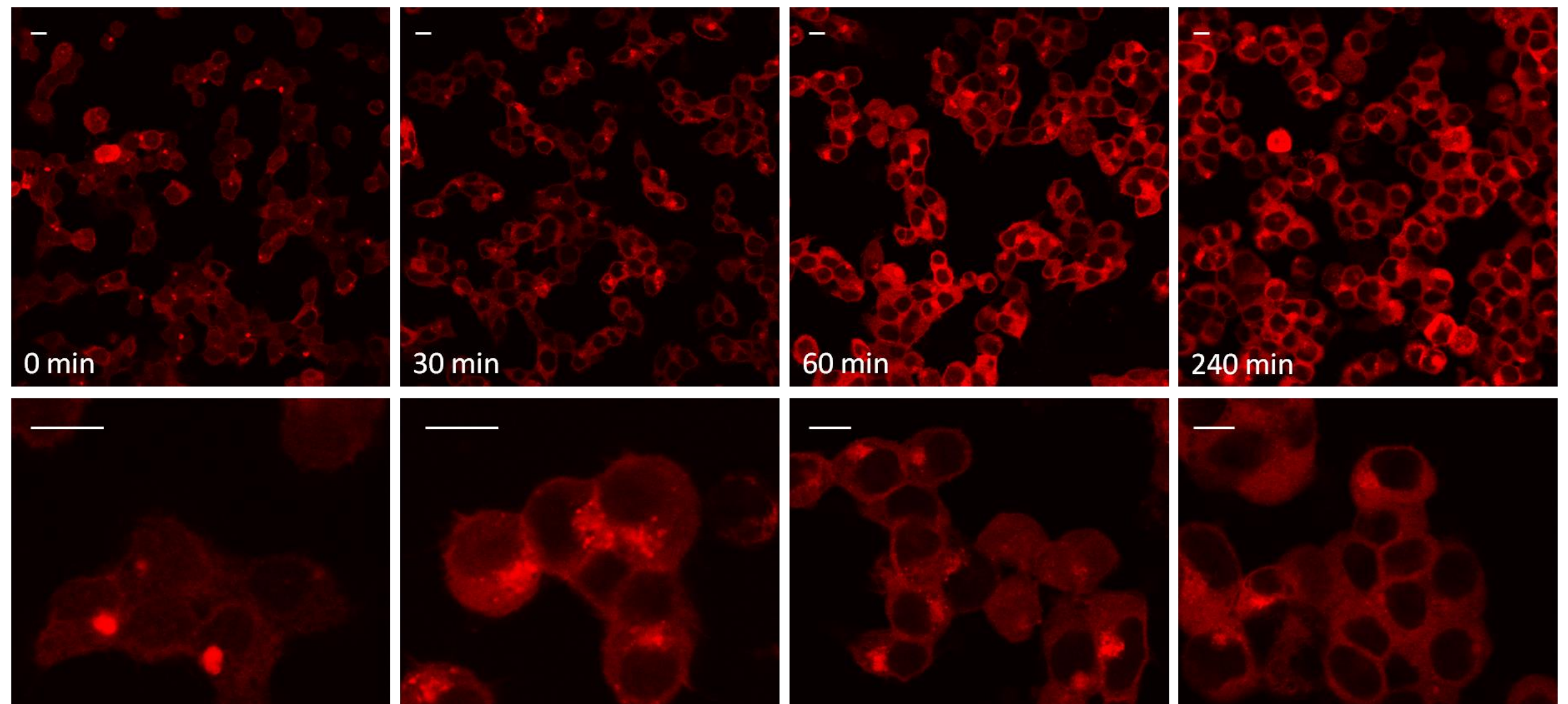

$0 \mathrm{~min}$
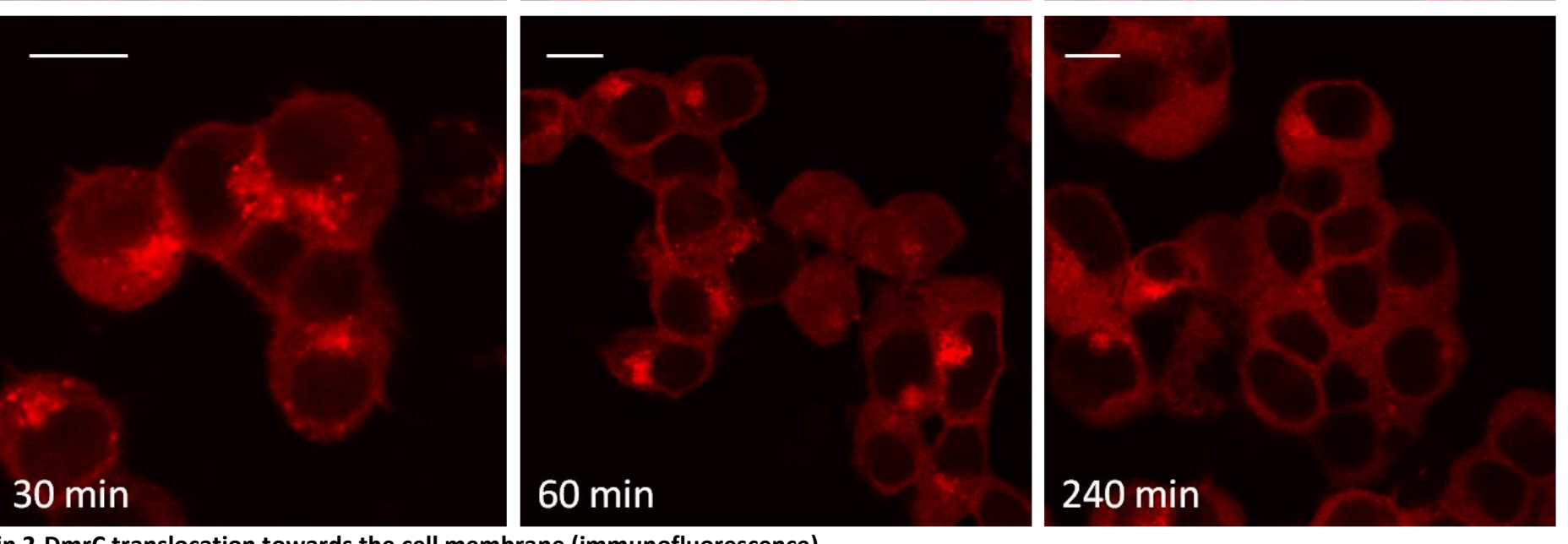

Figure 23: Kinetics of AP21967-induced $\beta$-arrestin 2-DmrC translocation towards the cell membrane (immunofluorescence)

Stable cotransfected CCR5-DmrA/ $\beta$-arrestin-DmrC HEK293 cells were incubated for 0 to 240 minutes with DMEM medium containing $0.5 \mu$ M AP21967. Cells were stained with biotin coupled anti-HA antibody (3F10) and streptavidin-alexa 647 and images were taken with a confocal laser microscope. Representative images of $n=3$ experiments are shown. Scale bar $10 \mu m$. 


\subsubsection{Ligand-vs. AP21967-stimulated $\beta$-Arrestin 2 translocation to the membrane}

The previous experiments showed that $\beta$-arrestin 2-DmrC is translocated to the receptor after AP21967 stimulation in a dose- (4.2.3.1) and time-dependent (4.2.3.2) manner. This time we compared the ligand-induced (physiological) recruitment of $\beta$-arrestin 2 with the AP21967-induced (chemical) translocation to CCR5 at the plasma membrane. Because HEK293 cells exhibit no suitable repertoire of $G$ proteins and GRKs for signal transduction induced by CXCR4/CCR5 (Atwood et al., 2011) we transiently transfected CCR5-DmrA/ $\beta$-arrestin 2-DmrC cells with a modified version of a $\mathrm{G}_{\alpha q-\text { protein }}\left(\mathrm{G}_{\mathrm{qo5}}\right)$ and/or $\mathrm{GRK2}$. The $\mathrm{G}_{\alpha q}$-subunit is capable to interact with phospholipase $\mathrm{C}$, which leads to a detectable calcium influx (Dorsam \& Gutkind, 2007). To increase the binding specificity of $\mathrm{G}_{\alpha \mathrm{q}}$ for CCR5 the last five amino acids were exchange to amino acids of the widely spread $\mathrm{G}_{\text {olf }}$-peptide $\left(G_{q 05}\right)$ which shows a high binding capacity to a variety of different GPCR's.(Robertson et al., 1988).

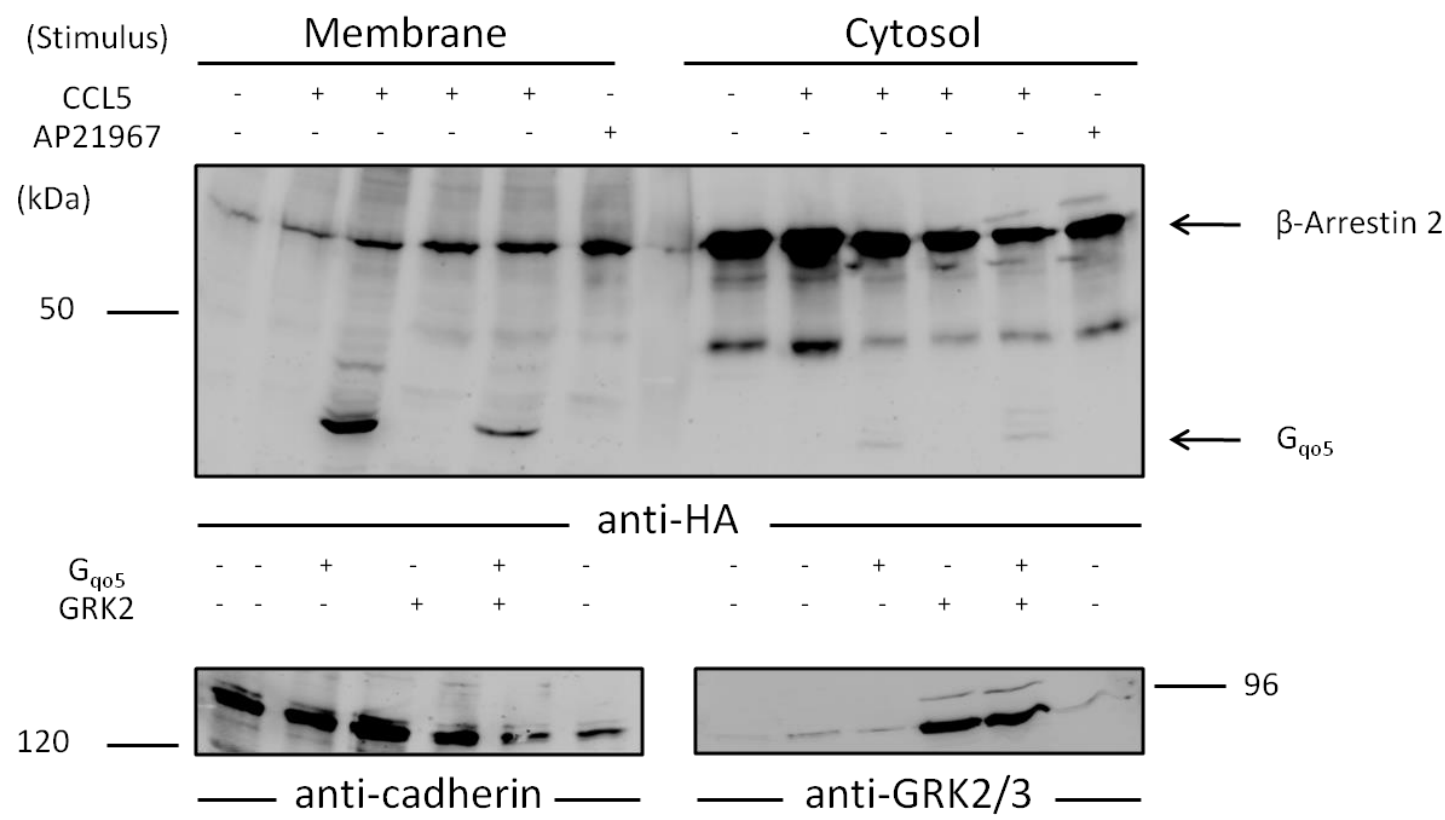

Figure 24: Comparision of ligand- and AP21967-induced $\beta$-Arrestin 2 translocation to the plasma membrane in stably transfected HEK293 CCR5-DmrA cells with $G_{q o}$ and GRK2 co-transfection

Stably co-transfected CCR5-DmrA/ $\beta$-Arrestin 2-DmrC cells were transiently transfected with pMaxKS-IE/G $\mathrm{G}_{\mathrm{qo}}$ and pCDNAI/GRK2. Cells were either stimulated with CCL5 $\left(30^{\prime} / 125 \mathrm{nM}\right)$ or AP21967 $\left(60^{\prime} / 500 \mathrm{nM}\right)$ and membrane fractions were purified by ultracentrifugation. Samples were probed by immunoblotting with anti-HA (3F10), anti-pan-cadherin or anti-GRK2/3 (C5/1) antibodies.

GRK2 is required for receptor phosphorylation after ligand binding, which is crucial for receptor desensitization and $\beta$-arrestin binding (Ribas et al., 2007).

Cells were either stimulated with CCL5 or AP21967 and membrane or cytosolic fractions were purified by ultracentrifugation (3.5.4) and probed by immunoblotting with anti-HA (3F10), anti-pan-cadherin and anti-GRK2/3 (C5/1) antibodies (Figure 24). Since both $\beta$-arrestin 2-DmrC and $\mathrm{G}_{\mathrm{qo5}}$ contain HA-tags both constructs could be detected by $3 \mathrm{~F} 10$ anti-HA antibodies and could be differentiated by their different molecular weight (59 vs. $42 \mathrm{kDa}$; arrows). The blot also shows that if HEK293 cells were complemented with $G_{q 05}$ and GRK2 that the ligand-induced translocation of $\beta$-arrestin 2 to the plasma membrane is comparable to the AP21967-induced translocation (left; last two lanes). Under non optimal conditions the ligand induced $\beta$-arrestin 2 translocation is decreased (lanes three and four). As already observed (4.2.3.1 and 4.2.3.2) the amount of cytosolic $\beta$-arrestin 2 remains unaltered (right). Reprobing with anti-pan-cadherin confirms an equal protein amount in all 
samples. In summary this experiment shows that the extent of $\beta$-arrestin 2-DmrC recruitment to the plasma membrane after AP21967 stimulation is comparable to the ligand-induced translocation of $\beta$-arrestin 2 in HEK293 cells with an optimal complement of functional G proteins and GRKs. Thus, AP21967 (chemical)-induced $\beta$-arrestin 2 translocation can be expected to cause biological effects in a similar manner as after ligand stimulation.

\subsubsection{Functional consequences of chemical-induced $\beta$-Arrestin 2 translocation in the absence of ligand binding}

Previous experiments showed that AP21967 is capable of recruiting $\beta$-Arrestin 2-DmrC to the cell membrane in a dose- (4.2.3.1) and time-dependent manner (4.2.3.2). To study potential consequences of membrane recruitment of $\beta$-Arrestin 2 in the absence of ligand binding and in a fully $G$ protein-independent manner we performed CXCR4/CCR5 receptor desensitization, endocytosis and signaling experiments.

\subsubsection{1 $\beta$-Arrestin 2 translocation leads to desensitization of ligand-induced calcium- mobilization}

We asked whether the AP21967-induced recruitment of $\beta$-Arrestin 2-DmrC to the plasma membrane mimics the effect of $\beta$-Arrestin 2-mediated receptor desensitization after ligand binding. To this end, cells which stably express Rec-DmrA or Rec-DmrA / $\beta$ Arr-DmrC were transiently transfected with $G_{\alpha q}$ variants and incubated with AP21967 prior to the calcium measurement.

\subsection{Expression of $\mathrm{G}_{\alpha q}$-proteins in stable co transfected HEK293 cells using a bicistronic vector system}

To provide HEK293 cells with the optimal repertoire of $G_{\alpha q}$-proteins for $G$ protein-mediated effects after ligand stimulation HEK293 WT and stably cotransfected cells (Rec-DmrA/BArr-DmrC) were additionally transfected with two variants of the $\mathrm{G}_{\alpha q}$-subunit $\left(\mathrm{G}_{\mathrm{q} i} / \mathrm{G}_{\mathrm{qo}}\right)$ (4.2.3.3). For the expression in HEK293 cells the $G_{\alpha}$-subunits were ligated into the bicistronic expression vector pMaxKS-IE (3.2.1), which allows identification of positively transfected cells through GFP in flow cytometry. In comparison to the control cells positive transfected cells show $40 \%$ green fluorescence (Figure 25, A, left). For subsequent calcium measurements online GFP positive cells were used (Figure 25, A, right).

Expression of the $G_{\alpha q}$-subunits, which contain a HA-TAG aswell, was tested by immunoblotting (3.5.2) (Figure 25, B). $G_{\alpha q}$-subunits were expressed either in HEK293 WT, which was used as controls to ensure expression of $G_{\alpha q}$-subunits and $\beta$-Arrestin 2 (Figure 25 , B left) or in stably cotransfected cells (Figure 25, B right). The results showed that both GFP and $G_{\alpha q}$-subunits are sufficiently expressed in transtly transfected HEK cells. Because of the better expression of $G_{q o}$ in comparison to $G_{q i 5}$ this subunit was used in subsequent experiments. 
A
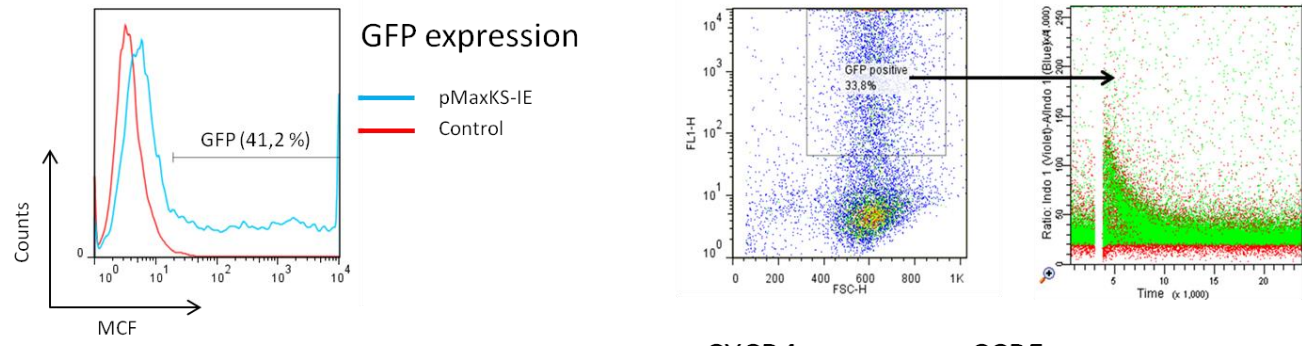

CXCR4

CCR5
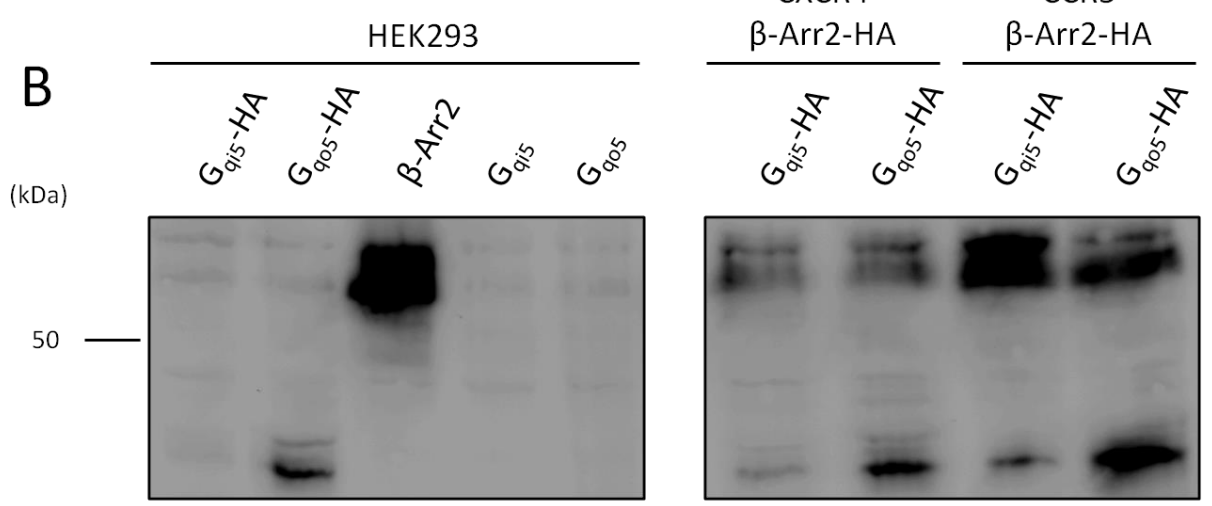

$\longleftarrow \beta$-Arrestin 2

anti-HA

50

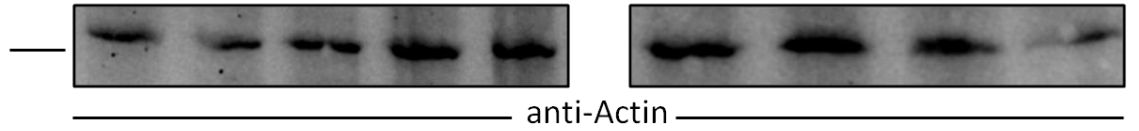

Figure 25: Expression of $G_{\alpha q}$ variants $\left(G_{q 05} / G_{q i 5}\right)$ in HEK293 and stably cotransfected Rec-DmrA/ $\beta A r r-D m r C$ cells using a bicistronic vector system

The $G_{\alpha q}$-variants $G_{q 05} / G_{q i 5}$ were ligated with the bicistronic expression vector pMaxKS-IE and transiently transfected into HEK293 WT and stably cotransfected Rec-DmrA/BArr-DmrC cells. A: The expression of GFP was checked by flow cytometry (left) and used for selection of a GFP-gate. Only GFP-positive cells were used in subsequent calcium measurements (right). B: Cell lysates were probed by immunoblotting with anti-HA detection antibodies. As a control, cells were additionally transfected with $\beta$-Arrestin 2-DmrC or the untagged versions of $\mathrm{G}_{\mathrm{q0}} / \mathrm{G}_{\mathrm{qi5}}$. The blot was re probed with anti-actin antibodies (13E5).

4.2.4.1.2 Effect of $\mathrm{G}_{\alpha q}$ supplementation on ligand induced calcium-mobilization in transiently transfected cells

To test whether supplementation with $\mathrm{G}_{\mathrm{q} 05}$ induced a more robust calcium response upon ligand stimulation CXCR4-/CCR5-DmrA cells were transiently transfected (3.3.4.2) with the pMaxKS-IE/ $G_{\text {qo5 }}$ plasmid. The calcium release after CCL5- or CXCL12-stimulation was measured using flow cytometry and GFP positive cells were gated as illustrated in Figure 25, A. For both cell lines the GFP negative cells (red) show a lower calcium release than cells which coexpress $G_{\text {qo5 }}$ (blue) (Figure 26). This result indicates that $\mathrm{G}_{\mathrm{q0} 5}$ supplemented HEK293 cells have a more robust calcium release in comparison to untransfected cells. 

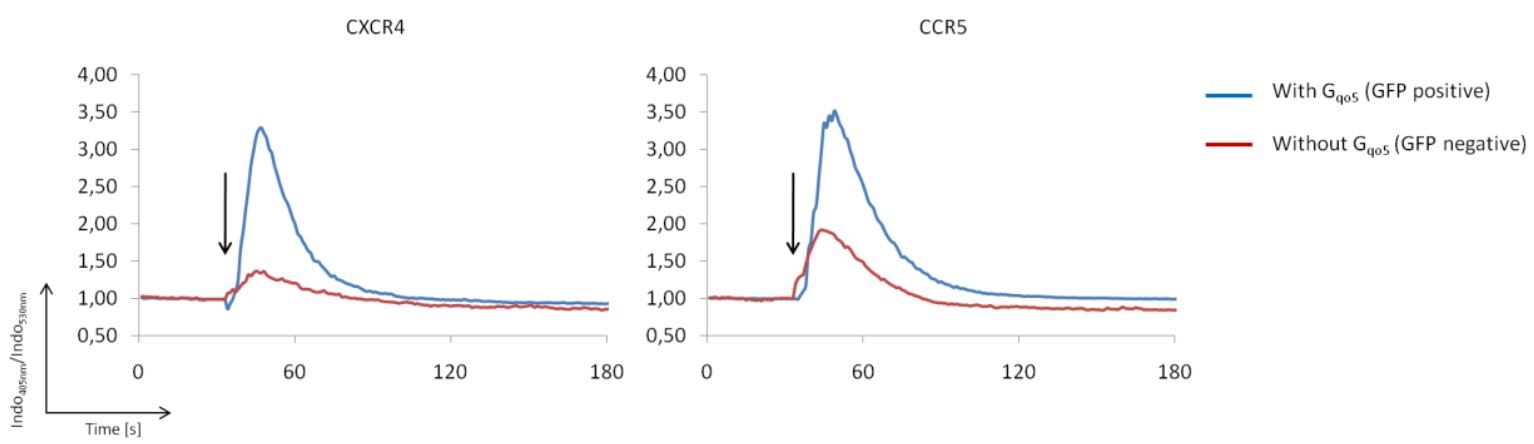

Figure 26: Ligand-induced calcium mobilization in CXCR4- or CCR5- cell lines which coexpress $\mathbf{G}_{\mathrm{q} 05}$ Stably cotransfected HEK293 cells (Rec-DmrA/BArr-DmrC) were transiently transfected with $\mathrm{G}_{\mathrm{qo5}}$ and loaded with Indo-1-AM. The intracellular calcium mobilization was determined by flow cytometry in GFP-positive (blue) or GFP-negative (red) cells. After baseline recording cells were stimulated with $125 \mathrm{nM} \mathrm{CCL5}$ or CXCL12. The graph shows the ratio of two emmission rates of Indo-1-AM $(405 / 530 \mathrm{~nm})$.Values were normalized to the mean value of the baseline.

\subsection{Attenuation of ligand-induced calcium mobilization by forced arrestin/receptor-complex formation}

We asked whether the AP21967-induced translocation of $\beta$-arrestin 2-DmrC to the receptor at the plasma membrane can interfere with $G$ protein coupling to these receptors in a manner similar to normal ligand-induced $\beta$-arrestin recruitment and, thus, mimic receptor desensitization. Since $G_{\mathrm{q} 05}$ further enhances the ligand-induced calcium response (4.2.4.1.2) cells were transiently transfected with $\mathrm{G}_{\text {q05 }}$ and incubated with or without AP21967 for one hour prior to ligand stimulation. Cells which express only CXCR4- or CCR5-DmrA in the absence of $\beta$-arrestin 2-DmrC and, thus, lack the appropriate fusion partner show exactly the same calcium response upon ligand stimulation, regardless of whether cells were pretreated with AP21967 or not (Figure 27, right).
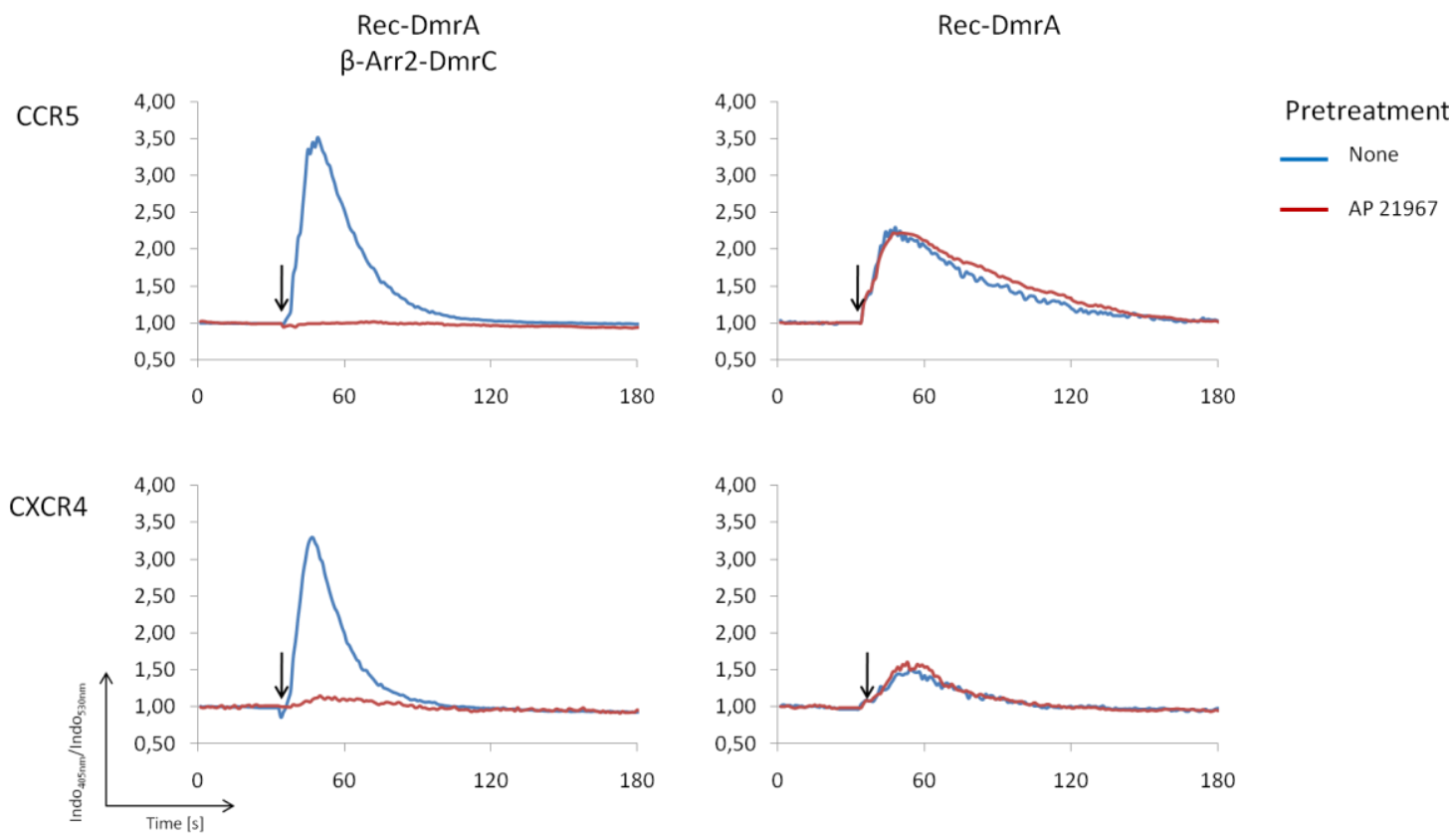

Figure 27: Alterations of the calcium signal in CXCR4- CCR5- cell lines after AP21967 pretreatment

Stably transfected Rec-DmrA (right) and cotransfected Rec-DmrA/BArr-DmrC (left) cells were transiently transfected with $\mathrm{G}_{\mathrm{q0} 5}$, and pretreated with (red) or without (blue) $500 \mathrm{nM}$ AP21967 for one hour and loaded with Indo-1-AM. Calcium release was measured by flow cytometry. The graph shows the ratio of two emmission rates of Indo-1-AM (405/530 nm).Values were normalized to the mean value of the baseline. 
However, in those cells which coexpressed $\beta$-arrestin 2-DmrC the ligand-induced calcium signal was completely abrogated upon pretreatment with AP21967 (Figure 27, left). This result shows that AP21967-induced $\beta$-arrestin 2 translocation to these receptors interferes with $G$ protein-mediated signaling and thus fully mimics $\beta$-arrestin-mediated receptor desensitization after ligand stimulation.

\subsubsection{AP21967- vs. ligand-induced receptor internalization}

4.2.4.2.1 Kinetics of receptor internalization as determined by flow cytometry

To analyze if the recruitment of $\beta$-arrestin 2 to the receptor on its own and in the absence of ligand stimulation is sufficient to induce receptor internalization stably transfected cell lines, which express either CXCR4-DmrA (Figure 28, top) or CCR5 (bottom) alone (Rec; open symbols) or together with BArr-DmrC (RecArr; filled symbols) were stimulated with ligand (CCL5/CXCL12) or AP21967. Cell surface expression of the receptors was evaluated by flow cytometry and loss of cell surface expression was interpreted as receptor internalization. Treatment with AP21967 leads to a receptor internalization on a comparable level to ligand-induced internalization. Ap21967 treatment of CCR5-DmrA/ $\beta A r r-D m r C$ cells leads to stronger internalization compared to ligand-stimulated cells, whereas in CXCR4-DmrA/BArr-DmrC cells the opposite was the case. Rec-DmrA cell lines which lack the interaction partner BArr-DmrC show no distinct receptor internalization upon AP21967 treatment. Ligand-stimulated cells reach the maximal level of internalization faster compared to AP21967-treated cells, which indicates a delayed internalization reaction after AP21967 treatment. Furthermore $\beta$-arrestin overexpression in Rec-DmrA/BArr-DmrC cells lead to a significant enhancement of receptor internalization after ligand stimulation in comparison to Rec-DmrA cells.

In summary we could show that AP21967 treatment leads to a delayed receptor internalization which is on a comparable level as ligand-induced internalization. Furthermore we could prove that the internalization was triggerd by $\beta A$ rr-DmrC translocation to the receptor, because receptor internalization was not observed in cell lines lacking $\beta$ Arr-DmrC. Also we could show that the $\beta$-arrestin overexpression leads to an increased receptor internalization after ligand stimulation. 


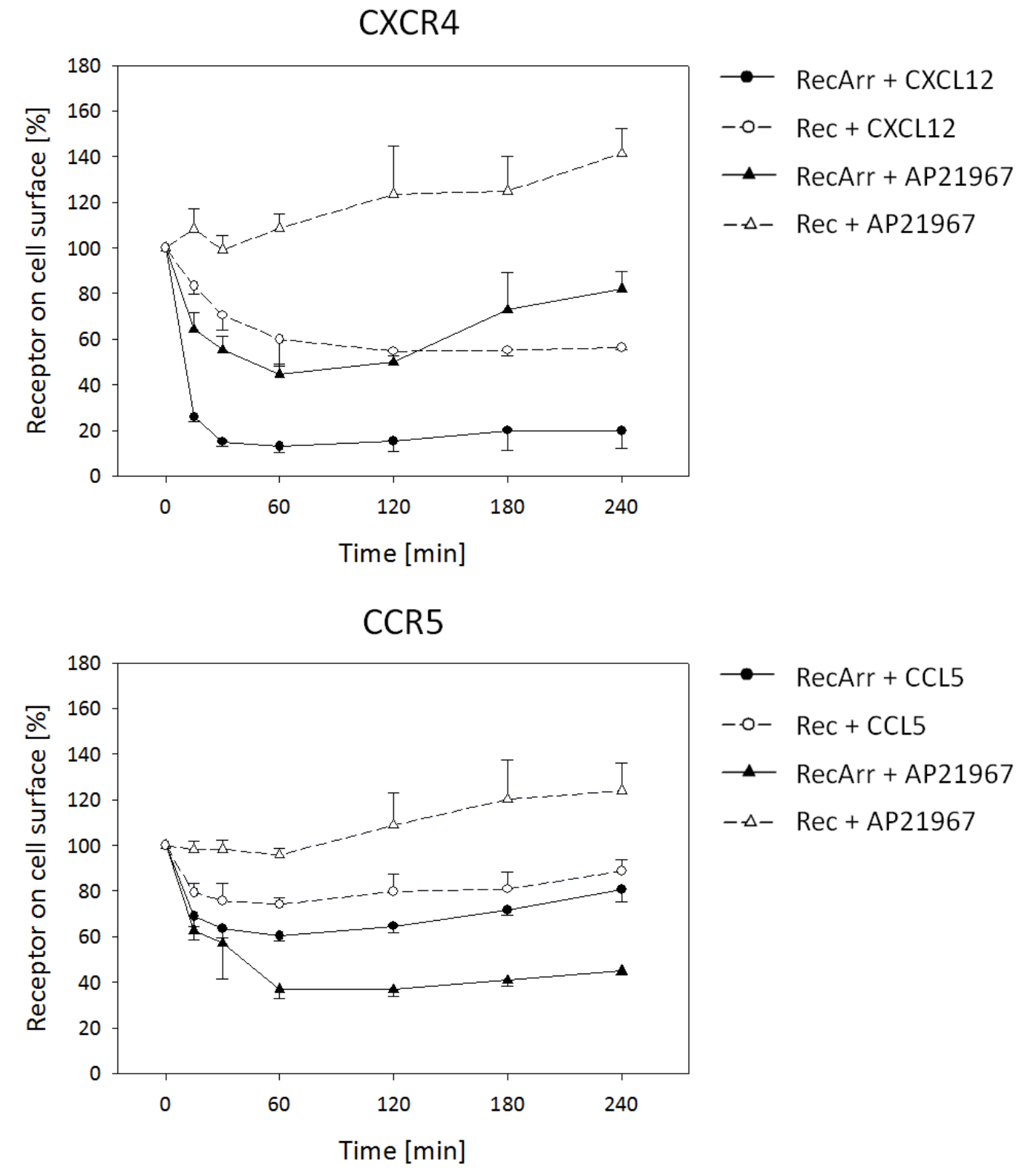

Figure 28: Ligand- and AP21967-induced receptor internalization in stably transfected Rec-DmrA/ $\beta A r r-D m r C$ or Rec-DmrA cells

CXCR4- (top) or CCR5-DmrA (bottom) cells with (RecArr) or without $\beta$-arrestin 2-DmrC (Rec) were stimulated with

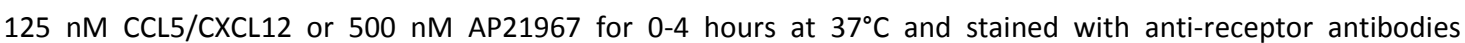
(anti-CXCR4 12G5; anti-CCR5 T21/8) (1 hour $\left./ 4^{\circ} \mathrm{C}\right)$. The MCF was determined by flow cytometry, non-stained cells were used for background control. The graphs show the mean percentage (+/- s.d.) of receptor expressed on the cell surface as compared to the MCF value of untreated cells. 
4.2.4.2.2 Kinetics of AP21967-induced receptor internalization as determined by immunofluorescence

In order to validate these results (4.2.4.2.1) by an independent method and to more precisely determine the intracellular localization of internalized CXCR4 and CCR5, respectively, stably cotransfected HEK293 cells were incubated $\left(0-240^{\prime}\right)$ with 500 nM AP21967 and subsequently stained with anti-receptor antibodies (anti-CXCR4 12G5; anti-CCR5 T21/8) and FITC labeled detection antibodies. Figure 29 shows a representative selection of images which were obtained by confocal laser scanning microscopy. Untreated CXCR4- cells (left panels) show a distinct membrane fluorescence and additional intracellular fluorescence. Upon prolonged treatment the membrane fluorescence is progressively reduced, whereas the intracellular fluorescence increases and is distributed in the cytoplasm after four hours (Figure 29). While loss of membrane fluorescence is also observed in AP21967-treated CCR5 cells (Figure 30) interestingly, the internalized CCR5 receptors are sequestered into a different intracellular localization, which appears peri-nuclear, as compared to the more homogenously, distributed CXCR4 receptors (Figure 29). Thus, the immunofluorescence experiments confirm the results from flow cytometry and in addition demonstrate that AP21967 treatment leads to accumulation of the two receptors in distinct intracellular compartments. 


\section{CXCR4}
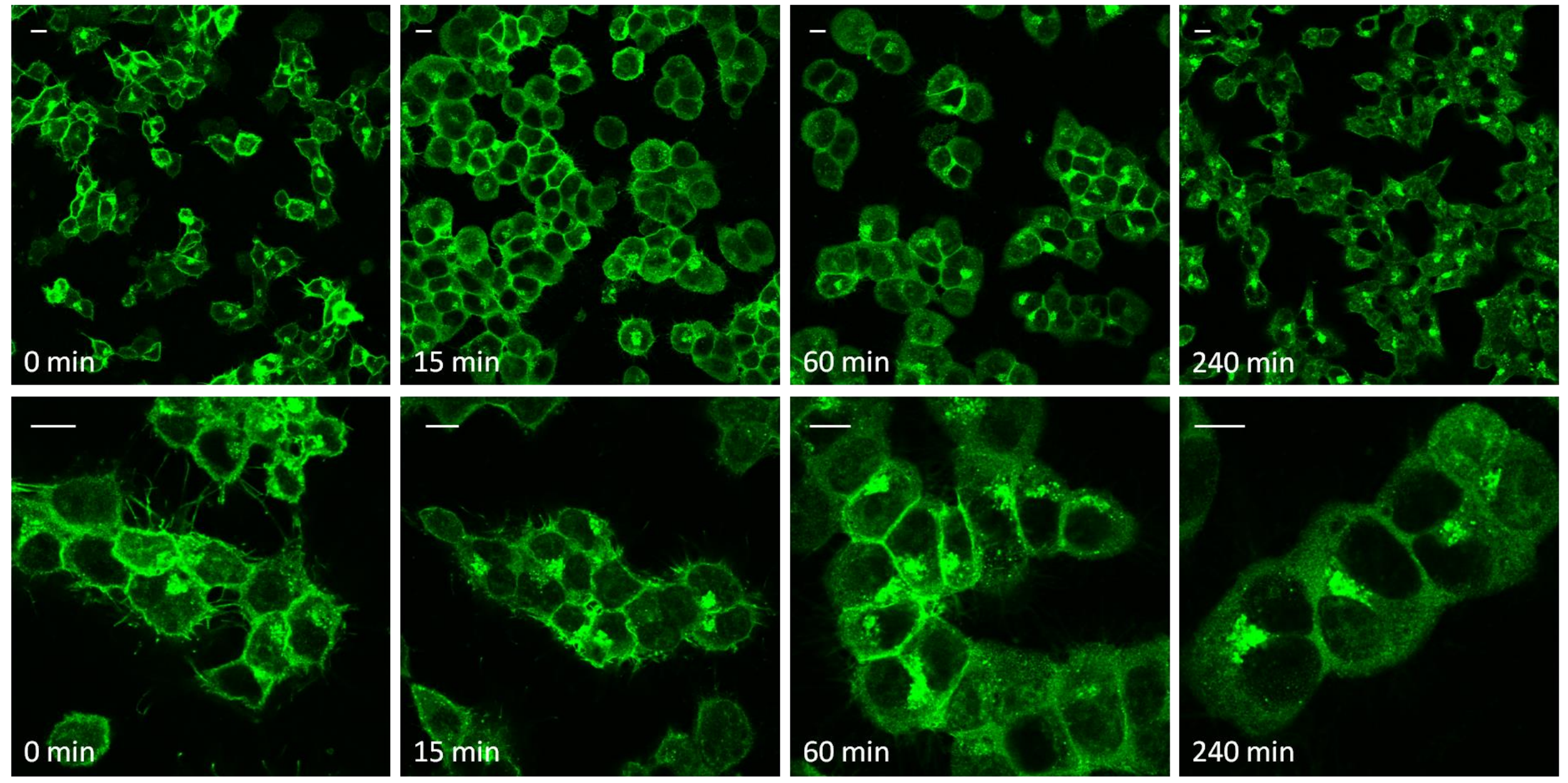

Figure 29: Kinetics of AP21967-induced receptor internalization in CXCR4-DmrA/ $\beta$-Arrestin 2-DmrC cells (immunofluorescence)

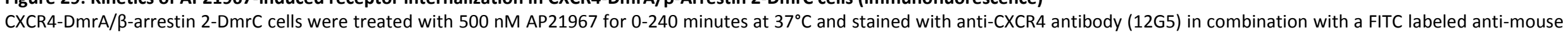
IgG antibody (green). The samples were analyzed by confocal laser microscope. Scale bar $10 \mu \mathrm{m}$. 


\section{CCR5}
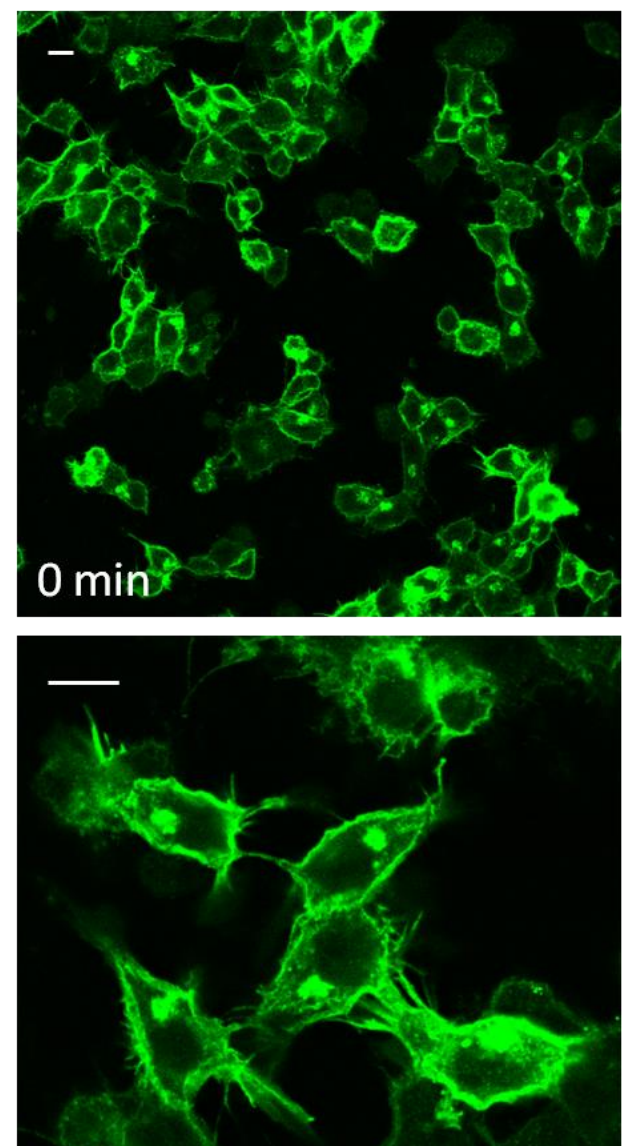

$0 \mathrm{~min}$
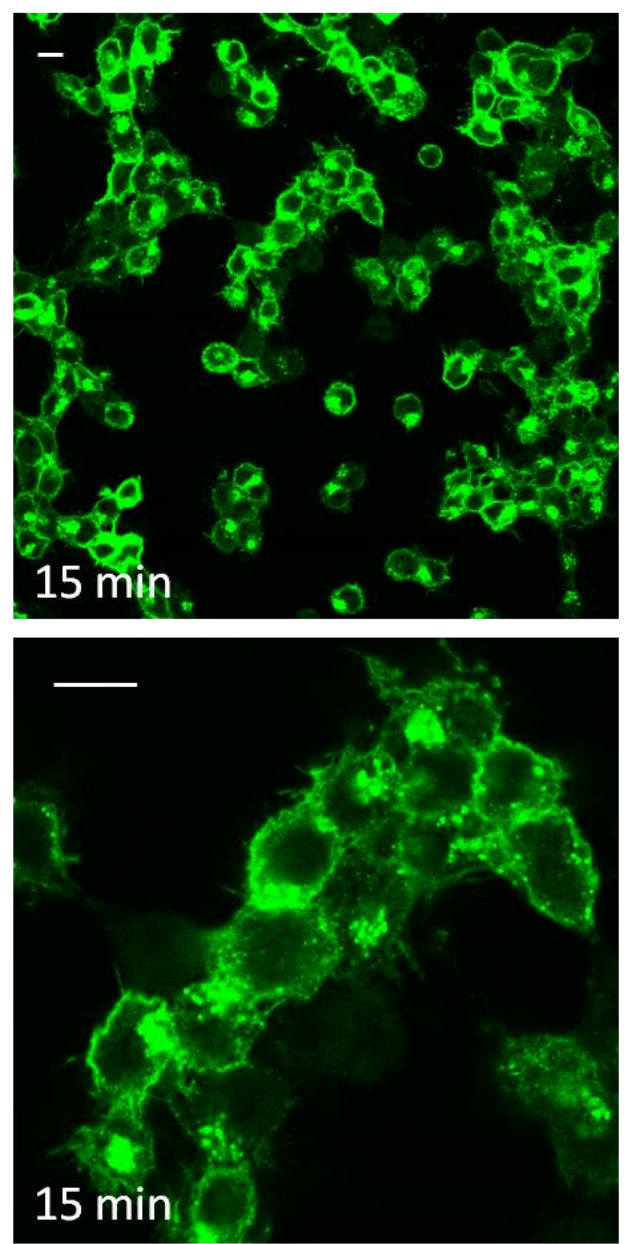
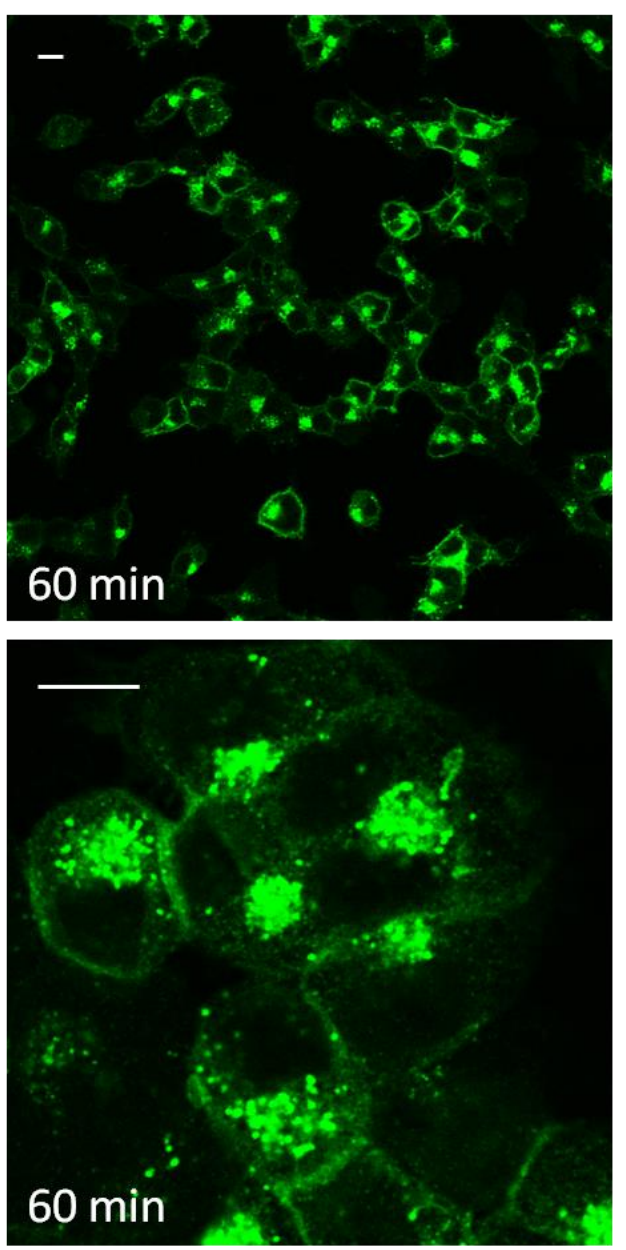
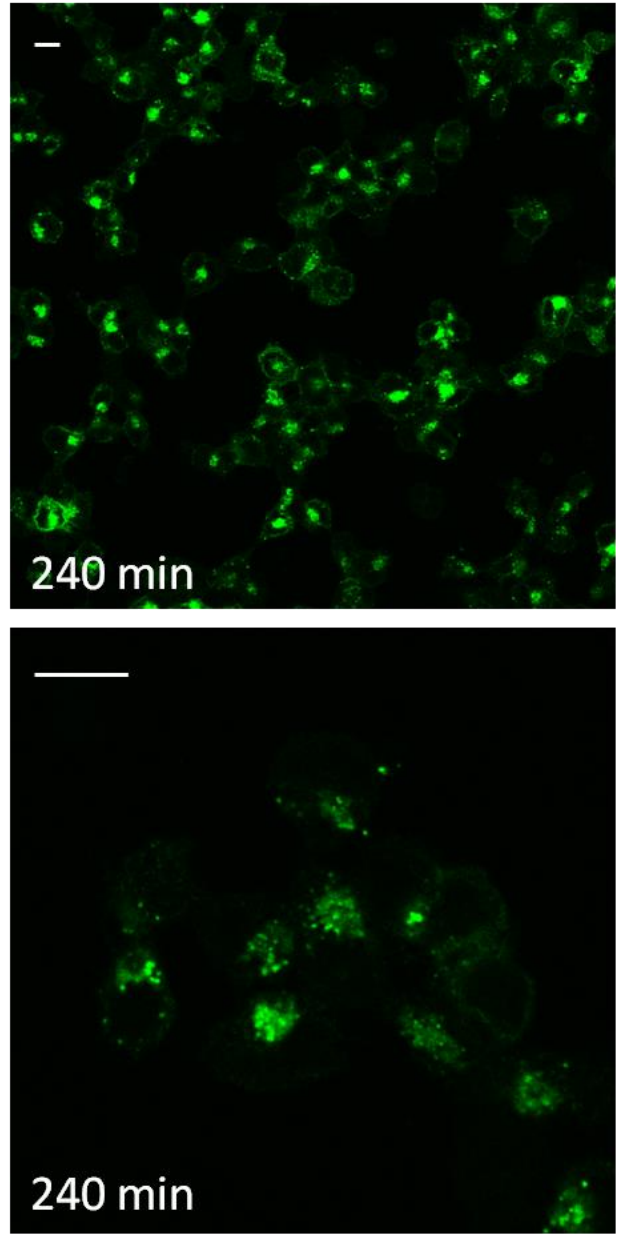

Figure 30: Kinetics of AP21967-induced receptor internalization in CCR5-DmrA/ $\beta$-Arrestin 2-DmrC cells (immunofluorescence)

CCR5-DmrA/ $\beta$-arrestin 2-DmrC cells were treated with $500 \mathrm{nM} \mathrm{AP21967}$ for 0-240 minutes at $37^{\circ} \mathrm{C}$ and stained with anti-CCR5 antibody (T21/8) in combination with a FITC labeled anti-mouse IgG antibody (green). The samples were analyzed by confocal laser microscope. Scale bar $10 \mu \mathrm{m}$. 


\subsection{Intracellular localization of receptors $/ \beta$-arrestin following ligand- or} AP21967-treatment

In previous experiments we demonstrated that AP21967 induced $\beta$-arrestin 2 translocation to the membrane (4.2.3) and internalization of CXCR4 and CCR5 receptors (Figure 29 and Figure 30) with slightly slower kinetics, albeit into distinct intracellular compartments. AP21967 treatment mimics important aspects of $\beta$-arrestin 2 biological functions under physiological conditions, e.g. after ligand stimulation To test whether $\beta$-arrestin 2 and receptors form stable complexes which together are sequestered from the plasma membrane or rapidly dissociate we treated HEK293 with AP21967 or stimulated RBL cells with ligand, costained them with anti-receptor- (green) and anti-HA-antibodies (red) and analyzed the slides with a confocal laser microscope (3.3.6.2). A representative selection of images is depicted in Figure 31. Both untreated CXCR4/CCR5 cells show a distinct membrane fluorescence of both receptors, while $\beta$-arrestin 2 is homogenously expressed in the cytoplasm (0 min). After 30 minutes of AP21967 treatment the intracellular vesicle formation is enhanced (30 $\mathrm{min}$ ), which goes hand in hand with the reduction of membrane-located receptor. The overlay shows that $\beta$-arrestin 2 is localized in close proximity to the receptors. After 240 minutes the majority of all receptors are internalized $(240 \mathrm{~min})$. In contrast, $\beta$-arrestin does not follow CCR5 into the perinuclear region but remains homogenously expressed within the cytoplasm. Thus, intracellular trafficking of CCR5 (and CXCR4) appears to proceed independent of $\beta$-arrestin complex formation, once receptor internalization has been triggered. The dissociation between receptors and $\beta$-arrestin localization was more prominent in CCR5-expressing cells, where the receptors accumulate in the perinuclear region, while CXCR4 remain near the plasma membrane. These findings resemble the intracellular distribution of CCR5 or CXCR4 In ligand-stimulated RBL-cells (lower panels). 


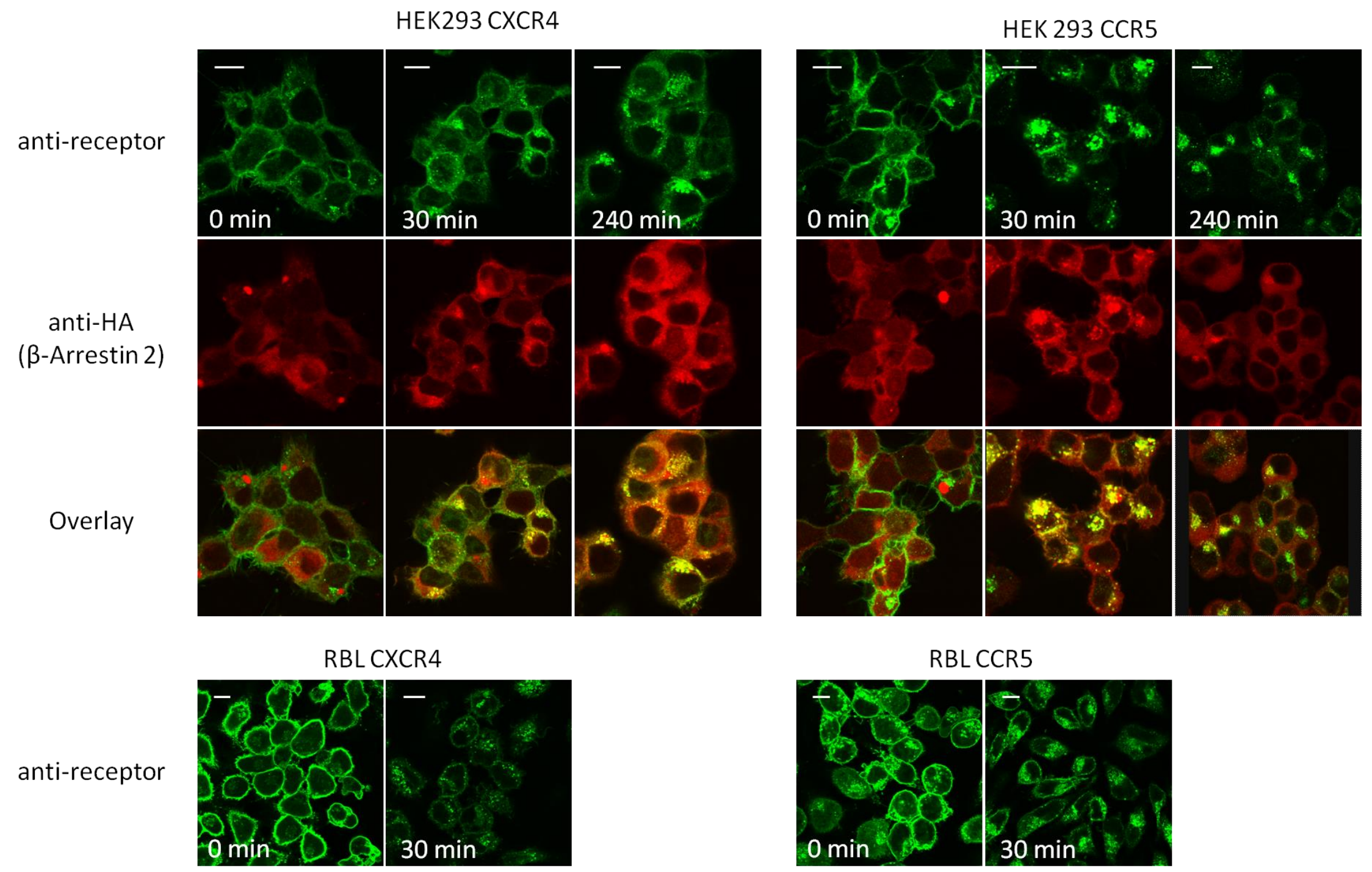

Figure 31:Ligand- vs. AP21967-induced internalization

HEK293 cells (CXCR4-(top left) or CCR5-DmrA (top right) which co-express $\beta$-arrestin 2-DmrC were treated with $500 \mathrm{nM}$ AP21967 for 0.5 or 4 hours at $37^{\circ} \mathrm{C}$. RBL-CXCR4 or-CCR5 cells were stimulated with 0 or $50 \mathrm{nM} \mathrm{CCL5}$ or CXCL12 for 30 minutes at $37^{\circ} \mathrm{C}$. Cells were prepared for immunofluorescence microscopy and stained with anti-receptor antibody (anti-CXCR4 12G5; anti-CCR5 T21/8) (green) and anti-HA antibody (3F10) (red). Slides were analyzed by confocal laser scanning microcopy. Scale bar $10 \mu \mathrm{m}$. 


\subsubsection{AP21967-vs. ligand-induced MAP kinase activation}

We next asked whether AP21967-induced recruitment of $\beta$-arrestin 2-DmrC to the plasma membrane is sufficient to activate downstream signaling pathways as exemplified by the activation of p42/p44 MAP kinases. To this end we performed immunoblot experiments with phosphosite-specific mAbs. PMA- or CCL5-treated cells served as positive control. The intensity of all bands was determined by quantitative image analysis and results were normalized to the results obtained after PMA stimulation.

\subsection{Ligand- and AP21967-induced MAP kinase activation: effect of PTX}

To test the ability of $\beta$-arrestin 2-DmrC to activate p42/p44 MAPK HEK CCR5-DmrA cells with or without $\beta$-arrestin 2-DmrC were additionally pre-treated with PTX prior to AP21967/CCL5 stimulation (Figure 32). Both cell lines show p42/p44 MAPK activation after CCL5 stimulation. The levels of phosphorylated p42/p44 MAPK are higher in cells which co-express $\beta$-arrestin 2-DmrC, compared to cells which lack $\beta$-arrestin overexpression- Pre-incubation with the $G_{\alpha i}$ inhibitor PTX abolishes the ligand-induced MAP p42/p44 phosphorylation in both cell lines. AP21967 treatment does not noticeably affect p42/p44 as compared to untreated cells nor does PTX pretreatment show any effect.

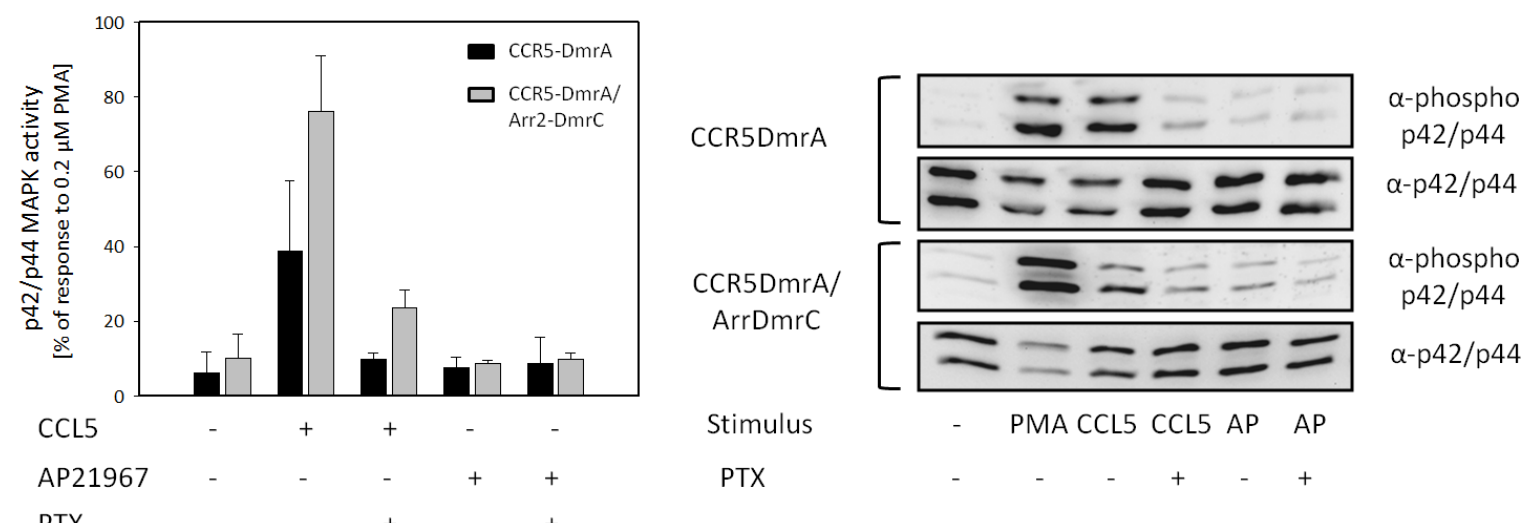

PTX

Figure 32: AP21967- vs. ligand-induced activation of p42/p44 MAPK; inhibition by PTX pretreatment HEK CCR5-DmrA cells with (grey bars) or without (black bars) $\beta$-arrestin 2 -DmrC were cultivated in serum free DMEM medium $\left(16\right.$ hours $\left./ 37^{\circ} \mathrm{C}\right)$, pretreated with 0 or $0.2 \mu \mathrm{M}$ PTX (16 hours $/ 37^{\circ} \mathrm{C}$ ) and stimulated with $50 \mathrm{nM}$ CCL5 or $500 \mathrm{nM}$ AP21967 (AP; 5' $\left./ 37^{\circ} \mathrm{C}\right)$. Stimulation with $200 \mathrm{nM}$ PMA $\left(30^{\prime} / 37^{\circ} \mathrm{C}\right)$ served as a positive control. Phosphorylation of p42/p44 MAPK was detected with anti-phospho-p42/p44 antibodies (D13.14.E) in combination with HRP-coupled detection antibodies. The blot was analyzed by chemiluminescence. Blots were stripped and reprobed with anti-pan-p42/p44 antibodies (137F5). Quantification was done by scanning the signal intensity with Image ${ }^{\circledR}$. The results were normalized to the PMA-treated samples (100\%). The results represent the mean values +/- s.d. of three independent experiments.

\subsection{Ligand- and AP21967-induced MAP kinase activation: effect of co-expressed $\beta$-arrestin 2-DmrC}

To test whether lack of $\mathrm{p} 42 / \mathrm{p} 44$ phosphorylation is due to a wrong time frame of cellular stimulation, CCR5-DmrA cells with or without $\beta$-arrestin 2-DmrC and HEK293 WT cells (black) were stimulated with CCL5 or AP21967 for 5 or 30 minutes (Figure 33). Untreated cells were used as a negative, PMA treated cells were used as a positive control. As previously shown (4.2.4.3.1) 5 minutes of stimulation with CCL5 leads to a p42/p44 phosphorylation in both transfected cell lines which decreases after 30 minutes. Ap21967 treatment does not induce significant MAPK activation at 5 or 30 minutes stimulation. 


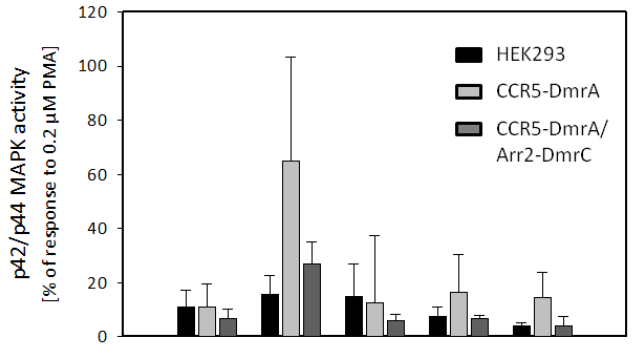

CCL5

AP21967

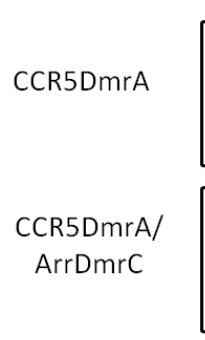

Stimulus

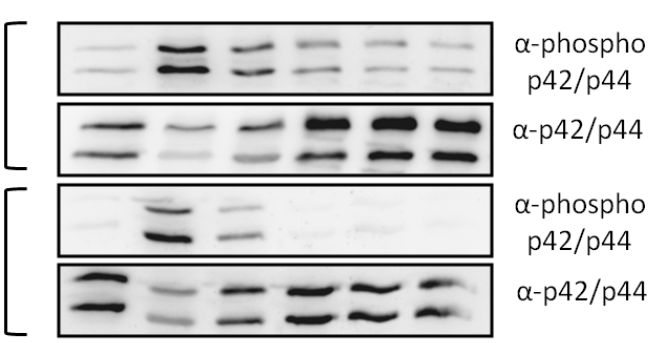

PMA CCL5 CCL5 AP AP

$5^{\prime} 30^{\prime} 5^{\prime} 30^{\prime}$

Figure 33: Kinetic of AP21967 vs. ligand induced activation of p42/p44 MAPK and their inhibition with PTX (immunoblot)

HEK CCR5-DmrA cells with (dark grey bars) or without (light grey bars) $\beta$-Arrestin 2 -DmrC or HEK293 WT cells (black bars) were cultivated in serum free DMEM medium $\left(16\right.$ hours $\left./ 37^{\circ} \mathrm{C}\right)$ and treated with AP21967 (AP) or CCL5 ( $5^{\prime}$ or $30^{\prime} / 37^{\circ} \mathrm{C}$ ). Staining, evaluation and quantifications were carried out as described in Figure 33 . The bars represent the mean values +/- s.d. of at least three independent experiments. Shown is a representative immunoblot.

\subsection{Activation of $\mathrm{p} 42 / \mathrm{p} 44-\mathrm{MAPK}$ at different time points after ligand- and AP21967- treatment}

Since p42/p44 MAP kinases are only transiently activated upon CCL5 stimulation, we performed a more detailed kinetic study. CCR5-DmrA cells with (bottom) or without (top) $\beta$-arrestin 2-DmrC overexpression were stimulated with AP21967 or CCL5 for different time intervals up to 60 minutes. PMA or untreated cells were used as controls. The immunoblot (Figure 34) shows that in CCL5-stimulated cells p42/p44 MAPK are clearly phosphorylated after 2 minutes and this level is maintained for up to 15 minutes. The signal is lost after 30 and 60 minutes. AP21967 treatment shows at no time point a phosphorylation above background level.

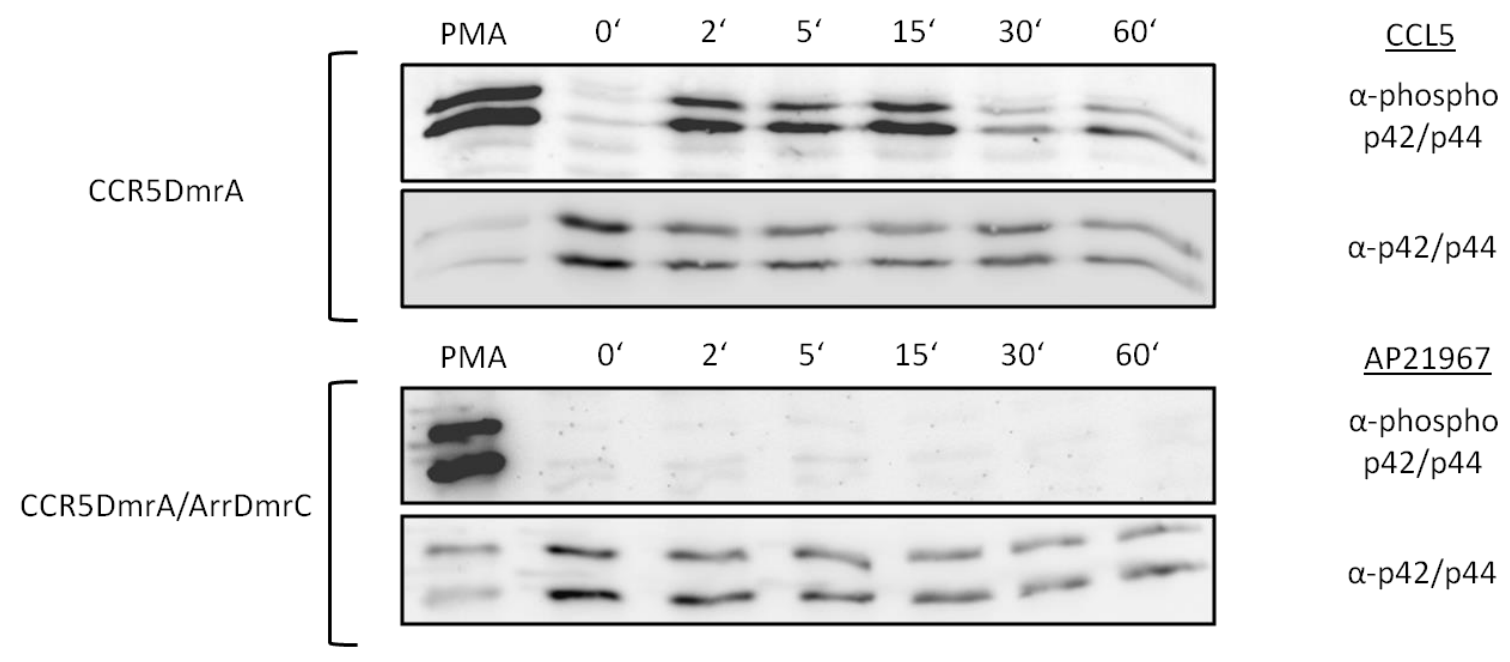

Figure 34: Detailed kinetics of AP21967- or ligand- induced activation of p42/p44 MAPK

HEK CCR5-DmrA cells with (bottom images) or without $\beta$-Arrestin 2 -DmrC (top images) co-expression were treated

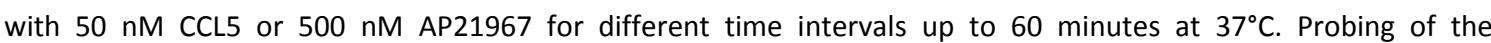
immunoblot with anti-phosphor p42/p44 (top) or anti-pan p42/p44 (bottom) was done according to the legend from figure Figure 32. The images are representative of three independent experiments. 


\subsection{Activation of $\mathrm{p} 42 / \mathrm{p} 44-\mathrm{MAPK}$ after incubation with different concentrations of AP21967}

Since activation maybe inhibited with too high concentrations of a hetero-dimerizing linker we also tested for MAPK activation at a wider range of AP21967 concentrations. To this end we treated CCR5-DmrA/BArr-DmrC cells with different concentrations of AP21967 (31.6-1000 nM). PMA and untreated cells were used as controls (Figure 35). At no concentration did we observe a detectable p42/p44 phosphorylation.

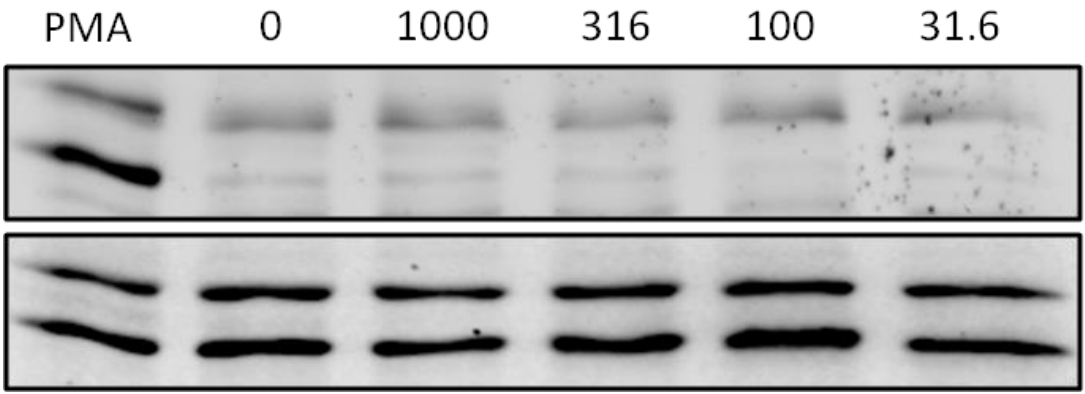

AP21967 [nM]

$\alpha$-phospho p42/p44

$\alpha-p 42 / p 44$

Figure 35: Dose response of AP21967-induced p42/p44 MAPK activation HEK CCR5-DmrA/ $\beta$-Arr-DmrC cells were treated with 0-1000 nM AP21967 for 5 minutes at $37^{\circ} \mathrm{C}$. The immunoblot was probed with anti-phospho p42/p44 (top) or anti-pan p42/p44 (bottom) antibodies and developed as described in the legend of Figure 32. The images are representative of three independent experiments.

\subsubsection{Functional consequences of AP20187-induced receptor homodimerization}

In a separate set of experiments functional consequences of chemical-induced CXCR4 or CCR5 homodimerization was investigated, since previous studies had suggested that ligand stimulation is followed by oligomerization of these receptors and subsequent cellular stimulation (Mellado et al., 2001a). We therefore treated HEK cells which expressed Rec-DmrA in the absence of $\beta$ Arr-DmrC with a different linker reagent, AP20187, which simultaneously binds to two adjacent DmrA domains and thereby induces their homodimerization.

\subsubsection{Effect of AP20187 treatment on ligand-induced calcium-mobilization in Rec-DmrA cells}

In these experiments we asked whether AP20187 on its own stimulates calcium release, or whether AP20187 pretreatment alters subsequent calcium response in Rec-DmrA cells. To this end HEK293 cells which stable express Rec-DmrA were transiently transfected with $\mathrm{G}_{\mathrm{qo5}}$ and pre treated with 0 or $0.1 \mu \mathrm{M}$ AP20187. Cells were then stimulated with ligand and the intracellular calcium-mobilization was monitored as described in 4.2.4.1.2 (Figure 36). In both cell lines the ligand-induced calcium release was identical regardless of whether cells were pre treated with AP20187 (red) or not (blue). Stimulation with AP20187 did not lead to any calcium release on its own (data not shown). 
CXCR4

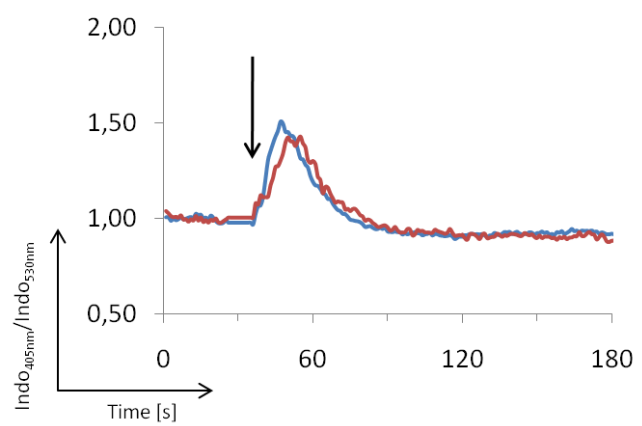

CCR5

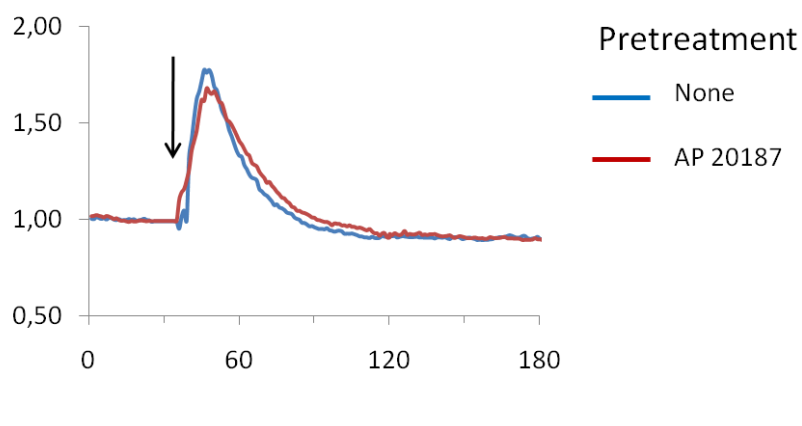

Figure 36: Influence of AP20187 on the ligand induced calcium release in stable tranfected HEK293 cells (transient transfection of $\mathrm{G}_{\mathrm{qo5}}$ )

HEK293 cells which were stable transfected with Rec-DmrA and transiently with $\mathrm{G}_{\mathrm{qo5}}$ were pre incubated with 0 or $100 \mathrm{nM}$ of AP20187 for 60 minutes at $37^{\circ} \mathrm{C}$ and stimulated with $100 \mathrm{nM}$ AP20187 or $50 \mathrm{nM}$ ligand. Calcium measurement was done as described in the legend of Figure 27. The graphs show a represantative results out of three independent measurements.

\subsubsection{Effect of AP20187 on receptor internalization in Rec-DmrA/BArr-DmrC or Rec-DmrA cells}

We pretreated Rec-DmrA/BArr-DmrC or Rec-DmrA expressing cells with 0 or $1 \mu \mathrm{M}$ Ap20187. Cells were then stimulated with ligand (CCL5/CXCL12). The effect on receptor internalization from the cell surface was evaluated using flow cytometry as described before. While AP20187 treatment alone does not affect cell surface expression of CXCR4 or CCR5, pretreatment with AP20187 significantly $(p<0.001)$ enhances subsequent ligand-induced receptor internalization. This effect was reproducibly seen with both CCR5-expressing cells, regardless of whether they co-expressed $\beta$-arrestin or not. Moreover, $\beta$-arrestin coexpression significantly $(p<0.001)$ enhanced CCR5 internalization (Figure 37, left). In summary the results suggested that receptors in a homodimerized state are internalized more efficiently as compared to receptor monomers. 


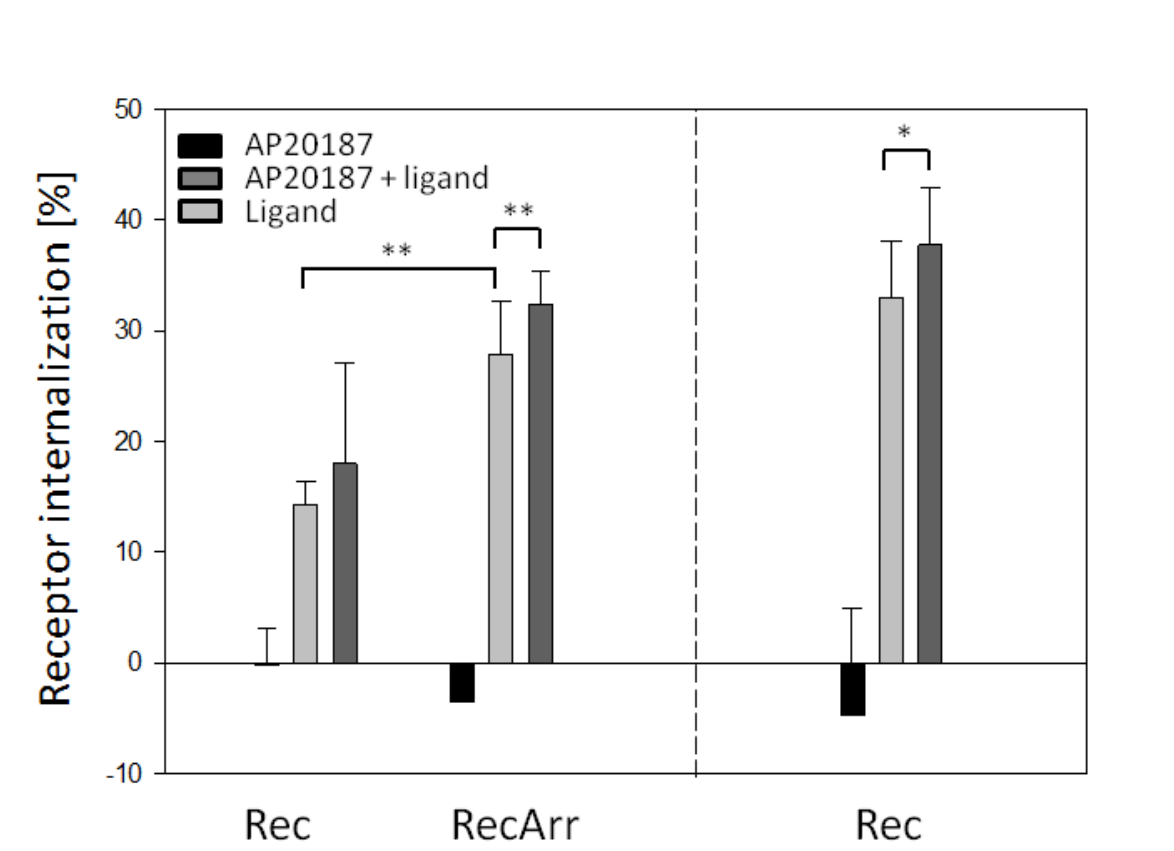

CCR5

\title{
CXCR4
}

\begin{abstract}
Figure 37: Effect of AP20187 pretreatment on ligand-induced receptor internalization

Stably transfected HEK293 cells (CXCR4-DmrA [right]/CCR5-DmrA [left]) were pretreated with $100 \mathrm{nM}$ AP20187 (dark grey bars) $\left(60^{\prime} / 37^{\circ} \mathrm{C}\right.$ ) or remained untreated. Cells were stimulated with $50 \mathrm{nM}$ ligand (CCL5/CXCL12) or $100 \mathrm{nM}$ AP20187 $\left(30^{\prime} / 37^{\circ} \mathrm{C}\right)$, and receptor expression on the cell surface was monitored by flow cytometry using receptor-specific antibodies (anti-CXCR4 12G5; anti-CCR5 $\mathrm{T} 21 / 8)$. The percentage of receptor internalization as compared to non-stimulated cells is shown (mean values $+/$ - s.d. of three independent experiments). ${ }^{*}, p<0.01$; $* * p<0.001$.
\end{abstract}

\subsubsection{Effect of AP20187 treatment on p42/p44-MAPK phosphorylation in Rec-DmrA cells}

To test if AP20187 treatment affects p42/p44 MAPK phosphorylation we used the experimental setup described in 4.2.4.3.1. Receptor-DmrA (CXCR4 [dark grey]/CCR5 [light grey]) or HEK293 WT (black) cells were cultivated in serum free DMEM medium and stimulated either with ligand (CCL5/CXL12) or AP20187. The resulting immunoblot is shown in Figure 38. Whereas ligand stimulation leads to p42/p44 phosphorylation in receptor expressing cells, neither CXCR4- nor CCR5-expressing cells show any changes in p42/p44 phosphorylation after AP20187 treatment. 


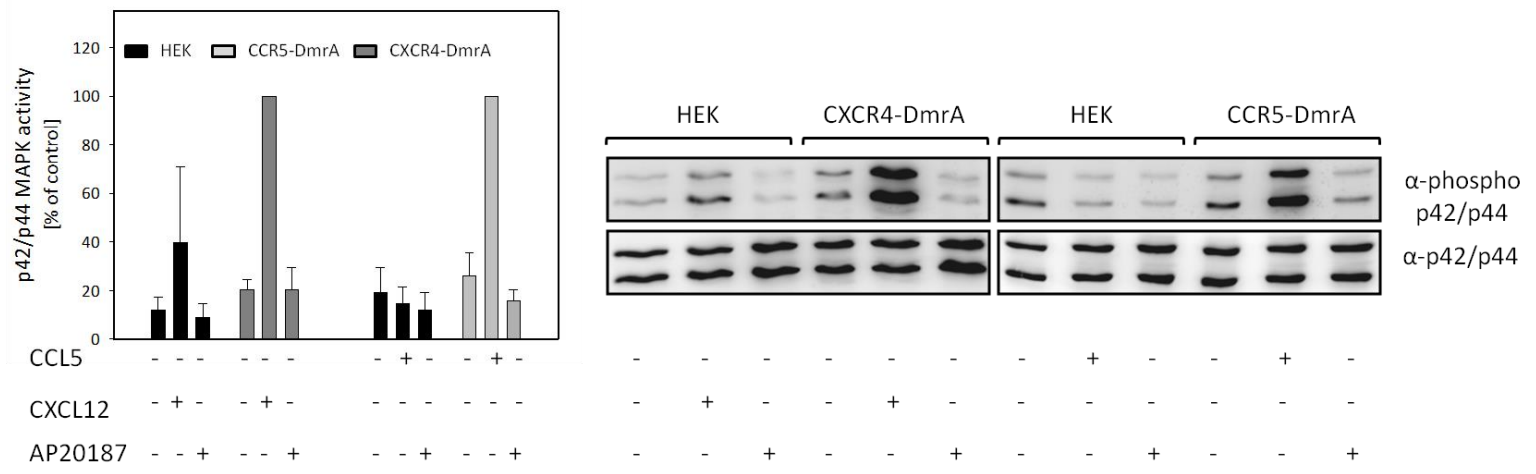

Figure 38: AP20187- vs. ligand-induced activation of p42/p44 MAPK in HEK Rec-DmrA cells

Stably transfected HEK293 cells (CXCR4-/CCR5-DmrA) (light or dark grey) or HEK293 WT cells (black) were cultivated in serum free DMEM medium $\left(16\right.$ hours $\left./ 37^{\circ} \mathrm{C}\right)$ and stimulated $\left(5^{\prime} / 37^{\circ} \mathrm{C}\right)$ with $50 \mathrm{nM}$ ligand $(\mathrm{CXCL} 12 / \mathrm{CCL}$ ) or $100 \mathrm{nM}$ AP20187. Phosphorylation of the p42/p44 MAPK was detected with anti-phospho-p42/p44 antibodies. The blot was reprobed using an anti-pan p42/p44 antibody. Evaluation and quantification was done as described in the legend of Figure 32 (mean values +/- s.d. of three independent experiments).

\subsubsection{Dose-response and kinetic of AP20187 induced p42/p44-MAPK phosphorylation}

We also tested different concentrations (Figure 39 bottom) of AP20187 and time intervals of stimulation (Figure 39 top) (4.2.4.3.1) on p42/p44 phosphorylation levels. Modification of time intervals or concentrations did not result in any detectable changes in p42/p44 MAP kinase activation.

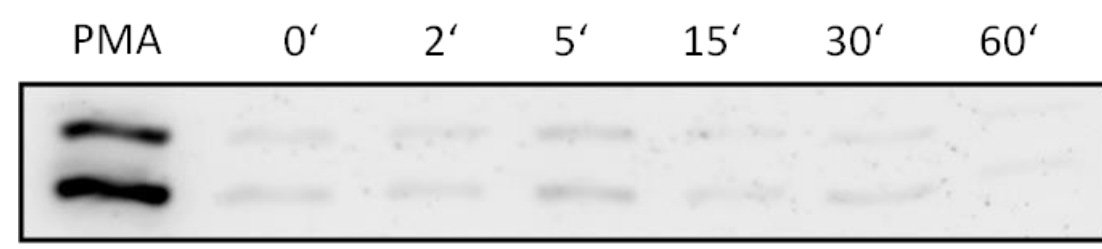

\section{AP20187}

$\alpha$-phospho

p42/p44

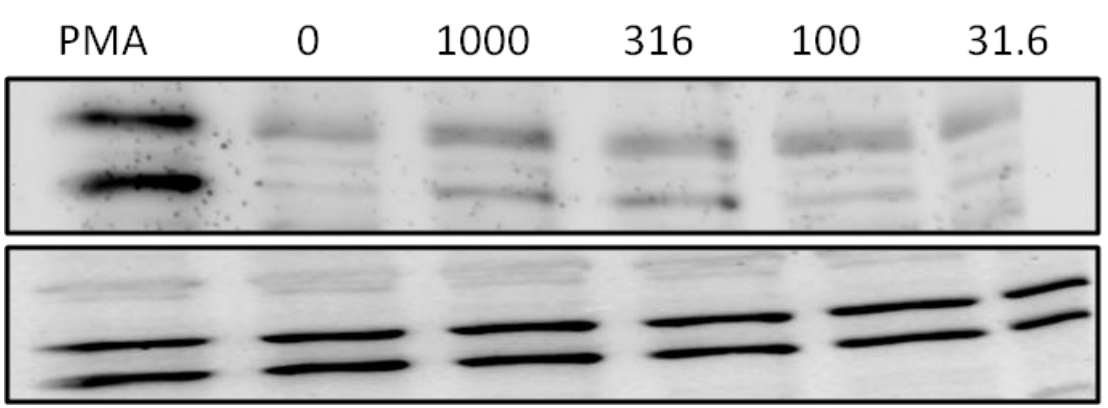

$\underline{\mathrm{AP} 20187[\mathrm{nM}]}$

$$
\begin{gathered}
\alpha \text {-phospho } \\
\text { p42/p44 }
\end{gathered}
$$

$\alpha-p 42 / p 44$

Figure 39: Detailed kinetic and dose response of AP20187 induced p42/p44 MAPK activation HEK293 CCR5-DmrA cells were treated with $0-1000$ nM AP20187 for 5 minutes at $37^{\circ} \mathrm{C}$ (bottom) or $100 \mathrm{nM}$ AP20187 for 0 - 60 minutes (top). p42/p44 phosphorylation levels were analyzed as described in legend of Figure 32 (representative for three independent experiments). 


\subsubsection{Effect of AP21967 and AP20187 on the activation of different MAP kinases}

To detect whether other MAP kinases apart from p42/p44 might be affected by AP21967- or AP20187-treatment, we stimulated CCR5-DmrA/BArr-DmrC or CCR5-DmrA cells with both reagents for 60 minutes and checked the phosphorylation levels of various kinases in cellular lysates by the MAPK array kit from R\&D systems (RnDsystems, 2013). The experiment was performed according to the manufacturer's guideline. The nitrocellulose membrane was incubated with a cocktail of different phosphor-specific antibodies (legend to Figure 40) and with HRP-labeled secondary antibodies. Overall, no significant changes in MAP kinase activation were observed apart from the positive control.
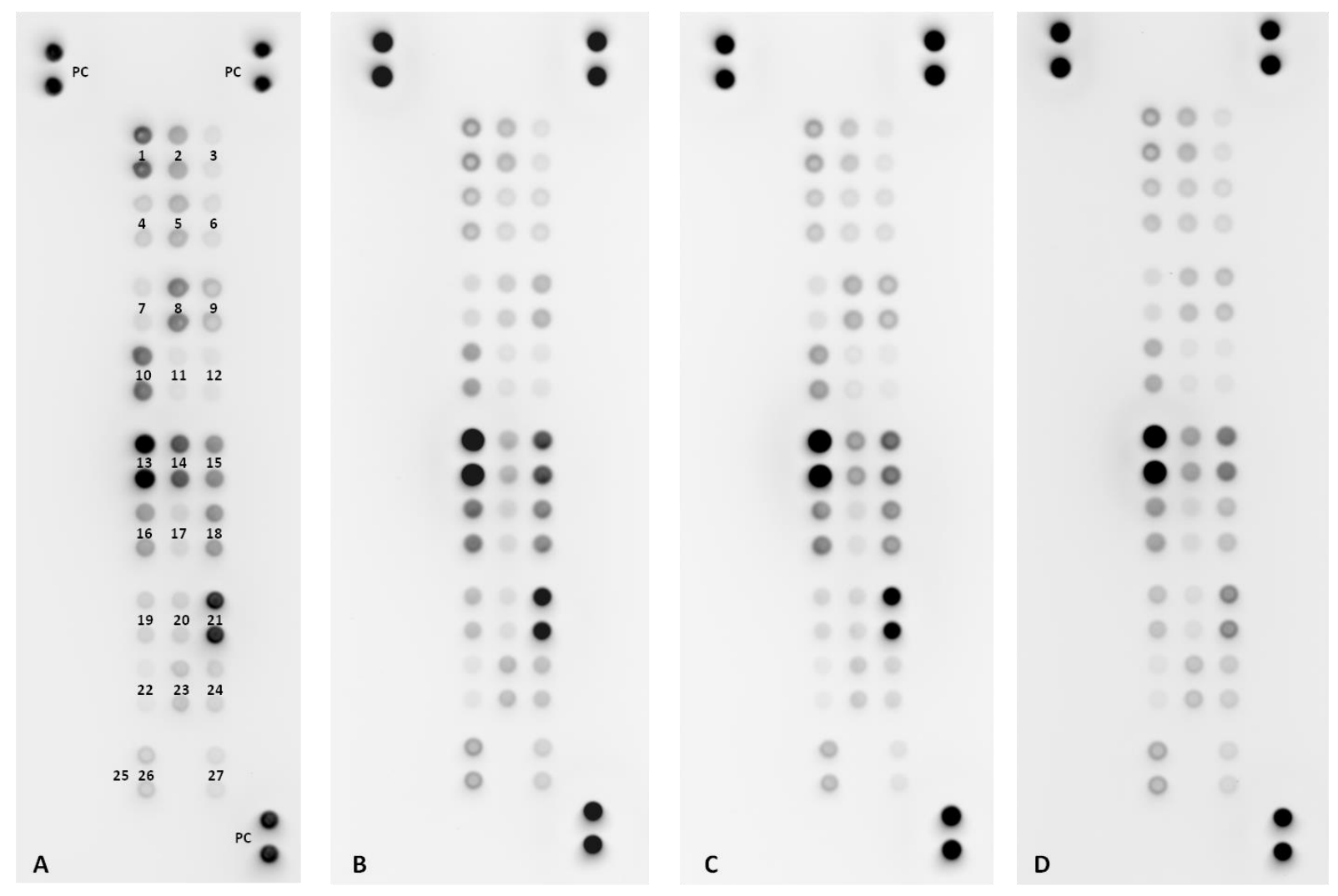

Figure 40: Effect of AP21967- or AP20187-treatment on the phosphorylation status of different MAP kinases in stably transfected HEK293 cells

Cells were cultivated with serum free DMEM medium (16 hours $/ 37^{\circ} \mathrm{C}$ ) and handled as described in the manufacturer's guideline. A: negative control, B: positive control (200 nM PMA/30'), C: AP21967 (500 nM/ 60'), D: AP20187 (100 nM/60'). Positions of different MAP kinases on the array (1. p38 $\alpha$, 2. HSp27, 3. Akt1, 4. p38 $\beta$, 5. JNK1, 6. Akt2, 7. p388, 8. JNK2, 9. Akt3, 10. p38y, 11. JNK3, 12. Akt pan, 13. p53, 14. JNK pan, 15. Crep, 16. p70S6 kinase,

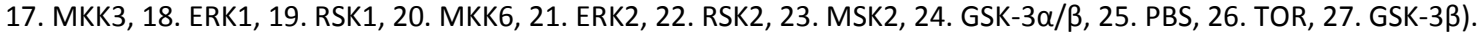




\section{Discussion}

The ant-/agonist-induced internalization of the chemokine receptor and HIV co-receptor CCR5 in the context of receptor phosphorylation has been studied in detail (Olbrich et al., 1999; Kraft et al., 2001). Furthermore, $\beta$-arrestin plays a key role during internalization of CCR5 homo- or hetero-oligomers (Hüttenrauch et al., 2005). The present study adds to these previous investigations the finding that binding of $\beta$-arrestin to the receptor alone and in the absence of ligand-induced phosphorylation and conformational changes of the receptor was sufficient to induce its internalization. In contrast, $\beta$-arrestin translocation to the receptor at the plasma membrane or receptor homodimerization did not result in signaling through MAP kinases.

A separate but related part of this thesis deals with a novel method which allowed to tag and analyzes trafficking of distinct populations of transmembrane proteins. Exemplified by CXCR4 and CCR5, we used the system to quantify constitutive receptor endocytosis and its modulation by receptor ant-/agonists. Furthermore, we used the system to quantify the net recycling rate after ligand-induced internalization and visualized differences in the intracellular localization of internalized and prestored receptors.

\subsection{A biotin-based detection system for the analysis of transmembrane protein trafficking exemplified by internalization and recycling studies on CXCR 4 and CCR5}

$\mathrm{G}$ protein coupled receptors are involved in the signal transduction of various biological stimuli. A complex network for the regulation of GPRC expression at the cellular surface is essential to maintain its proper function. Once expressed on the cell surface, receptors undergo a constant fluctuation induced by constitutive endocytosis and translocation of newly synthesized receptors to the cell membrane. Constitutive endocytosis is mediated by clathrin-dependent or -independent pathways in the absence of receptor agonists (Scarselli \& Donaldson, 2009; Uwada et al., 2014). To counteract the depletion of receptors from the cell membrane, receptors are sequestered and transported back to the membrane (Drake et al., 2006). This equilibrium can be modulated by treatment with receptor agonists. Ligand-receptor complexes undergo rapid internalization mostly mediated by the AP2 adapter complex and clathrin (Signoret et al., 1998). Whereas most of CCR5 is delivered to recycling endosomes to reaccumulate at the cell surface after ligand removal, internalized CXCR4 is mostly sorted for lysosomal degradation by ubiquitination (Signoret et al. 2000; Marchese et al. 2003). This discrepancy in their recycling characteristics between CXCR4 and CCR5 despite their high molecular homology on a structural and functional level signifies them as good model receptors for the investigation of GPCR trafficking in general.

During the years several methods have been established to analyze GPCR trafficking. Among these, fluorochrome-labeled anti-receptor antibodies in combination with flow cytometry are by far the most commonly applied methods (Anselmo et al., 2014). After internalization is triggered by receptor agonists, cells are stained with anti-receptor antibodies and analyzed by flow cytometry. This method allows the quantification of internalized/recycled receptors as compared to unstimulated cells (Mack et al., 1998; Mueller et al., 2002). Furthermore, this method is used to determine the intracellular localization of internalized receptors within the cells by immunofluorecence microscopy (Kershaw et al., 2009). Double immunofluorescence microscopy using dyes which accumulate in specific intracellular compartments (e.g. Lysotracker) allow an even more exact localization of internalized 
receptors (Signoret et al. 2000). Further but less commonly applied methods for the analysis of GPRC trafficking are the quantification of radioactivity during a radioligand uptake assay or antibody feeding. In antibody feeding experiments fluorochrome-labeled anti-receptor antibodies are co-internalized and detected by flow cytometry or immunofluorescence microscopy (ArancibiaCárcamo et al. 2006; Sorkin \& Duex 2010).

When antibodies are being used for receptor detection it is necessary to ensure that antibody binding does not induce receptor internalization on its own or interfere with ligand binding (Signoret \& Marsh, 2000). It is not recommended to use labeled chemokine ligands alternatively since most of them are not receptor specific and fluorochrome labeling may alter their binding affinity (Blanpain et al., 1999; Kershaw et al., 2009).

The methods introduced so far are sufficient to detect rapid changes in receptor expression levels e.g. after ligand stimulation, but they are not applicable to study constitutive receptor internalization in the absence of receptor ligand. In this case the internalization process would be masked by parallel processes such as receptors recycling or translocation of newly synthesized receptors to the plasma membrane. To address this problem we adapted a method for the site-specific labeling of membrane proteins originally described by Alice Ting to establish an assay for the analysis of chemokine receptor trafficking (Howarth \& Ting, 2009). This method may be generally used for studies of other cell surface proteins, as well. The method is based on a 15 amino acid AP-peptide which is enzymatically biotinylated by BirA biotin ligase (Schatz, 1993). In contrast to chemical biotinylation with biotin-XNHS this reaction is highly specific and does not require subsequent cleavage of remaining proteins (Cao et al., 1998; Schläger, 2007).

As described before, the overall expression level of receptors at the cell surface is affected by different receptor cycling mechanisms (constitutive endocytosis, receptor recycling, translocation of new receptors) altogether. For that reason, results which are obtained by flow cytometry using anti-receptor antibodies represent the gross internalization/recycling of the receptor. In contrast, specific receptor biotinylation offers the possibility to quantifiy the net internalization and recycling of a distinct receptor population. Therefore, biotinylated cells were stimulated with receptor agonists and receptor expression was measured with fluorochrome-labeled streptavidin by flow cytometry. The results are not affected by constitutive cycling receptors or translocation of newly sequestered receptors to the plasma membrane. Besides quantification of constitutive and ligand-induced internalization by flow cytometry the method was also suitable to track internalization and recycling of a distinct receptor population without unwanted background signals from prestored receptors, using immunofluorescence microscopy.

In order to detect the whole receptor population expressed within a given cell we generated a monoclonal antibody (YC8) which specifically bound to the AP-peptide and was not affected by prior ligand binding. YC8 binding was not altered by biotinylation or binding of streptavidin, which made YC8 the perfect tool for double immunofluorescence analysis. At the same time it would have been useful to generate another antibody where AP-binding is negatively affected by biotinylation/streptavidin-binding since this would have allowed to quantify the translocation rate of newly synthesized receptors. YC8 may be useful in further studies on the regulation of other AP-tagged transmembrane proteins which still lack specific antibodies (Fredriksson et al., 2003; Tang et al., 2012).

We utilized the biotin/streptavidin system to quantify constitutive internalization of CXCR4 and CCR5. Without agonist induction CXCR4 was internalized from the cell surface at a constant rate of $12.1 \%$ cell surface expressed receptors per hour. Compared to $13.7 \%$ internalization per hour in 
CCR5-expressing cells both endocytosis rates were at a comparable level. Classical antibody staining with YC8 did not reveal any changes of receptor expression due to signal overlap of recycled receptors together with those receptors which were freshly expressed on the cell surface. Previous studies on constitutive endocytosis of transmembrane proteins were done using immunofluorescence or immunoblot images or by flow cytometry using anti-receptor antibodies. Results from these studies (approx. 59 \% internalization after 45 minutes for CXCR4 or approx. $60 \%$ after 1 hour for the prostate-specific membrane antigene) clearly differ from our own results (Liu et al., 1998; Zhang et al., 2004). Recent studies on the constitutive internalization of a serotonin transporter protein using a biotin-based detection system obtained results of $10.8 \%$ internalization per hour, which were more in line with our results (Rahbek-Clemmensen et al., 2014). Especially the discrepancy between the reported constitutive internalization rates of CXCR4, which were obtained by flow cytometry using anti-receptor antibodies, is conspicuous since we observed comparable internalization rates for CXCR4, but in presence of receptor agonist.

Apart from reliable methods for their quantification other functional aspects of constitutive endocytosis have been a topic of recent studies. Mutations of the C-terminal domain of CXCR4 revealed that constitutive and ligand-dependent internalization is modulated by different C-terminal sequence motifs (Marchese \& Benovic, 2001; Futahashi et al., 2007). Furthermore, it is assumed that constitutive receptor internalization is part of the regulatory system regarding the accessibility of chemokines (Coggins et al., 2014). Whereas binding of CXCL12 to CXCR4 induces typical chemokine receptor mediated cell signaling, CXCR7 is utilized as a decoy receptor for the removal of the same ligand CXCL12 by constitutive endocytosis and subsequent degradation, in the absence of activation of signaling pathways (Busillo \& Benovic, 2007; Naumann et al., 2010; Marchese, 2014). To increase efficiency of ligand removal the binding affinity of CXCL12 to CXCR7 is enhanced (Luker et al., 2011). A comparable system was observed for the Duffy antigen receptor D6 and CCR5, where D6 functions as a signaling-incompetent decoy receptor for the chemokine ligand CCL3 (Galliera et al., 2004; Weber et al., 2004).

Despite these facts the detailed mechanisms of constitutive internalization are not fully understood, yet. Besides clathrin-mediated internalization it becomes more and more evident that clathrin-independent mechanisms play also an important role (Mueller et al., 2002; Zhang et al., 2004; Scarselli \& Donaldson, 2009; Uwada et al., 2014). In this context our system is well suited to detect potential alterations of constitutive internalization of CXCR4 and CCR5 after inhibiting the clathrin uptake system.

Furthermore, it is still a matter of debate whether constitutive receptor internalization is merely a consequence of normal turnover of the plasma membrane in a passive manner or whether it is attributed to an equilibrium between an active and inactive form of the receptor where the subpopulation of active receptors have the potential to undergo constitutive internalization (Shinitzky, 1984; Lagane et al., 2005). Our results which showed an almost identical internalization rate of approx. $13 \%$ per hour for both CXCR4 and CCR5 favor the hypothesis of a strictly passive receptor uptake mechanism. To address this question in detail we incubated CCR5 cells with an excess of the inverse receptor antagonist TAK779 and the partial antagonist Met-CCL5 (Baba et al., 1999; Longden et al., 2008). In parallel we tested modulation triggered by the receptor agonist CCL5. TAK779 treatment inhibited constitutive internalization by $2.8 \%$ (10.9 \% per hour with TAK779 vs. $13.7 \%$ without TAK779). Partial antagonist Met-CCL5 accelerated the internalization process (15.6\% per hour) but not as much as the full agonist CCL5 did (9.3\% per minute). The results obtained with TAK779 are in conflict with the hypothesis of passive receptor internalization triggered by membrane fluidity, since binding of an inverse antagonist should not influence the internalization rate. Instead, 
the result favors the hypothesis of basal receptor activity of a receptor subpopulation which triggers constitutive internalization. Binding of the inverse receptor antagonist TAK779 partially inhibits this activity, which then results in reduced internalization.

Previous studies assumed partial antagonism of Met-CCL5 (Olbrich et al., 1999; Longden et al., 2008). However, the detection methods applied were not sensitive enough to reveal minor effects on receptor activities, whereas our results with the improved internalization assay now clearly show the partial antagonism of Met-CCL5 regarding receptor internalization. Studies in CHO cells provide a possible explanation for the agonistic behavior of Met-CCL5. It is hypothesized that an endogenous aminopeptidase is responsible for the cleavage of the $\mathrm{N}$-terminal methionine retransforming Met-CCL5 into the full agonist form CCL5, which results in receptor internalization (Longden et al., 2008). It should also be of interest whether well established CCR5 entry inhibitors in HIV therapy such as maraviroc or vicriviroc affect constitutive receptor internalization, since therapeutics which induce a faster receptor removal from the cell surface without triggering cell signaling should be preferred, because of the depletion of potential viral entry ports (Westby \& van der Ryst, 2005).

In contrast to constitutive GPCR internalization, which came into focus only during recent years, ligand-induced receptor internalization has been studied in detail for more than two decades. In order to quantify ligand-induced internalization and subsequent recycling of CXCR4 and CCR5 we stimulated cells with adequate ligand concentrations. The results obtained with anti-AP antibodies demonstrated receptor internalization of approx. $50 \%$ after 30 minutes for both receptors. Streptavidin staining of BirA-biotinylated receptors showed the same result, thus confirming the validity of the new method. Even though CXCR4 and CCR5 showed an equal internalization rate in quantitative terms, their intracellular processing differs once they have entered the cell. After ligand stimulation primary vesicles, generated by clathrin-dependent or -independent processes, are fused with early endosomes, which catalyze ligand release under mild acidic conditions(Hanyaloglu \& von Zastrow, 2008). At this stage the internalized receptors are sorted into two different cycling pathways (Borroni et al., 2010). CCR5 is preferentially transferred into recycling endosomes and accumulates in the perinuclear area of the cells (Signoret et al. 2000; Pollok-Kopp et al. 2003). From the recycling endosomes CCR5 rapidly recycles back to the cell surface resulting in receptor resensitization (Oppermann, 2004). In contrast, CXCR4 undergoes early ubiquitination after ligand-binding, and this directs CXCR4 into late endosomes/lysosomes where the receptor is degraded (Marchese \& Benovic, 2001; Marchese et al., 2003). Later studies demonstrated that part of CXCR4 receptors are also directed into recycling endosomes depending on the duration of ligand stimulation (Zhang et al., 2004). These findings highlight CXCR4 and CCR5 as interesting model proteins for the study of receptor recycling.

In our studies with anti-AP staining approx. $30 \%$ of CXCR4 and $20 \%$ of CCR5 expression was restored, indicating a higher recycling rate for CXCR4 than for CCR5. The problem of those classical antibody-based methods is that during the recycling phase the results can be obscured by newly synthesized receptors which are translocated to the plasma membrane from internal stores. We used the biotin system to specifically detect the recycling of those receptors which were internalized after ligand stimulation. For those receptor populations no recycling was detected. The apparent lack of recycling in this receptor population could be due to restoration of cell surface expression of the receptor by de novo receptor synthesis or by translocation of prestored receptors to the plasma membrane (Geminder et al., 2001; Scott, 2011). Furthermore, it is known that recycled CCR5 receptors can rapidly reinternalize during prolonged agonist stimulation (Signoret et al. 2000). To prevent receptor reinternalization we added receptor antagonists during the recycling phase to 
facilitate dissociation of bound agonist and furthermore inhibit agonist-binding. TAK779-treated and biotinylated CCR 5 cells showed a significantly enhanced recycling rate as compared to untreated cells and this finding was confirmed by anti-AP staining. These results indicated that rapid reinternalization of recycled receptors was responsible for the lack of recycling. CXCR4 cells showed an identical behavior, yet to a lower degree. When biotinylated CXCR4 and CCR5 receptors were compared, they revealed a significant difference regarding their recycling behavior. Whereas CCR5 receptor recycled back to the plasma membrane, CXCR4 was retained within the cell. These findings correspond to data in the literature underlining that CXCR4 can indeed partially recycle back to the cell surface. Furthermore, the data emphasized the high relevance of receptor reinternalization after ligand stimulation. Differences between biotinylated and anti-AP stained receptors could be partially attributed to the translocation of prestored receptors from internal stores to the plasma membrane during the recycling phase. Overall these results showed that sensitivity of the biotin detection system was well suited to reveal and quantify minor differences in the recycling rate of transmembrane proteins.

The combination of receptor biotinylation and anti-AP staining was also applicable for the analysis of the intracellular distribution of internalized receptors via immunofluorescence microscopy. Unstimulated cells showed a bright ring fluorescence at the cell surface. Signals from anti-AP and streptavidin completely overlapped except for a small intracellular CCR5 population within the cytoplasm, which was only detected by anti-AP staining. According to localization studies with CCR5 in blood cells this intracellular signal probably represented prestored receptors in the secretory apparatus of golgi and ER (Achour et al., 2009; Scott, 2011). After 30 minutes of ligand stimulation the fluorescence at the cell surface disappeared and receptors accumulated in the perinuclear area of the cell. The overlay of both fluorescence signals indicated a higher concentration of biotinylated receptors in the perinuclear region, whereas additional receptor-containing vesicles showed a more disperse distribution. At this stage the highly concentrated vesicles most likely represented internalized CCR5 receptors which were located in transferin-positive recycling endosomes which were targeted for recycling back to the cell surface (Signoret et al. 2000). The more disperse distributed vesicles were presumably identical to prestored receptors in unstimulated cells. 30 minutes after ligand removal and TAK779 treatment biotinylated receptors were no longer present in the perinuclear region but, to some extent, recycled back to the cell surface. Anti-AP stained receptors showed a clear restoration of the ring fluorescence at the plasma membrane without significant reduction of the intracellular signal, which indicated a restoration of receptor cell surface expression from intracellular pools in combination with new receptor biosynthesis going on in parallel. Overall these morphological findings coincided with the results obtained by flow cytometry and data from the literature. Additionally, they revealed a significant contribution of receptor translocation for the reconstitution of receptor expression on the cell surface after ligand stimulation.

Since the internalization and recycling characteristics of many GPCR are determined by sequence motifs which are contained within their carboxyl terminus, we decided to create a CXCR4-CCR5 $5_{C T}$ chimeric receptor by substituting the entire C-terminus of CXCR4 with the equivalent sequence of CCR5 (X4 $\Delta$ (305-352);I R5 (306-352)) (Signoret et al., 1998; Lagane et al., 2005). We thereby addressed whether we could reconstruct the typical recycling behavior and the intracellular distribution of CCR5 by transferring its C-terminal region to CXCR4. A reverse approach with the substitution of the C-terminus of CCR5 for the C-terminal region of CXCR4 fails because of improper 
protein folding which results in low cell surface expression of the chimeric receptor (Venkatesan et al., 2001).

The chimeric receptor was expressed at sufficient expression levels and was functionally intact as demonstrated by ligand-induced $\mathrm{N}$-acetyl- $\beta$-D-glucosaminidase release. Compared to CXCR4 WT the $\mathrm{EC}_{50}$-value of enzyme release was slightly shifted to higher values ( $\mathrm{nM}$ vs. $29 \mathrm{nM}$ ), whereas the $E_{\max }$-value was unaffected.

In the absence of agonist the receptor showed a constant internalization rate of $12.1 \%$ per hour, which was identical to the constitutive internalization rate of CXCR4 WT. It was reported that a $S(E / D) S$ motif at position 344 to 346 in the C-terminal region of CXCR4 is crucial for constitutive endocytosis (Futahashi et al., 2007). Due to the substitution with the C-terminal region of CCR5 the motif was changed to GEQ. The high similarity to the original motif (glutamic acid flanked by two neutral amino acids) may explain why constitutive internalization of the chimeric receptor was very similar as compared to CXCR4 WT.

After stimulation with saturating concentrations of CXCL12, both AP-stained and biotinylated CXCR4-CCR5 $_{\text {CT }}$ receptors showed restricted receptor internalization compared to CXCR4 WT, which may be attributed to the lower efficacy of CXCR4-CCR5 $5_{C T}$. Other studies demonstrated that besides the $S(E / D) S$ motif, which is crucial for constitutive internalization, several other residues on CXCR4 are crucial for the ligand-dependent receptor internalization (Futahashi et al., 2007). Mutation of some of these motifs may contribute to the diminished ligand-induced receptor internalization. The intracellular distribution, visualized by immunofluorescence microscopy, resembled internalized CXCR4 WT receptors. Furthermore it was reported that a C-terminal motif of CXCR4 is crucial for ubiquitination and sorting for the degradative pathway (Marchese \& Benovic, 2001). According to our results other areas which were not located in the receptor $\mathrm{C}$-terminus were at least as important as the C-terminal motif for lysosomal sorting.

The recycling rate of approx. $20 \%$ was on a comparable level to WT receptors. This result underlined the hypothesis that restoration of membrane expressed receptors, measured by anti-AP staining, after ligand stimulation was attributed to a passive transport of receptors from the cytoplasm to the cell surface. In accordance to CXCR4 and CCR5 biotinylated and non antagonist-treated receptors showed no recycling. To ensure that this result was not affected by rapid reinternalization, as demonstrated for CXCR4 and CCR5, these experiments should be repeated in presence of receptor antagonist.

In summary, we demonstrated that the specific biotinylation of BirA biotin ligase could be utilized for in vivo studies of different transmembrane proteins. Exemplified by CXCR4, CCR5 and a corresponding chimera we quantified the constitutive endocytosis rate in the absence of receptor antagonist for the first time in a reliable manner. Furthermore, we demonstrated that the classical antibody-based detection system was not fully suitable for the quantification of receptor recycling after ligand stimulation, since the results could be altered by translocation of cytoplasmatic receptors and rapid receptor reinternalization. Additionally, we determined the intracellular location of internalized receptors after ligand treatment, which was in close proximity to prestored receptors but still separated in a compartment of high density. 


\subsection{Cellular response on ligand-independent translocation of $\beta$-arrestin 2 to the receptor and the role of receptor homodimerization for receptor trafficking}

Chemokine receptors including CXCR4 and CCR5, belong to the family of seven-transmembrane receptors also known as $\mathrm{G}$ protein-coupled receptors (GPCRs).The classical model of GPCR signaling is based on the interactions between heterotrimeric $\mathrm{G}$ proteins after agonist-mediated activation of the receptor (Janetopoulos, Jin, \& Devreotes, 2001). The interaction is accompanied by G protein activation and a subsequent dissociation into $\alpha$ and $\beta \gamma$-subunit, each activating different signaling pathways. Among other effects this results in intracellular calcium mobilization (Gilman \& Casey, 1988) and MAP kinase activation (Goldsmith \& Dhanasekaran, 2007). Regulation of GPCR signaling is achieved by various mechanisms which involve phosphorylation of the C-terminal receptor region. One of the main desensitization mechanisms is GRK ( $G$ protein-coupled receptor kinase) -mediated receptor phosphorylation followed by binding of $\beta$-arrestin proteins which inhibit rebinding of $G$ proteins by steric hindrance (Lefkowitz, 1998). $\beta$-Arrestin binding also mediates receptor endocytosis via clathrin coated pits, followed by translocation of the receptor complex into distinct intracellular compartments (Laporte et al., 1999). In this context it was shown that $\beta$-arrestin also mediates the ubiquitination of some receptors and this is crucial for their internalization (Pickart, 2001; Shenoy et al., 2001). Findings which suggested that $\beta$-arrestin is responsible for the G-proteinindependent activation of signaling proteins (Luttrell, 1999) created the base for the hypothesis of $\beta$-arrestin-mediated signaling (Lefkowitz \& Shenoy, 2005; Shukla et al., 2012). An overview of the major $\beta$-arrestin functions during GPCR signaling is shown in Figure 41. In order to clearly dissect the role of $\beta$-arrestin for signaling and trafficking of CXCR4 and CCR5 in the absence of ligand binding we utilized a chemical-induced heterodimerization system which consisted of three components. The FK506-binding protein (FKBP12), the FKBP rapamycin-binding domain from the protein mTOR (FRB) and the AP21967 rapamycin analog (rapalog) (Chen et al., 1995; Bayle et al., 2006; Leone et al., 2006; Edwards \& Wandless, 2007). In order to use the non-immunosuppressive rapalog AP21967, which can not bind native WT FRB, a mutated version of FRB was used (ARIAD, 2002; Clontech Laboratories, 2008). By fusing FKBP12 (DmrA) and FRB (DmrC) either to the C-terminus of CXCR4/CCR5 or $\beta$-arrestin 2 we achieved a ligand- and G protein-independent translocation of $\beta$-arrestin 2 to the receptor after treatment with AP21967. In contrast to PTX-based inhibition of G proteins, which leads to inhibition of both $\beta$-arrestin- and G protein-dependent signaling altogether (Denis et al., 2012), this method allowed a clear discrimination between $\beta$-arrestin- and $G$ protein-mediated signaling. 

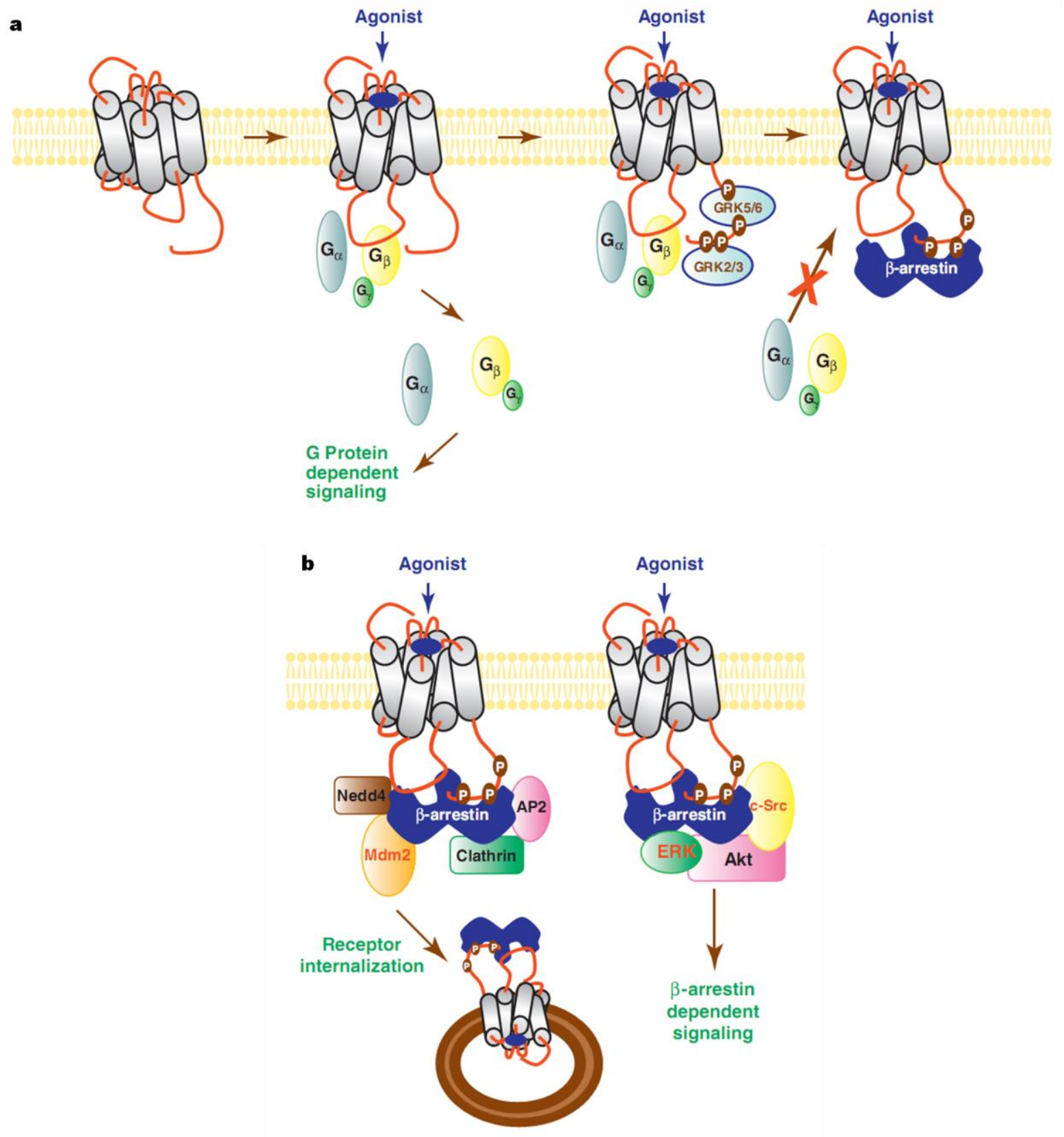

Figure 41: Overview of $\beta$-arrestin-mediated effects during GPCR signaling and trafficking

a) In the classical model of GPCR signaling receptor activation is induced by agonist binding, which leads to a conformational change of the receptor. The conformational change allows binding and activation of heterotrimeric $\mathrm{G}$ proteins which subsequently dissociate into $\alpha$ and $\beta \gamma$ subunit and these mediate $G$ protein dependent downstream signaling. C-terminal serine/threonine residues of the receptor are phosphorylated by GRKs and facilitate $\beta$-arrestin binding. Binding of $\beta$-arrestin to the receptor inhibits rebinding of $G$ proteins thus resulting in receptor desensitization. c) Besides desensitization, $\beta$-arrestin acts as a scaffold protein for various proteins which are crucial for receptor internalization (AP2) and ubiquitination (Mdm2 and Nedd4). Furthermore, $\beta$-arrestin interacts with Tyr kinases such as ERK or c-Src which are involved in G protein independent signaling. Figure modified from Shukla et al. 2012. 
To guarantee the stable expression of modified proteins cells were tested by flow cytometry and immunoblotting. The size shift (approx. $11 \mathrm{kDa}$ ) compared to WT proteins demonstrated the positive modification of both receptors and $\beta$-arrestin with the corresponding Dmr domains. Treatment of these cells with AP21967 led to accumulation of $\beta$-arrestin 2 in the plasma membrane fractions as demonstrated by sucrose gradient centrifugation of cell lysates and subsequent immunoblotting. The resulting immunoblot showed the size represented by the fusion protein (approx. $55 \mathrm{kDa}$ ) and a second band of approx. $48 \mathrm{kDa}$ which was only visible in ultracentrifuged samples. The size corresponded to the molecular weight of unmodified $\beta$-arrestin 2. It remains at presence unclear whether ultracentrifugation promoted dissociation of the Dmr domain or if endogenous arrestin is concentrated in the membrane fraction of the sucrose gradient.

Translocation of $\beta$-arrestin 2 to the cell membrane was concentration- and time-dependent and reached an optimal level after 2 hours of treatment with $0.1 \mu \mathrm{M}$ AP21967. Cytosolic fractions showed no alterations in $\beta$-arrestin 2 expression compared to untreated cells which suggested that $\beta$-arrestin-DmrC is expressed in large excess as compared to receptor-DmrA fusion partners at the plasma membrane. This would lead to an imbalance between arrestin and receptor resulting in a lack of potential binding partners for the AP21967/BArr-DmrC complex.

The result of time- and dose-dependent $\beta$-arrestin translocation to the cell membrane after AP21967 treatment was independently confirmed by immunofluorescence microscopy. With increasing AP21967 concentration and time the homogenously distributed arrestin was translocated from the cytoplasm to the cell membrane as visualized by increasing membrane fluorescence. Quantitative analysis after image processing revealed that the relative fluorescence in the cell membrane area of AP21967-treated cells was significantly higher as compared to untreated cells. However, significant fluorescence remained in the cytoplasmic area and this result underlined once again that only a minor portion of the transfected BArr-DmrC translocated to the cell membrane, whereas the rest of the protein remained cytosolic.

In the past it was hypothesized that upon GPCR-binding, activated $\beta$-arrestin undergoes a conformational change allowing $\beta$-arrestin to act as a scaffolding protein for interacting proteins(Gurevich \& Gurevich, 2004). It was assumed that $\beta$-arrestins exist in an inactive state and are transformed into an active form after binding to the phosphorylated residues of the GPCR (Gurevich \& Benovics, 1993). This model was challenged by studies showing that $\beta$-arrestin even in its inactive state interacts and subsequently activates the MAP kinase JNK3 (Song et al., 2006). In contrast, activation of ERK 1/2 depends on the binding to previously activated arrestins (Coffa et al., 2011). It is still not understood which $\beta$-arrestin-mediated cellular functions require the transition of $\beta$-arrestins from an inactive to an active state after binding to a phosphorylated GPCR. We utilized the AP21967 dimer system to test whether translocation of an inactive form of $\beta$-arrestin to the receptor alone is sufficient for receptor desensitization, receptor internalization and $\beta$-arrestinmediated signaling.

In order to test the ability of $\beta$-arrestin 2 to dampen ligand-induced calcium release we supertransfected stably transfected Rec-DmrA and Rec-DmrA/BArr-DmrC cells with a bicistronic vector carrying a chimeric version of $G_{\alpha q o}$. Cellular expression of a $G_{\alpha q}$-subunit enabled the PLC-mediated calcium release from the ER in a cellular background which lacks the appropriate G proteins (Ku et al., 1995). Additionally, the GFP marker allowed selecting for positively transfected cells by gating on GFP fluorescence during flow cytometry. After ligand stimulation we observed an increased calcium response in GFP-expressing cells which is attributed to the expression of $G_{\alpha q}$ since 
HEK293 cells do not provide the optimal G protein repertoire to transduce chemokine receptor signals into those cells (Atwood et al., 2011).

To test the potential of $\beta$-arrestin to attenuate ligand-induced calcium release Rec-DmrA and Rec-DmrA/BArr-DmrC cells were preincubated with AP21967 prior to ligand stimulation. Only in Rec-DmrA/BArr-DmrC expressing cells AP21967-induced translocation of $\beta$-arrestin-DmrC fully blocked the subsequent ligand-induced calcium response. This result confirmed the classical model of $\beta$-arrestin binding to the activated GPCR which results in desensitization by steric hindrance of G protein binding (Shukla et al., 2012). Binding to phosphorylated residues of the GPCR and an activation-induced conformational change was not necessary for the desensitizing effect of $\beta$-arrestin. One may argue that the desensitizing effect of AP21967 treatment could simply be due to receptor internalization and depletion of ligand binding sites from the cell surface. However, since stably transfected HEK cells expressed receptors in large excess, even reduction by $80 \%$ would not have impaired the signaling capacity of theses cell noticeably.

Apart from desensitization, GPCR signaling is also down-regulated by ligand-induced receptor internalization (Pierce et al., 2002). After $\beta$-arrestin binding to phosphorylated receptors $\beta$-arrestin interacts with the vesicle-forming protein clathrin and the $\beta_{2}$-subunit of the adaptor protein AP2, which mediates receptor internalization via early endosomes (Kim \& Benovic 2002; Kang et al. 2013). $\beta$-Arrestin 2 activation via binding to phosphorylated receptors was previously reported to be crucial for receptor internalization via AP2 (Gurevich \& Gurevich, 2014). Here we tested whether $\beta$-arrestin 2 translocation to the receptor is sufficient to induce receptor internalization in the absence of ligand stimulation.

In Rec-DmrA/BArr-DmrC expressing cell lines AP21967 treatment induced CXCR4 and CCR5 internalization to a comparable degree as ligand-induced internalization. Cell lines expressing only Rec-DmrA in the absence of $\beta$ Arr-DmrC did not undergo AP21967-induced receptor internalization. Additionally in these cells receptors were less efficiently internalized after ligand-stimulation as compared to $\beta$-arrestin 2 overexpressing cells. This underlined the importance of $\beta$-arrestin during the internalization process. The internalization kinetics in AP21967 treated cells was delayed compared to ligand-stimulated cells. This result was not unexpected since chemical-induced translocation of $\beta$-arrestin 2 to the cell membrane was not detectable prior to 30 minutes of AP21967 treatment. These results clearly showed that transition into an activated conformation was not necessary for $\beta$-arrestin-mediated receptor internalization, which stands in a direct contrast to previous reports postulating that binding to the phosphorylated receptor and subsequent conformational changes are crucial for the $\beta$-arrestin binding to $\beta_{2}$-adaptin and clathrin heavy chain (Kim \& Benovic 2002).

The results obtained by flow cytometry were confirmed by immunofluorescence microscopy of AP21967-treated cells. With increasing time the membrane expression of CXCR4 was progressively reduced, whereas the intracellular fluorescence increased. In ligand-stimulated CCR5-expressing cells internalized receptors are located primarily in recycling endosomes in the perinuclear area, whereas CXCR4 show a diffuse redistribution in form of small intracellular vesicles representing lysosomes (Orsini et al. 1999; Signoret et al. 2000; Marchese \& Benovic 2001). Interestingly, AP21967 treament mimicked the same intracellular distribution of internalized CXCR4 and CCR5 receptors as induced by their natural ligands CCL5 and CXCL12. This can may be explained with the arrestin-mediated ubiquitination of CXCR4 by the unbiquitin ligase AIP4, which targets the internalized receptor towards the proteosomal degradation machinery (Marchese et al., 2003; Kommaddi \& Shenoy, 2013). In parallel, truncation mutants of the C-terminal domain of CCR5 led to the identification of 
four amino acids which are crucial for receptor recycling independent of the phosphorylation status of the receptor (Delhaye et al., 2007). These results taken together suggest that ligand-induced and GRK-catalyzed receptor phosphorylation is not essential for receptor targeting towards either recycling or degradation. Instead it seems likely that the information for distinct receptor trafficking is encoded in the C-terminal region of either CXCR4 or CCR5 in form of either recycling or ubiquitination motifs which can be triggered or utilized by arrestin-related proteins. Activation of these motifs causes the activated receptors to follow a predetermined route back to the cell surface for restimulation or into proteasomes for degradation.

We also checked by immunofluorescence whether $\beta$-arrestin binds to the internalized receptor or whether this complex dissociates during receptor trafficking. Immunofluorescence microscopy in Rec-DmrA/ $\beta$ Arr-DmrC expressing cells revealed that in both cell lines $\beta$-arrestin is recruited to the receptor following AP21967 treatment, evident by brighter membrane fluorescence, but did not follow the sequestered receptor during intracellular trafficking. Studies regarding the binding affinity of $\beta$-arrestin towards phosphorylated receptor residues demonstrate that $\beta$-arrestin is cointernalized with receptors such as $A T_{1 A} R, V_{2} R$ or $N K_{1} R$, which express Ser and Thr clusters in the C-terminal region (class B GPCR) (Oakley et al., 2000; Oakley et al.,, 2001). It is assumed that accumulation of negatively charged phospho-serine and -threonine residues causes high affinity binding of $\beta$-arrestin to these receptors and thereby stabilizes complexes between these two proteins. Receptors with only single Ser and Thr residues (class A GPCR) are also internalized by $\beta$-arrestin-mediated AP2 binding, but $\beta$-arrestin quickly detaches from the receptor due to the lack of tight binding to phosphorylated residues (Marchese et al., 2010). Since receptors are not phosphorylated during AP21967 treatment an additional binding between receptor and $\beta$-arrestin apart from Dmr-mediated binding could not be expected. Thus, binding of $\beta$-arrestin followed by fast detachment induced by the lack of phosphorylated residues is likely.

Besides its role during receptor desensitization and internalization $\beta$-arrestin can also act as a signal transducer for $G$ protein independent signaling. According to the traditional model of G protein-mediated ERK activation inactive ERK exists in a signal complex together with Raf and MEK (Chang et al., 2003; Eishingdrelo \& Kongsamut, 2013). Raf activates the downstream protein kinase MEK by phosphorylation which facilitates ERK activation (Chang et al., 2003). Studies with $A T_{1 A} R$ demonstrate that $\beta$-arrestin acts as a scaffold protein for this signal complex and that prolonged binding of all three partners to $\beta$-arrestin results in enhanced ERK phosphorylation (Luttrell et al., 2001). This finding supported an alternative model of $G$ protein independent but $\beta$-arrestin-mediated signaling. Cells expressing either a mutated form of the $\beta_{2} A R$ receptor, which does not bind $G$ proteins, or were treated with the $G_{\alpha}$ inhibitor PTX still mounted a detectable ERK response (Shenoy et al., 2006). Due to the fact that PTX treatment does not inhibit all G proteins and receptor mutations may also affect other cell functions we checked for $\beta$-arrestin-mediated ERK activation in the absence of ligand stimulation utilizing the AP21967 dimer system (Mangmool \& Kurose, 2011). CCR5-DmA/BArr-DmrC or CCR5-DmrA expressing cells were treated either with CCL5 or AP21967 and checked for phosphorylated ERK $1 / 2$ by immunoblotting. In both cell lines ERK phosphorylation was detected after five minutes of CCL5 stimulation, which was abolished by PTX pretreatment. This effect was more prominent in cells lacking arrestin overexpression. A possible explanation might be a disturbed ratio between $\beta$-arrestin and other ERK-activating proteins such as Raf and MEK. Since it was reported that $\beta$-arrestin, Raf and MEK form a complex even in an inactive state it is possible that arrestin overexpression led to a lack of binding partners to form a functional ERK-activating complex (Chang et al., 2003; Eishingdrelo \& Kongsamut, 2013). Although we observed a CCL5-induced ERK 
phosphorylation, AP21067 treatment on its own did not result in ERK phosphorylation. Since $\beta$-arrestin-mediated ERK phosphorylation proceeds with slower kinetics we tested additional (later) time points with no success (Sudha K Shenoy et al., 2006).

A possible explanation for the absent ERK phosphorylation is lack of receptor phosphorylation which is necessary for $\beta$-arrestin activation. Previous studies on $\beta$-arrestin-mediated ERK activation were done using receptor mutants which cannot bind to $G$ proteins after ligand activation but are still phosphorylated by GRKs resulting in subsequent $\beta$-arrestin activation. Therefore our result indicated that the conformational change of $\beta$-arrestin, after its activation, is crucial for the $\beta$-arrestin-mediated ERK activation. Further studies confirm a weak binding of ERK to inactive $\beta$ arrestin which is strengthened after arrestin activation (Gurevich \& Gurevich, 2004). The conformational change of $\beta$-arrestin after its activation makes it a better substrate for MEK phosphorylation, which results in higher ERK phosphorylation (Coffa et al., 2011).

To address the question whether the defect in ERK phosphorylation is attributed to the lack of $\beta$-arrestin activation it would be interesting to test whether translocation of a constitutively active $\beta$-arrestin variant to the receptor induces a robust ERK phosphorylation (Gray et al., 2003). Such a constitutive $\beta$-arrestin with enhanced receptor binding in the absence of ligand-induced phosphorylation is available in form of the $\beta$-arrestin-1 R169E mutant with disrupted polar core (Penn et al., 2001). Furthermore, it should be studied whether AP21967 treatment and the resulting $\beta$-arrestin translocation to the receptor induces JNK3 phosphorylation as it was reported that JNK3 binds to $\beta$-arrestin even in its inactive form (Miller et al., 2001; Gurevich \& Gurevich, 2004). We already gained a rough overview of the phosphorylation status of many players of different signal pathways, including JNK3, using a commercial phospho-kinase array. However, neither ligand nor AP21967 treatment led to significant changes of the phosphorylation status of the tested proteins. A detailed analysis of the phosphorylation status of JNK3 after AP21967 treatment remains to be studied.

Another recent concept of $\beta$-arrestin-mediated signaling relates to the concept of biased signaling. According to this concept binding of biased receptor ant-/agonists stabilize a particular receptor conformation which favours the activation of either $G$ protein or $\beta$-arrestin-mediated signaling pathways (Reiter et al., 2012). Since $\beta$-arrestin is a multifunctional adaptor protein which interacts with various proteins, including protein kinases, it can be seen as a central regulator of cell signaling and trafficking (Xiao et al., 2007). It was reported that the $\beta$-blocker carvedilol, a weak $\beta$-arrestin biased agonist which binds to $\beta_{1}$ and $\beta_{2}$ adrenergic receptors, mediates transactivation of the epidermal growth factor receptor and $\mathrm{G}$ protein independent ERK phosphorylation, which is assumed to contribute to cardioprotection (Noma et al., 2007; Wisler et al., 2007; Reiter et al., 2012). In parallel it was reported that binding of the non biased ligand isoproterenol to the same receptors causes cardiotoxicity (Bristow, 2000; Lohse et al., 2003). This form of biased signaling was explained by phosphorylation of the receptor $\mathrm{C}$-terminus by different GRKs. Carvedilol induces phosphorylation only at GRK6 specific sites, whereas isoproterenol cause phosphorylation at both GRK2 and GRK6 sites (Wisler et al., 2014). Furthermore it was demonstrated that these different phosphorylation patterns are required for either receptor desensitization and internalization (GRK2/3) or $\beta$-arrestin mediated ERK activation (GRK5/6) (Kara et al., 2006; Zidar et al., 2009). Transferring these results to our own findings it would be interesting to see whether overexpression of GRK6 leads to partial ERK activation after AP21967 treatment, thus mimicking a form of $\beta$-arrestin biased signaling.

The model of biased signaling has interesting implications for the cell surface regulation of HIV co receptors CXCR4 and CCR5. Our results showed that $\beta$-arrestin mediates receptor desensitization and internalization, but did not result in noticeable cellular signaling. The results suggest that 
$\beta$-arrestin-biased ligands for CXCR4 and CCR5 may induce receptor internalization and thereby removal of HIV entry ports from the cell surface without activating detrimental cellular responses.

The classical concept of chemokine-induced receptor activation consists of monomeric chemokines binding to monomeric receptors which subsequently induces a cellular response (Rajarathnam et al., 1994). During recent years this concept was more and more challenged due to accumulation of studies which demonstrate that GPCRs indeed form hetero- or homo-dimers or even multimers (Milligan \& Bouvier, 2005; Pin et al., 2007; Ferré et al., 2010). The constitutive dimerization of GPCRs, especially class C GPCRs, is meanwhile well accepted (Kniazeff et al., 2011). Although GPCRs exist in a large variety to interact with all possible kinds of ligands the model of receptor dimerization increases the number of potential interaction partners even more following the principle of allosterism (Breitwieser, 2004). Allosteric interactions describe the process where binding of a compound to a different site than the active binding site induces a conformational or activity change, respectively (Ferré et al., 2014). $G A B A_{B}$ receptors in a dimeric complex, where the agonists binds specifically at the $G A B A_{B 1} R$, signal via $G$ proteins related to the $G_{A B A_{B 2} R}$ (Robbins et al., 2001). Nonetheless the model of monomeric receptor signaling is still valid, because it was demonstrated that several GPCRs are able to activate G proteins effectively in a strictly monomeric form (Whorton et al., 2007; Kuszak et al., 2009). Currently it is still a matter of debate whether ligand-binding affects receptor dimerization. Early reports postulated that CXCL12 binding to CXCR4 forces the receptor into a homodimeric form were challenged by results showing that the constitutive CXCR4 dimer is totally unaffected by CXCL12 (Babcock et. al., 2003; Milligan, 2004). Analysis of CCR5 dimers also were reported to influence ligand binding (Babcock et al., 2003; Milligan, 2004). A research group which postulated a ligand-induced homodimerization of CCR2, CXCR4 and CCR5 additionally hypothesized the subsequent activation of the JAK/STAT pathway as a consequence of this dimerization(Mellado et al. 2001b). According to these authors the homodimerization induces a JAKdependent receptor phosphorylation of the receptor leading to a recruitment of STAT proteins to the receptor followed by their activation (Mellado et al. 2001a). This concept would imply that ligandinduced receptor homodimerization would facilitate $G$ protein independent JAK/STAT activation followed by STAT-induced gene expression (Mellado et al. 2001b).

To test the hypothesis that receptor homodimerization can induce $\mathrm{G}$ protein independent receptor signaling we utilized the Dmr system in combination with the dimerizing agent AP20187. Hereby the DmrA domains of two receptors were bound by AP20187 which brought two receptors in close proximity, thus mimicking ligand-induced receptor homodimerization. We incubated Rec-DmrA expressing cells with AP20187 and tested for cellular responses. In contrast to previous studies receptor homodimerization induced by AP20187 was neither sufficient to induce calcium release nor to mediate ERK phosphorylation. Receptor homodimerization did not lead to receptor internalization on its own. We observed significantly enhanced ligand-induced receptor internalization after pretreatment with AP20187. This effect was present in CXCR4- and CCR5-expressing cell lines. The internalization rate was overall higher in $\beta$-arrestin overexpressing cell lines, underlining once again the crucial role of arrestin for receptor internalization.

Even though it had been reported that receptors may be preferentially expressed as dimers or forced into a dimeric state by agonist binding, the relevance for receptor trafficking and internalization is poorly understood (Milligan, 2004; Terrillon \& Bouvier, 2004b). Although we did not analyzed JAK/STAT activation after receptor homodimerization our results showed that receptor homodimerization is not sufficient to promote calcium release or ERK activation. However we did 
observe an increased ligand-induced uptake of receptor homodimers by the endocytic machinery indicating a potential preference for dimeric structures compared to monomers.

It should be noted, that we did not positively demonstrate that AP20187 indeed induced CXCR4/CCR5 homodimerization. This could be experimentally addressed using FRET or BRET technology (Angers et al., 2000; Kraft et al., 2001; Floyd et al., 2003).

In summary, our results underscore the versatility of $\beta$-arrestin during chemokine receptor trafficking. $\beta$-arrestin provided fast receptor desensitization after recruitment to the receptor C-terminus, without being activated through previous binding to phosphorylated residues. Additionally, arrestin binding was sufficient to induce $\mathrm{G}$ protein independent receptor internalization, which was on a comparable level to ligand-induced internalization. Furthermore, the intracellular distribution of receptors after $\beta$-arrestin-induced internalization mimics the distribution pattern after ligand-induced internalization. These results suggest that $\mathrm{C}$-terminal receptor motifs and arrestin associated proteins are at least partially responsible for the different intracellular fates of receptors. Whereas $\beta$-arrestin played a key role for receptor desensitization and internalization it did not mediate ERK $1 / 2$ phosphorylation. Receptor homodimerization was not sufficient to activate cell signaling on its own, but it enhanced ligand-induced receptor internalization.

\subsection{Conclusion and Outlook}

The results obtained in this work contribute to the understanding of GPCR trafficking in many ways. We established an improved method for the analysis of constitutive and ligand-induced receptor internalization which is generally applicable to the study of many transmembrane proteins. It allows studying receptor internalization/recycling with enhanced sensitivity even in cases where receptor-specific antibodies are lacking. Exemplified by CXCR4 and CCR5 receptors we quantified the rate of constitutive internalization and its modification by different ant-/agonists. A useful complement for this system would be the creation of a biotin/streptavidin affected antibody to provide the possibility to quantify the net recycling rate of internalized receptors.

The AP21967- or AP20187-inducible dimerization system revealed the importance of $\beta$-arrestin 2 especially for receptor internalization and determination of the intracellular fate of internalized receptors. Regarding the ability to mediate ERK $1 / 2$ phosphorylation it would be interesting to study whether translocation of a constitutively active arrestin variant to the receptor would have the potential to mediate ERK $1 / 2$ phosphorylation. GRK overexpression may also provide the possibility to activate translocated $\beta$-arrestin, which may result in activation of MAP kinases. Since it was reported that MAP kinases such as JNK3 are activated by $\beta$-arrestin even in its inactive form analysis of the phosphorylation state of JNK3 after AP21967-induced $\beta$-arrestin 2 translocation to the receptor would be interesting. Furthermore, a comparison of $\beta$-arrestin $1 / 2$ isoform-mediated effects would be interesting, since it was reported that $\beta$-arrestin 1 and 2 influence receptor trafficking in a divergent manner. 


\section{Bibliography}

Achour, L., Scott, M. G. H., Shirvani, H., Thuret, A., Bismuth, G., Labbé-Jullié, C., \& Marullo, S. (2009). CD4-CCR5 interaction in intracellular compartments contributes to receptor expression at the cell surface. Blood, 113, 1938-47.

Agarwal, U., Ghalayini, W., Dong, F., Weber, K., Zou, Y.-R., Rabbany, S. Y., Rafii, S., \& Penn, M. S. (2010). Role of cardiac myocyte CXCR4 expression in development and left ventricular remodeling after acute myocardial infarction. Circulation Research, 107, 667-76.

Alkhatib, G. (2010). The biology of CCR5 and CXCR4. Current Opinion in HIV and AIDS, 4, 96-103.

Allen, S. J., Crown, S. E., \& Handel, T. M. (2007). Chemokine: receptor structure, interactions, and antagonism. Annual Review of Immunology, 25, 787-820.

Andres, P. G., Beck, P. L., Mizoguchi, E., Mizoguchi, A., Bhan, A. K., Dawson, T., Kuziel, W. A., Maeda, N., Macdermott, R. P., Podolsky, D. K., \& Reinecker, H. (2000). Mice with a selective deletion of the CC chemokine receptors 5 or 2 are protected from dextran sodium sulfatemediated colitis: lack of CC chemokine receptor 5 expression results in a NK1.1+ lymphocyteassociated Th2-type immune response in the intestine. Journal of Immunology, 164, 6303-6312

Angers, S., Salahpour, A., Joly, E., Hilairet, S., Chelsky, D., Dennis, M., \& Bouvier, M. (2000). Detection of beta 2-adrenergic receptor dimerization in living cells using bioluminescence resonance energy transfer (BRET). Proceedings of the National Academy of Sciences, 97, 3684-9.

Anselmo, A., Mazzon, C., Borroni, E. M., Bonecchi, R., Graham, G. J., \& Locati, M. (2014). Flow cytometry applications for the analysis of chemokine receptor expression and function. Cytometry. Part A : Journal of the International Society for Analytical Cytology, 85, 292-301.

Appay, V., Brown, A., Cribbes, S., Randle, E., \& Czaplewski, L. G. (1999). Aggregation of RANTES is responsible for its inflammatory properties. Characterization of nonaggregating, noninflammatory RANTES mutants. The Journal of Biological Chemistry, 274, 27505-27512.

Arancibia-Cárcamo, I. L., Fairfax, B. P., Moss, S. J., \& Kittler, J. T. (2006). Studying the Localization , Surface Stability and Endocytosis of Neurotransmitter Receptors by Antibody Labeling and Biotinylation Approaches. In J. T. Kittler \& S. J. Moss (Eds.), The Dynamic Synapse: Molecular Methods in lonotropic Receptor Biology. CRC Press.

ARIAD. (2002). ARGENT ${ }^{\mathrm{TM}}$ Regulated Heterodimerization Kit, Manual, 1-15.

Arshavsky, V. Y., Lamb, T. D., \& Pugh, E. N. (2002). G proteins and phototransduction. Annual Review of Physiology, 64, 153-187.

Attramadal, H., Arriza, J. L., Aoki, C., Dawson, T. M., Codina, J., Kwatra, M. M., Snyder, S. H., Caron, M. G., \& Lefkowitz, R. J. (1992). Beta-arrestin2, a novel member of the arrestin/beta-arrestin gene family. The Journal of Biological Chemistry, 267, 17882-90. 
Atwood, B. K., Lopez, J., Wager-Miller, J., Mackie, K., \& Straiker, A. (2011). Expression of G proteincoupled receptors and related proteins in HEK293, AtT20, BV2, and N18 cell lines as revealed by microarray analysis. BMC Genomics, 12, 1-14.

Baba, M., Nishimura, O., Kanzaki, N., Okamoto, M., Sawada, H., lizawa, Y., Shiraishi, M., Aramaki, Y., Okonogi, K., Ogawa, Y., Meguro, K., \& Fujino, M. (1999). A small-molecule, nonpeptide CCR5 antagonist with highly potent and selective anti-HIV-1 activity. Proceedings of the National Academy of Sciences, 96, 5698-703.

Babcock, G. J., Farzan, M., \& Sodroski, J. (2003). Ligand-independent dimerization of CXCR4, a principal HIV-1 coreceptor. The Journal of Biological Chemistry, 278, 3378-85.

Baker, J. G., \& Hill, S. J. (2007). Multiple GPCR conformations and signalling pathways: implications for antagonist affinity estimates. Trends in Pharmacological Sciences, 28, 374-381.

Balabanian, K., Lagane, B., Pablos, L., Laurent, L., Planchenault, T., Verola, O., Lebbe, C., Kerob, D., Dupuy, A., Hermine, O., \& Bordigoni, P. (2005). WHIM syndromes with different genetic anomalies are accounted for by impaired CXCR4 desensitization to CXCL12. Blood, 105, 2449-2457.

Ballou, L. M., \& Lin, R. Z. (2008). Rapamycin and mTOR kinase inhibitors. The Journal of Chemical Biology, 1, 27-36.

Banaszynski, L. a, Liu, C. W., \& Wandless, T. J. (2005). Characterization of the FKBPrapamycin FRB ternary complex. Journal of the American Chemical Society, 127, 4715-21.

Barmania, F., \& Pepper, M. S. (2013). C-C chemokine receptor type five (CCR5): An emerging target for the control of HIV infection. Applied and Translational Genomics, 2, 3-16.

Bayle, J. H., Grimley, J. S., Stankunas, K., Gestwicki, J. E., Wandless, T. J., \& Crabtree, G. R. (2006). Rapamycin analogs with differential binding specificity permit orthogonal control of protein activity. Chemistry and Biology, 13, 99-107.

Beckett, D., Kovaleva, E., \& Schatz, P. J. (1999). A minimal peptide substrate in biotin holoenzyme synthetase-catalyzed biotinylation. Protein Science , 8, 921-9.

Bjarnadóttir, T. K., Gloriam, D. E., Hellstrand, S. H., Kristiansson, H., Fredriksson, R., \& Schiöth, H. B. (2006). Comprehensive repertoire and phylogenetic analysis of the $G$ protein-coupled receptors in human and mouse. Genomics, 88, 263-73.

Blanpain, C., Migeotte, I., Lee, B., Vakili, J., Doranz, B. J., Govaerts, C., Vassart, G., Doms, R. W., \& Parmentier, M. (1999). CCR5 binds multiple CC-chemokines: MCP-3 acts as a natural antagonist. Blood, 94, 1899-905.

Bleul, C., Farzan, M., Choe, H., Parolin, C., Clark-Lewis, I., Sodroski, J., \& Springer, T. (1996). The lymphocyte chemoattractant SDF-1 is a ligand for LESTR/fusin and blocks HIV-1 entry. Nature, $382,829-833$.

Borroni, E. M., Mantovani, A., Locati, M., \& Bonecchi, R. (2010). Chemokine receptors intracellular trafficking. Pharmacology and Therapeutics, 127, 1-8. 
Bosier, B., \& Hermans, E. (2014). Promises of Biased Signaling in the Development of Improved Therapeutics. In B. Arey (Ed.), Biased Signaling in Physiology, Pharmacology and Therapeutics. Academic Press.

Breitwieser, G. E. (2004). G protein-coupled receptor oligomerization: implications for G protein activation and cell signaling. Circulation Research, 94, 17-27.

Brent, R. (2004). A partnership between biology and engineering. Nature Biotechnology, 22, 1211-4.

Bristow, M. R. (2000). B-Adrenergic Receptor Blockade in Chronic Heart Failure. Circulation, 101, 558-569.

Busillo, J. M., \& Benovic, J. L. (2007). Regulation of CXCR4 signaling. Biochimica et Biophysica Acta, $1768,952-963$.

Cabrera-Vera, T. M. (2003). Insights into G Protein Structure, Function, and Regulation. Endocrine Reviews, 24, 765-781.

Cao, T. T., Mays, R. W., \& von Zastrow, M. (1998). Regulated Endocytosis of G-protein-coupled Receptors by a Biochemically and Functionally Distinct Subpopulation of Clathrin-coated Pits. The Journal of Biological Chemistry, 273), 24592-24602.

Chang, F., Steelman, L. S., Lee, J. T., Shelton, J. G., Navolanic, P. M., Blalock, W. L., Franklin, R. a, \& McCubrey, J. a. (2003). Signal transduction mediated by the Ras/Raf/MEK/ERK pathway from cytokine receptors to transcription factors: potential targeting for therapeutic intervention. Leukemia, 17, 1263-93.

Charo, I. F., \& Ransohoff, R. M. (2006). The many roles of chemokines and chemokine receptors in inflammation. The New England Journal of Medicine, 354, 610-21.

Chen, I., Howarth, M., Lin, W., \& Ting, A. Y. (2005). Site-specific labeling of cell surface proteins with biophysical probes using biotin ligase. Nature Methods, 2, 99-104.

Chen, J., Zheng, X. F., Brown, E. J., \& Schreiber, S. L. (1995). Identification of an 11-kDa FKBP12rapamycin-binding domain within the 289-kDa FKBP12-rapamycin-associated protein and characterization of a critical serine residue. Proceedings of the National Academy of Sciences, 92, 4947-51.

Chuang, T. T., lacovelli, L., Sallese, M., \& De Blasi, A. (1996). G protein-coupled receptors: Heterologous regulation of homologous desensitization and its implications. Trends in Pharmacological Sciences, 17, 416-21

Cilliers, T., Nhlapo, J., Coetzer, M., Ketas, T., Olson, W. C., Moore, J. P., Trkola, A., Morris, L., \& Orlovic, D. (2003). The CCR5 and CXCR4 Coreceptors Are Both Used by Human Immunodeficiency Virus Type 1. Journal of Virology, 77, 4449-4456.

Clackson, T. (1998). Redesigning small molecule-protein interfaces. Current Opinion in Structural Biology, 8, 451-458.

Clontech Laboratories, I. (2008). iDimerize ${ }^{T M}$ Inducible Heterodimer System, Manual,1-16 . 
Coffa, S., Breitman, M., Hanson, S. M., Callaway, K., Kook, S., Dalby, K. N., \& Gurevich, V. V. (2011). The effect of arrestin conformation on the recruitment of c-Raf1, MEK1, and ERK1/2 activation. PloS One, 6, e28723.

Coffa, S., Breitman, M., Spiller, B., \& Gurevich, V. (2012). A single mutation in arrestin-2 prevents ERK1/2 activation by reducing c-Raf1 binding. Biochemistry, 50, 6951-6958.

Coggins, N. L., Trakimas, D., Chang, S. L., Ehrlich, A., Ray, P., Luker, K. E., Linderman, J. J., \& Luker, G. D. (2014). CXCR7 Controls Competition for Recruitment of $\beta$-Arrestin 2 in Cells Expressing Both CXCR4 and CXCR7. Plos One, 9, e98328.

Comps-Agrar, L., Kniazeff, J., Brock, C., Trinquet, E., \& Pin, J.-P. (2012). Stability of GABAB receptor oligomers revealed by dual TR-FRET and drug-induced cell surface targeting. The FASEB Journal, $26,3430-9$.

Contento, R. L., Molon, B., Boularan, C., Pozzan, T., Manes, S., Marullo, S., \& Viola, A. (2008). CXCR4-CCR5: a couple modulating T cell functions. Proceedings of the National Academy of Sciences, 105, 10101-6.

Cowell, R. M., Xu, H., Parent, J. M., \& Silverstein, F. S. (2006). Microglial expression of chemokine receptor CCR5 during rat forebrain development and after perinatal hypoxia-ischemia. Journal of Neuroimmunology, 173, 155-165.

Craft, C. M. (1995). The arrestin superfamily: Cone arrestins are a fourth family. FEBS Letters, 362, 247-255.

Czaplewski, L. G., McKeating, J., Craven, C. J., Higgins, L. D., Appay, V., Brown, A., Dudgeon, T., Howard, L. a., Meyers, T., Owen, J., Palan, S. R., Tan, P., Wilson, G., Woods, N. R., Heyworth, C. M., Lord, B. I., Brotherton, D., Christison, R., Craig, S., Cribbes, S., Edwards, R. M., Evans, S. J., Gilbert, R., Morgan, P., Randle, E., Schofield, N., Varley, P. G., Fisher, J., Waltho, J. P., \& Hunter, M. G. (1999). Identification of amino acid residues critical for aggregation of human CC chemokines macrophage inflammatory protein (MIP)-1alpha, MIP-1beta, and RANTES. Characterization of active disaggregated chemokine variants. The Journal of Biological Chemistry, 274, 16077-16084.

Das, R., Esposito, V., Abu-Abed, M., Anand, G. S., Taylor, S. S., \& Melacini, G. (2007). cAMP activation of PKA defines an ancient signaling mechanism. Proceedings of the National Academy of Sciences of the United States of America, 104, 93-8.

Delhaye, M., Gravot, A., Ayinde, D., Niedergang, F., Alizon, M., \& Brelot, A. (2007). Identification of a Postendocytic Sorting Sequence in CCR5. Molecular Pharmacology, 72, 1497-1507.

Denis, C., Sauliere, A., Galandrin, S., Senard, J.-M., \& Gales, C. (2012). Probing Heterotrimeric G Protein Activation: Applications to Biased Ligands. Current Pharmaceutical Design, 18, 128-44.

DeRose, R., Miyamoto, T., \& Inoue, T. (2013). Manipulating signaling at will: chemically-inducible dimerization (CID) techniques resolve problems in cell biology. Pflügers Archiv: European Journal of Physiology, 465, 409-17.

Dorsam, R. T., \& Gutkind, J. S. (2007). G-protein-coupled receptors and cancer. Nature Reviews. Cancer, 7, 79-94. 
Drake, M. T., Shenoy, S. K., \& Lefkowitz, R. J. (2006). Trafficking of G protein-coupled receptors. Circulation Research, 99, 570-82.

Drake, M. T., Violin, J. D., Whalen, E. J., Wisler, J. W., Shenoy, S. K., \& Lefkowitz, R. J. (2008). beta arrestin-biased agonism at the beta 2-adrenergic receptor. The Journal of Biological Chemistry, 283, 5669-5676.

Edwards, S. R., \& Wandless, T. J. (2007). The rapamycin-binding domain of the protein kinase mammalian target of rapamycin is a destabilizing domain. The Journal of Biological Chemistry, $282,13395-401$.

Eishingdrelo, H., \& Kongsamut, S. (2013). Minireview: Targeting GPCR Activated ERK Pathways for Drug Discovery. Current Chemical Genomics and Translational Medicine, 7, 9-15.

Exton, J. H. (1996). Regulation of phosphoinositide phospholipases by hormones, neurotransmitters, and other agonists linked to G proteins. Annual Review of Pharmacology and Toxicology, 36, 481-509.

Falkenburger, B. H., Dickson, E. J., \& Hille, B. (2013). Quantitative properties and receptor reserve of the DAG and PKC branch of G(q)-coupled receptor signaling. The Journal of General Physiology, 141, 537-55.

Fegan, A., White, B., Carlson, J. C. T., \& Wagner, C. R. (2010). Chemically controlled protein assembly: techniques and applications. Chemical Reviews, 110, 3315-36.

Feng, Y., Broder, C. C., Kennedy, P. E., \& Berger, E. a. (1996). HIV-1 entry cofactor: functional cDNA cloning of a seven-transmembrane, G protein-coupled receptor. Science, 272, 872-7.

Ferré, S., Baler, R., Michel, B., Caron, M., Devi, L., Durroux, T., Fuxe, K., George, S., Javitch, J., Lohse, M., Mackie, K., Milligan, G., Pfleger, K., Pin, J.-P., Volkow, N., Waldhoer, M., Woods, A., \& Franco, R. (2010). Building a new conceptual framework for receptor heteromers. Nature Chemical Biology, 5, 131-134.

Ferré, S., Casadó, V., Devi, L. a, Filizola, M., Jockers, R., Lohse, M. J., Milligan, G., Pin, J.-P., \& Guitart, X. (2014). G protein-coupled receptor oligomerization revisited: functional and pharmacological perspectives. Pharmacological Reviews, 66, 413-34.

Filmore, D. (2004). It's a GPCR World. American Chemical Society, 7, 24-27.

Floyd, D. H., Geva, A., Bruinsma, S. P., Overton, M. C., Blumer, K. J., \& Baranski, T. J. (2003). C5a receptor oligomerization. II. Fluorescence resonance energy transfer studies of a human $G$ protein-coupled receptor expressed in yeast. The Journal of Biological Chemistry, 278, 3535461.

Fredriksson, R., Lagerström, M. C., Lundin, L.-G., \& Schiöth, H. B. (2003). The G-protein-coupled receptors in the human genome form five main families. Phylogenetic analysis, paralogon groups, and fingerprints. Molecular Pharmacology, 63, 1256-72.

Futahashi, Y., Komano, J., Urano, E., Aoki, T., Hamatake, M., Miyauchi, K., Yoshida, T., Koyanagi, Y., Matsuda, Z., \& Yamamoto, N. (2007). Separate elements are required for ligand-dependent and -independent internalization of metastatic potentiator CXCR4. Cancer Science, 98, 373-9. 
Galliera, E., Jala, V. R., Trent, J. O., Bonecchi, R., Lefkowitz, R. J., \& Chem, J. B. (2004). Mechanisms of Signal Transduction: $\beta$-Arrestin-dependent Constitutive Internalization of the Human Chemokine Decoy Receptor D6 " Human Chemokine Decoy Receptor D6. The Journal of Biological Chemistry, 279, 25590-25597.

Garcia-Perez, J., Rueda, P., Staropoli, I., Kellenberger, E., Alcami, J., Arenzana-Seisdedos, F., \& Lagane, B. (2011). New insights into the mechanisms whereby low molecular weight CCR5 ligands inhibit HIV-1 infection. The Journal of Biological Chemistry, 286, 4978-90.

Geminder, H., Sagi-Assif, O., Goldberg, L., Meshel, T., Rechavi, G., Witz, I. P., \& Ben-Baruch, A. (2001). A Possible Role for CXCR4 and Its Ligand, the CXC Chemokine Stromal Cell-Derived Factor-1, in the Development of Bone Marrow Metastases in Neuroblastoma. The Journal of Immunology, 167, 4747-4757.

Gilman, G., \& Casey, P. J. (1988). G proteins control diverse pathways of transmembrane signaling. The FASEB Journal, 3, 2125-2131.

Goldsmith, Z. G., \& Dhanasekaran, D. N. (2007). G protein regulation of MAPK networks. Oncogene, 26, 3122-42.

Goodman, O. B., Krupnick, J. G., Santini, F., Gurevich, V. V, Penn, R. B., Gagnon, A. W., Keen, J. H., \& Benovic, J. L. (1996). Beta-arrestin acts as a clathrin adaptor in endocytosis of the beta2adrenergic receptor. Nature, 383, 447-450.

Gray, J. a, Bhatnagar, A., Gurevich, V. V, \& Roth, B. L. (2003). The interaction of a constitutively active arrestin with the arrestin-insensitive 5-HT(2A) receptor induces agonist-independent internalization. Molecular Pharmacology, 63, 961-72.

Gulino, A. V., Moratto, D., Sozzani, S., Cavadini, P., Otero, K., Tassone, L., Imberti, L., Pirovano, S., Notarangelo, L. D., Soresina, R., Mazzolari, E., Nelson, D. L., Notarangelo, L. D., \& Badolato, R. (2004). Altered leukocyte response to CXCL12 in patients with warts hypogammaglobulinemia , infections, myelokathexis ( WHIM ) syndrome. Blood, 104, 444-452.

Gurevich, V. V. (Ed).(2014). Arrestins - Pharmacology and Therapeutic Potential. (V. V. Gurevich, Ed.) (219th ed.). Springer Verlag, Heidelberg.

Gurevich, V. V, \& Benovics, J. L. (1993). Visual Arrestin Interaction with Rhodopsin. Journal of Biological Chemistry, 268, 11628-11638.

Gurevich, V. V, \& Gurevich, E. V. (2004). The molecular acrobatics of arrestin activation. Trends in Pharmacological Sciences, 25, 105-11.

Gurevich, V. V, \& Gurevich, E. V. (2014). Extensive shape shifting underlies functional versatility of arrestins. Current Opinion in Cell Biology, 27, 1-9.

Gurevich, V., \& Gurevich, E. (2009). How and why do GPCRs dimerize. Trends in Pharmacological Sciences, 29, 234-240.

Gurevich, V. V., \& Gurevich, E. V. (2006). The structural basis of arrestin-mediated regulation of Gprotein-coupled receptors. Pharmacology and Therapeutics, 110, 465-502. 
Hanyaloglu, A. C., \& von Zastrow, M. (2008). Regulation of GPCRs by endocytic membrane trafficking and its potential implications. Annual Review of Pharmacology and Toxicology, 48, 537-568.

Haribabu, B., Richardson, R. M., Fisher, I., Sozzani, S., Peiper, S. C., Horuk, R., Ali, H., \& Snyderman, R. (1997). Regulation of Human Chemokine Receptors CXCR4: Role of phosphorylation in desensitization and internalization. The Journal of Biological Chemistry, 272, 28726-28731.

Hatzivassiliou, E. G., Tsichritzis, T., \& Mosialos, G. (2005). Induction of Apoptosis by Rewiring the Signal Transduction of Epstein-Barr Virus Oncoprotein LMP1 toward Caspase Activation Induction of Apoptosis by Rewiring the Signal Transduction of Epstein-Barr Virus Oncoprotein LMP1 toward Caspase Activation. Journal of Virology 79, 5215-5219.

Hendrix, C. W., Collier, A. C., Lederman, M. M., Schols, D., Pollard, R. B., Brown, S., Jackson, J. B., Coombs, R. W., Glesby, M. J., Flexner, C. W., Bridger, G. J., Badel, K., MacFarland, R. T., Henson, G. W., \& Calandra, G. (2004). Safety, pharmacokinetics, and antiviral activity of AMD3100, a selective CXCR4 receptor inhibitor, in HIV-1 infection. Journal of acquired immune deficiency syndromes, 37, 1253-1262.

Henze, S. (2013). Chemical-versus ligand-induced heterodimerization of B-arrestin and chemokine receptors CXCR4/CCR5, Master thesis, Universität Göttingen.

Hernandez, P. a, Gorlin, R. J., Lukens, J. N., Taniuchi, S., Bohinjec, J., Francois, F., Klotman, M. E., \& Diaz, G. a. (2003). Mutations in the chemokine receptor gene CXCR4 are associated with WHIM syndrome, a combined immunodeficiency disease. Nature Genetics, 34, 70-4.

Hoffmann, C., Zürn, A., Bünemann, M., \& Lohse, M. J. (2008). Conformational changes in G-proteincoupled receptors-the quest for functionally selective conformations is open. British Journal of Pharmacology, 153, 358-66.

Howarth, M., \& Ting, A. Y. (2009). Imaging proteins in live mammalian cells with biotin ligase and monovalent streptavidin. Nature Protocols, 3, 534-545.

Hüttenrauch, F., Pollok-Kopp, B., \& Oppermann, M. (2005). G protein-coupled receptor kinases promote phosphorylation and beta-arrestin-mediated internalization of CCR5 homo- and hetero-oligomers. The Journal of Biological Chemistry, 280, 37503-15.

Janetopoulos, C., Jin, T., \& Devreotes, P. (2001). Receptor-mediated activation of heterotrimeric Gproteins in living cells. Science , 291, 2408-11.

Janowski, M. (2009). Functional diversity of SDF-1 splicing variants. Cell Adhesion \& Migration, 3, 243-9.

Juarez, J., \& Bendall, L. (2004). SDF-1 and CXCR4 in normal and malignant hematopoiesis. Histology and Histopathology, 19, 299-309.

Kang, D. S., Tian, X., \& Benovic, J. L. (2013). B-Arrestins and G protein-coupled receptor trafficking. Methods in enzymology, 521, 91-108.

Kara, E., Crépieux, P., Gauthier, C., Martinat, N., Piketty, V., Guillou, F., \& Reiter, E. (2006). A phosphorylation cluster of five serine and threonine residues in the C-terminus of the folliclestimulating hormone receptor is important for desensitization but not for beta-arrestinmediated ERK activation. Molecular Endocrinology, 20, 3014-26. 
Kershaw, T., Wavre-Shapton, S. T., Signoret, N., \& Marsh, M. (2009). Analysis of chemokine receptor endocytosis and intracellular trafficking. Methods in Enzymology, 460, 357-77.

Kim, Y.-M., \& Benovic, J. L. (2002a). Differential roles of arrestin-2 interaction with clathrin and adaptor protein 2 in $\mathrm{G}$ protein-coupled receptor trafficking. The Journal of Biological Chemistry, $277,30760-8$.

Kim, Y.-M., \& Benovic, J. L. (2002b). Differential roles of arrestin-2 interaction with clathrin and adaptor protein 2 in $\mathrm{G}$ protein-coupled receptor trafficking. The Journal of Biological Chemistry, $277,30760-8$.

Kniazeff, J., Prézeau, L., Rondard, P., Pin, J. P., \& Goudet, C. (2011). Dimers and beyond: The functional puzzles of class C GPCRs. Pharmacology and Therapeutics, 130, 9-25.

Kommaddi, R. P., \& Shenoy, S. K. (2013). Arrestins and protein ubiquitination. Progress in Molecular Biology and Translational Science, 118, 175-204.

Kraft, K., Olbrich, H., Majoul, I., Mack, M., Proudfoot, A., \& Oppermann, M. (2001). Characterization of sequence determinants within the carboxyl-terminal domain of chemokine receptor CCR5 that regulate signaling and receptor internalization. The Journal of Biological Chemistry, 276, 34408-18.

Krasel, C., Zabel, U., Lorenz, K., Reiner, S., Al-Sabah, S., \& Lohse, M. J. (2008). Dual role of the beta2adrenergic receptor $\mathrm{C}$ terminus for the binding of beta-arrestin and receptor internalization. The Journal of Biological Chemistry, 283, 31840-31848.

Ku, C. Y., Qian, A., Wen, Y., Anwer, K., \& Sanborn, B. M. (1995). Oxytocin stimulates myometrial guanosine triphosphatase and phospholipase-C activities via coupling to $G$ alpha $q / 11$. Endocrinology, 136, 1509-1515.

Kuritzkes, D. R. (2010). HIV-1 entry inhibitors: an overview. Current Opinion in HIV and AIDS, 4, 8287.

Kuszak, A. J., Pitchiaya, S., Anand, J. P., Mosberg, H. I., Walter, N. G., \& Sunahara, R. K. (2009). Purification and functional reconstitution of monomeric mu-opioid receptors: allosteric modulation of agonist binding by Gi2. The Journal of Biological Chemistry, 284, 26732-26741.

Lagane, B., Chow, K. Y. C., Balabanian, K., Levoye, A., Harriague, J., Planchenault, T., Baleux, F., Gunera-Saad, N., Arenzana-Seisdedos, F., \& Bachelerie, F. (2008). CXCR4 dimerization and beta-arrestin-mediated signaling account for the enhanced chemotaxis to CXCL12 in WHIM syndrome. Blood, 112, 34-44.

Lagane, B., Planchenault, T., Balabanian, K., Poul, E. Le, Percherancier, Y., Staropoli, I., Vassart, G., Oppermann, M., \& Parmentier, M. (2005). Mutation of the DRY Motif Reveals Different Structural Requirements for the CC Chemokine Receptor 5-Mediated Signaling and Receptor Endocytosis. Molecular Pharmacology, 67, 1966-1976.

Laporte, S. a, Oakley, R. H., Zhang, J., Holt, J. a, Ferguson, S. S., Caron, M. G., \& Barak, L. S. (1999). The beta2-adrenergic receptor/betaarrestin complex recruits the clathrin adaptor AP-2 during endocytosis. Proceedings of the National Academy of Sciences, 96, 3712-7. 
Lefkowitz, R. J. (1998). G Protein-coupled Receptors III. New roles for receptor kinases and betaarrestins in receptor signaling and desensitization. Journal of Biological Chemistry, 273, 1867718680.

Lefkowitz, R. J. (2013). A brief history of G-protein coupled receptors (Nobel Lecture). Angewandte Chemie (International Ed. in English), 52, 6366-78.

Lefkowitz, R. J., \& Shenoy, S. K. (2005a). Transduction of receptor signals by beta-arrestins. Science , $308,512-7$.

Lefkowitz, R. J., \& Shenoy, S. K. (2005b). Transduction of receptor signals by beta-arrestins. Science , $308,512-7$.

Leone, M., Crowell, K. J., Chen, J., Jung, D., Chiang, G. G., Sareth, S., Abraham, R. T., \& Pellecchia, M. (2006). The FRB domain of mTOR: NMR solution structure and inhibitor design. Biochemistry, 45, 10294-302.

Li, M., \& Ransohoff, R. (2009). Multiple roles of chemokine CXCL12 in the central nervous system: A migration from immunology to neurobiology. Progress in Neurobiology, 84, 116-131.

Liu, H., Rajasekaran, A. K., Moy, P., Xia, Y., Kim, S., Navarro, V., \& Bander, N. H. (1998). Constitutive and Antibody-induced Internalization of Prostate-specific Membrane Antigen. Cancer Research,58, 4055-4060.

Loetscher, M., Geiser, T., O’Reilly, T., Zwahlen, R., Baggiolini, M., \& Moser, B. (1994). Cloning of a human seven-transmembrane domain receptor, LESTR, that is highly expressed in leukocytes. The Journal of Biological Chemistry, 269, 232-7.

Lohse, M. J., Benovic, J. L., Codina, J., Caron, M. G., \& Lefkowitz, R. J. (1990). beta-Arrestin: a protein that regulates beta-adrenergic receptor function. Science, 248, 1547-1550.

Lohse, M. J., \& Calebiro, D. (2013). Cell biology: Receptor signals come in waves. Nature, 495, 457-8.

Lohse, M. J., Engelhardt, S., \& Eschenhagen, T. (2003). What is the role of beta-adrenergic signaling in heart failure? Circulation Research, 93, 896-906.

Longden, J., Cooke, E.-L., \& Hill, S. J. (2008). Effect of CCR5 receptor antagonists on endocytosis of the human CCR5 receptor in CHO-K1 cells. British Journal of Pharmacology, 153, 1513-27.

Luker, K. E., Steele, J. M., Mihalko, L. A., Ray, P., \& Gary, D. (2011). Constitutive and Chemokinedependent Internalization and Recycling of CXCR7 in Breast Cancer Cells to Degrade Chemokine Ligands. Oncogene, 29, 4599-4610.

Luttrell, L. M. (1999). ß-Arrestin-Dependent Formation of 2 Adrenergic Receptor-Src Protein Kinase Complexes. Science, 283, 655-661.

Luttrell, L. M., \& Lefkowitz, R. J. (2002). The role of beta-arrestins in the termination and transduction of G-protein-coupled receptor signals. Journal of Cell Science, 115, 455-65. 
Luttrell, L. M., Roudabush, F. L., Choy, E. W., Miller, W. E., Field, M. E., Pierce, K. L., \& Lefkowitz, R. J. (2001). Activation and targeting of extracellular signal-regulated kinases by beta-arrestin scaffolds. Proceedings of the National Academy of Sciences, 98, 2449-54.

Ma, L., \& Pei, G. (2007). Beta-arrestin signaling and regulation of transcription. Journal of Cell Science, $120,213-8$.

Ma, Q., Jones, D., Borghesani, P. R., Segal, R. a, Nagasawa, T., Kishimoto, T., Bronson, R. T., \& Springer, T. a. (1998). Impaired B-lymphopoiesis, myelopoiesis, and derailed cerebellar neuron migration in CXCR4- and SDF-1-deficient mice. Proceedings of the National Academy of Sciences, 95, 9448-53.

Mack, B. M., Luckow, B., Nelson, P. J., Cihak, J., Simmons, G., Clapham, P. R., Signoret, N., Marsh, M., Stangassinger, M., Borlat, F., Wells, T. N. C., Schlöndorff, D., \& Proudfoot, A. E. I. (1998). Aminooxypentane-RANTES Induces CCR5 Internalization but Inhibits Recycling: A Novel Inhibitory Mechanism of HIV Infectivity. Journal of Cell Biology, 187, 1215-24.

Mack, M., Cihak, J., Simonis, C., Luckow, B., Proudfoot, a. E. I., Plachy, J., Bruhl, H., Frink, M., Anders, H.-J., Vielhauer, V., Pfirstinger, J., Stangassinger, M., \& Schlondorff, D. (2001). Expression and Characterization of the Chemokine Receptors CCR2 and CCR5 in Mice. Journal of Immunology, 166, 4697-4704.

Mangmool, S., \& Kurose, H. (2011). G(i/o) protein-dependent and -independent actions of Pertussis Toxin (PTX). Toxins, 3, 884-99.

Marchese, A. (2014). Endocytic trafficking of chemokine receptors. Current Opinion in Cell Biology, $27,72-7$.

Marchese, A., \& Benovic, J. L. (2001). Agonist-promoted ubiquitination of the G protein-coupled receptor CXCR4 mediates lysosomal sorting. The Journal of Biological Chemistry, 276, 45509-12.

Marchese, A., Chen, C., Kim, Y.-M., \& Benovic, J. L. (2003). The ins and outs of G protein-coupled receptor trafficking. Trends in Biochemical Sciences, 28, 369-376.

Marchese, A., Paing, M. M., Temple, B. R. S., \& Trejo, J. (2010). G Protein-Coupled Receptor Sorting to Endosomes and Lysosomes. Annual Review of Pharmacology and Toxicology, 48, 601-29.

Marchese, A., Raiborg, C., Santini, F., Keen, J. H., Stenmark, H., \& Benovic, J. L. (2003). The E3 ubiquitin ligase AIP4 mediates ubiquitination and sorting of the $\mathrm{G}$ protein-coupled receptor CXCR4. Developmental Cell, 5, 709-22.

Marks, K. M., Braun, P. D., \& Nolan, G. P. (2004). A general approach for chemical labeling and rapid, spatially controlled protein inactivation. Proceedings of the National Academy of Sciences, 101, 9982-7.

Marks, K. M., \& Nolan, G. P. (2006). Chemical labeling strategies for cell biology. Nature Methods, 3, 591-596.

Mellado, M., Rodríguez-Frade, J. M., Mañes, S., \& Martínez-A, C. (2001). Chemokine signaling and functional responses : The Role of Receptor Dimerization and TK Pathway Activation. Annual Review of Immunology, 19, 397-421. 
Mellado, M., Rodríguez-Frade, J., Vila-Coro, J., Fernández, S., Martín de Ana, A., Jones, R., Torán, L., \& Martínez-A, C. (2001). Chemokine receptor homo- or heterodimerization activates distinct signaling pathways. The EMBO Journal, 20, 2497-507.

Milde, S., Gilley, J., \& Coleman, M. P. (2013). Subcellular localization determines the stability and axon protective capacity of axon survival factor Nmnat2. PLoS Biology, 11, e1001539.

Miller, W. E., \& Lefkowitz, R. J. (2001). Expanding roles for beta-arrestins as scaffolds and adapters in GPCR signaling and trafficking. Current Opinion in Cell Biology, 13, 139-45.

Miller, W. E., McDonald, P. H., Cai, S. F., Field, M. E., Davis, R. J., \& Lefkowitz, R. J. (2001). Identification of a motif in the carboxyl terminus of beta -arrestin2 responsible for activation of JNK3. The Journal of Biological Chemistry, 276, 27770-7.

Milligan, G. (2004). G protein-coupled receptor dimerization: function and ligand pharmacology. Molecular Pharmacology, 66, 1-7.

Milligan, G. (2013). The prevalence, maintenance, and relevance of $G$ protein-coupled receptor oligomerization. Molecular Pharmacology, 84, 158-69.

Milligan, G., \& Bouvier, M. (2005). Methods to monitor the quaternary structure of G proteincoupled receptors. The FEBS Journal, 272, 2914-25.

Milligan, G., \& Kostenis, E. (2006). Heterotrimeric G-proteins: a short history. British Journal of Pharmacology, 147, 46-55.

Moore, C. a C., Milano, S. K., \& Benovic, J. L. (2007). Regulation of receptor trafficking by GRKs and arrestins. Annual Review of Physiology, 69, 451-82.

Mueller, A., Kelly, E., \& Strange, P. G. (2002). Pathways for internalization and recycling of the chemokine receptor CCR5. Blood, 99, 785-91.

Mueller, A., \& Strange, P. G. (2004). Mechanisms of internalization and recycling of the chemokine receptor, CCR5. European Journal of Biochemistry, 271, 243-252.

Murdoch, C., \& Finn, A. (2000). Review article Chemokine receptors and their role in inflammation and infectious diseases. Blood, 95, 3032-3043.

Murphy, M., \& Tiffany, H. L. (1996). Cloning and functional expression of CC CKR5, selective a human for MIP-la , monocyte receptor. Journal of Leukocyte Biology, 60, 147-152.

Nagasawa, T., Hirota, S., Tachibana, K., Takakura, N., Nishikawa, S., Kitamura, Y., Yoshida, N., Kikutani, H., \& Kishimoto, T. (1996). Defects of B-cell lymphopoiesis and bone-marrow myelopoiesis in mice lacking the CXC chemokine PBSF/SDF-1. Nature, 382, 635 - 638.

Naumann, U., Cameroni, E., Pruenster, M., Mahabaleshwar, H., Raz, E., Zerwes, H.-G., Rot, A., \& Thelen, M. (2010). CXCR7 functions as a scavenger for CXCL12 and CXCL11. PloS One, 5, e9175.

Neumann, E., Khawaja, K., \& Müller-Ladner, U. (2014). G protein-coupled receptors in rheumatology. Nature Reviews Rheumatology, 10, 429-36. 
Newton, a. C. (1995). Protein Kinase C: Structure, Function, and Regulation. The Journal of Biological Chemistry, 270, 28495-28498.

Noma, T., Lemaire, A., Prasad, S. V. N., Barki-harrington, L., Tilley, D. G., Chen, J., Corvoisier, P. Le, Violin, J. D., Wei, H., Lefkowitz, R. J., \& Rockman, H. A. (2007). Transactivation of the EGFR confers cardioprotection. The Jounal of Clinical Investigation, 117, 2445-2458.

Oakley, R. H., Laporte, S. a, Holt, J. a, Barak, L. S., \& Caron, M. G. (2001). Molecular determinants underlying the formation of stable intracellular $G$ protein-coupled receptor-beta-arrestin complexes after receptor endocytosis. The Journal of Biological Chemistry, 276, 19452-60.

Oakley, R. H., Laporte, S. a, Holt, J. a, Caron, M. G., \& Barak, L. S. (2000). Differential affinities of visual arrestin, beta arrestin1, and beta arrestin2 for $\mathrm{G}$ protein-coupled receptors delineate two major classes of receptors. The Journal of Biological Chemistry, 275, 17201-10.

Olbrich, H., Proudfoot, a E., \& Oppermann, M. (1999). Chemokine-induced phosphorylation of CC chemokine receptor 5 (CCR5). Journal of Leukocyte Biology, 65, 281-5.

Oppermann, M. (2004). Chemokine receptor CCR5: Insights into structure, function, and regulation. Cellular Signalling, 16, 1201-10.

Oppermann, M., Mack, M., Proudfoot, E. I., \& Olbrich, H. (1999). Differential Effects of CC Chemokines on CC Chemokine Receptor 5 (CCR5) Phosphorylation and Identification of Phosphorylation Sites on the CCR5 Carboxyl Terminus. Journal of Biological Chemistry, 274, 8875-8885.

Orsini, M. J., Parent, J.-L., Mundell, S. J., \& Benovic, J. L. (1999). TTrafficking of the HIV coreceptor CXCR4. Role of arrestins and identification of residues in the c-terminal tail that mediate receptor internalization. Journal of Biological Chemistry, 274, 31076-31086.

Paavola, C., Hemmerich, S., Grunberger, D., Polsky, I., Bloom, A., Freedman, R., Mulkins, M., Bhakta, S., McCarley, D., Wiesent, L., Wong, B., Jarnagin, K., \& Handel, T. (1998). Monomeric Monocyte Chemoattractant Protein-1 (MCP-1) Binds and Activates the MCP-1 Receptor CCR2B. Journal of Biological Chemistry, 273, 33157-33165.

Pakianathan, D. R., Kuta, E. G., Artis, D. R., Skelton, N. J., \& He, C. A. (1997). Distinct but Overlapping Epitopes for the Interaction of a CC-Chemokine with. Biochemistry, 2960, 96429648.

Pearson, G., Robinson, F., Beers Gibson, T., Xu, B. E., Karandikar, M., Berman, K., \& Cobb, M. H. (2001). Mitogen-activated protein (MAP) kinase pathways: regulation and physiological functions. Endocrine Reviews, 22, 153-183.

Peled, A., \& Tavor, S. (2013). Role of CXCR4 in the pathogenesis of acute myeloid leukemia. Theranostics, 3, 34-9.

Peled, A., Wald, O., \& Burger, J. (2012). Development of novel CXCR4-based therapeutics. Expert Opinion on Investigational Drugs,21, 341-353.

Penn, R. B., Pascual, R. M., Kim, Y. M., Mundell, S. J., Krymskaya, V. P., Panettieri, R. a, \& Benovic, J. L. (2001). Arrestin specificity for $G$ protein-coupled receptors in human airway smooth muscle. The Journal of Biological Chemistry, 276, 32648-56. 
Peters, J. H., \& Baumgarten, H. (1992). Monoclonal antibodies. Springer Verlag, Heidelberg.

Pickart, C. M. (2001). Mechanisms underlying ubiquitination. Annual Review of Biochemistry, 70, 503-33.

Pierce, K. L., Premont, R. T., \& Lefkowitz, R. J. (2002). Seven-transmembrane receptors. Nature Reviews. Molecular Cell Biology, 3, 639-50.

Pin, J., Neubig, R., Bouvier, M., Devi, L., Filizola, M., \& Javitch, J. A. (2007). International Union of Basic and Clinical Pharmacology. LXVII. Recommendations for the Recognition and Nomenclature of G Protein-Coupled Receptor Heteromultimers. Pharmacological Reviews, 59, 5-13.

Pin, J. P. (2000). Molecular tinkering of G protein-coupled receptors : an evolutionary success. The EMBO Journal, 18, 1723-1729.

Pollok-Kopp, B., Schwarze, K., Baradari, V. K., \& Oppermann, M. (2003). Analysis of ligandstimulated CC chemokine receptor 5 (CCR5) phosphorylation in intact cells using phosphositespecific antibodies. The Journal of Biological Chemistry, 278, 2190-8.

Rahbek-Clemmensen, T., Bay, T., Eriksen, J., Gether, U., \& Jørgensen, T. N. (2014). The serotonin transporter undergoes constitutive internalization and is primarily sorted to late endosomes and lysosomal degradation. The Journal of Biological Chemistry, 289,23004-19.

Rajagopal, S., Bassoni, D. L., Campbell, J. J., Gerard, N. P., Gerard, C., \& Wehrman, T. S. (2013). Biased agonism as a mechanism for differential signaling by chemokine receptors. The Journal of Biological Chemistry, 288, 35039-48.

Rajagopal, S., Rajagopal, K., \& Lefkowitz, R. (2010). Teaching old receptors new tricks: biasing seventransmembrane receptors. Nature Reviews Drug Discovery, 9, 373-386.

Rajarathnam, K., Sykes, B. D., Kay, C. M., Dewald, B., Geiser, T., \& Baggiolini, M. (1994). Neutrophil Activation by Monomeric Interleukin-8. Science, 6073, 1993-1995.

Randall, T. D., Carragher, D. M., \& Rangel-moreno, J. (2009). Development of secondary lymphoid organs. Annual Review of Immunology, 26, 627-650.

Reiter, E., Ahn, S., Shukla, A. K., \& Lefkowitz, R. J. (2012). Molecular mechanism of $\beta$-arrestin-biased agonism at seven-transmembrane receptors. Annual Review of Pharmacology and Toxicology, $52,179-97$.

Ribas, C., Penela, P., Murga, C., Salcedo, A., García-Hoz, C., Jurado-Pueyo, M., Aymerich, I., \& Mayor, F. (2007). The G protein-coupled receptor kinase (GRK) interactome: role of GRKs in GPCR regulation and signaling. Biochimica et Biophysica Acta, 1768, 913-22.

Ritter, S. L., \& Hall, R. a. (2009). Fine-tuning of GPCR activity by receptor-interacting proteins. Nature Reviews. Molecular Cell Biology, 10, 819-30.

RnDsystems. (2013). Human Phospho-MAPK Array Kit, Manual, 1-10. 
Robbins, M. J., Calver, a R., Filippov, a K., Hirst, W. D., Russell, R. B., Wood, M. D., Nasir, S., Couve, A., Brown, D. a, Moss, S. J., \& Pangalos, M. N. (2001). GABA(B2) is essential for g-protein coupling of the GABA(B) receptor heterodimer. The Journal of Neuroscience, 21, 8043-52.

Robertson, J. M., Henderson, E., Scheinman, A., Clark, M., Lake, A., Hegerl, R., Hoppe, W., Glitz, D. G., Ohgi, K., Kojoutiarova, M. S., Bogdanov, A. A., Woese, C. R., Gutell, R. R., Gupta, R., Weiser, B., Noller, F., Carbon, P., Ebel, J. P., Ehresmann, C., Stiege, W., Maly, P., Zwieb, C., Stolk, V., Stern, S., Moazed, D., Wilson, R. C., Craven, G. R., Noller, H. F., Nomura, M., Mizushima, S., Sogin, M., Woese, C., Kurland, C. G., Muto, A., Fellner, P., Branlant, C., Ungewickell, E., Garrett, R., Garrett, R. A., Rhode, M. F., Cooper, S., Aune, K. C., Brimacombe, R., Wower, I., Aunadja, J., Osswald, M., Stoffler, G., Fanning, T. G., Chang, C., Fiser, I., Kuechler, E., Thomas, G., Shimizu, M., Craven, R., Birge, E. A., Kurland, G., Wagner, R., Stutz, E., Gilbert, W., Gorini, L., Tissikres, A., Lengyel, P., Harbor, C. S., Lemieux, C., \& Res, V. A. (1988). Golf: An Olfactory Neuron Specific-G Protein Involved in Odorant Signal Transduction. Science, 244, 790-795.

Rollins, B. J. (1997). Chemokines. Blood, 90, 909-928.

Sabeti, P. C., Walsh, E., Schaffner, S. F., Varilly, P., Fry, B., Hutcheson, H. B., Cullen, M., Mikkelsen, T. S., Roy, J., Patterson, N., Cooper, R., Reich, D., Altshuler, D., O’Brien, S., \& Lander, E. S. (2005). The case for selection at CCR5-Delta32. PLoS Biology, 3, e378.

Salazar, N., Chen, J., \& Rockman, H. (2007). Cardiac GPCRs: GPCR signaling in healthy and failing hearts. Biochimica et Biophysica Acta, 1768, 1006-1018.

Samson, M., Libert, F., Doranz, B. J., Rucker, J., Liesnard, C., Farber, C. M., Saragosti, S., Lapoumeroulie, C., Cognaux, J., Forceille, C., Muyldermans, G., Verhofstede, C., Burtonboy, G., Georges, M., Imai, T., Rana, S., Yi, Y., Smyth, R. J., Collman, R. G., Doms, R. W., Vassart, G., \& Parmentier, M. (1996). Resistance to HIV-1 infection in caucasian individuals bearing mutant alleles of the CCR-5 chemokine receptor gene. Nature, 382, 722-725.

Scarselli, M., \& Donaldson, J. G. (2009). Constitutive internalization of G protein-coupled receptors and $\mathrm{G}$ proteins via clathrin-independent endocytosis. The Journal of Biological Chemistry, 284, 3577-85.

Schaeffer, E., Soros, V. B., Greene, W. C., \& Irol, J. V. (2004). Compensatory Link between Fusion and Endocytosis of Human Immunodeficiency Virus Type 1 in Human CD4 T Lymphocytes. Journal of Virology, 78, 1375-1383.

Schall, T. J., \& Proudfoot, A. E. I. (2011). Overcoming hurdles in developing successful drugs targeting chemokine receptors. Nature Reviews. Immunology, 11, 355-63.

Schatz, P. J. (1993). Use of Peptide Libraries to Map the Substrate Specificity of a Peptide-Modifying Enzyme: A 13 Residue Consensus Peptide Specifies Biotinylation in Escherichia coli. Nature Biotechnology, 11, $1138-1143$.

Schiöth, H. B., \& Fredriksson, R. (2005). The GRAFS classification system of G-protein coupled receptors in comparative perspective. In General and Comparative Endocrinology, 142, 94-101.

Schläger, C. (2007). Etablierung und Anwendung eines Antikörper-unabhängigen Internalisierungsund Rezyklisierungstests für den CC Chemokinrezeptor 5 (CCR5). Diploma thesis, Universität Göttingen. 
Scott, M. G. H. (2011). Evidence for internal stores of CCR5 in blood cells. Blood, 118, 1175-1176.

Shenoy, S. K., Drake, M. T., Nelson, C. D., Houtz, D. a, Xiao, K., Madabushi, S., Reiter, E., Premont, R. T., Lichtarge, O., \& Lefkowitz, R. J. (2006). beta-arrestin-dependent, G protein-independent ERK1/2 activation by the beta2 adrenergic receptor. The Journal of Biological Chemistry, 281, 1261-73.

Shenoy, S. K., McDonald, P. H., Kohout, T. a, \& Lefkowitz, R. J. (2001). Regulation of receptor fate by ubiquitination of activated beta 2-adrenergic receptor and beta-arrestin. Science, 294, 1307-13.

Shinitzky, M. (1984). Membrane Fluidity and Receptor Function. In M. Kates (Ed.), Membrane Fluidity. Springer Verlag, Heidelberg.

Shukla, A. K., Westfield, G. H., Xiao, K., Reis, R. I., Huang, L.-Y., Tripathi-Shukla, P., Qian, J., Li, S., Blanc, A., Oleskie, A. N., Dosey, A. M., Su, M., Liang, C.-R., Gu, L.-L., Shan, J.-M., Chen, X., Hanna, R., Choi, M., Yao, X. J., Klink, B. U., Kahsai, A. W., Sidhu, S. S., Koide, S., Penczek, P. a., Kossiakoff, A. a., Woods Jr, V. L., Kobilka, B. K., Skiniotis, G., \& Lefkowitz, R. J. (2014). Visualization of arrestin recruitment by a G-protein-coupled receptor. Nature, 512, 218-222.

Shukla, A., Manglik, A., Kruse, A., Xiao, K., Reis, R., Tseng, W.-C., Staus, D., Hilger, D., Uysal, S., Huang, L.-Y., Paduch, M., Tripathi-Shukla, P., Koide, A., Koide, S., Weis, W. I., Kossiakoff, A., Kobilka, B. K., \& Lefkowitz, R. (2013). Structure of active $\beta$-arrestin-1 bound to a G-proteincoupled receptor phosphopeptide. Nature, 497, 137-41.

Shukla, A., Xiao, K., \& Lefkowitz, R. (2012). Emerging paradigms of $\beta$-arrestin-dependent seven transmembrane receptor signaling. Trends Biochemical Science, 36, 457-469.

Shukla AK, Manglik A, Kruse AC, Xiao K, Reis RI, Tseng WC, Staus DP, Hilger D, Uysal S, Huang LY, Paduch M, Tripathi-Shukla P, Koide A, Koide S, Weis WI, Kossiakoff AA, Kobilka BK, L. R. (2013). Structure of active $\beta$-arrestin-1 bound to a G-protein-coupled receptor phosphopeptide. Nature, 497, 137-141.

Sibley, D. R., Benovic, J. L., Caron, M. G., \& Lefkowitz, R. J. (1987). Molecular mechanisms of betaadrenergic receptor desensitization. Advances in Experimental Medicine and Biology, 221, 253273.

Signoret, N., \& Marsh, M. (2000). Analysis of chemokine receptor endocytosis and recycling. Methods in Molecular Biology, 138, 197-207.

Signoret, N., Oldridge, J., Pelchen-Matthews, A., Klasse, P. J., Tran, T., Brass, L. F., Rosenkilde, M. M., Schwartz, T. W., Holmes, W., Dallas, W., Luther, M. a, Wells, T. N., Hoxie, J. a, \& Marsh, M. (1997). Phorbol esters and SDF-1 induce rapid endocytosis and down modulation of the chemokine receptor CXCR4. The Journal of Cell Biology, 139, 651-64.

Signoret, N., Pelchen-Matthews, A., Mack, M., Proudfoot, a E., \& Marsh, M. (2000). Endocytosis and recycling of the HIV coreceptor CCR5. The Journal of Cell Biology, 151, 1281-94.

Signoret, N., Rosenkilde, M. M., Klasse, P. J., Schwartz, T. W., Malim, M. H., Hoxie, J. a, \& Marsh, M. (1998). Differential regulation of CXCR4 and CCR5 endocytosis. Journal of Cell Science, 111, 2819-30. 
Sohy, D., Parmentier, M., \& Springael, J.-Y. (2007). Allosteric transinhibition by specific antagonists in CCR2/CXCR4 heterodimers. The Journal of Biological Chemistry, 282, 30062-9.

Sohy, D., Yano, H., de Nadai, P., Urizar, E., Guillabert, A., Javitch, J. a, Parmentier, M., \& Springael, J.-Y. (2009). Hetero-oligomerization of CCR2, CCR5, and CXCR4 and the protean effects of "selective" antagonists. The Journal of Biological Chemistry, 284, 31270-9.

Song, X., Raman, D., Gurevich, E. V, Vishnivetskiy, S. a, \& Gurevich, V. V. (2006). Visual and both non-visual arrestins in their "inactive" conformation bind JNK3 and Mdm2 and relocalize them from the nucleus to the cytoplasm. The Journal of Biological Chemistry, 281, 21491-9.

Sorkin, A., \& Duex, J. (2010). Quantitative Analysis of Endocytosis and Turnover of Epidermal Growth Factor (EGF) and EGF Receptor. Current Protocols of Cell Biology, 15.14, 1-25.

Spencer, D. M., Wandless, T. J., Schreiber, S. L., \& Crabtree, G. R. (1993). Controlling signal transduction with synthetic ligands. Science, 262, 1019-1024.

Sunahara, R. K., Dessauer, C. W., \& Gilman, A. G. (1996). Complexity and diversity of mammalian adenylyl cyclases. Annual Review of Pharmacology and Toxicology, 36, 461-480.

Tachibana, K., Seiichi Hirota, H. I., Hisahiro Yoshida, Kenji Kawabata, Y. K., Yukihiko Kitamura, Kouji Matsushima, N. Y., Shin-ichi Nishikawak, T. K., \& Nagasawa, \& T. (1998). The chemokine receptor CXCR4 is essential for vascularization of the gastrointestinal tract. Nature, 393, 591594.

Takabatake, Y., Sugiyama, T., Kohara, H., Matsusaka, T., Kurihara, H., Koni, P. A., Nagasawa, Y., Hamano, T., Matsui, I., Kawada, N., Imai, E., Nagasawa, T., Rakugi, H., \& Isaka, Y. (2009). The CXCL12 (SDF-1)/CXCR4 axis is essential for the development of renal vasculature. Journal of the American Society of Nephrology, 20, 1714-1723.

Tan, Q., Zhu, Y., Li, J., Chen, Z., Han, G. W., Kufareva, I., Li, T., Ma, L., Fenalti, G., Li, J., Zhang, W., Xie, X., Yang, H., Jiang, H., Cherezov, V., Liu, H., Stevens, R. C., Zhao, Q., \& Wu, B. (2013). Structure of the CCR5 chemokine receptor-HIV entry inhibitor maraviroc complex. Science, 341 , 1387-90.

Tang, X., Wang, Y., Li, D., Luo, J., \& Liu, M. (2012). Orphan G protein-coupled receptors (GPCRs): biological functions and potential drug targets. Acta Pharmacologica Sinica, 33, 363-71.

Terrillon, S., \& Bouvier, M. (2004a). Receptor activity-independent recruitment of betaarrestin2 reveals specific signalling modes. The EMBO Journal, 23, 3950-61.

Terrillon, S., \& Bouvier, M. (2004b). Roles of G-protein-coupled receptor dimerization. EMBO Reports, 5, 30-4.

Uwada, J., Yoshiki, H., Masuoka, T., Nishio, M., \& Muramatsu, I. (2014). Intracellular localization of the M1 muscarinic acetylcholine receptor through clathrin-dependent constitutive internalization is mediated by a C-terminal tryptophan-based motif. Journal of Cell Science, 127, 3131-40.

Vassart, G., \& Costagliola, S. (2011). G protein-coupled receptors: mutations and endocrine diseases. Nature Reviews. Endocrinology, 7(6), 362-72. 
Veldkamp, C., Seibert, C., Peterson, F., De la Cruz, N., Haugner, J., Basnet, H., Sakmar, T., \& Volkman, B. (2009). Structural basis of CXCR4 sulfotyrosine recognition by the chemokine SDF1/CXCL12. Science Signaling, 1, 1-18.

Venkatesan, S., Petrovic, A., Locati, M., Kim, Y. O., Weissman, D., \& Murphy, P. M. (2001). A membrane-proximal basic domain and cysteine cluster in the C-terminal tail of CCR5 constitute a bipartite motif critical for cell surface expression. The Journal of Biological Chemistry, 276, 40133-45.

Vilella-Bach, M. (1999). The FKBP12-Rapamycin-binding Domain Is Required for FKBP12-Rapamycinassociated Protein Kinase Activity and G1 Progression. The Journal of Biological Chemistry, 274, 4266-4272.

Vishnivetskiy, S. A., Raman, D., Wei, J., Kennedy, M. J., Hurley, J. B., \& Gurevich, V. V. (2007). Regulation of arrestin binding by rhodopsin phosphorylation level. The Journal of Biological Chemistry, 282, 32075-32083.

Wacker, W. B., Donoso, L. A., Kalsow, C. M., Yankeelov, A., \& Organisciak, D. T. (1977). Experimental Allergic Uveitis . Isolation, Characterization, and Localization of a Soluble Uveitopathogenic Antigen from Bovine Retina. Journal of Immunology, 119, 1949-1958.

Wald, O., Shapira, O. M., \& Izhar, U. (2013). CXCR4/CXCL12 axis in non small cell lung cancer (NSCLC) pathologic roles and therapeutic potential. Theranostics, 3, 26-33.

Weber, M., Blair, E., Simpson, C. V, Hara, M. O., Blackburn, P. E., Rot, A., Graham, G. J., \& Nibbs, R. J. B. (2004). The Chemokine Receptor D6 Constitutively Traffics to and from the Cell Surface to Internalize and Degrade. Molecular Biology of the Cell, 15, 2492-2508.

Westby, M., \& van der Ryst, E. (2005). CCR5 antagonists: host-targeted antivirals for the treatment of HIV infection. Antiviral Chemistry \& Chemotherapy, 16, 339-54.

Wettschureck, N., \& Offermanns, S. (2005). Mammalian G Proteins and Their Cell Type Specific Functions. Physiological Reviews, 85, 1159-1204.

Whorton, M. R., Bokoch, M. P., Rasmussen, S. G. F., Huang, B., Zare, R. N., Kobilka, B., \& Sunahara, R. K. (2007). A monomeric $G$ protein-coupled receptor isolated in a high-density lipoprotein particle efficiently activates its G protein. Proceedings of the National Academy of Sciences, 104, 7682-7.

Wilden, U., Hall, S. W., \& Kühn, H. (1986). Phosphodiesterase activation by photoexcited rhodopsin is quenched when rhodopsin is phosphorylated and binds the intrinsic 48-kDa protein of rod outer segments. Proceedings of the National Academy of Sciences, 83, 1174-8.

Wisler, J. W., DeWire, S. M., Whalen, E. J., Violin, J. D., Drake, M. T., Ahn, S., Shenoy, S. K., \& Lefkowitz, R. J. (2007). A unique mechanism of beta-blocker action: carvedilol stimulates betaarrestin signaling. Proceedings of the National Academy of Sciences, 104, 16657-62.

Wisler, J. W., Xiao, K., Thomsen, A. R. B., \& Lefkowitz, R. J. (2014). Recent developments in biased agonism. Current Opinion in Cell Biology, 27, 18-24.

Woehler, A., \& Ponimaskin, E. G. (2009). G protein--mediated signaling: same receptor, multiple effectors. Current Molecular Pharmacology, 2, 237-248. 
Wu, B., Chien, E. Y. T., Mol, C. D., Fenalti, G., Liu, W., Abagyan, R., Brooun, A., Wells, P., Bi, F. C., Damon, J., Kuhn, P., Handel, T. M., Cherezov, V., \& Stevens, R. C. (2011). Structures of the CXCR4 chemokine receptor in complex with small molecule and cyclic peptide antagonists. Science, 330, 1066-1071.

Xiao, K., McClatchy, D. B., Shukla, A. K., Zhao, Y., Chen, M., Shenoy, S. K., Yates, J. R., \& Lefkowitz, R. J. (2007). Functional specialization of beta-arrestin interactions revealed by proteomic analysis. Proceedings of the National Academy of Sciences, 104, 12011-6.

Yamada, M., Inanobe, A., \& Yoshihisa, K. (1998). G Protein Regulation of Potassium Ion Channels. Pharmacological Reviews, 50, 5-7.

Yu, L., Cecil, J., Peng, S., \& Schrementi, J. (2006). Identification and expression of novel isoforms of human stromal cell-derived factor 1 . Gene, 374, 174-179.

Zhang, Y., Foudi, A., Geay, J., Berthebaud, M., \& Buet, D. (2004). Intracellular Localization and Constitutive Endocytosis of CXCR4 in Human CD34+Hematopoietic Progenitor Cells. Stem Cells, $22,1015-1029$.

Zhou, Y., Kurihara, T., Ryseck, R. P., Yang, Y., Ryan, C., Loy, J., Warr, G., \& Bravo, R. (1998). Impaired macrophage function and enhanced $T$ cell-dependent immune response in mice lacking CCR5, the mouse homologue of the major HIV-1 coreceptor. Journal of Immunology, 160, 4018-25.

Zidar, D. a, Violin, J. D., Whalen, E. J., \& Lefkowitz, R. J. (2009). Selective engagement of G protein coupled receptor kinases (GRKs) encodes distinct functions of biased ligands. Proceedings of the National Academy of Sciences, 106, 9649-54.

Zimnik, S., Gaestel, M., \& Niedenthal, R. (2009). Mutually exclusive STAT1 modifications identified by Ubc9/substrate dimerization-dependent SUMOylation. Nucleic Acids Research, 37, e30.

Zlotnik, A., Yoshie, O., \& Nomiyama, H. (2006). The chemokine and chemokine receptor superfamilies and their molecular evolution. Genome Biology, 7, 243.

Zou, Y. R., Kottmann, a H., Kuroda, M., Taniuchi, I., \& Littman, D. R. (1998). Function of the chemokine receptor CXCR4 in haematopoiesis and in cerebellar development. Nature, 393, 595-9.

Zuckerman, R., \& Cheasty, J. E. (1986). A 48 kDa protein arrests cGMP phosphodiesterase activation in retinal rod disk membranes. FEBS Letters, 207, 35-41. 